\title{
TENSILE STRENGTH OF CEMENT-TREATED CHAMPLAIN SEA CLAY: AN EXPERIMENTAL AND NUMERICAL STUDY
}

\author{
BY \\ KUN YANG, B.A.Sc. \\ University of Toronto, 2015
}

\begin{abstract}
A THESIS
Presented to Ryerson University in partial fulfillment of the requirements for the degree of Master of Applied Science in the program of Civil Engineering
\end{abstract}

TORONTO, ONTARIO, CANADA, 2020

(C) KUN YANG 2020 


\section{AUTHOR'S DECLARATION}

I hereby declare that I am the sole author of this thesis. This is a true copy of the thesis, including any required final revisions, as accepted by my examiners.

I authorize Ryerson University to lend this thesis to other institutions or individuals for the purpose of scholarly research.

I further authorize Ryerson University to reproduce this thesis by photocopying or by other means, in total or in part, at the request of other institutions or individuals for the purpose of scholarly research.

I understand that my thesis may be made electronically available to the public. 


\title{
TENSILE STRENGTH OF CEMENT-TREATED \\ CHAMPLAIN SEA CLAY: AN EXPERIMENTAL AND \\ NUMERICAL STUDY
}

\author{
Kun Yang \\ Master of Applied Science (M.A.Sc) \\ Department of Civil Engineering \\ Ryerson University
}

2020

\begin{abstract}
The deep soil mixing method is becoming increasingly popular in the treatment of problematic soils in Canada. Champlain Sea clay, found throughout the St. Laurence River basin from Ontario to Quebec, is well-known for its high compressibility and a sudden loss of its shear strength due to disturbance. The tensile strength of a stabilized soil is an important design parameter for structures, such as embankments and retaining walls. Currently, there is no study available on the tensile strength of cement-treated Champlain Sea clay. This study is to address this knowledge gap by using indirect tensile strength testing approaches, such as the Brazilian tensile test and unconfined penetration test. General use cement was selected for mixing with clay. The tensile strength results of cement-treated clay were compared and correlated with its unconfined compressive strength to establish a relationship. According to this study, the tensile strength of cementtreated Champlain Sea clay was approximately $6 \%$ of its unconfined compressive strength. The Brazilian tensile strength is recommended for future studies over the unconfined penetration test due to its reliability and consistency in the test results. A numerical simulation using Abaqus CAE was also performed on the behavior of a Brazilian tensile testing sample during loading. A fair agreement was observed between experimental and numerical simulation results up to crack initialization
\end{abstract}




\section{ACKNOWLEDGEMENTS}

First of all, I would like to express my gratitude for my supervisor, Dr. Jinyuan Liu for his invaluable guidance throughout the course of the development of this thesis. The completion of this study would not have been possible without his prompt and thorough answers to my questions and tireless review of my work. Always kind and patient, the knowledge and wisdom Dr. Liu imparts has helped and continues to help me greatly in academic matters as well as in life.

Appreciation is also expressed to the Natural Sciences and Engineering Research council of Canada, NSERC for the financial support of this research and Ontario Power Generation for providing the clay samples for this study.

I would also like to thank the committee members: Dr. Songnian Li, Dr. Laifa Cao, Dr. Haitham Aboshosha for taking their time to review and offer advice for the thesis.

Also, I would like to give thanks to current and graduated members of Ryerson's geotechnical engineering research team, who provided me with advice and assistance throughout the course of this project, namely Mr. Moulay Youssef Monsif, Mr. Mohammad Afroz and Mr. Ali Ahmad.

I would also like to express my gratitude to my wife, Xiaoshan, whose unwavering support and encouragement was vital to the completion of this study. I would also like to thank my parents for their continual financial and morale support. 


\section{TABLE OF CONTENTS}

AUTHOR'S DECLARATION........................................................................................ ii

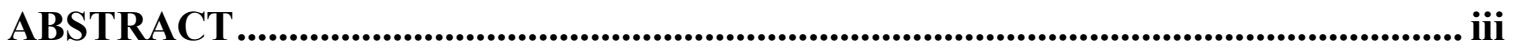

ACKNOWLEDGEMENTS ......................................................................................... iv

LIST OF FIGURES ..................................................................................................... vii

LIST OF TABLES.............................................................................................................

1. INTRODUCTION .........................................................................................

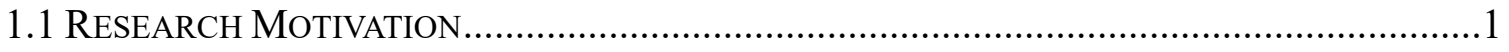

1.2 RESEARCH OBJECTIVES AND SCOPE ………………............................................

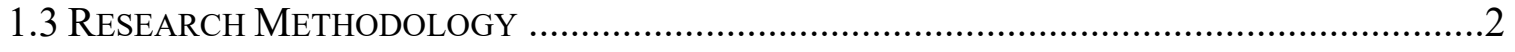

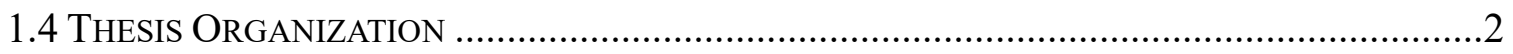

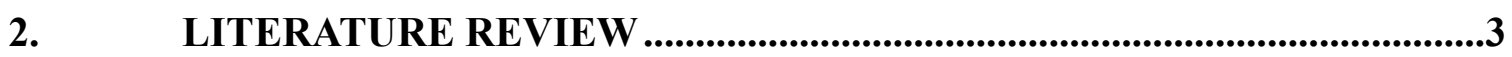

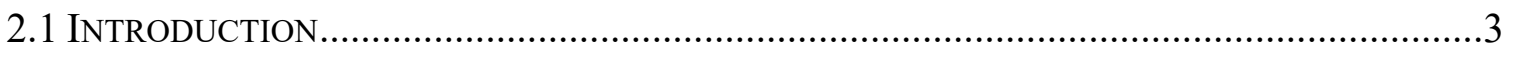

2.2 Soil Cement TREATMENT AND DeEP SoIL MiXING ......................................................

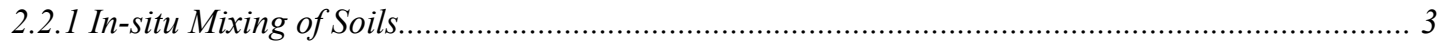

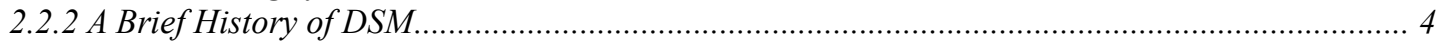

2.2.3 Deep Mixing Methodologies and Tools ................................................................................. 6

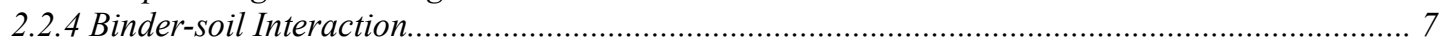

2.2.5 Application of Deep Soil Mixing...................................................................................... 9

2.2.6 Factors Affecting Strength Gain ....................................................................................12

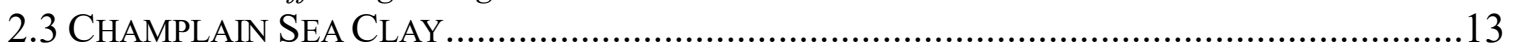

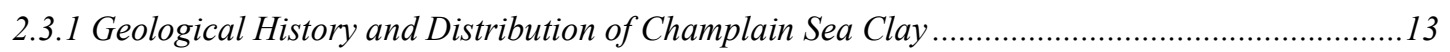

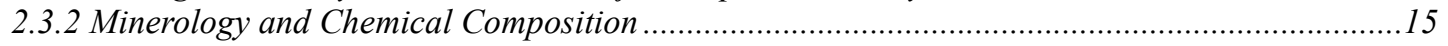

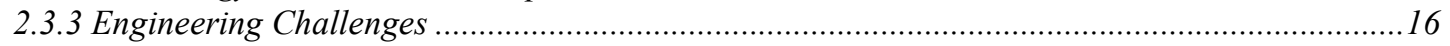

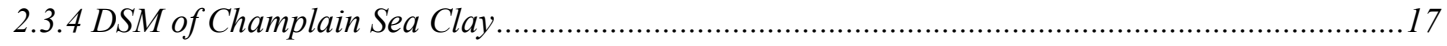

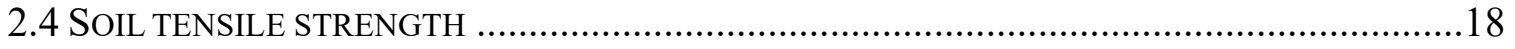

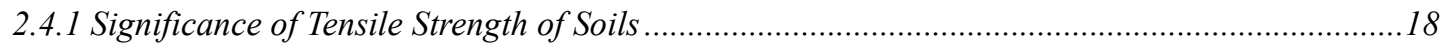

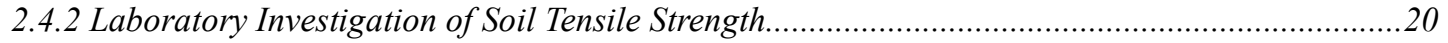

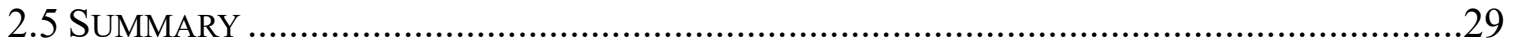

3. EXPERIMENTAL PROGRAM...................................................................30

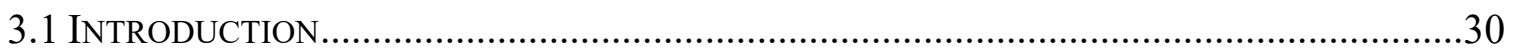

3.2 MATERIAL PROPERTIES OF ChaMPlain SEA ClaY ....................................................30

3.2.1 Grain Size Distribution.....................................................................................................30

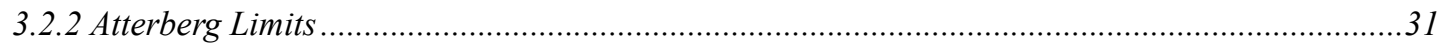

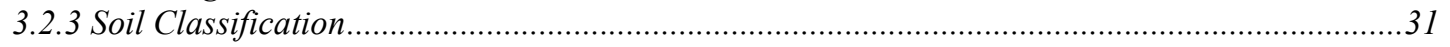

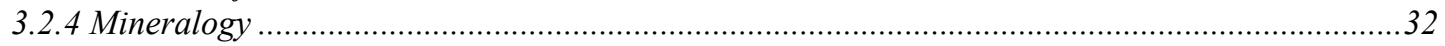

3.2.5 Undrained Shear Strength ………………………………………………………………...33

3.2.6 Specific Gravity and Total Unit Weight ...............................................................................33

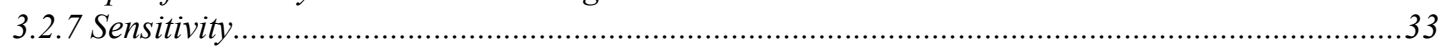

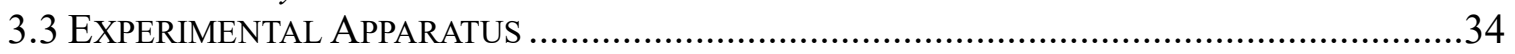

3.3.1 Unconfined Compression Strength (UCS) Test.............................................................................34

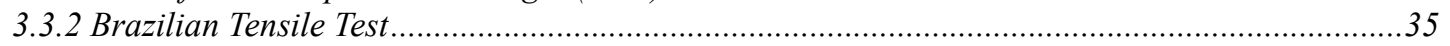

3.3.3 Unconfined Penetration Test (UPT) ………………………………………………………....36

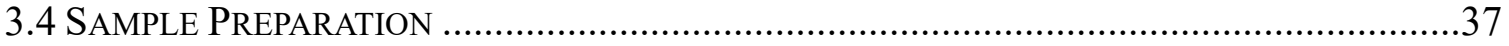




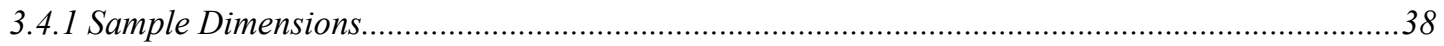

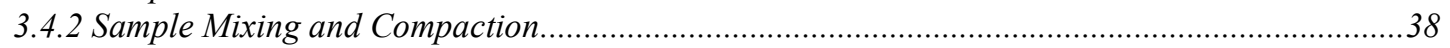

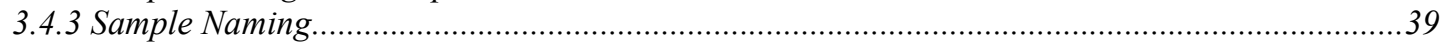

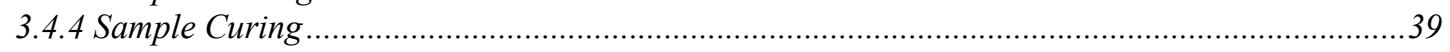

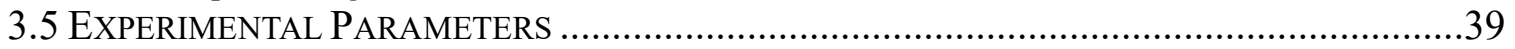

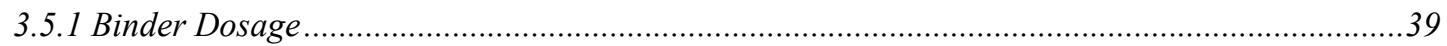

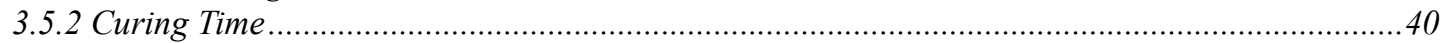

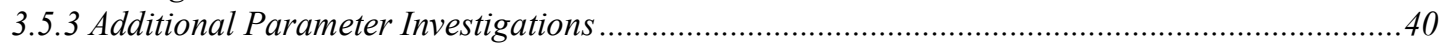

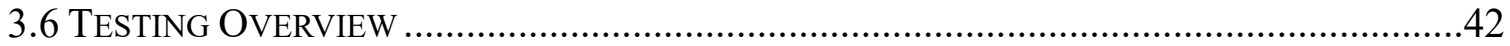

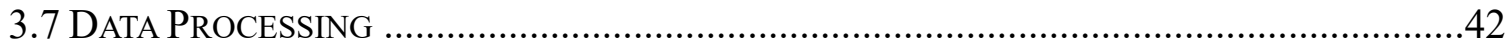

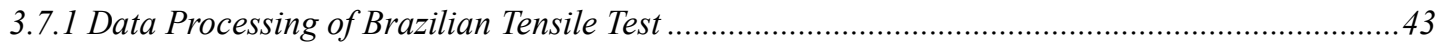

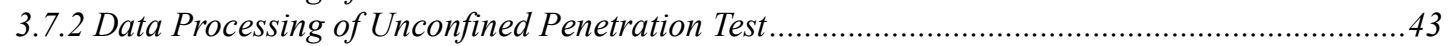

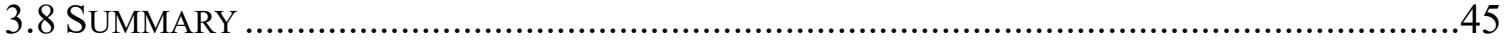

4. LABORATORY RESULTS AND ANALYSIS .........................................46

4.1 INTRODUCTION

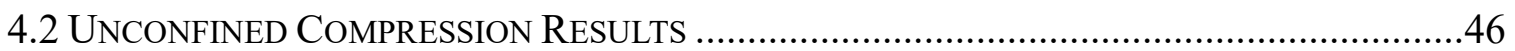

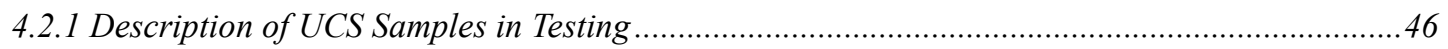

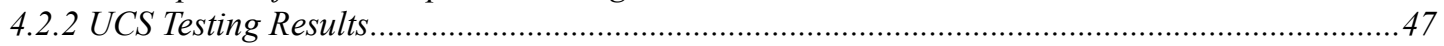

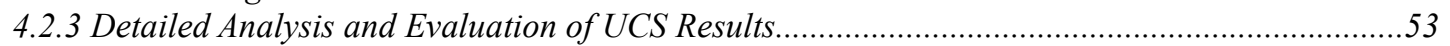

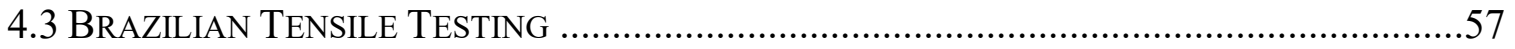

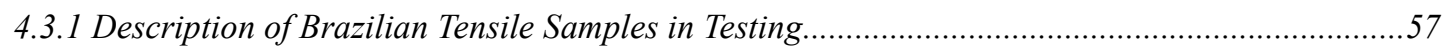

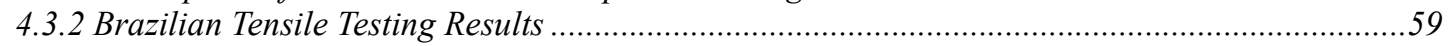

4.3.3 Detailed Analysis of Brazilian Tensile Testing Results .............................................................63

4.3.4 Numerical Correlation between BTS and UCS Results .........................................................65

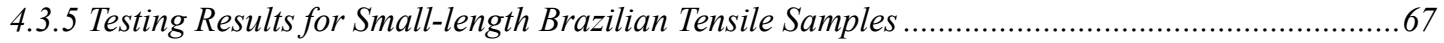

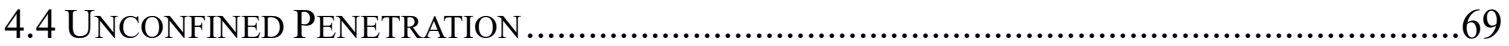

4.4.1 Description of Unconfined Penetration Samples in Testing .....................................................69

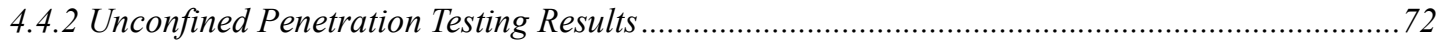

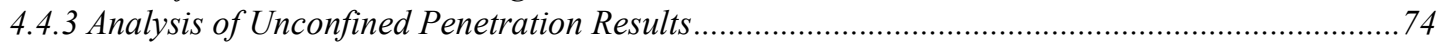

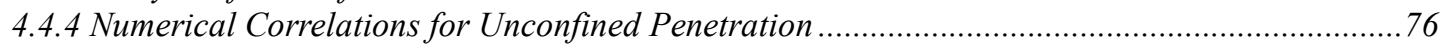

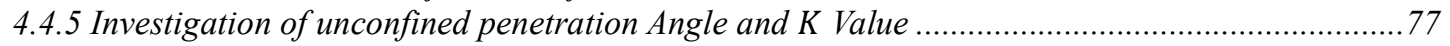

4.4.6 Test Results for Unconfined Penetration with Angled Penetration Discs....................................80

4.4.7 Comparison between Brazilian Tensile and Unconfined Penetration Results.............................82

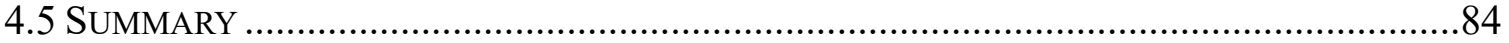

5. NUMERICAL MODELLING ...................................................................88

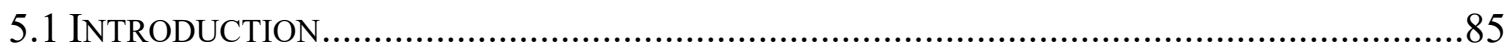

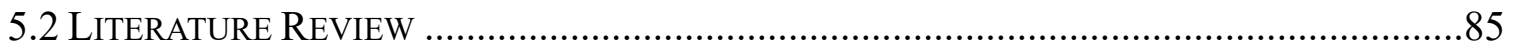

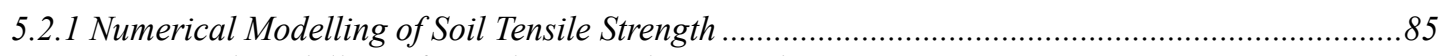

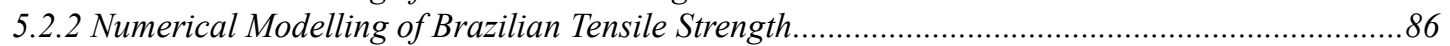

5.2.3 Numerical Modelling of Concrete Brazilian Tensile Testing ...................................................86

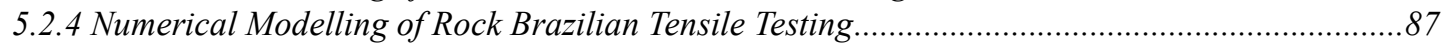

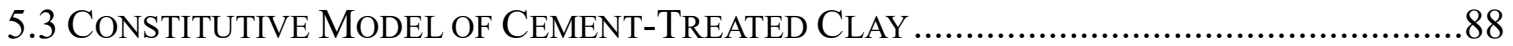

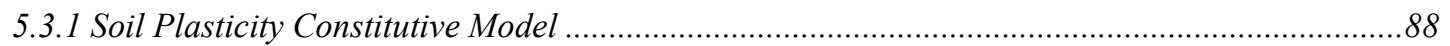

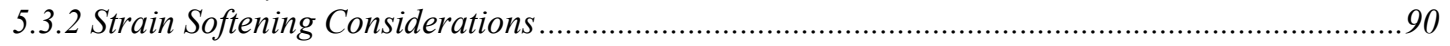

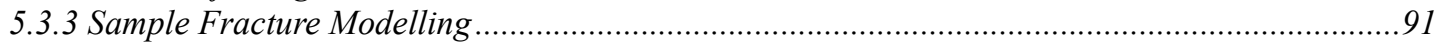

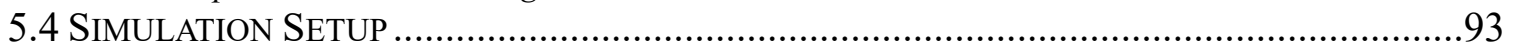

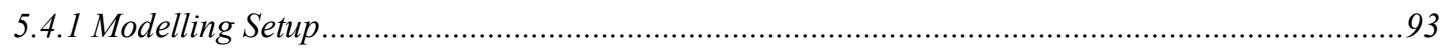

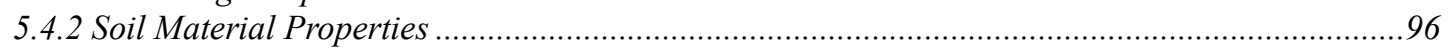

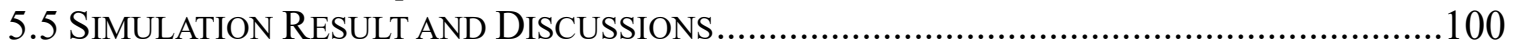

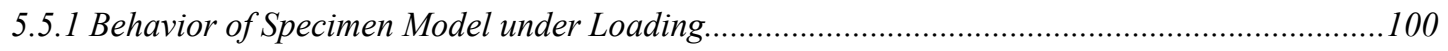

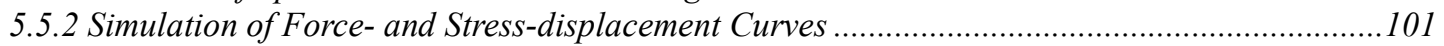




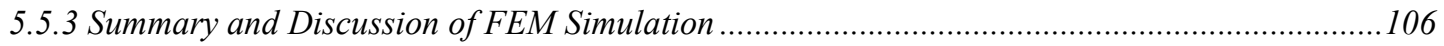

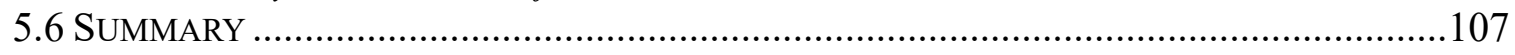

6. SUMMARY AND CONCLUSIONS ……......................................................109

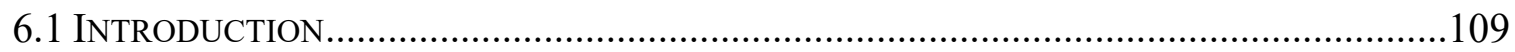

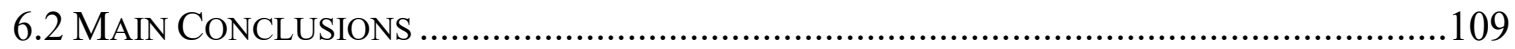

6.3 RECOMMENDATIONS FOR FUTURE RESEARCH .....................................................110

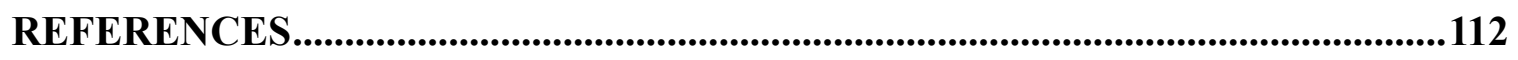




\section{LIST OF FIGURES}

Figure 2-1: Illustration of dry mixing (Keller Holding GmbH, 2017)..................................................... 4

Figure 2-2: Illustration of wet mixing (Keller Holding GmbH, 2017) ....................................................... 4

Figure 2-3: Different Types of Deep Mixing Blade (Kitazume, 2017) ..................................................... 6

Figure 2-4: Trenching Machine Used in Horizontal Axis Deep Mixing (Massarsch \& Topolnicki, 2005) .... 7

Figure 2-5: Illustration of Cement-Mixed Soil Microstructure (Saitoh et al., 1985) .................................... 9

Figure 2-6: DSM Column Configurations for Different Applications (Terashi, 1997).................................10

Figure 2-7: Schematic Configuration of DSM Retaining Wall (Shao et al., 2005) .......................................11

Figure 2-8: A DSM Retaining Wall (Denies \& Huybrechts, 2017) ........................................................11

Figure 2-9: Lattice Arrangement of DSM Columns for the Purpose of Liquefaction Mitigation (Porbaha et a 1., 1999).

Figure 2-10: Current Champlain Sea Clay Deposits in Canada (Lewis \& Todd, 2019) ..............................14

Figure 2-11: Ice Sheet Retreat and Champlain Sea Formation, Approximately 12,800 to 10,000 Years BP (L

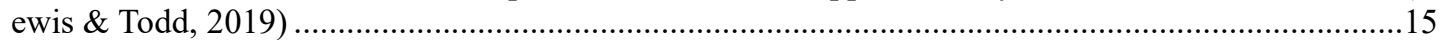

Figure 2-12: Physical Model of DSM Columns Under Loading. Certain Parts of the Columns Are Under Te

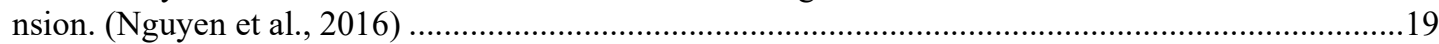

Figure 2-13: The Impact of Tensile Strength on Lateral Displacement of a DSM Pile (Voottipruex et al., 201

1)

Figure 2-14: Direct Tensile Testing Setup (Wang et al., 2007) ..................................................................2

Figure 2-15: Failure Envelopes Obtained through Triaxial Tensile Tests ...................................................23

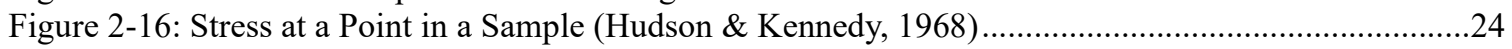

Figure 2-17: Illustration of Unconfined Penetration Test ......................................................................25

Figure 2-18: Tensile Strength Testing Using Flexure Test (Unamunzaga et al., 2019)................................27

Figure 3-1: Grain distribution of clay used in this study (Ahmad, 2018; Afroz, 2019) .................................31

Figure 3-2: Soil classification data for Champlain Sea clay (Liu, et al., 2017) ..........................................32

Figure 3-3: Elemental composition of Champlain Sea Clay (Monsif et al., 2020)........................................33

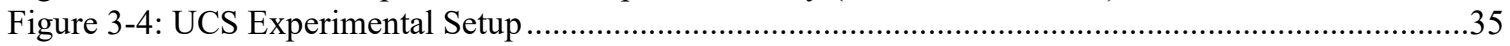

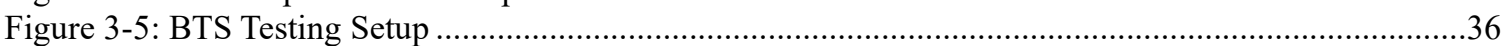

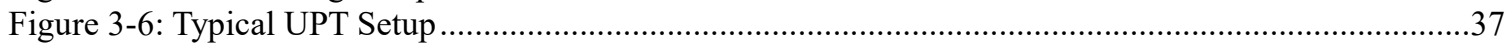

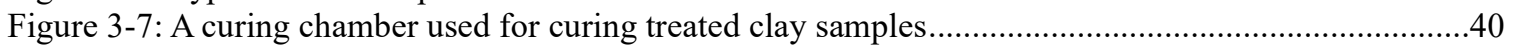

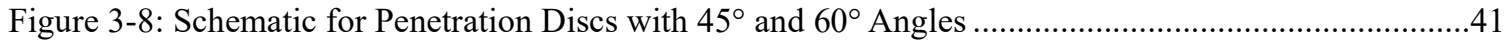

Figure 3-9: Illustration of failure cone angle at penetration disc (Kim et al.,2012).......................................44

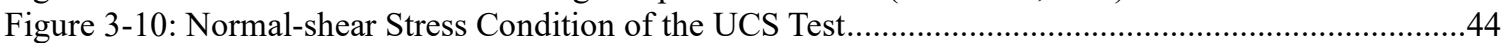

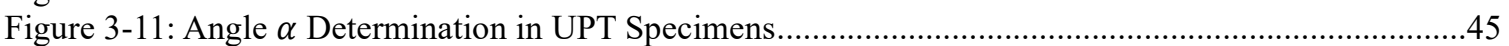

Figure 4-1: Conical Failure Observed in Cement-treated Clay Sample ......................................................47

Figure 4-2: Shear Failure Observed in Cement-treated Clay Sample ........................................................47

Figure 4-3: UCS Results for different curing days and binder content....................................................48

Figure 4-4: A Comparison of UCS Test Results with Previous Studies on the Same Clay (Monsif et al., 201

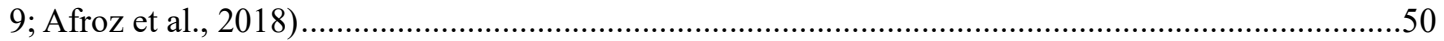

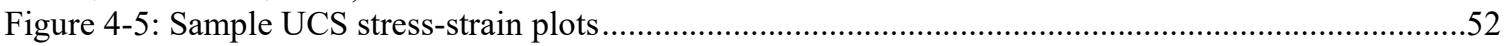

Figure 4-6: An Example for Seating Error Correction ..............................................................................55

Figure 4-7: A Relationship between UCS values vs Failure Strains for All UCS Samples ...........................53

Figure 4-8: Relationship between Soil Modulus and Cement Dosage and Curing Time .............................54

Figure 4-9: Total Water-to-binder Ratio by Weight for UCS Samples .......................................................55

Figure 4-10: Relationship between UCS and Soil Parameters ....................................................................56

Figure 4-11: Failure and crack formation of a Brazilian tensile specimen .................................................58

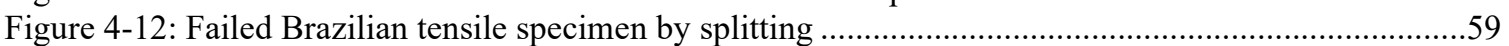

Figure 4-13: Select Load-displacement Curves for BTS Testing Samples................................................61

Figure 4-14: Brazilian Tensile Strength Sorted by Curing Time and Binder Content .................................62

Figure 4-15: Total Water-to-binder Ratios by Weight for Brazilian Tensile Samples.....................................64

Figure 4-16: Relationship between BTS and Soil Parameters....................................................................65

Figure 4-17: Correlation between BTS and UCS for average values of all tests........................................66

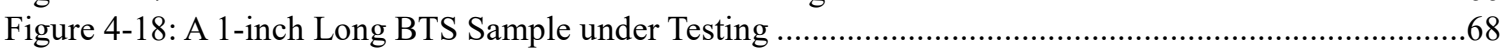

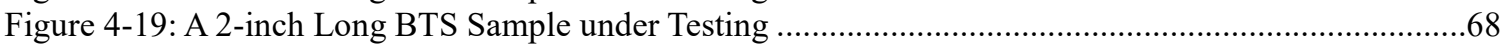


Figure 4-20: The Impact of Sample Sizing on Tensile Strength of BTS Tests .....................................69

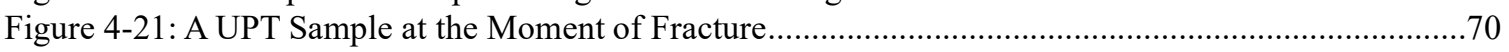

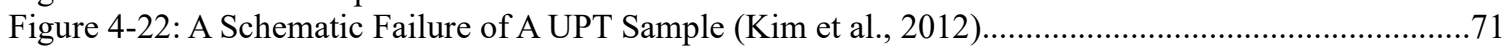

Figure 4-23: Typical Failure Surfaces in UPT Samples.................................................................. 71

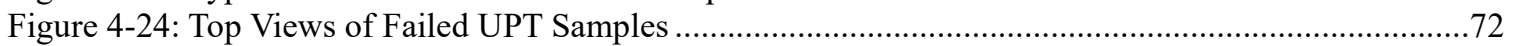

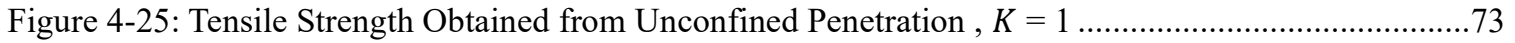

Figure 4-26: Typical Load-Deformation Curves for UPT Samples ....................................................74

Figure 4-27: Relationship between Tensile Strength and Soil Parameters for UPT Samples......................76

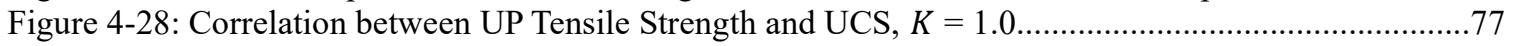

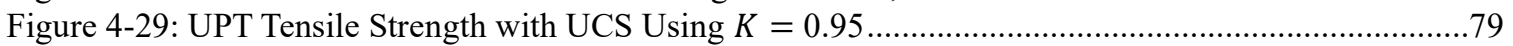

Figure 4-30: A UPT Sample Tested with a $45^{\circ}$ Penetration Disc .............................................................80

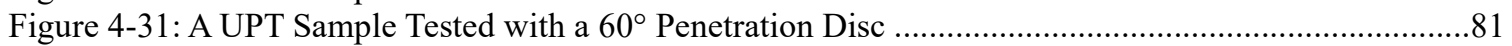

Figure 4-32: A Fractured Surface of Sample Tested with a $60^{\circ}$ Penetration Disc ....................................81

Figure 4-33: Relationship between Failure Loads with Penetration Disc Angle ......................................82

Figure 4-34: Plot of Average Tensile Strengths from UPT against BTS ................................................83

Figure 4-35: Correlation between Tensile Strength and UCS of Cement-Treated Champlain Sea clay ........83

Figure 5-1: Abaqus Simulation of a Concrete Sample in BTS Test (Denneman et al., 2011) .....................87

Figure 5-2: Development of Crack Formation in a Rock Sample (Mahabadi et al, 2013) .........................88

Figure 5-3: Drucker Prager Shear Failure Surfaces and Equations (Simulia, 2016) ...............................89

Figure 5-4: Strain Softening as Documented by Li et al. (2019) .....................................................91

Figure 5-5: One Way for Modelling of Specimen Damage (Troncone, 2005) ........................................91

Figure 5-6: Theoretical Illustration of Linear Traction Separation Model (Simulia, 2012).........................92

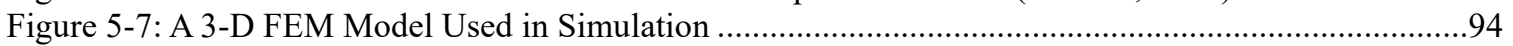

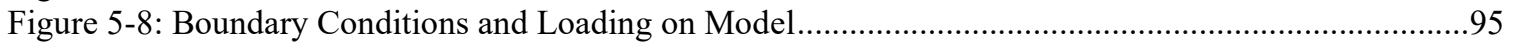

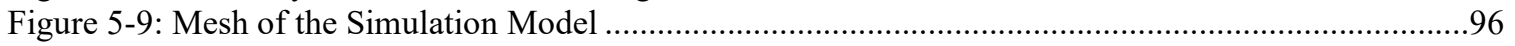

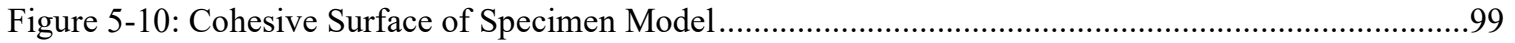

Figure 5-11: The Tensile Stress Contour of a BTS Specimen during Loading .......................................100

Figure 5-12: Vertical Stress Details of Elements in Contact with Loading Plates....................................101

Figure 5-13: Comparisons between FEM Simulated and Experimental Load-Displacement Curves .........104

Figure 5-14: Comparisons between Simulated and Experimental Tensile Stress-Displacement Curves.....106 


\section{LIST OF TABLES}

Table 2-1: Factors Affecting DSM Strength Gain (Terashi, 1997) ……..................................................13

Table 2-2: Mineral Deposits of Champlain Sea Clay at Select Sampling Sites (Locat et al., 1984)..............16

Table 2-3: Oxide Concentration in Champlain Sea Clay Samples (Locat et al., 1984) .................................16

Table 2-4: Values of $\mathrm{K}$ for Different Types of Soil Molds (Kim et al., 2012) ............................................26

Table 3-1: Mineral composition of Waba Dam clay (Qualitas, 2016) ...........................................................

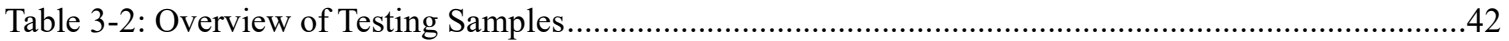

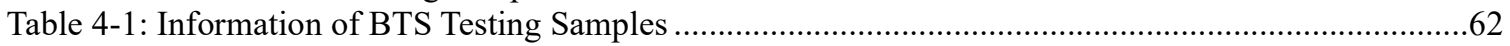

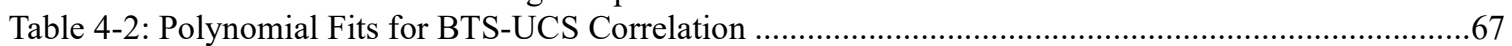

Table 4-3: Value of $K$ for Different Soil Sample Molds ................................................................................ 79

Table 5-1: Drucker Prager Softening Definitions for Cement-Treated Sample $\left(50 \mathrm{~kg} / \mathrm{m}^{3}\right) \ldots \ldots \ldots \ldots \ldots \ldots \ldots \ldots \ldots . . .97$

Table 5-2: Summary of Modelling Input Parameters Used in FEM ……................................................100

Table 5-3: Relationship between Stresses on Two Elements for Force Calculation ......................................102

Table 5-4: Calculation of Average Vertical Load on the Sample .................................................................103

Table 5-5: Comparison between Experimental Results and FEM Simulation.............................................107 


\section{INTRODUCTION}

\subsection{RESEARCH MOTIVATION}

The deep soil mixing (DSM) method is a ground improvement technique where cement and/or other binders are blended with soil in-situ to improve its strength and compressibility (Topolnicki, 2013; Frikha et al., 2017). In Canada, this method has seen greater industry use and research interest. Champlain Sea clay found along St. Laurence River is one of prevalent soil types in Eastern Canada and is characterized by its high sensitivity and propensity for landslides (Eden \& Mitchell, 1970). The DSM-treated Champlain Sea clay and its behavior remain topics of geotechnical research interest.

The tensile strength of soils has been a topic in soil mechanics that has not been very thoroughly studied. In industry practice and early research the soil tensile strength has often been assumed as zero or negligible (Morris et al., 1992; Li et al., 2014). Though often low compared with compressive strength, soil tensile strength is significant in many geotechnical applications involving slopes, embankments and dams where soil is often subject to tensile stress. As a result, there have been growing research efforts to investigate the tensile strength in different types of soils. There is currently no information on the tensile behavior of this clay treated with cement. With the current expansion of the use of DSM in Canadian soils comprised of Champlain Sea clay, as well as the need for further study in the tensile behavior of soils in general, it would be of research interest to investigate the behavior of Champlain Sea clay under tensile loading.

\subsection{RESEARCH OBJECTIVES AND SCOPE}

The objectives of this research are to investigate the behavior of cement-treated Champlain Sea clay under tensile stress and establish a relationship between its tensile strength ad compressive strength for the practice. Both laboratory experiments and numerical modelling were employed in this study, and their results were compared and discussed. Soil samples were be prepared by the wet mixing method using general use cement as the binder to simulate the deep mixing condition in the field. Indirect tensile testing methods of Brazilian tensile strength (BTS) test and unconfined penetration testing (UPT) were employed, the theory and rational of which was covered in detail in the next chapter. On 
the other hand, numerical modelling using the finite element method (FEM) was performed to simulate the behavior of a cement-treated clay sample under BTS testing. The results of laboratory testing and FEM were compared and discussed.

\subsection{RESEARCH METHODOLOGY}

The laboratory testing approach of tensile strength of Champlain Sea clay is as follows:

- The index properties of soil were determined in testing or from existing literature.

- Champlain Sea clay was blended with cement to simulate soil treatment in DSM. Binder content were selected as 50,100 and $200 \mathrm{~kg} / \mathrm{m}^{3}$ per mixture volume.

- The cement-treated clay was put into 2" by 4" cylinders and cured in a humid curing chamber at room temperature for 7,14 , or 28 days before testing.

- After curing, the samples were tested separately using unconfined compressive strength (UCS), BTS, and UPT tests.

\subsection{THESIS ORGANIZATION}

This thesis is organized into six chapters for an investigation and discussion of the tensile strength of Champlain Sea clay.

Chapter 1 presents the motivation, objectives and methodology of this research, as well as the organization of the entire thesis.

Chapter 2 includes an overview of current literature on deep soil mixing applications, geotechnical properties of Champlain Sea clay and information on soil tensile testing.

Chapter 3 describes the experimental program for tensile testing of Champlain Sea specimens, including Brazilian tensile test and unconfined penetration test.

Chapter 4 presents the numerical modelling of tensile specimen behavior in Brazilian tensile test and unconfined penetration test.

Chapter 5 contains the numerical simulation of Brazilian tensile testing and discussions on the fitness of simulated and experimental results in load- and stress-displacement curves. Chapter 6 provides summary and conclusion of this study as well as recommendations for future research topics. 


\section{LITERATURE REVIEW}

\subsection{INTRODUCTION}

The literature review begins with the research significance of the soil improvement method of deep soil mixing and its applications in Section 2.1. An overview of the soil under investigation, Champlain Sea clay from eastern Canada, is then covered in Section 2.2. Section 2.3 contains soil tensile strength and its significance, direct and indirect methods of testing, as well as current literature on tensile testing of soil treated in deep mixing.

\subsection{SOIL CEMENT TREATMENT AND DEEP SOIL MIXING}

The deep soil mixing method is a ground improvement technique which involves adding a cementitious material, known as binder, to improve the strength and compressibility properties of weaker soils by stirring the binder and soil together and forming a mixed column (Topolnicki, 2013). First practiced in Japan and Scandinavia since 1950s, this method has been established in geotechnical engineering practice globally. In Canada the practice of DSM is still scarce, but there has been a growing amount of literature on the applicability of this practice on weak soils in the country (Li et al., 2016a \& 2016b; Li et al., 2017; Afroz, 2019).

\subsubsection{IN-SITU MIXING OF SOILS}

In DSM, soil is blended in-situ with the binder to induce chemical reactions which will form compounds with superior material properties, namely in strength and compressibility. DSM is defined as DSM as in-situ soil stabilization to at least $3 \mathrm{~m}$ depth in by the European Committee for Standardization (CEN) in EN 14679:2005 (CEN, 2005).

There are two major types of mixing: dry mixing and wet mixing. In dry mixing, binder material is mechanically blended into the soil using a mixing tool whereas in wet mixing binder material is first processed into slurry form before mixing. In both methods, a mixed column is formed and left for curing as the binder material reacts with soil substances and the improved columns function the same way as deep foundation, i.e. piles or shafts (Terashi, 1997). 


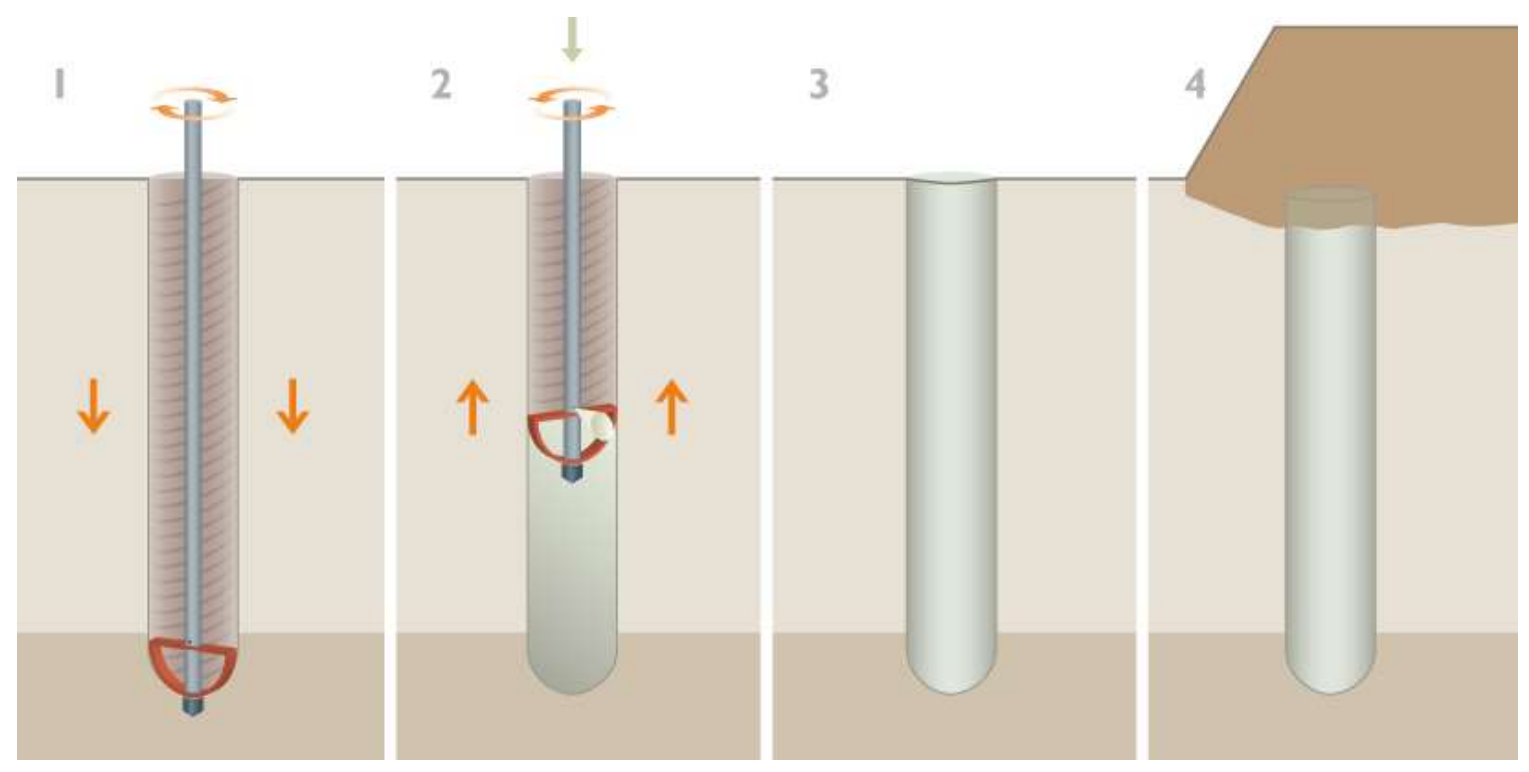

Figure 2-1: Illustration of dry mixing (Keller Holding GmbH, 2017)
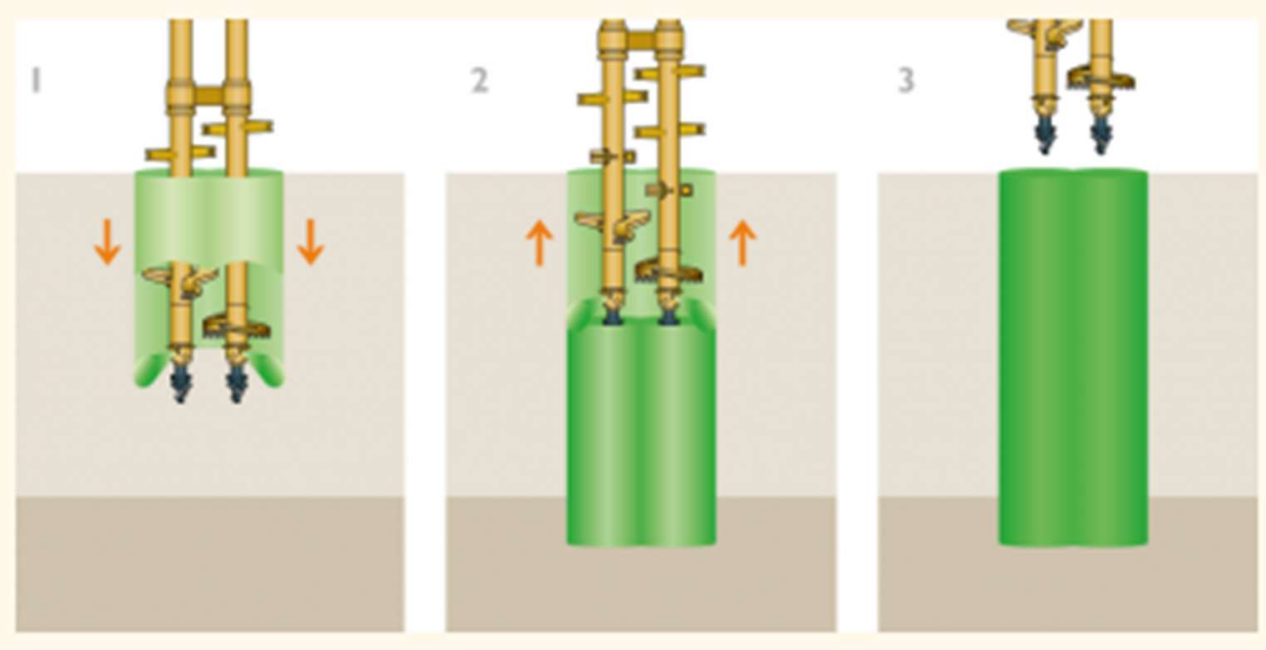

Figure 2-2: Illustration of wet mixing (Keller Holding GmbH, 2017)

\subsubsection{A BRIEF HISTORY OF DSM}

The earliest developments of DSM can be traced to the mixed-in-place single auger piling technique applied by Intrusion-Prepakt Inc. in the United States in 1954 (Federal Highway Administration [FHWA], 2000). However, the use of DSM in North America had been scarce until the 1980s when Geo-Con Inc. pioneered several DSM technologies in the U.S. (FHWA, 2000). On the other hand, systematic, industrial-scale DSM applications developed almost simultaneously in Japan and Scandinavia in the early 1970s (Terashi, 1998; Holm, 2002). 
In Japan, the first commercial DSM application on land was performed in 1974 on reclaimed soft clay using lime with dry, mechanical mixing in Chiba Prefecture. The first marine application was in 1975 at Tokyo Port (Terashi, 2002). The first use of cement as binder followed shortly after in 1976 in the construction of soil mixed walls. Wet mixing was pioneered in 1977 and the Cement Deep Mixing Association was established in Japan to advance DSM technologies. By late 1970s, the use of DSM expanded to the application of cutoff walls, excavation support, liquefaction reduction, as well as primarily marine applications of quay walls and revetments. Japan remained one of the world's leaders in DSM innovations to this day. Further Japanese innovations in DSM include the spreadable wing (SWING) in late 1980s that combined dry and wet mixing to form large diameter mixed columns (FHWA, 2000), as well as the trench remixing and deep wall method (TRD) in 1990s that allowed an one-phase application of excavation and in-situ mixing (Evans, 2008).

The research of DSM in Scandinavia began in laboratory stabilization of soft clay with unslaked lime in Sweden in 1967. Commercial use of lime columns began in 1975 in Sweden and the use of cement as binder began in Finland in 1988. Unlike in Japan where wet mixing is more prominent (Terashi, 1997), early uses of DSM in Scandinavia usually involved the dry mixing of two substances, cement and lime, as binders, which later became known as the "Nordic method" (Holm, 2002). The uses of the Nordic method primarily encompassed settlement reduction in road and railroad embankments, and the soil being improved were typically soft, compressible clay or organic soils.

From late 1970s to 1980s, DSM spread to other parts of the world such as China (Han, et al., 2002), United Kingdom (Blackwell, 1994), Continental Europe, Southeast Asia and the United States (FHWA, 2000). In North America, large scale application of DSM began in mid-1980s, notably in the foundation improvement of Jackson Lake Dam in Wyoming for the purpose of liquefaction mitigation (Ryan \& Jasperse, 1989). The largest DSM structure in North America to date is the New Orleans East Bank Levee (LPV 111), which involved more than 1.3 million cubic meters of mixed soil (Bruce et al., 2012). In Canada, DSM has been applied primarily in the western part of the country. Current uses include slope stabilization, embankments and mixed walls, especially cutter soil mixing walls (Pacific Ground Engineering, 2020; Menard Canada, 2020). 


\subsubsection{Deep Mixing Methodologies And Tools}

Deep mixing usually requires specialized equipment. The mixing setup typically consists of a drill rig, one or more blades to perform mixing action and a binder supply and storage unit, which may vary greatly depending on whether the type of mixing is wet or dry and may also differ based on the specific mixing method (Topolincki, 2013).

\subsubsection{Dry Mixing}

In dry mixing, the mixing tool with rotating impeller (blade) at the tip is driven into the soil, either vertically or horizontally, and binder material is blended with the soil using inverse action, usually using compressed air through an umbilical cord (Dahlström, 2013). The diameter of mixing blades typically ranges between $1.0 \mathrm{~m}$ and $1.6 \mathrm{~m}$ (Nozu, 2005). There are mainly two types of binder delivery methods in dry mixing: the Japanese Dry Jet Mixing (DJM) method and the Nordic method (Terashi, 2003). In the Japanese DJM method, the pneumatic binder system, developed in 1978, has a torque capacity between 20 to $30 \mathrm{kNm}$ and is suited for clays with maximum shear strength of $70 \mathrm{kPa}$ or sands with SPT-N of 15. The mixing tool developed in the Nordic method is best suited for soft to very soft soils with shear strength below $25 \mathrm{kPa}$ and has a torque capacity typically between 30 to $40 \mathrm{kNm}$. For the majority of dry mixing applications, the drilling and blade unit usually consists of one or two shafts, with maximum mixing depth between 16 to $33 \mathrm{~m}$. In early DSM applications in Japan and Scandinavia, single shaft systems were used. More recently, the dual mixing shaft system has become more common (Topolincki, 2013).

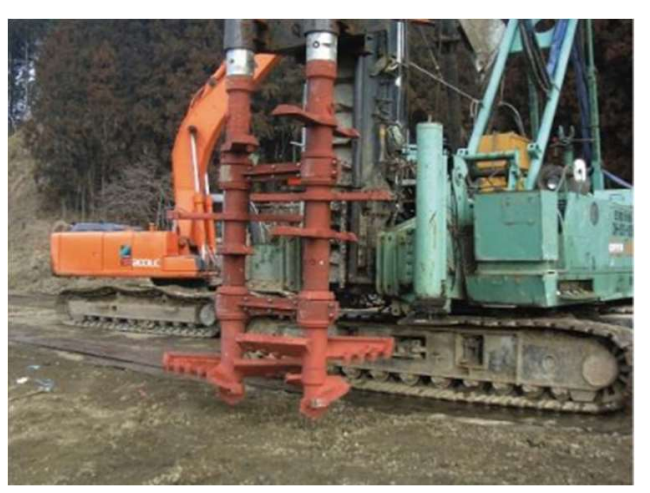

a). Dual shaft

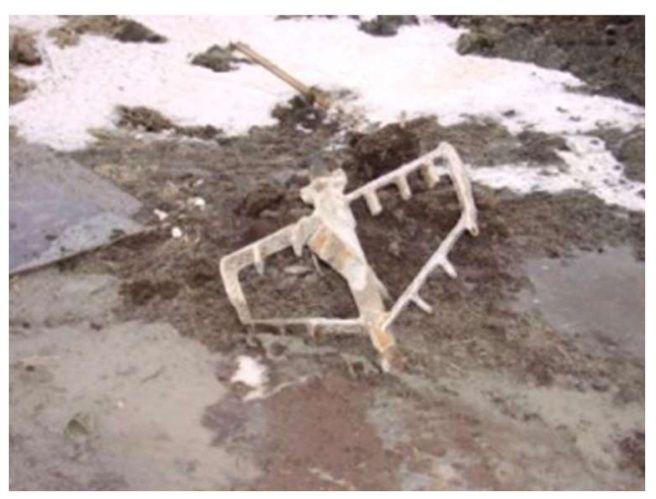

b). Single shaft

Figure 2-3: Different Types of Deep Mixing Blade (Kitazume, 2017) 


\subsubsection{Wet Mixing}

In wet mixing, binder material is first mixed with water to form a slurry then pumped into the soil in-situ. The mixing complex often includes a batched mixing plant to process slurry, as well as a mixing unit for slurry injection and soil blending. The batched mixing plant consists of silos, water tanks, storage units and batching units. Slurry is typically pumped to mixing unit using piston pump (Topolinicki, 2013). There are different methods in the rotation of mixing tools: rotating about the vertical axis, which reduces the number of joints and wastes less material, rotating about horizontal axis, which allows mass stabilization (Keller Holding GmbH, 2020), and along the cutting arm in vertical trenching which allows an one-step action for excavation and mixing in building a mixed wall (BAUER Maschinen $\mathrm{GmbH}, 2016)$.

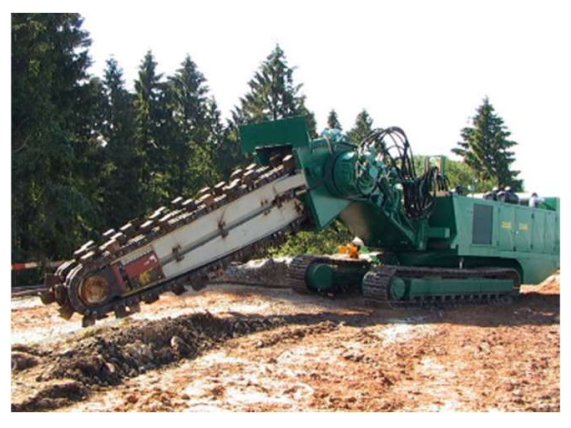

Figure 2-4: Trenching Machine Used in Horizontal Axis Deep Mixing (Massarsch \& Topolnicki, 2005)

\subsubsection{BINDER-SOIL INTERACTION}

DSM functions through the chemical bonds formed between soil and binder particles after mixing takes place. The most common cementitious material used as binder in DSM is ordinary portland cement due to its rather high strength compared with other materials, as well as high availability in most areas in the world. Other materials such as lime, a combination of cement and lime, fly ash or slag are also used (Abramson \& Brinckerhoff, 1997). The main process of strength improvement of cement-treated soil in DSM occurs when portland cement encounters soil pore water through the hydration of silicate and aluminate compounds in cement. Compounds in cement which achieve this effect include tricalcium silicate $\left(3 \mathrm{CaO} \cdot \mathrm{SiO}_{2}\right.$, or $\mathrm{C}_{3} \mathrm{~S}$ in cement chemist notation), bicalcium silicate $\left(\mathrm{CaO} \cdot \mathrm{SiO}_{2}\right.$, or $\left.\mathrm{C}_{2} \mathrm{~S}\right)$, which make up to $75 \%$ of portland cement in mass. Other cementitious compounds include tricalcium aluminate $\left(\mathrm{CaO} \cdot \mathrm{Al}_{2} \mathrm{O}_{3}\right.$, or $\left.\mathrm{C}_{3} \mathrm{~A}\right)$ and tetracalcium alumino- 
ferrite $\left(\mathrm{CaO} \cdot \mathrm{Al}_{2} \mathrm{O}_{3} \cdot \mathrm{Fe}_{2} \mathrm{O}_{3}\right.$, or $\left.\mathrm{C}_{4} \mathrm{AF}\right)$ (Bergado et al., 1996). The hydration reactions of these compounds, known as primary hydration, are as follows:

$$
\begin{aligned}
& 2\left(3 \mathrm{CaO} \cdot \mathrm{SiO}_{2}\right)+6 \mathrm{H}_{2} \mathrm{O} \rightarrow 3 \mathrm{CaO} \cdot 2 \mathrm{SiO}_{2} \cdot 3 \mathrm{H}_{2} \mathrm{O}+3 \mathrm{Ca}(\mathrm{OH})_{2} \quad \text { (Equation 2-1) } \\
& { }_{2} \mathrm{C}_{3} \mathrm{H} \quad \mathrm{C}_{3} \mathrm{~S}_{2} \mathrm{H}_{3} \quad \text { Calcium } \\
& \text { Tricalcium Silicate Hydroxide (Lime) } \\
& 2\left(2 \mathrm{CaO} \cdot \mathrm{SiO}_{2}\right)+4 \mathrm{H}_{2} \mathrm{O} \rightarrow 3 \mathrm{CaO} \cdot 2 \mathrm{SiO}_{2} \cdot 3 \mathrm{H}_{2} \mathrm{O}+\mathrm{Ca}(\mathrm{OH})_{2} \quad \text { (Equation 2-2) } \\
& 2 \mathrm{C}_{2} \mathrm{H} \\
& \text { Bicalcium Silicate } \\
& \underset{\text { Cricalcium Aluminate }}{3 \mathrm{CaO} \cdot \mathrm{Al}_{2} \mathrm{O}_{3}+\underset{\mathrm{AaH}}{12 \mathrm{H}_{2} \mathrm{O}}+\underset{\text { Tetracalcium Aluminate Hydrate }}{\text { (Equation 2-3) }}} \\
& \text { Tricalcium Aluminate }
\end{aligned}
$$

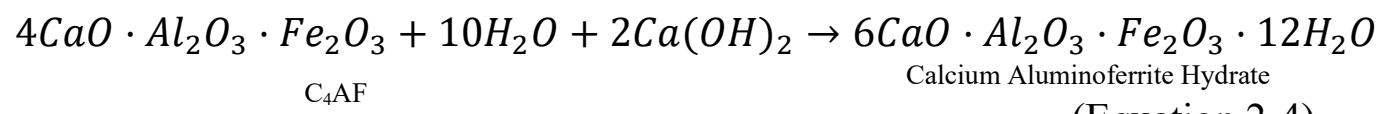

$$
\begin{aligned}
& \text { Tetracalcium Aluminoferrite }
\end{aligned}
$$

$\mathrm{C}_{3} \mathrm{~S}_{2} \mathrm{H}_{3}$ is the main provider of cement strength after hydration through the formation of a hydrated skeleton around soil particles. In clays, a secondary process, known as pozzalanic reactions, takes place when silica and alumina from the soil is dissolved after a $\mathrm{pH}$ increase due to the presence of $\mathrm{OH}^{-}$ions as a result of primary hydration. The combination of silica and alumina from the soil with calcium ions from cement leads to the formation of calcium silicate hydrates and calcium aluminate hydrates, which reinforces the strength of the soilcement mixture and reduces the soil's sensitivity to environmental factors. It has been documented that pozzolanic reaction continues to improve soil stabilization over a much longer time frame, usually lasting for months or years (Bergado et al., 1996; Ouhadi et al., 2014).

$$
\begin{aligned}
& \mathrm{Ca}(\mathrm{OH})_{2} \rightarrow \mathrm{Ca}^{2+}+2(\mathrm{OH})^{-} \\
& \text {(Equation 2-5) } \\
& \mathrm{Ca}^{2+}+2(\mathrm{OH})^{-}+\underset{\text { Silica }}{\mathrm{SiO}_{2}} \underset{\text { Calcium Silicate }}{\rightarrow} \underset{\text { Hydrate }}{\mathrm{CSH}} \\
& \mathrm{Ca}^{2+}+2(\mathrm{OH})^{-}+\mathrm{Al}_{2} \mathrm{O}_{3} \rightarrow \mathrm{CAH} \\
& \text { Alumina Calcium Aluminate } \\
& \text { Hydrate }
\end{aligned}
$$



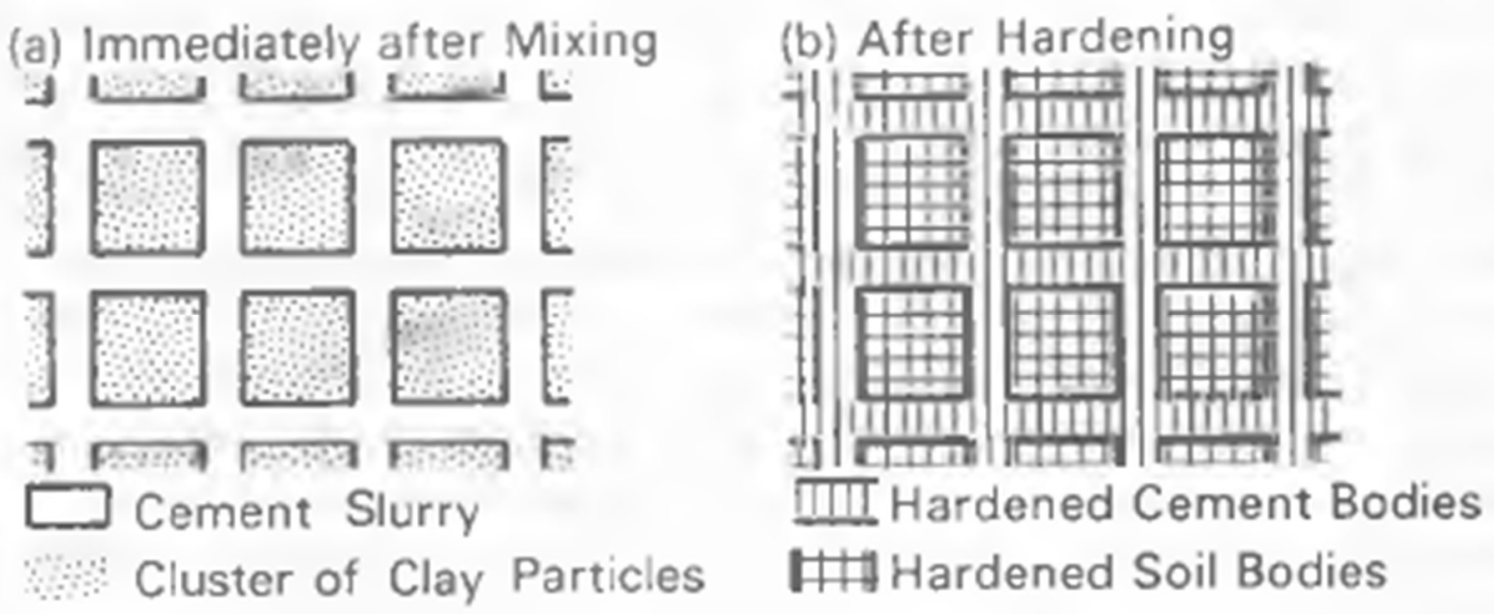

Figure 2-5: Illustration of Cement-Mixed Soil Microstructure (Saitoh et al., 1985)

\subsubsection{ApPliCAtion OF DeEP SoIl MiXing}

In geotechnical engineering, main applications of DSM include foundation support, retention systems, liquefaction mitigation and environmental remediation (Topolnicki, 2013).

\subsubsection{Foundation Support}

Foundation support is a major application of DSM where columns of treated soil provide reduction of settlement and improvement of bearing capacity on weak soils. DSM columns can be found in foundations of embankments, buildings, retaining walls and bridge abutments on land structures, as well as in marine structures such as quay walls, revetments and breakwaters. There is a great variety of DSM column installation patterns, which greatly vary based on the type of loading and application (Terashi, 1997). For example, higher loads often require combined lattices of mixed columns (Topolnicki, 2013). 

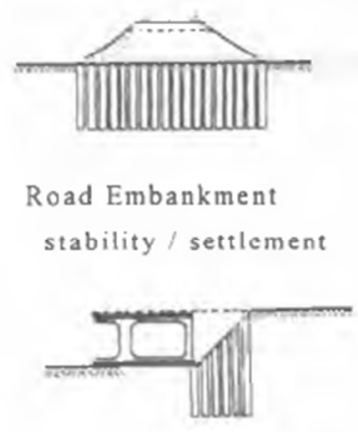

Stability of Cut Slope

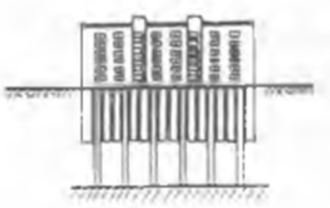

Pile foundation

lateral resistance

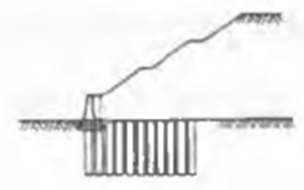

High embankment

stability

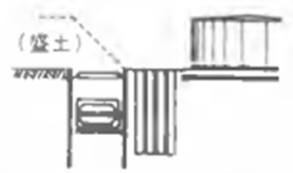

Reducing the influence

from nearby constructio

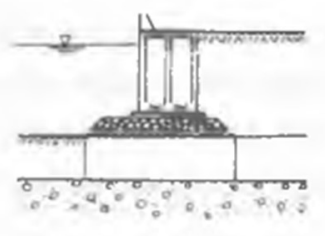

Sea wall

bearing capacity

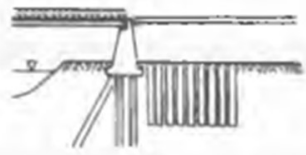

Bridge Abutment

uneven settlement

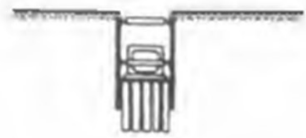

Braced Excavation

n

earth pressure/ heave

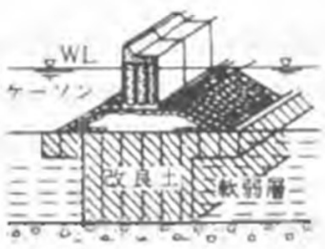

Break-water

bearing capacity

Figure 2-6: DSM Column Configurations for Different Applications (Terashi, 1997)

\subsubsection{Retention Systems}

Another common application of DSM columns is the use in retaining systems. A continuous wall of DSM columns forms the structure to resist lateral earth pressure. Compared with a metal sheet pile wall, which is very commonly used, DSM column retaining walls have the advantage of preventing groundwater seepage while being much cheaper than a cast-in-place reinforced concrete diaphragm wall. However, it has the disadvantage of a lower tensile strength than reinforced concrete. Under lateral pressure, a DSM wall tends to form tensile cracks and allow water seepage more readily than a reinforced concrete diaphragm wall would (Shao et al., 2005). To mitigate this, steel beams or reinforced concrete bored piles can be installed at intervals inside the mixed wall and an arched arrangement of mixed columns was used to transmit earth-water pressures into the steel beams (Shao et al., 2005; Denies \& Huybrechts, 2017). 


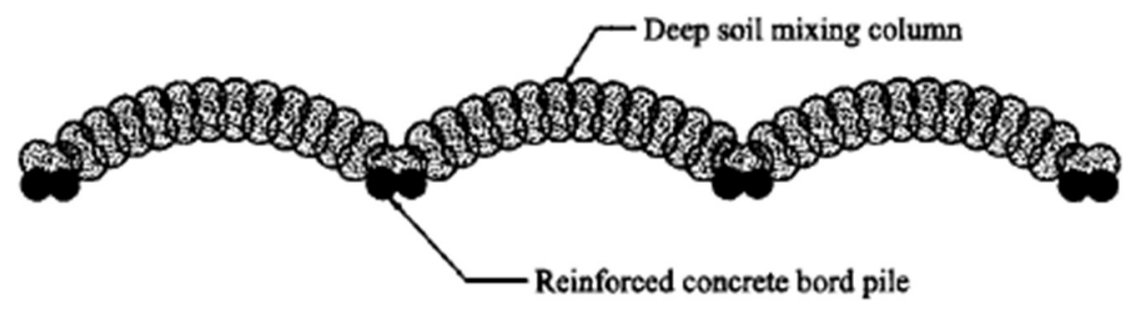

Figure 2-7: Schematic Configuration of DSM Retaining Wall (Shao et al., 2005)

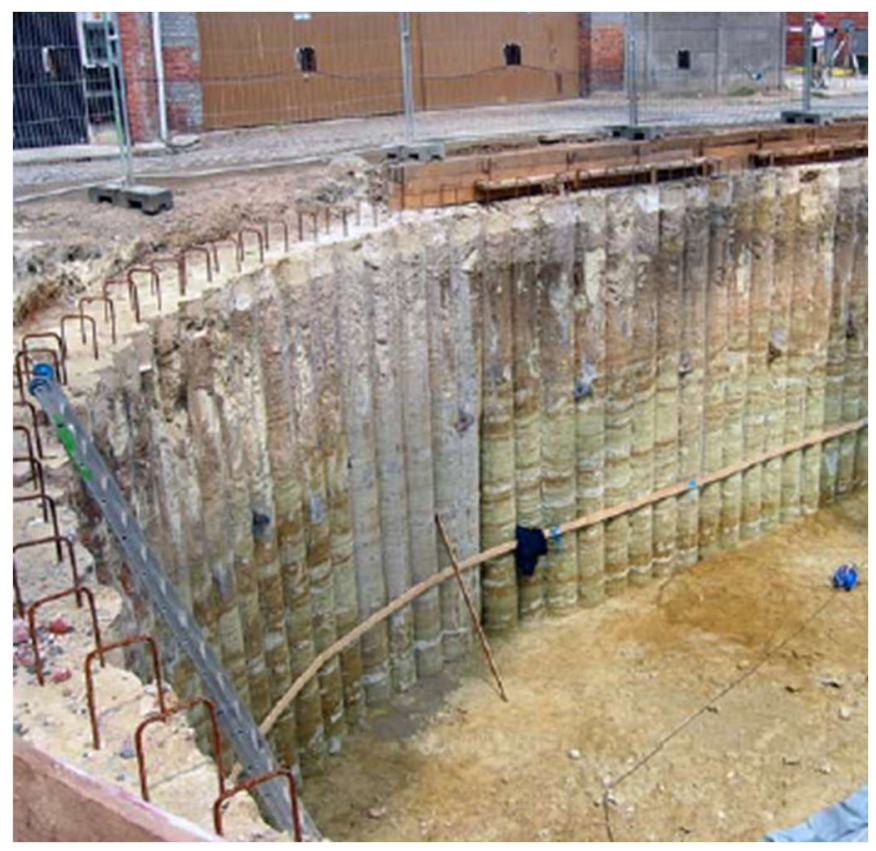

Figure 2-8: A DSM Retaining Wall (Denies \& Huybrechts, 2017)

\subsubsection{Liquefaction Mitigation}

Liquefaction refers to the sudden loss of shear strength in a cohesionless soil caused by an earthquake, coupled with a steep increase in excess pore water pressure, which essentially turns the soil into liquid and leads to rapid loss of strength that often caused landslides and structural damages (Porbaha et al., 1999; Higashi et al., 2010). The deep mixing method, based on the principle of solidification, often employs a lattice arrangement to create a solid skeleton to resist displacement of unimproved soil around it. Liquefaction mitigation using DSM has been applied to road embankments, river dikes, excavations and building foundations. It achieves resistance against soil displacement through a combination of effects including increased bearing resistance and uplift and seepage prevention (Porbaha et al., 1999). 


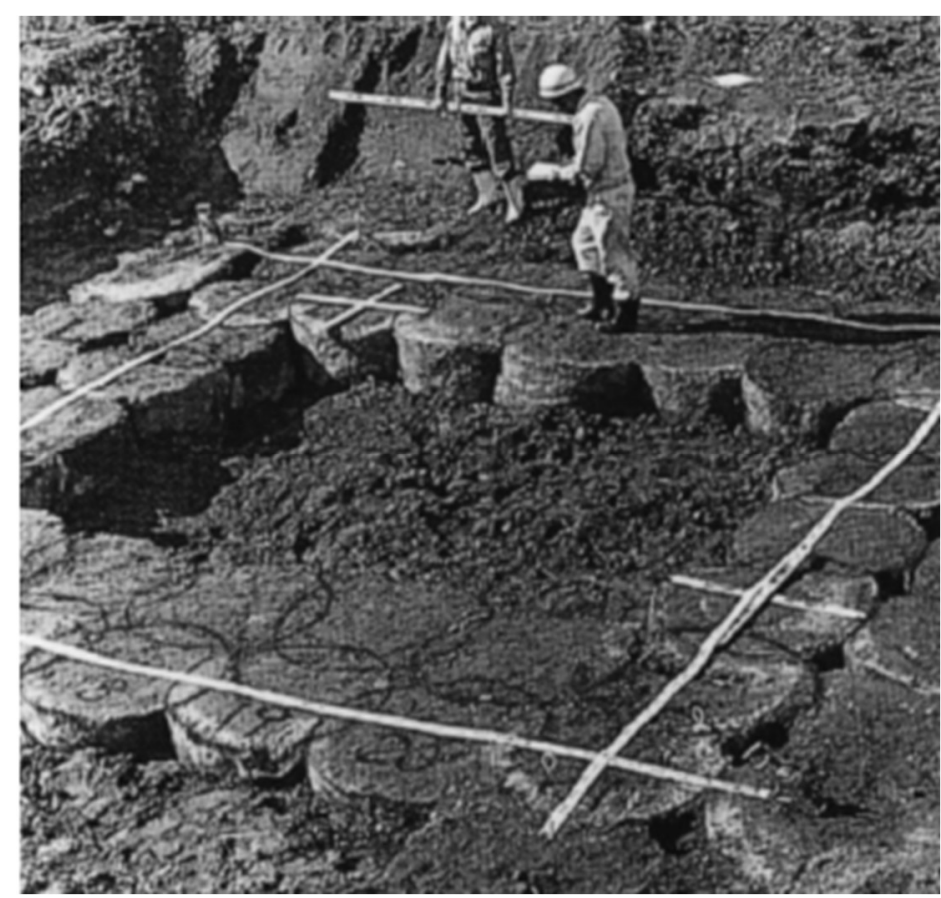

Figure 2-9: Lattice Arrangement of DSM Columns for the Purpose of Liquefaction Mitigation (Porbaha et al., 1999)

\subsubsection{Environmental Improvement}

In addition to direct foundational support, DSM can also be used to stabilize problematic soil, such as contaminated sediments or soft clay in estuary or marine environments for land reclamation purposes (Maher et al., 2005, Bryson, 2014). Costal sediments, such as that from New York/New Jersey harbor area studied by Maher et al., can contain contaminants such as dioxins, PCBs and pesticides and would require great effort and cost to remove by dredging. In situ deep mixing allows the reduction of moisture content and improvement in shear strength of the treated sediments, thereby reducing the potential for contaminants to be released into the environment by water movement. The mixed soil may be removed from the site and treated or left in place and potentially used for foundation purposes (Maher et al., 2005).

\subsubsection{FACTORS AfFecting StRENGTH GAIN}

According to Terashi (1997), there are four major classes of factors which affect strength gain in DSM: characteristics of hardening agent, conditions of soil, mixing conditions and curing conditions. Conventionally, it was assumed that in laboratory conditions, only amount of hardening agents (binders) and curing time can be controlled in the investigation 
of class III and IV factors (Terashi, 1997). In this study, the more easily manipulated factors of curing time and binder content (quantity of hardening agent) are investigated in the testing samples.

Table 2-1: Factors Affecting DSM Strength Gain (Terashi, 1997)

I. Characteristics of hardening agent
1. Type of hardening agent
2. Quality
3. Mixing water and additives
II. Characteristics and conditions of soil
1. Physical, chemical and mineralogical properties of soil
2. Organic content
3. pH of pore water
4. Water content
III. Mixing conditions
1. Degree of mixing
2. Timing of mixing / re-mixing
3. Quantity of hardening agent
IV. Curing conditions
1. Temperature
2. Curing time
3. Humidity
4. Wetting and drying / freezing and thawing, etc

\subsection{CHAMPLAIN SEA CLAY}

Champlain Sea clay, also known as Leda clay, has a significant presence in Eastern Canada and this clay can be classified into a wider category of clays known as quick clay, defined by the high ratio between its undisturbed and remoulded strength, i.e. high sensitivity (Brydon \& Patry, 1961; Mairesse, 1976). It is characterized by low strength, high moisture content, high compressibility and propensity to landslides, which pose engineering difficulties for construction projects in the area. In recent literature, there have been increasing discussions in the use of DSM in Champlain Sea clay (Li et al., 2017; Li et al., 2016).

\subsubsection{Geological History and Distribution of Champlain SEa Clay}

Champlain Sea clay refers to marine clay deposits in eastern Canada spanning from St. Lawrence lowlands to the vicinity of city of Ottawa (Lewis \& Todd, 2019). The origin of this deposit can be traced to the Wisconsin Ice Sheet of the last ice age that reached its 
maximum reach around 18,000 to 20,000 years $\mathrm{BP}$ (before present) and covered much of present day Hudson Bay area, eastern Canada and northeastern United States. Glacial retreat occurred between 18,000 to 6,000 years BP (Lewis \& Todd, 2019) and during this process, a glacial sea known as Champlain Sea covered present day St Lawrence River valley between 12,000 to 10,000 years BP and directly fed into Early Lake Ontario (Quigley, 1980; Lewis \& Todd, 2019). The ice sheet and bodies of water formed through melting of glaciers retreated in stages. By 10,000 years BP most of Champlain Sea turned into land. A large portion of present day Champlain Sea clay was deposited at this stage from sediments with origins in rock flour from Canadian Shield and the Appalachians. A smaller amount of sediment deposit occurred in present day eastern Quebec with the formation and disappearance of Mer La Flamme between 10,400 to 8,000 years BP. A final stage of deposition was completed with the retreat of Tyrrell and Iberville glacial seas before the coast line reached approximate present position by 6,000 years BP (Quigley, 1980).

The deposit is characterized by a $30 \mathrm{~m}$ to $60 \mathrm{~m}$ thick clayey layer covered by $1 \mathrm{~m}$ to $2 \mathrm{~m}$ thick stiff crust at the very top. The clayey layer contained $75 \%$ to $90 \%$ clay-sized material. Within the clayey layer, the top $1 \mathrm{~m}$ to $5 \mathrm{~m}$ contained mostly oxidized soft clay; below that layer a medium to stiff gray clay. At $15 \mathrm{~m}$ to $20 \mathrm{~m}$, the soil transitions to mostly stiff clay (Quigley et al., 1983).

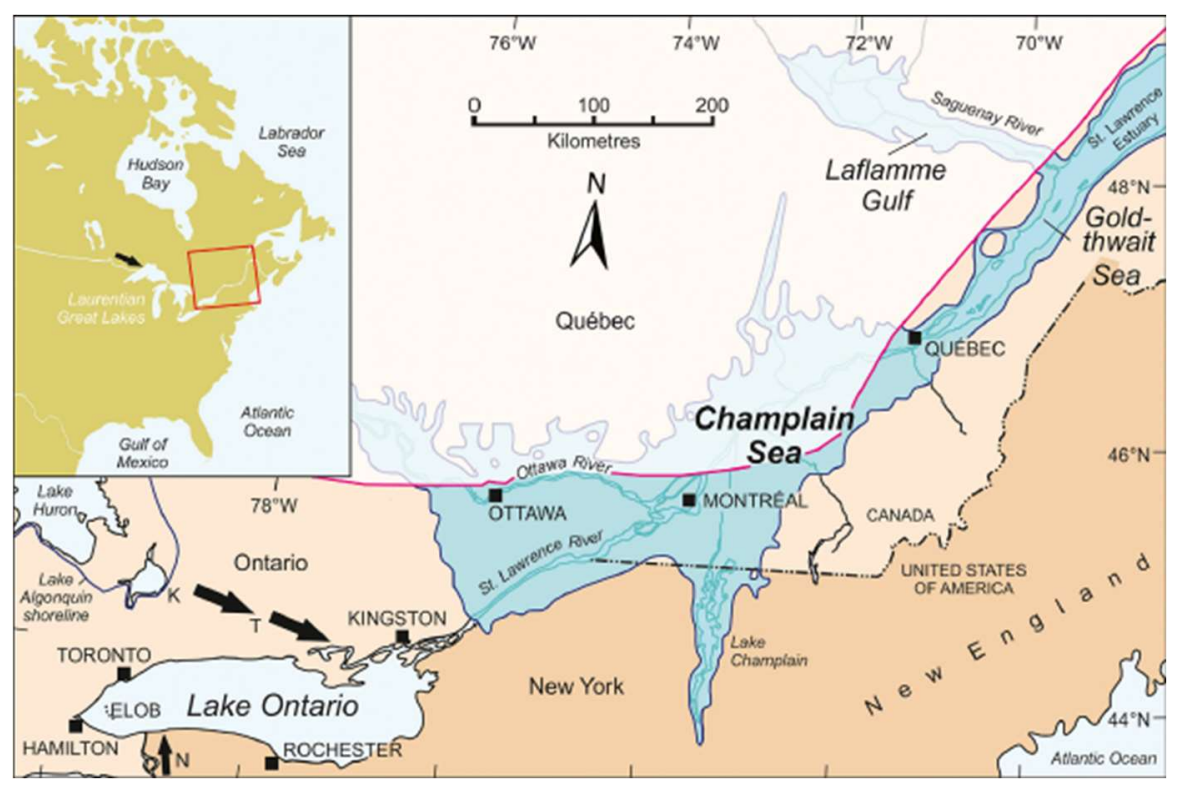

Figure 2-10: Current Champlain Sea Clay Deposits in Canada (Lewis \& Todd, 2019) 

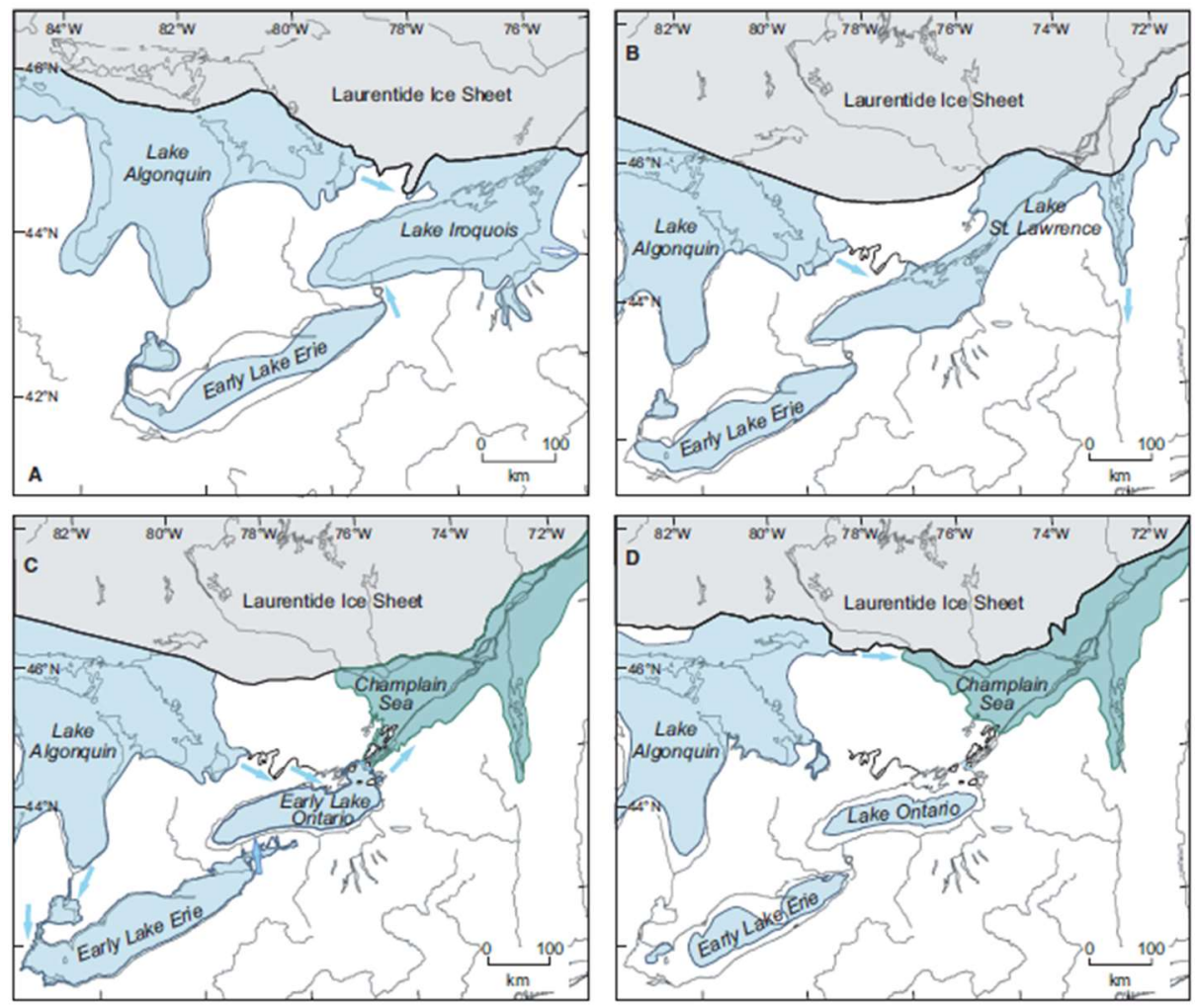

Figure 2-11: Ice Sheet Retreat and Champlain Sea Formation, Approximately 12,800 to 10,000 Years BP (Lewis \& Todd, 2019)

\subsubsection{Minerology and Chemical Composition}

The minerology and chemical composition of Champlain Sea clay was studied by Locat et al. (1984). The dominate mineral in Champlain Sea clay is plagioclase $\left(P_{L}\right)$, a mineral of the feldspar group, which ranged between $25 \%$ to $48 \%$ of total mass. Other minerals of significant amount included quartz $\left(Q_{Z}\right)$, microcline, homblende, dolomite and calcite. The dominate types of oxides in Champlain Sea clay were found to be $\mathrm{SiO}_{2}$ and $\mathrm{Al}_{2} \mathrm{O}_{3}$, which are able to facilitate pozzolanic reactions after cement treatment in deep soil mixing (Bergado et al., 1996; Ouhadi et al., 2014). 
Table 2-2: Mineral Deposits of Champlain Sea Clay at Select Sampling Sites (Locat et al., 1984)

\begin{tabular}{|c|c|c|c|c|c|c|c|c|c|c|}
\hline Site No. & Site & $N$ & $\begin{array}{l}P_{\mathrm{L}} \\
(\%)\end{array}$ & $\frac{Q_{z}}{(\%)}$ & $\begin{array}{l}\text { Microcline } \\
(\%)\end{array}$ & $\begin{array}{l}\text { Hornblende } \\
(\%)\end{array}$ & $\begin{array}{l}\text { Dolomite } \\
(\%)\end{array}$ & $\begin{array}{c}\text { Calcite } \\
(\%)\end{array}$ & $\begin{array}{c}P \\
(\%)\end{array}$ & $\begin{array}{l}\text { Illite } \\
(\%)\end{array}$ \\
\hline i $a$ & Grande-Baleine & 4 & $\begin{array}{c}41.3 \\
(39-46)\end{array}$ & $\begin{array}{c}15.3 \\
(14-16)\end{array}$ & $\begin{array}{c}13.5 \\
(13-14)\end{array}$ & $\begin{array}{c}12.7 \\
(11-15)\end{array}$ & $\begin{array}{c}1.0 \\
(0-2)\end{array}$ & $\begin{array}{l}0.3 \\
(0-0.5)\end{array}$ & 15.9 & 7.5 \\
\hline $1 b$ & Grande-Baleine & 5 & $\begin{array}{c}47.9 \\
(41-57)\end{array}$ & $\begin{array}{c}13.9 \\
(13-16)\end{array}$ & $\begin{array}{c}13.8 \\
(12-16)\end{array}$ & $\begin{array}{c}11.8 \\
(11-13)\end{array}$ & $\begin{array}{c}3.5 \\
(1-5)\end{array}$ & $\begin{array}{c}0.6 \\
(0.3-0.9)\end{array}$ & 8.5 & 7.2 \\
\hline $1 c$ & Grande-Baleine & 5 & $\begin{array}{c}40.4 \\
(37-48)\end{array}$ & $\begin{array}{c}16.8 \\
(13-20)\end{array}$ & $\begin{array}{c}14.5 \\
(13-16)\end{array}$ & $\begin{array}{l}11.0 \\
(9-14)\end{array}$ & $\begin{array}{c}1.9 \\
(1-3)\end{array}$ & $\begin{array}{c}0.4 \\
(0.2-0.6)\end{array}$ & 15.0 & 5.7 \\
\hline $2 a$ & Olga & 6 & $\begin{array}{c}29.1 \\
(22-34)\end{array}$ & $\begin{array}{c}11.4 \\
(10-13)\end{array}$ & $\begin{array}{c}9.6 \\
(8-11)\end{array}$ & $\begin{array}{c}9.4 \\
(7-10)\end{array}$ & $\begin{array}{c}3.7 \\
(0-5)\end{array}$ & $\begin{array}{c}2.3 \\
(1.5-2.7)\end{array}$ & 34.5 & 10.2 \\
\hline $2 c$ & Olga & 3 & $\begin{array}{c}33.1 \\
(31-36)\end{array}$ & $\begin{array}{c}13.0 \\
(11-15)\end{array}$ & $\begin{array}{l}10.8 \\
(8-13)\end{array}$ & $\begin{array}{r}8.6 \\
(7-9)\end{array}$ & $\begin{array}{c}2.5 \\
(2-3)\end{array}$ & $\begin{array}{c}0.7 \\
(0.5-0.9)\end{array}$ & 31.3 & 9.4 \\
\hline $3 a$ & St. Marcel & 3 & $\begin{array}{c}35.6 \\
(35-36)\end{array}$ & $\begin{array}{l}11.0 \\
\text { (11) }\end{array}$ & $\begin{array}{c}8.9 \\
(8-10)\end{array}$ & $\begin{array}{l}11.4 \\
(9-14)\end{array}$ & $\begin{array}{c}5.2 \\
(3-8)\end{array}$ & $\begin{array}{c}1.2 \\
(1.0-1.6)\end{array}$ & 26.7 & 9.2 \\
\hline $3 b$ & St. Marcel & 3 & $\begin{array}{l}33.7 \\
(34)\end{array}$ & $\begin{array}{c}13.9 \\
(13-14)\end{array}$ & $\begin{array}{c}9.8 \\
(8-11)\end{array}$ & $\begin{array}{l}11.1 \\
(9-12)\end{array}$ & $\begin{array}{c}5.0 \\
(5-6)\end{array}$ & $\begin{array}{c}1.6 \\
(1.5-1.7)\end{array}$ & 24.9 & 8.9 \\
\hline 4 & St. Léon & 15 & $\begin{array}{c}36.3 \\
(27-45)\end{array}$ & $\begin{array}{c}11.8 \\
(10-13)\end{array}$ & $\begin{array}{c}13.4 \\
(11-16)\end{array}$ & $\begin{array}{c}12.6 \\
(10-16)\end{array}$ & $\begin{array}{c}3.6 \\
(2-5)\end{array}$ & $\begin{array}{l}0.1 \\
(0-0.4)\end{array}$ & 32.2 & 11.1 \\
\hline 5 & St. Alban & 19 & $\begin{array}{c}25.1 \\
(22-33)\end{array}$ & $\begin{array}{c}20.5 \\
(17-24)\end{array}$ & $\begin{array}{c}9.5 \\
(8-13)\end{array}$ & $\begin{array}{c}9.5 \\
(5-14)\end{array}$ & $\begin{array}{l}1.5 \\
(0-5)\end{array}$ & $\begin{array}{c}0.7 \\
(0-1.2)\end{array}$ & 33.2 & 11.2 \\
\hline 6 & St. Barnabé & 3 & $\begin{array}{c}37.0 \\
(33-40)\end{array}$ & $\begin{array}{c}12.2 \\
(11-13)\end{array}$ & $\begin{array}{c}14.4 \\
(12-16)\end{array}$ & $\begin{array}{c}13.3 \\
(12-15)\end{array}$ & $\begin{array}{c}3.5 \\
(3-5)\end{array}$ & $\begin{array}{c}0.2 \\
(0.2-0.3)\end{array}$ & 19.4 & 6.9 \\
\hline 7 & Shawinigan & 5 & $\begin{array}{c}36.8 \\
(32-42)\end{array}$ & $\begin{array}{c}19.6 \\
(17-24)\end{array}$ & $\begin{array}{c}15.0 \\
(14-16)\end{array}$ & $\begin{array}{c}13.4 \\
(12-17)\end{array}$ & $\begin{array}{l}2.4 \\
(0-4)\end{array}$ & - & 12.8 & 9.4 \\
\hline 8 & Chicoutimi & 8 & $\begin{array}{c}41.1 \\
(35-44)\end{array}$ & $\begin{array}{c}19.8 \\
(17-23)\end{array}$ & $\begin{array}{c}13.2 \\
(12-16)\end{array}$ & $\begin{array}{c}9.7 \\
(7-13)\end{array}$ & $\begin{array}{l}1.5 \\
(0-3)\end{array}$ & $\begin{array}{c}0.7 \\
(0.4-1.0)\end{array}$ & 14.0 & 2.7 \\
\hline
\end{tabular}

\subsubsection{ENGINEERING CHALLENGES}

Numerous engineering failures have been observed in Champlain Sea clay soil. Since the 19th century, several dozens of landslides in Quebec have been attributed to the structural weakness of the clay. The landslide which claimed the highest number of human lives was the 1908 Notre-Dame-de-la-Salette landslide when 33 people were killed and the landslide with the largest property damage was the 1955 Nicolet landslide with damage of $\$ 5$ million in 1955 Canadian dollars (La Rochelle et al., 1970).

Table 2-3: Oxide Concentration in Champlain Sea Clay Samples (Locat et al., 1984)

\begin{tabular}{|c|c|c|c|c|c|c|c|c|}
\hline \multirow[b]{2}{*}{ Compound } & \multicolumn{8}{|c|}{ Site No. } \\
\hline & $\begin{array}{c}\text { Grande- } \\
\text { Baleine } \\
(1 b)\end{array}$ & $\begin{array}{l}\text { Olga } \\
(2 a)\end{array}$ & $\begin{array}{l}\text { St. Marcel } \\
\qquad(3 a)\end{array}$ & $\begin{array}{l}\text { St. Léon } \\
\text { (4) }\end{array}$ & $\begin{array}{l}\text { St. Alban } \\
\text { (5) }\end{array}$ & $\begin{array}{l}\text { St. Barnabé } \\
\text { (6) }\end{array}$ & $\begin{array}{c}\text { Shawinigan } \\
\text { (7) }\end{array}$ & $\begin{array}{c}\text { Chicoutimi } \\
(8)\end{array}$ \\
\hline $\mathrm{SiO}_{2}$ & 59.33 & 52.83 & 53.36 & 55.36 & 59.79 & 58.26 & 61.87 & 62.43 \\
\hline $\mathrm{TiO}_{2}$ & 0.77 & 0.61 & 0.72 & 0.92 & 0.89 & 0.97 & 0.87 & 0.80 \\
\hline $\mathrm{Al}_{2} \mathrm{O}_{3}$ & 16.10 & 17.05 & 16.42 & 16.38 & 15.28 & 16.15 & 15.55 & 16.37 \\
\hline $\mathrm{CaO}$ & 2.90 & 4.41 & 4.26 & 3.60 & 3.73 & 3.51 & 3.62 & 5.40 \\
\hline $\mathrm{K}_{2} \mathrm{O}$ & 3.59 & 3.72 & 3.19 & 3.51 & 3.40 & 3.71 & 3.32 & 2.38 \\
\hline $\mathrm{Na}_{2} \mathrm{O}$ & 4.10 & 2.47 & 2.88 & 3.89 & 2.60 & 3.98 & 3.63 & 3.74 \\
\hline $\mathrm{MgO}$ & 3.78 & 4.06 & 4.75 & 3.95 & 2.88 & 3.23 & 2.70 & 2.06 \\
\hline $\mathrm{Fe}$ (total) & 4.22 & 4.72 & 5.16 & 5.19 & 4.46 & 4.86 & 4.32 & 3.07 \\
\hline $\mathrm{FeO}$ & 3.25 & 2.99 & 4.11 & 3.19 & 2.92 & 3.85 & 3.58 & 2.52 \\
\hline $\mathrm{Fe}_{2} \mathrm{O}_{3}$ & 2.42 & 3.42 & 2.80 & 3.87 & 3.13 & 2.66 & 2.19 & 1.58 \\
\hline $\mathrm{P}_{2} \mathrm{O}_{5}$ & 0.25 & 0.20 & 0.18 & 0.29 & 0.27 & 0.34 & 0.32 & 0.22 \\
\hline $\mathrm{CO}_{2}$ & 0.48 & 3.74 & 3.96 & 2.13 & 1.50 & 0.72 & 0.43 & 1.06 \\
\hline $\mathrm{H}_{2} \mathrm{O}$ (total) & 2.24 & 4.15 & 3.51 & 3.03 & 2.32 & 1.84 & 1.12 & 0.83 \\
\hline $\mathrm{MnO}$ & 0.09 & 0.08 & 0.11 & 0.12 & 0.10 & 0.11 & 0.11 & 0.08 \\
\hline
\end{tabular}


Champlain Sea clay is known for its high sensitivity (Mairesse, 1976; Ahmad, 2018; Afroz, 2019). Sensitivity is defined as the ratio between a soil's undisturbed strength and remoulded (or disturbed) strength. It has been well documented that Champlain Sea clay often has a sensitivity value of over 20 and tends to turn into a liquid state once remoulded, due to its high moisture content (Mairesse, 1976). Another challenged presented by Champlain Sea clay was the effect of leaching, i.e. the loss of salinity through the addition of fresh water. As the clay originated from marine deposits, the pore water usually has a rather high salinity. A high salinity has been documented to have a positive impact on soil undisturbed strength (Torrance, 1984). However, as fresh water infiltrates the clay, salinity is reduced and so is the soil strength, jeopardizing structures if they were designed as if soil strength at the soil's original salinity were permanent (Ahmad, 2018; Afroz, 2019).

\subsubsection{DSM of Champlain Sea Clay}

The investigation of the use of DSM in Champlain Sea clay is a relative new research topic on this soil. Nevertheless, there has been several laboratory studies already demonstrating that the use of cement and other binder materials in Champlain Sea clay mixing resulted in improvements of strength and compressibility (Li et al., 2016a \& 2016b; Li et al., 2017; Afroz et al., 2018)

Li et al. (2016a \& 2016b) investigated the use of cement and slag-cement as binders in the treatment of Champlain Sea clay and performed unconfined compression strength (UCS) testing. Cement treated clay was found to be approximately ten times higher in UCS strength than undisturbed clay. Higher binder content and curing time were generally associated with higher UCS strength and soil elastic modulus.

Li et al. (2017) performed UCS testing on cement and lime treated Champlain Sea clay and further observed strength and compressibility improvement with the addition of binder materials. Cement was found to be more effective in strength gain than lime, achieving 13 times strength increase and $21 \%$ compressibility reduction compared with the undisturbed sample. Strength did not seem to increase with binder content linearly and strength increase gradually plateaued beyond $100 \mathrm{~kg} / \mathrm{m}^{3}$ cement content. 
Another study on strength and compressibility of cement-treated Champlain Sea clay was performed by Afroz et al. (2018) using laboratory UCS and constant rate of strain (CRS) testing. Significant improvement in strength and compressibility was again found.

Ahmad (2018) studied the effect of leaching on the compressibility of cement-treated Champlain Sea clay. Leached samples were found to have undergone better compressibility improvement with cement treatment. Afroz (2019) investigated the impact on leaching on both shear strength and compressibility. Leached samples, though showing inferior strength and compressibility parameter values compared with unleached ones, showed better compressibility improvement after cement treatment.

Monsif and Liu (2019) investigated the usage of a wide variety of binder material in the DSM treatment of Champlain Sea clay in USC testing. A scanning electron microscope (SEM) imaging investigation was also performed. Cement treated samples were again found to increase in strength with increasing cement content and curing time. Other binder materials investigated included cement with silica fume, slag-cement and cement with kiln dust but none of these materials showed higher strength than general use (GU) cement. The SEM images showed a great reduction of voids in treated clay as voids were filled with hydration products such as calcium silicate hydrates, which resulted in strength increase.

\subsection{SOIL TENSILE STRENGTH}

This section presents the current literature on the significance of soil tensile strength and its testing methods, as well as specific applications of tensile strength in soil treated in deep mixing.

\subsubsection{Significance of Tensile Strength of Soils}

Tensile strength is a significant mechanical parameter of soils when an earth structure, such as dam, embankment or slope, is subject to cracking (Tang et al., 2014; Li et al., 2014). Morris et al. (1992) observed tensile stress in soil strength envelopes in crack formation of desiccating soils. Tang et al. (2010) noted that crack formation occurs when tensile stress induced by desiccation exceeds soil tensile strength. Cracking has been associated with structural failures in dams (Tang et al., 2011), embankments and dikes (Tang et al., 2014), which makes tensile strength an important parameter in the design of these structures. On 
the other hand, differential settlement may also induce tensile stress in soil structures, as observed by Rajesh and Viswanadham (2015) in landfill covers.

In the case of soil treated in deep mixing, tensile strength has additional significance. The DSM column used for foundational or retaining support can be subject to tensile stress when under loading. In the case of a DSM retaining wall, it has been documented that the rather weak tensile strength of the system compared with that of reinforced concrete may limit the depth of the design retaining wall (Shao et al., 2005; Denies \& Huybrechts, 2017). For DSM columns used for embankment support, Nguyen et al. (2016) demonstrated that such columns are exposed to tensile stress under compressive loading. Therefore the tensile strength value of the mixed soil would be significant for design. Voottipruex et al. (2011) performed field testing and numerical analysis of DSM piles under lateral loading. Tensile strength values were shown in simulation to be critical in predicting lateral displacements.

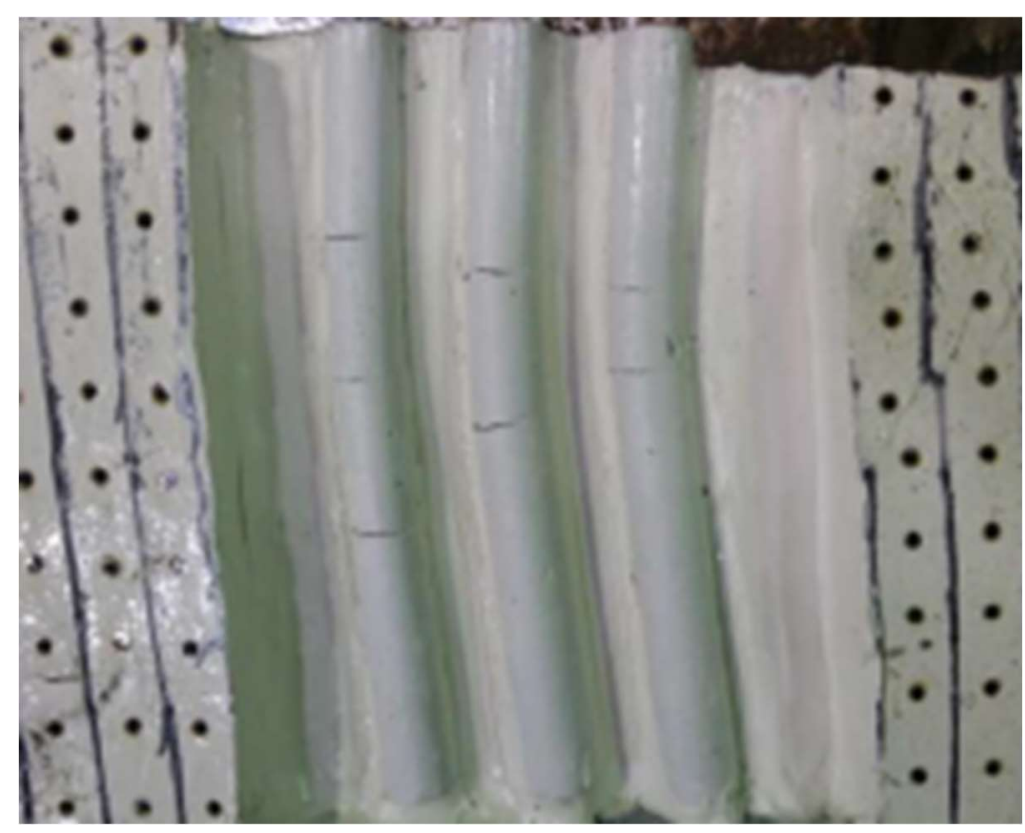

Figure 2-12: Physical Model of DSM Columns Under Loading. Certain Parts of the Columns Are Under Tension. (Nguyen et al., 2016) 


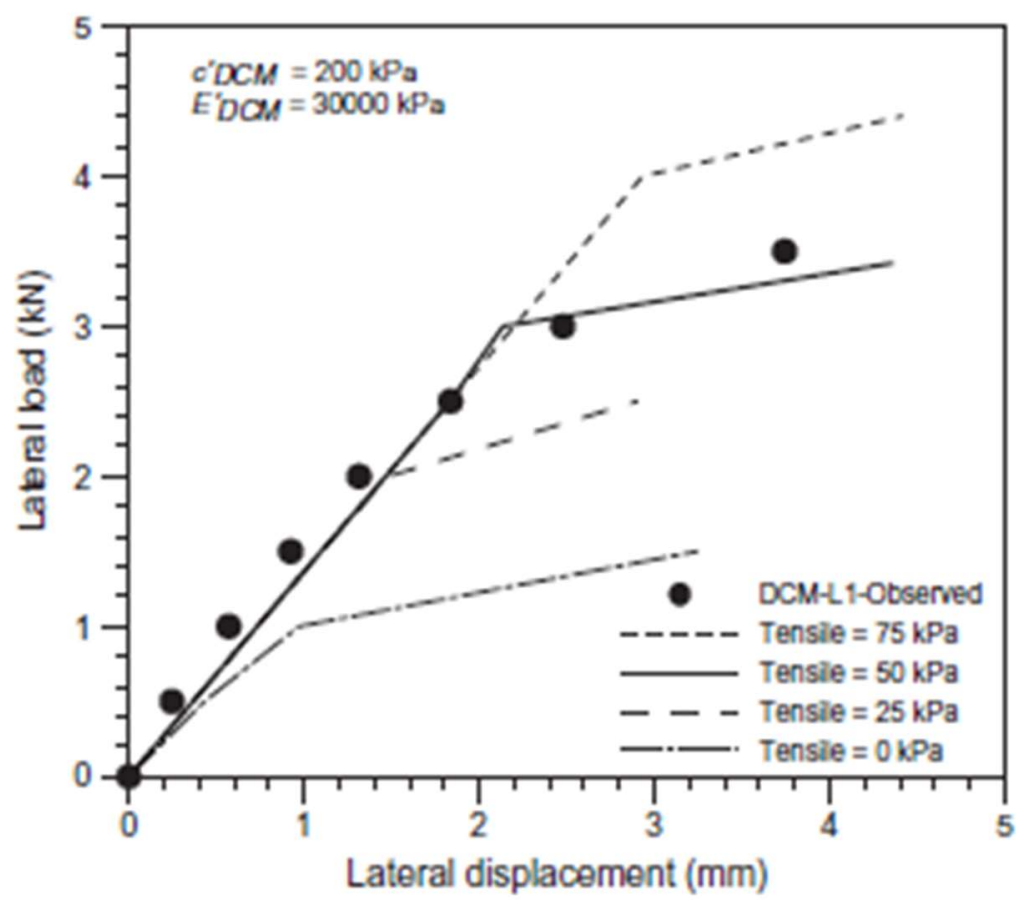

Figure 2-13: The Impact of Tensile Strength on Lateral Displacement of a DSM Pile (Voottipruex et al., 2011)

Up to 1990s, soil tensile strength was rarely studied (Morris et al., 1992). In recent years there has been a gradual increase in the amount of available literature, mainly on laboratory experimentations of tensile strength measurement (Li et al., 2014). However, there is still a limited amount of studies on the tensile behavior of soils treated with cement in DSM and there has been no information on the tensile strength of cement-treated Champlain Sea clay. With the increasing amount of geotechnical construction in Eastern Canada involving Champlain Sea clay, it would be great research interest to investigate the tensile behavior of this type of soil.

\subsubsection{LABORATORY InVESTIGATION OF SOIL TENSILE StREngth}

Two major types of laboratory tensile testing methods exist: direct and indirect testing. Brazilian tensile testing and unconfined penetration, both indirect methods, have been chosen as experimental methods for this study. Other types of indirect testing will also be covered. 


\subsubsection{Direct Tensile Testing}

Direct tensile testing refers to pulling the experimental sample directly in tension. The most common type of direct testing is the direct tensile test, also known as uniaxial tensile test, where a simple cylindrical soil sample is used ( $\mathrm{Li}$ et al., 2019). It makes measurements of the material's stress-stress behavior directly without any assumptions and is able to provide the complete stress-strain response of the soil (Leavell \& Peters, 1987). However, this method has a major drawback. It is nearly impossible to grip the specimen at its ends without inducing non-uniform stress fields or stress concentrations. Such stress concentrations are very likely to develop, especially at the ends of the specimen (Leavell \& Peters, 1987; Li, et al.., 2019). Nahlawi et al. (2004) developed the technique of reduced section at the center of specimen to mitigate the problem of undesired failure at specimen end. A more modern standard setup of uniaxial tensile test was documented by Wang et al. (2007), as well as Zhang, et al. (2006), who noted that the uniaxial tensile test is adequate for testing tensile strength measurement but not for gauging deformation. Uniaxial tensile testing with a steel mold for better gripping was devised by Li et al. (2019). However, these improvements are still far from achieving a reliable, easy-to-use direct tensile testing regimen that is readily applicable in the industry.

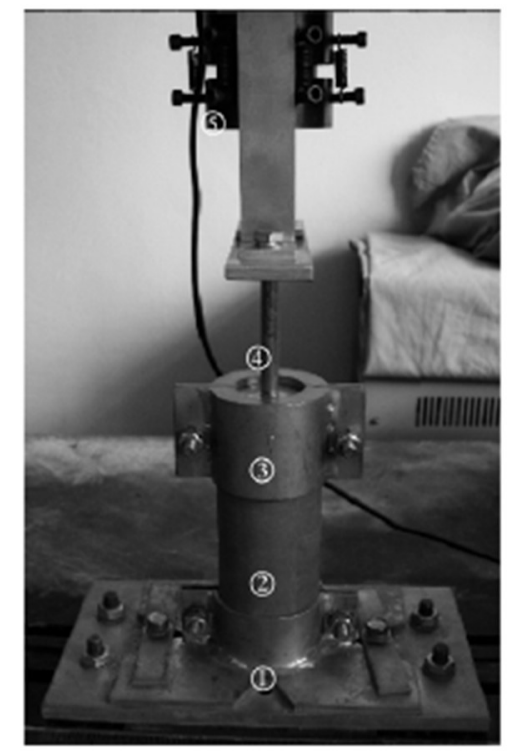

(1): Lower clamp; (2): Specimen; (3) Upper clamp;

(4): Loading pole: (5): Load sensor and displacement sensor

Figure 2-14: Direct Tensile Testing Setup (Wang et al., 2007) 


\subsection{Triaxial Tensile Test}

The triaxial test, which is one of the most reliable method of laboratory testing to obtain shear strength parameters such as friction angle and undrained shear strength (Das \& Sobhan, 2010), can be fitted to test for tensile strength (Namikawa \& Mihira, 2007; Namikawa et al., 2007). Namikawa and Mihira (2007) and Namikawa et al. (2017) conducted triaxial tensile testing as well as related numerical modelling on cement treated sand. Instead of a positive deviator stress as in compressive triaxial tests, a negative deviator stress was applied along with a confining pressure in the triaxial tension. Consolidated drained testing was performed and failure envelopes that is a combination of Mohr-Coulomb shear failure surface and a vertical tensile failure surface, were attained. For the purpose of this study, triaxial tension testing was not considered due to the lack of appropriate equipment in the laboratory and its rather complexity in application in the context of industry use.

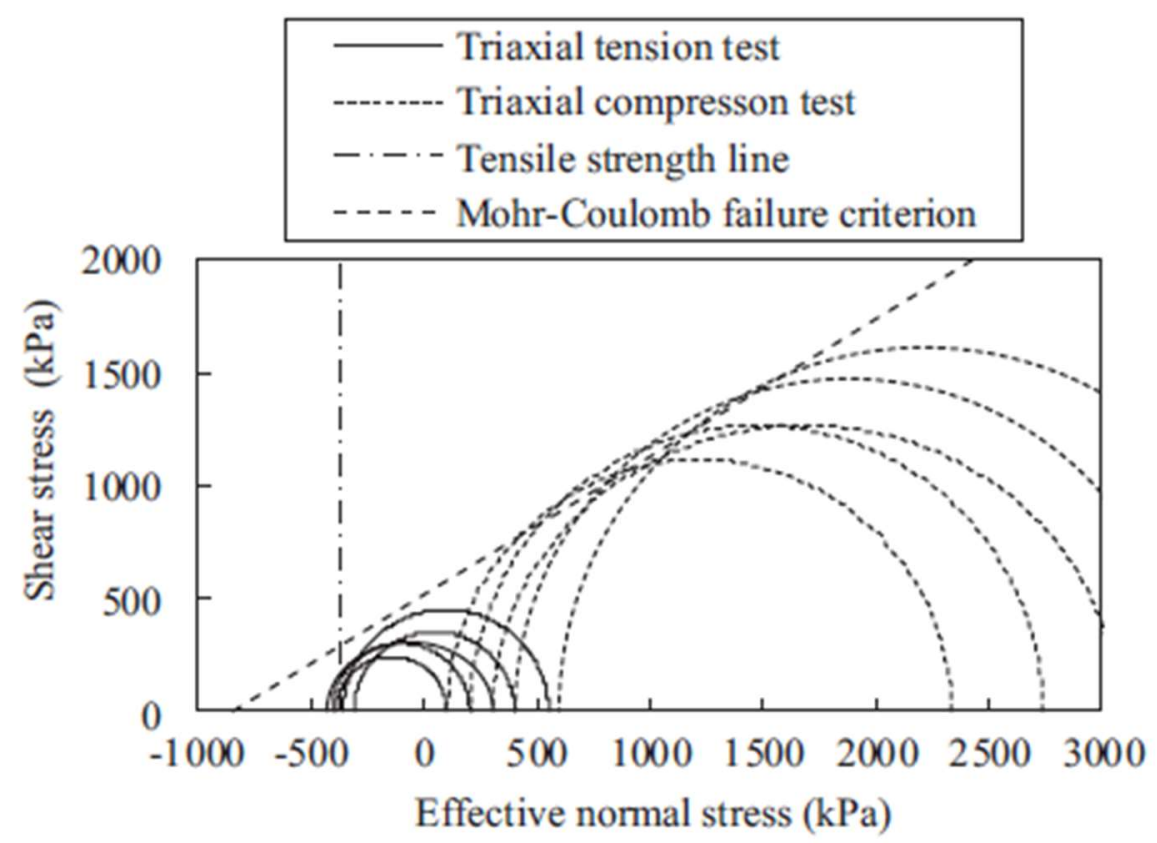

a). Namikawa and Mihira (2007) 


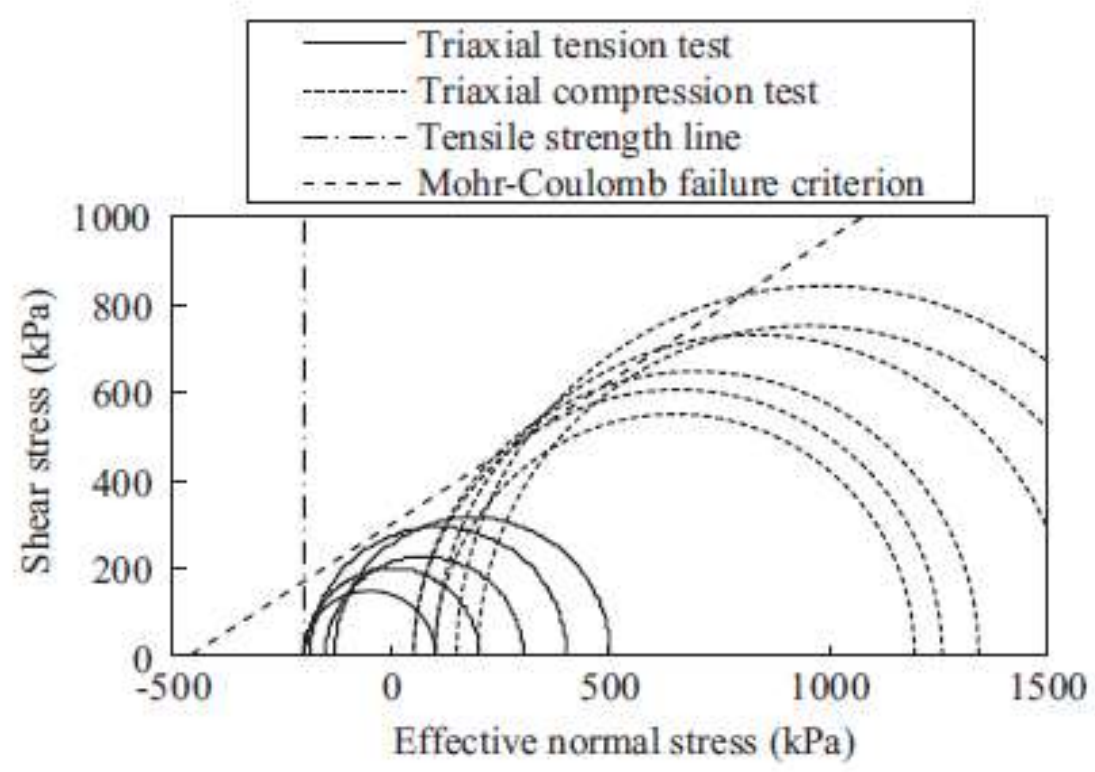

b) Namikawa et al. (2017)

Figure 2-15: Failure Envelopes Obtained through Triaxial Tensile Tests

\subsubsection{Indirect Tensile Testing}

Due to the difficulties in sample preparation for direct tensile testing, various indirect methods have been developed. Though indirect methods rely on assumptions on the soil stress-strain behavior and often involve a combination of tensile and compressive stresses (Leavell \& Peters, 1987), many of these methods can simply performed with easy-toprepare samples. The two types of indirect tensile testing planned for this study were the Brazilian tensile test and the unconfined penetration test.

\subsection{Brazilian Tensile Test}

The Brazilian tensile test, also known as the split tensile test or simply the indirect tensile test in earlier literature (Al-Omar, 1983), is an indirect testing setup utilizing compressive action to obtain tensile strength through a relationship. In this setup, two identical testing plates are compressed uniaxially towards each other, deforming a horizontally placed sample in between. The tensile strength relationship was developed based on Frocht's equations for stress at a point (Figure 2-16) (Hudson \& Kennedy, 1968). At the center of the sample, at $x=0$ and $y=0$, the shear stress and vertical stress are both zero while horizontal stress can be simplified to the equation $\sigma_{x}=2 P / \pi t d$, which is the tensile 
strength formula for this test when the force value is force at failure. This type of testing was intended for a brittle crystalline material such as concrete (Hudson \& Kennedy, 1968). Since the properties of cement-treated soil has been documented to exhibit behaviors closer to concrete (Bergado et al, 1996), it has been assumed that this type of testing can be applicable to the tensile testing of our cement-treated clay.

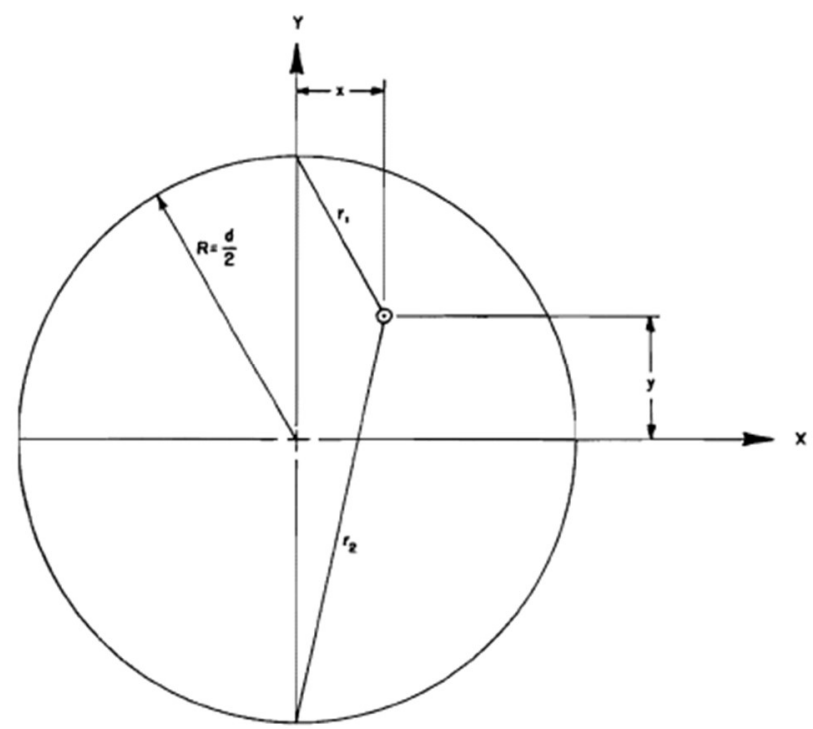

Figure 2-16: Stress at a Point in a Sample (Hudson \& Kennedy, 1968)

At any point $x, y$ (Frocht, 1957):

$$
\begin{aligned}
& \sigma_{x}=\frac{-2 P}{\pi t}\left[\frac{(R-y) x^{2}}{r_{1}^{4}}+\frac{(R+y) x^{2}}{r_{2}^{4}}-\frac{1}{d}\right] \\
& \sigma_{y}=\frac{-2 P}{\pi t}\left[\frac{(R-y)^{3}}{r_{1}^{4}}+\frac{(R+y)^{3}}{r_{2}^{4}}-\frac{1}{d}\right] \\
& \tau_{x y}=\frac{2 P}{\pi t}\left[\frac{(R-y) x}{r_{1}^{4}}+\frac{(R+y) x}{r_{2}^{4}}\right]
\end{aligned}
$$

Where $P$ = applied load

$t=$ thickness of the sample

At $x=0$ and $y=0$, i.e., the center of the specimen, the above equations reduce to:

$$
\sigma_{x}=\frac{2 P}{\pi t d}
$$




$$
\begin{gathered}
\sigma_{y}=\frac{-6 P}{\pi t d} \\
\tau_{x y}=0
\end{gathered}
$$

Therefore, the equation $\sigma_{x}=\frac{2 P}{\pi t d}$ can be used to evaluate $\sigma_{t}$ at the center of the sample (Hudson \& Kennedy, 1968).

The Brazilian tensile testing is arguably the most commonly used indirect tensile testing method, with wide application in concrete (Neville \& Brooks, 2010) and untreated soils (Akin \& Likos, 2017). For soil treated in deep mixing, there have been a recent expansion in the available literature encompassing a variety of soil types and binder materials.

\subsection{Unconfined Penetration}

In this type of test, a compressive stress is applied to a sample place upright, as in an unconfined compressive strength (UCS) testing, using two small-diameter testing plates known as discs (Kim et al., 2012). Similar to the Brazilian test, the tensile stress is derived based on a mathematical relationship. The test was initially developed from the doublepunch test intended for concrete (Fang, 1971). Like the Brazilian tensile testing, the similar nature of cement-treated soil to concrete (Bergado et al, 1996) also makes this type of testing a potential candidate for the evaluation of tensile strength.

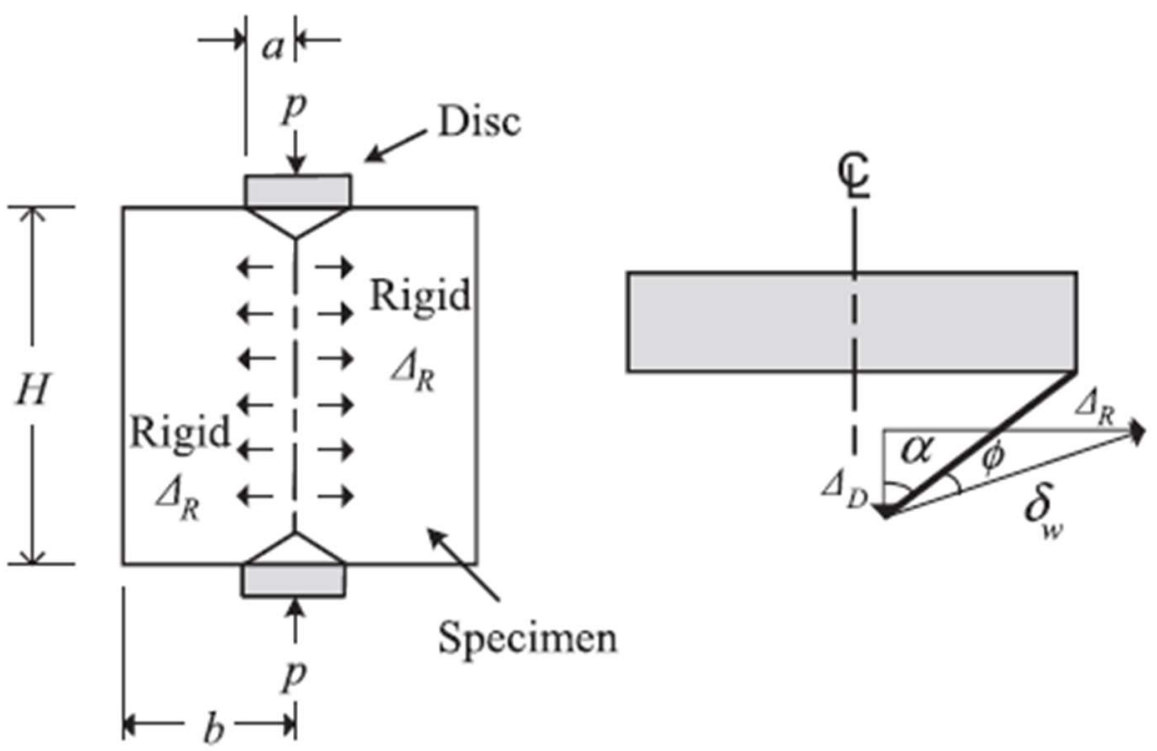

Figure 2-17: Illustration of Unconfined Penetration Test 
The applied load at failure, $P_{\max }$, can be used to calculate the tensile strength based on the following relationship (Kim et al., 2012):

$$
\frac{P_{\max }}{\pi a^{2}}=\frac{1-\mathrm{si}}{\sin \alpha \mathrm{c}(\alpha+\varphi)} * \frac{q_{u}}{2}+\tan (\alpha+\varphi)\left(\frac{b H}{a^{2}}-\cot \alpha\right) \sigma_{t} \quad \text { (Equation 2-10) }
$$

When $\partial P / \partial \alpha=0$, the above equation can be reduced to:

$$
\sigma_{t}=\frac{P}{\pi *\left(K R H-a^{2}\right)}
$$

where:

$\sigma_{t}=$ tensile strength of sample

$P=$ force applied at failure

$R=$ radius of the sample

$H=$ height of the sample

$a=$ radius of penetration disc

$K$ is a factor and its values were provided for different types of soil molds, shown in Table 2-4. In earlier literature such as Fang (1971), $K$ was assume to be 1.0 for all soils.

Table 2-4: Values of K for Different Types of Soil Molds (Kim et al., 2012)

\begin{tabular}{|l|l|}
\hline Soil Mold & $K$ Value \\
\hline Harvard miniature compaction mold $(3.3 \times 7.2 \mathrm{~cm})$ & $1.05 \sim 1.10$ \\
\hline Proctor mold $(10.2 \times 11.3 \mathrm{~cm})$ & 1.0 \\
\hline CBR mold $(15.2 \times 17.8 \mathrm{~cm})$ & 0.8 \\
\hline
\end{tabular}

Alternatively, $K$ can be calculated using the formula below:

$$
K=\tan (2 \alpha+\varphi)
$$

where $\alpha=$ angle measured at failure cone

$\varphi=$ undrained friction angle of soil

Recent literature on unconfined penetration of untreated soils such as Kim et al. (2012) and Liang et al. (2014) made use of the equation for $K$. However, the papers did not describe 
in detail how the angle $\alpha$ is measured. It is assumed that measurement were made through visual inspection.

\subsection{Other Indirect Testing Methods}

Another way of obtaining tensile strength using an indirect method is to apply flexure instead of compression and documenting the stress at tensile crack of the tension side of the specimen under bending, i.e. the modulus of rupture (Neville \& Brooks, 2010). LinaresUnamunzaga, et al. (2019) documented the measuring of flexural strength of a cement treated soil sample and observed failure on the tension side of the specimen. Flexual strength were observed to be about $11 \%$ of UCS, not far from tensile strength measurements made from the Brazilian test based on other studies.

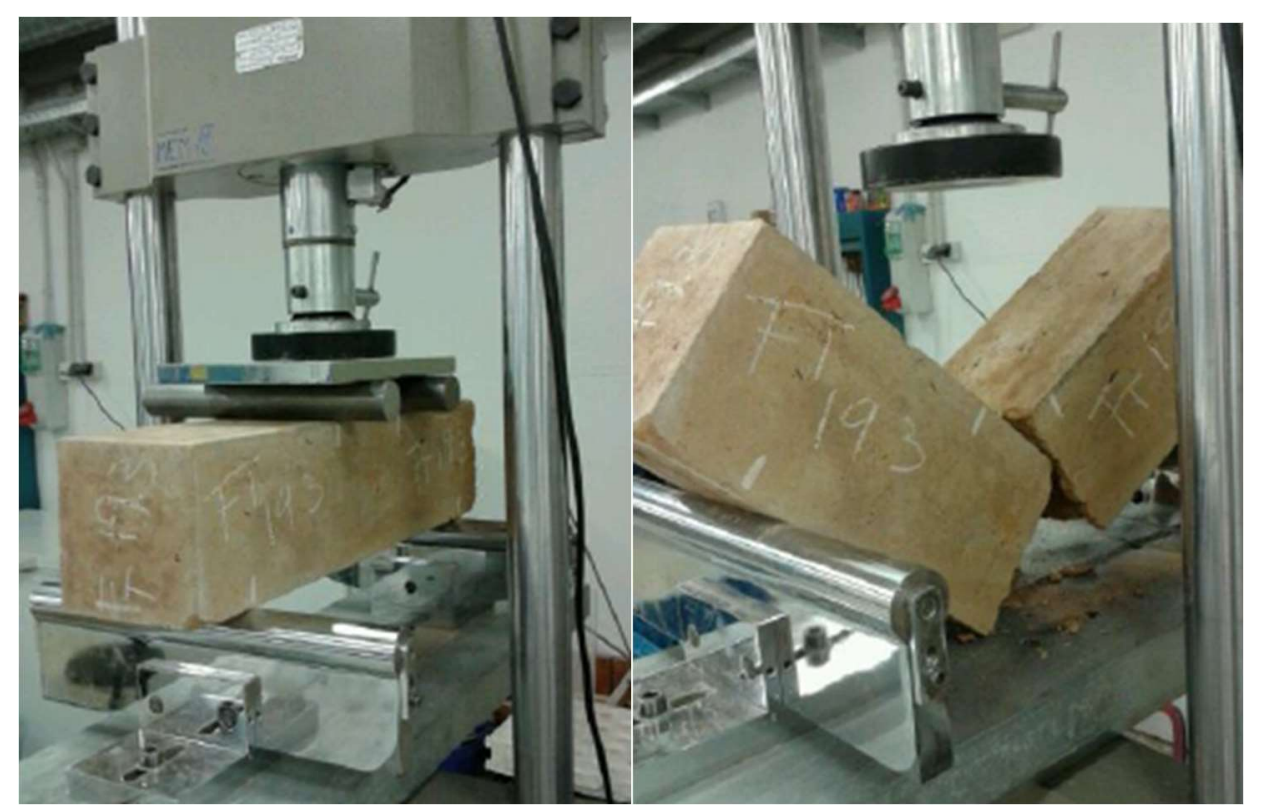

a) Before Sample Failur

b) After Sample Failure

Figure 2-18: Tensile Strength Testing Using Flexure Test (Unamunzaga et al., 2019)

Varsei et al. (2016) developed a novel approach to tensile strength measurement by applying load cells to obtain stresses a clay soils experiences when it forms desiccation cracks under drying. However, due to the long hours required for testing, as well as sensitivity to initial water content and compaction, this method would be better suited for natural soils than cement treated soils. 


\subsubsection{Existing Studies on Indirect Tensile Strength Testing of Stabilized Soil}

In recent decades, there has been a notable increase in available literature on soil tensile strength (Tang et al., 2014), including those involving soil stabilization. However, the current literature is still far from covering most prominent soil types. According to current literature, tensile strength for soil treated with cement or other binder materials generally falls between $6 \%$ to $20 \%$ of its compressive strength (Kitazume \& Terashi, 2012).

Terashi et al. (1980) was one of the earliest experimental investigation of tensile strength of cement and lime treated soil. Brazilian tensile testing were performed on cement-lime treated marine clays from Kawasaki and Kurihama, Japan. Four different configurations of Brazilian tensile testing setups were attempted, differing in testing plate type (flat vs. curved), testing plate width and sample diameter. It was found that all cases achieved about a 0.10 correlation between $\sigma_{t}$ and $q_{u}$ except in the case of a relatively large sample diameter $(100 \mathrm{~mm})$ and a curved plate with a small width $(25 \mathrm{~mm})$, where the correlation was 0.159 .

Al-Omar (1983) performed Brazilian testing and unconfined penetration testing on limetreated clay. Tensile results from both types of testing fell between $8 \%$ and $11 \%$ in correlation to compression testing. The author also noted stress loading rate can potentially alter tensile-compressive correlations.

Onwuka (1983) conducted Brazilian tensile testing on cement-treated sand. Average values of $\sigma_{t} / q_{u}$ was found to be between $10 \%$ and $11 \%$ for cement dosages of $4 \%$ and $5 \%$, respectively. However, for cement dosage of $3 \%$, average $\sigma_{t} / q_{u}$ was $18.1 \%$. Compressive strength values increased steadily with cement dosage increase, suggesting that tensile strength might not decrease steadily as cement dosage decreases.

Namikawa and Koseki (2007) performed Brazilian tensile, bending test and direct tensile test on cement treated sand. In general, tensile strength obtained through bending test $(20 \%$ to $50 \%$ of UCS) were found to be higher than direct tensile results ( $10 \%$ to $30 \%$ of UCS), which were higher than Brazilian tensile results (10\% to $20 \%$ of UCS) for the cementtreated soils investigated.

Consoli et al.. (2011) studied the tensile behavior of clayey and silty sands treated with cement using Brazilian tensile testing. Binder content was found to correlate with tensile 
strength linearly, while a higher porosity was found to decrease tensile strength in an exponential growth model.

Consoli et al. (2013) performed tensile experimental investigation of a Brazilian sand treated with cement and polypropylene fibers. Tensile strength was found to increase dramatically with the addition of fibers (by 86\%), more than the extent of improvement in UCS (by 34.5\%). Non-reinforced treated sand on average had a tensile to compressive strength correlation of $10 \%$ whereas cement treated sand with fiber reinforcement averaged $14 \%$.

Another study on fiber reinforced stabilized sand was performed by Mu (2013) on fly ash stabilized kaolinite clay. As opposed to UCS, where all types of fiber would result in strength increase once enough fiber content is reached, not all types of fiber promoted strength gain in Brazilian tensile strength. In this study, $\sigma_{t}$ of treated soil un-reinforced with fiber correlated to about $15 \%$ of UCS.

\subsection{SUMMARY}

Deep soil mixing is an effective soil treatment method in improving the strength of weak soils that are high in water content and compressibility. Champlain Sea clay, as a weak soil posing many engineering challenges, could benefit from the use in DSM in constructions within it. The tensile strength of cement-treated soil used in DSM remains scarcely studied, especially in Champlain Sea clay. Indirect tensile testing methods such as Brazilian tensile testing and unconfined penetration can be effective ways of testing soil tensile strength with relative ease of operation. Due to the current unavailability of existing studies on the tensile behavior of Champlain Sea clay, whether in its undisturbed state or cement-treated, it is of research interest to develop a testing program to investigate the tensile strength of this clay. The relative ease of setting up indirect tensile testing methods compared with the complexity as well as potential for mistakes make indirect testing methods such as Brazilian tensile test and unconfined penetration favorable methods for analysis in this study. 


\section{EXPERIMENTAL PROGRAM}

\subsection{INTRODUCTION}

In this section, the experimental setup and tensile testing methods used in this study are explained in details. First of all, clay material properties, for example, grain size distribution and Atterberg limits, are covered. The tensile testing setup and sample preparation procedures are then explained. In the end, the necessary data processing to obtain tensile strength for both testing methods are outlined. Unconfined compressive strength (UCS) tests were performed using the same parameters so that a correlation between tensile and compressive strength could be established once the tensile testing results became available. In this study, to obtain tensile strength values, the Brazilian tensile strength (BTS) test and unconfined penetration tensile (UPT) testing will be performed to obtain the failure loads for calculating the tensile strength using pertinent mathematical relationships. The calculated tensile strength values will then be analyzed with UCS values to obtain a correlation between tensile and compressive strengths.

\subsection{MATERIAL PROPERTIES OF CHAMPLAIN SEA CLAY}

The clay used in this study was obtained at a dam site near Ontario, Canada using a Laval sampler. The soil used to make samples is primarily from depths between $25 \mathrm{~m}$ and $30 \mathrm{~m}$. The clay is Champlain Sea clay and has been characterized as highly sensitive in previous studies (Ahamd, 2018; Afroz, 2019).

\subsubsection{GRAin Size Distribution}

Sieve analyses of clay samples were performed according to the specifications in ASTM D6913 by Afroz (2019) and Ahmad (2018). However, a large portion of soil particles is clay, which would be retained at sand level in a typical sieve analysis. An oven-dried, ground sample of the soil was to form a slurry with water in a dispersion cup before being mixed mechanically to separate clay particles in a procedure documented by Ahmad (2018). The grain size distribution results referenced in this study are shown in the graph below. It is evident that throughout the soil profile from where the testing soil is obtained, clay sized particles form the majority of soil mass, agreeing with observations on Champlain Sea clay by Quigley et al. (1983). 


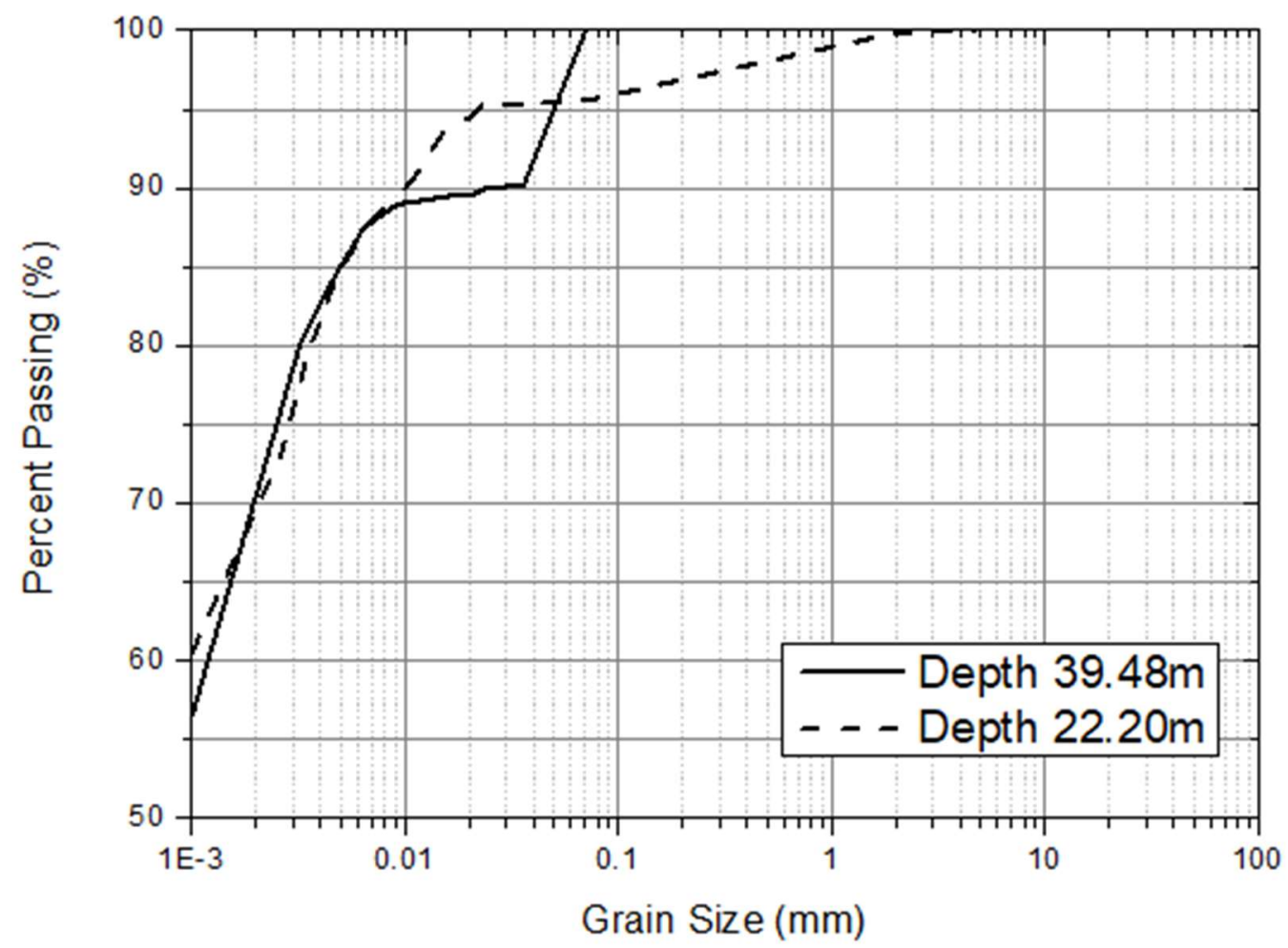

Figure 3-1: Grain distribution of clay used in this study (Ahmad, 2018; Afroz, 2019)

\subsubsection{ATTERBERG LIMITS}

Atterberg limit values, obtained according to specifications in ASTM D4318 for Champlain Sea clay have been obtained by Liu, et al. (2017). Between $25 \mathrm{~m}$ and $30 \mathrm{~m}$, where the test soil of this study is obtained, the liquid limit and plastic limit can be taken as rough $35 \%$ and $90 \%$, respectively. Water content obtained in the test soil was observed to be between $70 \%$ and $80 \%$.

\subsubsection{SOIL ClassificATION}

Liu et al. (2017) documented and organized soil classification data obtained in Champlain Sea clay at different depths from several studies. Based on the data, the test soil used in this study, at between $25 \mathrm{~m}$ to $30 \mathrm{~m}$ depth, can be classified as $\mathrm{CH}$ (clay with high plasticity). 

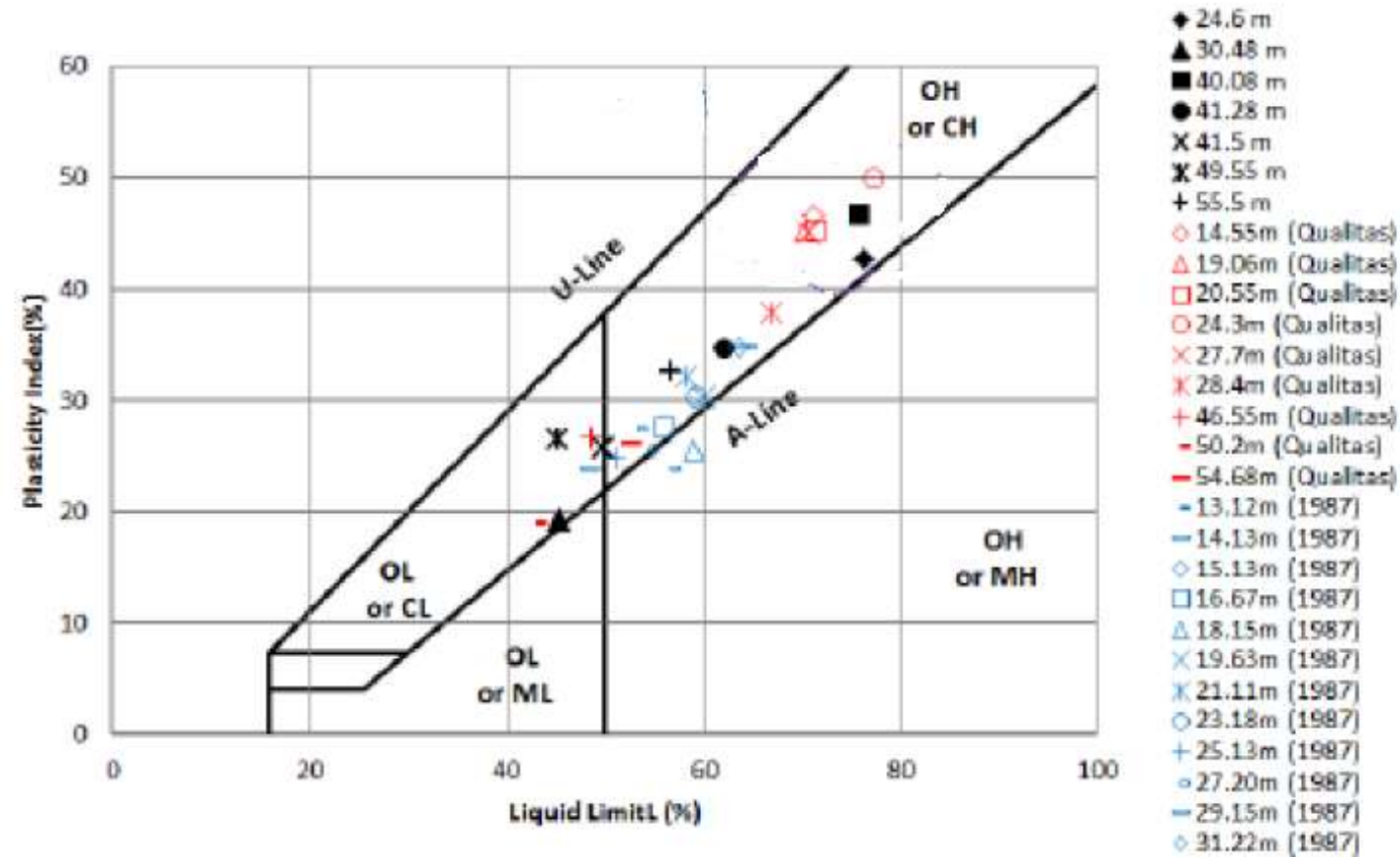

Figure 3-2: Soil classification data for Champlain Sea clay (Liu, et al., 2017)

\subsubsection{MiNERALOGY}

The X-ray diffraction (XRD) analysis on mineralogical composition of Champlain Sea clay, shown in Table 3-1 (Qualitas, 2016). Clay was found to be the primary soil type in all three samples from various depth, accounting for over $70 \%$ in weight. The dominant type of mineral was found to be illite, which made up around $60 \%$ of total weight.

Table 3-1: Mineral composition of Waba Dam clay (Qualitas, 2016)

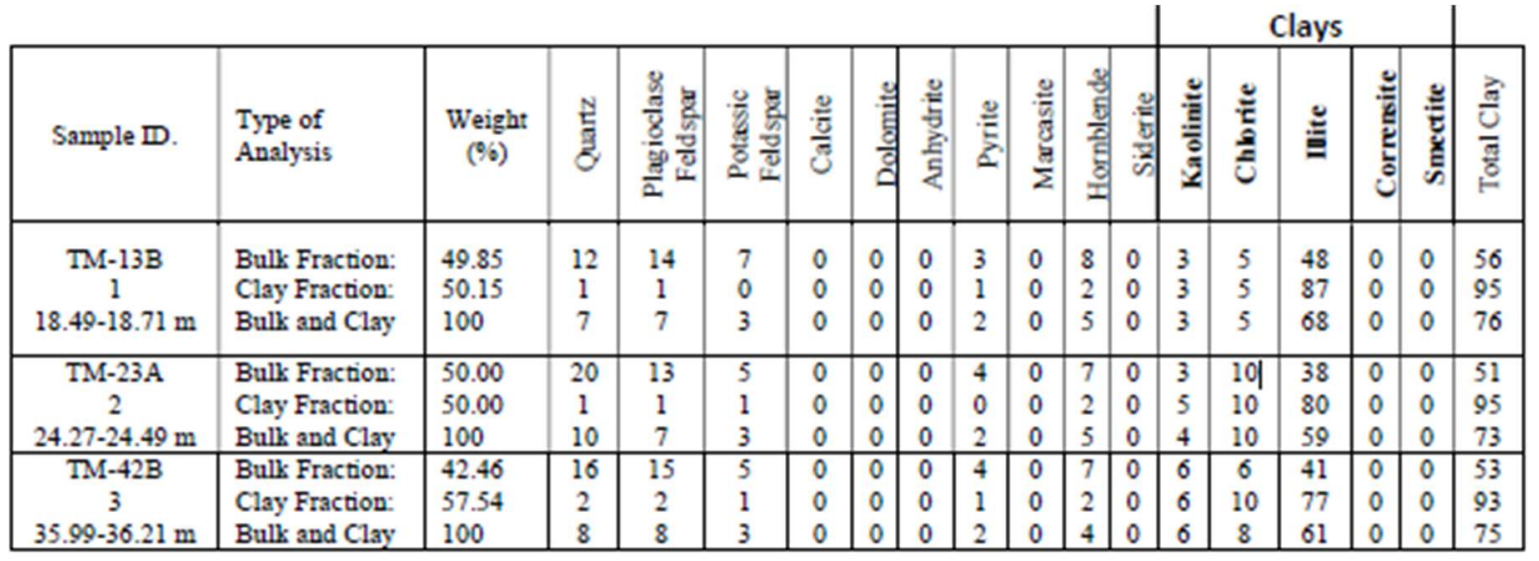

The elemental composition of Champlain Sea clay was investigated by Monsif et al. (2019) using the energy dispersive spectrum (EDS) detector on XRD spectrums on the clay sample 
from the depth $21.6 \mathrm{~m}$, as shown in Figure 3-3. The readings were average values of XRD readings of a micrograph. The dominant elements in the clay, which are above $10 \%$ in weight composition, are oxygen, sodium. chlorine, carbon and silicon.

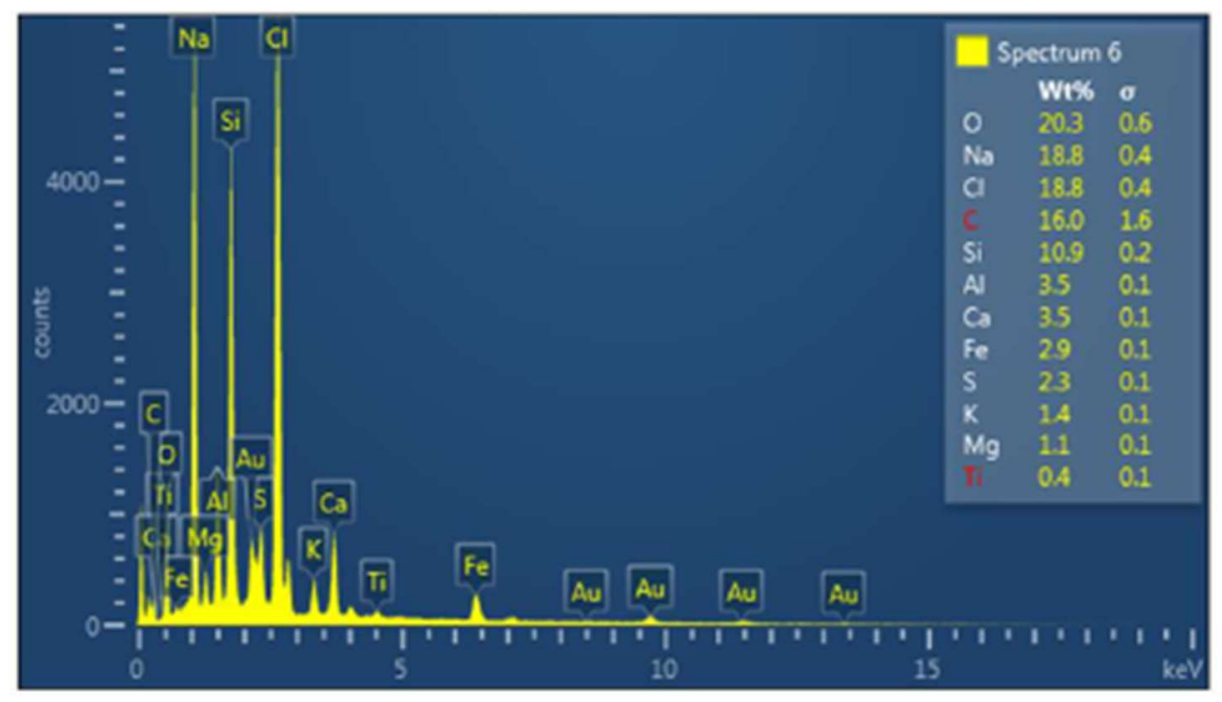

Figure 3-3: Elemental composition of Champlain Sea Clay (Monsif et al., 2020)

\subsubsection{UNDRAINED SHEAR STRENGTH}

The undrained shear strength of clay was studied in several previous studies using different methods such as mini vane shear test and UCS. A value range for undrained shear strength which can be referenced is $35 \mathrm{kPa}$ to $45 \mathrm{kPa}$, obtained using mini vane shear test by Afroz (2019) from the depths between $20 \mathrm{~m}$ to $25 \mathrm{~m}$.

\subsubsection{Specific Gravity and Total Unit Weight}

The specific gravity of Waba Dam clay was documented as 2.67 according to specifications in ASTM D854 by Ahamd (2018). For mix design purposes, the total unit weight, i.e. the unit weight of the wet soil in its natural state, is taken as $1549 \mathrm{~kg} / \mathrm{m}^{3}$ based on experimental values documented by Afroz (2019).

\subsubsection{SENSITIVITY}

As discussed in previous chapters, Champlain Sea clay is a sensitive clay (Ahmad, 2018; Mairesse, 1976). The sensitivity of Champlain Sea clay used in this study was measured by comparing mini vane shear testing according to ASTM D4648M. The result showed the clay sample has a sensitivity of 4 to 14 according to research performed by Li et al. (2016b) and Ahmad (2018). 


\subsection{EXPERIMENTAL APPARATUS}

In this section, the experimental apparatus and setup are covered for both BTS and UPT tests. Both BTS and UPT tests were performed using specially customized parts attached to a UCS test machine.

\subsubsection{UnCONFINED COMPRESSION STRENGTH (UCS) TEST}

In order to gain experimental understanding of the tensile behavior of Champlain Sea clay using indirect testing methods such as the BTS and UPT, compression testing must be completed as a benchmark. Compressive strength results were collected in order to form correlation with tensile strength results. In this study, the UCS test as per ASTM D163317 was used as the compressive benchmark test. Humboldt HM-3000 compression testing machine was used for compression crushing, as well as Humboldt HM-2310.20 Linear Variable Differential Transformer (LVDT) and load cell with a maximum capacity of $10 \mathrm{kN}$ for displacement and force measurement.

In UCS testing, as shown in Figure 3-4, a cylindrical plate with a flat end was attached to the load cell using a threaded nut. As testing commences, the bottom plate on which the sample rests is slowly raised by the testing machine with a loading rate of $1.00 \mathrm{~mm} / \mathrm{min}$, which conforms ASTM D1633-17. The load cell has been calibrated with the threaded plate attached for accurate measurement of loads applied on the sample.

Before testing started, the sample was raised by the base plate to the height of roughly less than $1 \mathrm{~mm}$ below the top plate. However, the sample was not intended to touch the plate, as doing so would induce build-up of stress before measurement begins. After testing begins, it would take the sample a number of seconds until it touched the top plate. This would introduce a difference in the strain measurement in the testing system, which would be adjusted in data recording.

Stress was to be applied until the sample reached $10.0 \%$ strain, or when it fractured or failed which prevented further loading. Failure was defined as the point where the applied load begins to decrease steadily with increasing deformation, as outlined per ASTM D1633-17. 


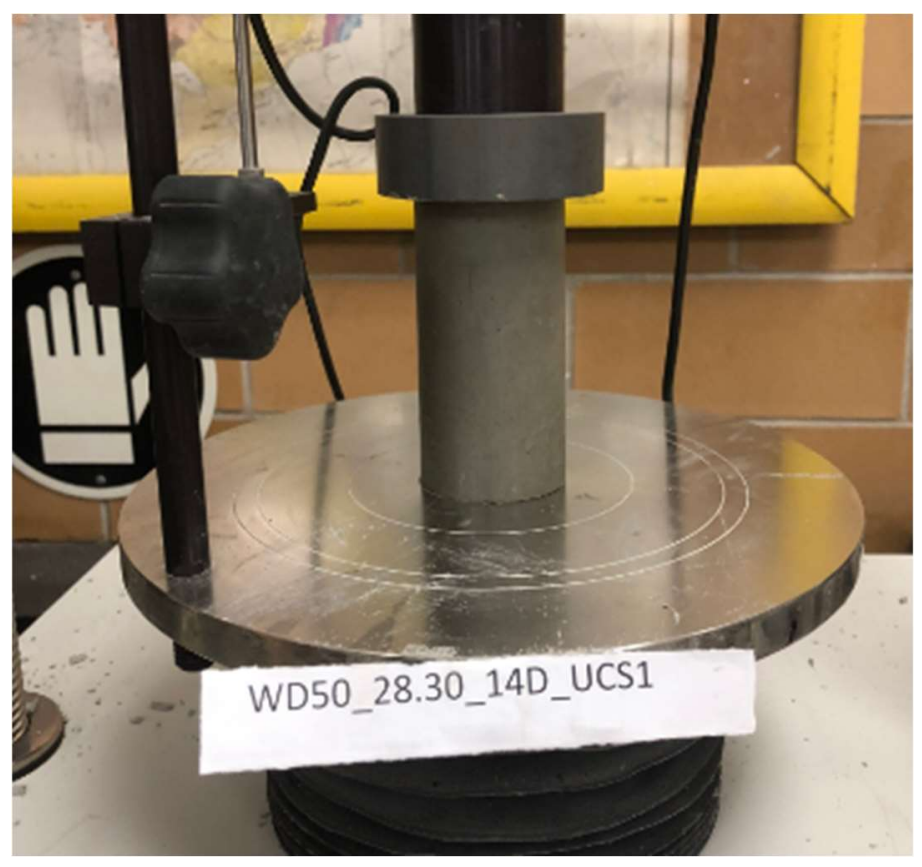

Figure 3-4: UCS Experimental Setup

\subsubsection{BRAZILIAN TENSILE TEST}

The BTS testing setup involves two identical inward-arced loading plates which are used to secure the sample in place, as shown in Figure 3-5. One side of the steel loading plate is an arc surface with a radius of 6" to contact the sample. The other side has a threaded hole for attachment to the testing machine. BTS testing was performed on the UCS machine. Care was taken to ensure the plate did not touch the sample before starting the test.

In testing, the soil sample was put horizontally in the center of the loading plate, the bottom plate of the UCS machine would then slowly raise until the sample was snuggly fit between the two plates. As with UCS tests, a thin gap was to be left between the top of the sample and the top loading plate.

The loading process is similar to an unconfined compressive strength (UCS) test, as the BTS test uses a mathematical relationship to obtain the tensile strength from the compressive force. The loading rate was determined as $0.50 \mathrm{~mm} / \mathrm{min}$, half of that of UCS. This value was chosen due to the Brazilian tensile sample being half the height of the UCS sample in the axis of crushing. As ASTM D3967-16 requires sample failure taking place between 1 and 10 minutes (ASTM, 2016), the chosen loading rate of $0.50 \mathrm{~mm} / \mathrm{min}$ is appropriate for this requirement. The sample was considered failed after the peak force was 
reached, at which visible cracks would be observed, usually at the center of the specimen along the axis of crushing.

ASTM D3967-16 recommends, but does not require, bearing strips on top and bottom plate at the location of contact with the specimen for the reduction of stress concentration (ASTM, 2016). However, as a gap is left between the top of the sample and the top plate, it would be difficult to keep the sample securely standing without introducing an initial stress if bearing plates were installed. A few trial tests with bearing plates showed much more gradual and ductile load-displacement behavior in the Brazilian specimen. The peak load results were also more varied. Therefore, bearing plates were not used in this study.

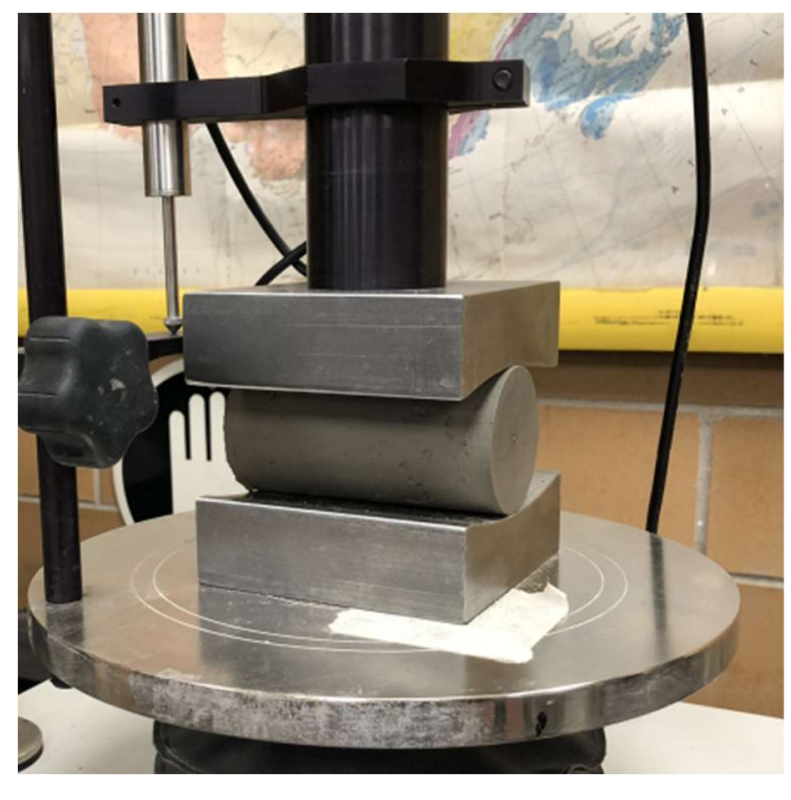

Figure 3-5: BTS Testing Setup

\subsubsection{UnCONFInEd PENETRATION TEST (UPT)}

The UPT test, as shown in Figure 3-6, also utilizes the UCS machine to obtain tensile strength through a mathematical relationship after compressive crushing. Three types of steel penetration testing plates, also known as discs, were specifically made for this study, all $1 / 2$ " in diameter. The loading disc has a flat end, same as used in earlier studies. A stand, also with a diameter of $1 / 2$ ", was made to support the sample. The bottom plate of the compressive testing machine had circles with fixed diameter for the ease of sample positioning. Therefore the bottom portion of the stand was dimensioned 2-inch in diameter, so it would fit inside one of the circles on the bottom plate of the UCS machine, placing 
the sample directly underneath the load cell to avoid the eccentricity during loading. In order to be able for the testing plates to be easily removed from the testing machine to change to another type of testing plate, a feature that would be relevant for industry application, a deviation from the theoretical schematic of Kim et al. (2012) is that no mechanism was put in place to ensure the perfect alignment of the top and bottom discs. This is remedied by the circle mark on the bottom plate of the UCS machine, which would help mitigate the positioning issue.

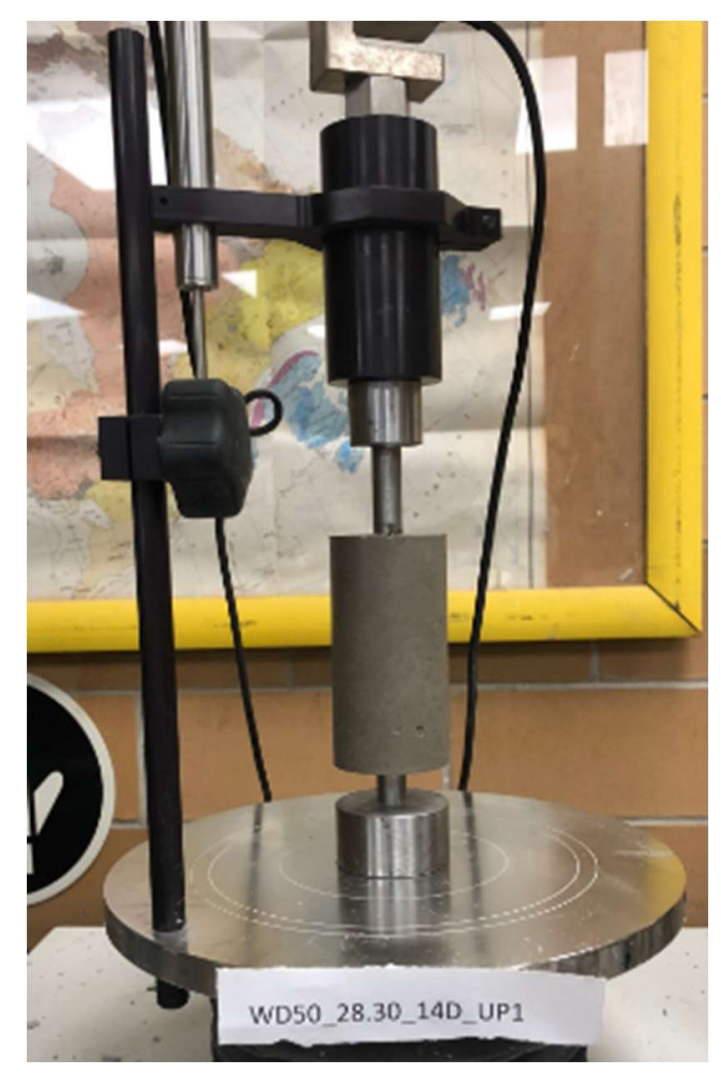

Figure 3-6: Typical UPT Setup

During sample testing, the sample was loaded in compression similar to BTS testing. Failure was observed at the maximum stress, or an abrupt fracture of the specimen that prevents further loading.

\subsection{SAMPLE PREPARATION}

In this section, the details of sample mixing, compaction and curing are covered, for UCS, BTS, and UPTs, as all tests used the same sample sizes. 


\subsubsection{SAMPLE DiMENSIONS}

For the indirect tensile tests, plastic concrete test cylinders with 2 inch $(50.8 \mathrm{~mm})$ in diameter by 4 in $(101.6 \mathrm{~mm})$ in height were used. Due to tolerances in the cylinders as well as errors introduced by compaction, the cured samples' dimensions ranged between 51.5 $\mathrm{mm}$ to $52.0 \mathrm{~mm}$ in diameter and between $101.5 \mathrm{~mm}$ to $102.3 \mathrm{~mm}$ in height. The cylinders had removable lids to cover the sample from any moisture loss. A 1-mm diameter hole was drilled at the center of the bottom of the cylinder to facilitate sample extrusion using compressed air once the sample was ready for extrusion before testing. The hole was to be sealed using duct tape once sample compaction was complete, as a completely sealed test cylinder is required in the curing process of deep mixing samples per FHWA guidelines (FHWA, 2000).

\subsubsection{SAMPLE MIXING AND COMPACTION}

To prepare for mixing, the binder was first mixed with water for the slurry used for wet mixing in a Humboldt H-4260 soil dispersion mixer. Slurry mixing would last for three (3) minutes as per FHWA requirements. The water to binder ratio used in all mixes was 1 to 1 by weight, as this has been used in previous Champlain Sea clay studies such as Afroz (2019). Slurry was poured into the soil in a mixing bowl after determining the required slurry and soil weight. The mixture was then blended in a KitchenAid kitchen mixer for ten (10) minutes. The mixer would only be momentarily turned off when it would be necessary to keep the soil from being stuck to the wall of the mixing bowl. After mixing is complete, the mixture was manually placed into a plastic mold. The compaction process involves placing the mixed soil into the mold in three steps, each step adding in one third of the mixture. For each step, 25 manual taps on the table top were applied to the soil inside the mold for compaction. The mold was rotated by hand once after 5 taps. After the last third of the soil was in the mold and tapping was complete, a spatula was used to clean excess soil and smooth the surface of the sample at the top opening of the cylinder. After that, the lid was tightly closed and sample was ready for curing. 


\subsubsection{SAMPLE NAMING}

The name of the samples recorded followed the naming convention below:

$$
\text { WD21.6m_50C_7D_BT1 }
$$

Where WD - soil sample location, WD stands for Waba Dam

$21.6 \mathrm{~m}$ - sample depth

$50 \mathrm{C}$ - cement content, unit is $\mathrm{kg} / \mathrm{m} 3$

$7 \mathrm{D}$ - curing time in days

BT1 - testing type and number: BT for BTS testing, UP for UPT, UCS for unconfined compression testing.

After sample preparation was complete, sample name was written on a piece of adhesive tape and attached to the cylinder. The tape was not part of the weight measurement of the cylinder and was removed once the sample was ready for testing.

\subsubsection{SAMPLE CURING}

After samples were mixed, compacted and the lid closed, they were placed in the curing chamber, as shown in Figure 3-7, for a set period of time for cement hydration. The curing temperature was kept between 20 to 25 degrees, relative humidity above $95 \%$, per FHWA specifications. Water at the bottom was used to maintain humidity and samples stood on the floor of the chamber, completed covered by water in the chamber. Water level was checked weekly to ensure it never fell too much below the lid of the samples so that proper humidity was maintained.

\subsection{EXPERIMENTAL PARAMETERS}

In this study, the experimental parameters for the treated samples are mainly the binder dosage and curing time.

\subsubsection{BINDER DOSAGE}

The binder dosages under investigation were 50,100 and $200 \mathrm{~kg}$ per cubic meter of the mixture, as prescribed in FHWA guidelines (FHWA, 2000) as well as for comparison with previous studies (Li et al., 2016a; Li et al., 2017). 


\subsubsection{CURING TIME}

The curing time under investigation are 7 days, 14 days and 28 days, as per FHWA guidelines (FHWA, 2000) and previous studies (Monsif et al., 2019; Afroz et al., 2018).

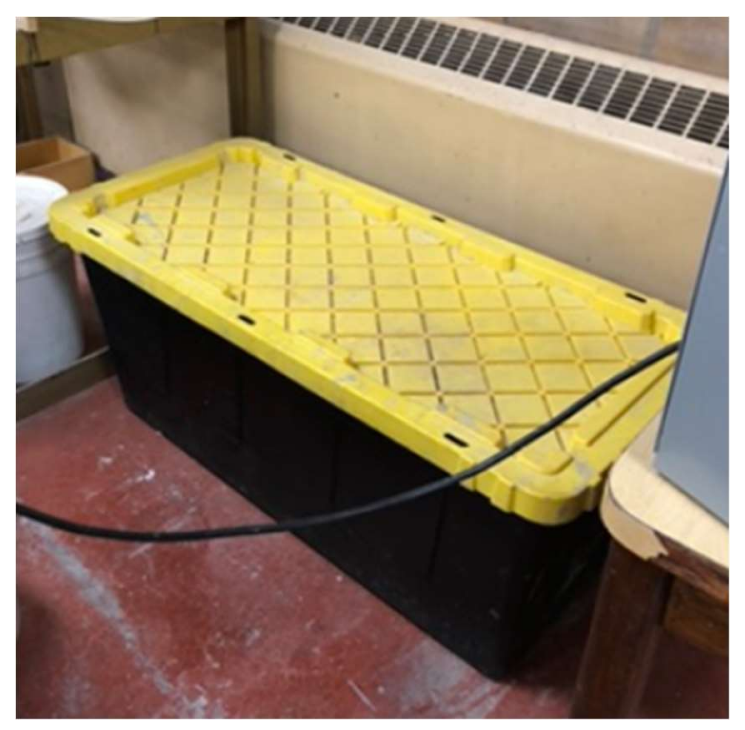

Figure 3-7: A curing chamber used for curing treated clay samples

\subsubsection{AdDITIONAL PARAMETER INVESTIGATIONS}

\subsubsection{Unconfined Penetration Disc Angle}

The effects of having an angled penetration disc opposed to a flat surface are investigated using samples with $100 \mathrm{~kg} / \mathrm{m}^{3}$ cement content cured for 7, 14 and 28 days. For the sake of simplicity in testing, no other binder contents were used. The details of these angled discs are shown in Figure 3-8.

\subsubsection{Smaller Sized Brazilian Tensile Specimens}

The effects of BTS specimens with shorter lengths are also investigated. Rather than using the standard specimen size of $2 \times 4$-inch used in UCS tests, the tensile strength performance of 2-inch and 1-inch long specimens are also investigated. The smaller samples sizes are actually more in line with the recommendations in ASTM D3967-16, but were not used in mass testing in this study due to the consideration of having the same sample size in BTS and UCS test. The curing time and binder content used for the smaller samples are 14 days and $100 \mathrm{~kg} / \mathrm{m}^{3}$, respectively. 

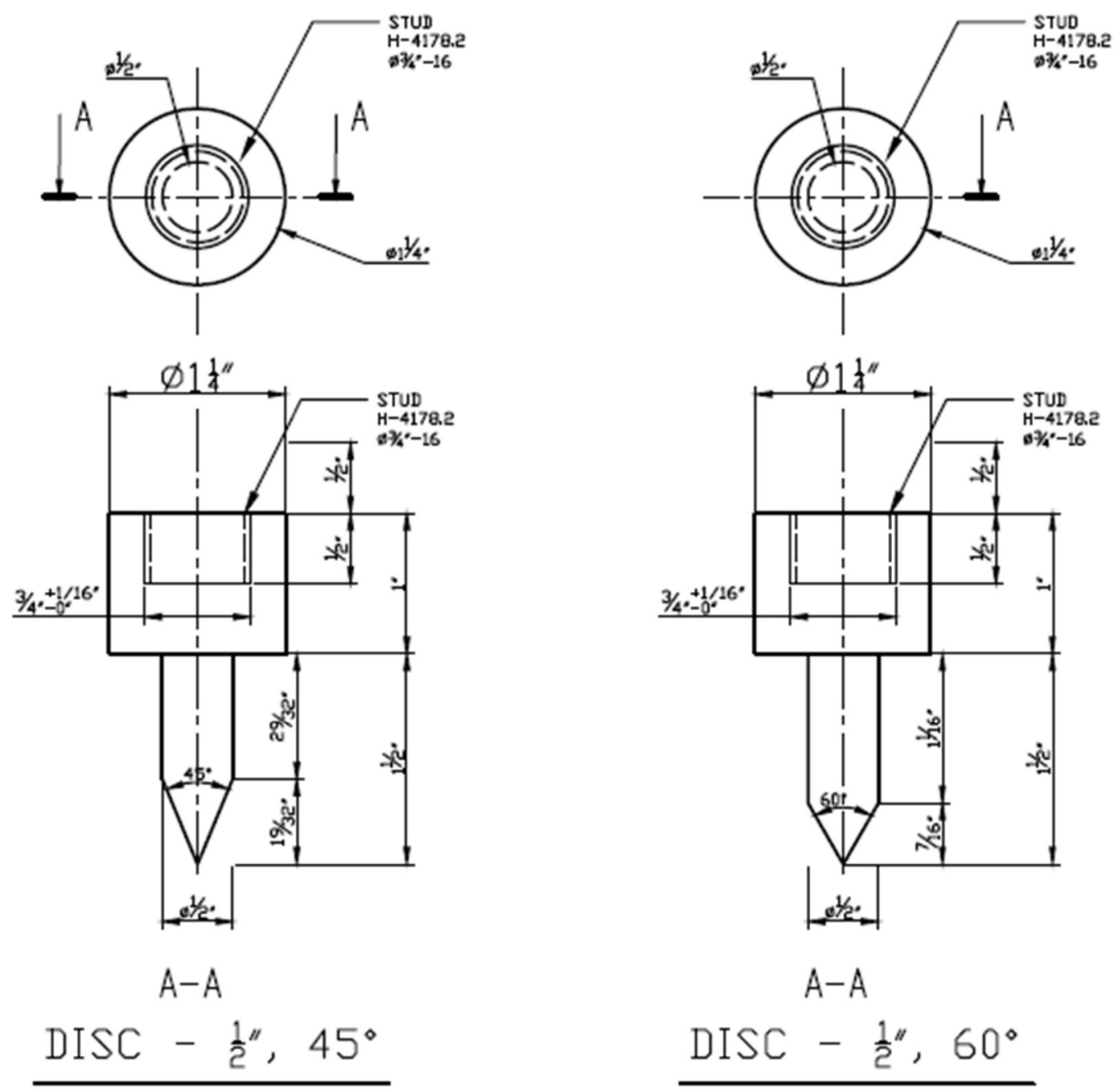

Figure 3-8: Schematic for Penetration Discs with $45^{\circ}$ and $60^{\circ}$ Angles 


\subsection{TESTING OVERVIEW}

An overview of standard indirect tensile tests performed in this study are summarized in the table below:

Table 3-2: Overview of Testing Samples

\begin{tabular}{|c|c|c|c|c|}
\hline \multicolumn{5}{|c|}{ Regular Testing } \\
\hline & & \multicolumn{3}{|c|}{ Curing Time (Days) } \\
\hline & & $7 \mathrm{~d}$ & $14 \mathrm{~d}$ & $28 \mathrm{~d}$ \\
\hline \multirow{7}{*}{ Binder Content $\left(\mathrm{kg} / \mathrm{m}^{3}\right.$ cement $)$} & 50 & $\begin{array}{c}2 \times \mathrm{UCS} \\
2 \times \mathrm{BT} \\
2 \times \mathrm{UP}\end{array}$ & $\begin{array}{c}2 \times \mathrm{UCS} \\
2 \times \mathrm{BT} \\
2 \times \mathrm{UP}\end{array}$ & $\begin{array}{c}2 \times \mathrm{UCS} \\
2 \times \mathrm{BT} \\
2 \times \mathrm{UP}\end{array}$ \\
\hline & & $2 \times \mathrm{UCS}$ & $2 \times \mathrm{UCS}$ & $2 \times \mathrm{UCS}$ \\
\hline & 100 & $2 \times \mathrm{BT}$ & $2 \times \mathrm{BT}$ & $2 \times \mathrm{BT}$ \\
\hline & & $2 \times \mathrm{UP}$ & $2 \times \mathrm{UP}$ & $2 \times \mathrm{UP}$ \\
\hline & & $2 \times \mathrm{UCS}$ & $2 \times \mathrm{UCS}$ & $2 \times \mathrm{UCS}$ \\
\hline & 200 & $2 \times \mathrm{BT}$ & $2 \times \mathrm{BT}$ & $2 \times \mathrm{BT}$ \\
\hline & & $2 \times \mathrm{UP}$ & $2 \times \mathrm{UP}$ & $2 \times U P$ \\
\hline \multicolumn{5}{|c|}{ Additional Investigations } \\
\hline \multicolumn{5}{|c|}{ Unconfined Penetration - Angled Discs } \\
\hline & & $7 \mathrm{~d}$ & $14 \mathrm{~d}$ & $28 \mathrm{~d}$ \\
\hline Binder Content $\left(\mathrm{kg} / \mathrm{m}^{3}\right.$ cement $)$ & 100 & $1 \times 45^{\circ}$ & $2 \times 45^{\circ}$ & $2 \times 45^{\circ}$ \\
\hline & & $1 \times 60^{\circ}$ & $2 \times 60^{\circ}$ & $2 \times 60^{\circ}$ \\
\hline \multicolumn{5}{|c|}{ Brazilian Tensile - Smaller Specimens } \\
\hline & & $7 \mathrm{~d}$ & $14 \mathrm{~d}$ & $28 \mathrm{~d}$ \\
\hline Binder Content $\left(\mathrm{kg} / \mathrm{m}^{3}\right.$ cement $)$ & 100 & & $\begin{array}{l}2 \times 1 \text {-in } \\
2 \times 2 \text {-in }\end{array}$ & \\
\hline
\end{tabular}

* UCS - unconfined compression strength; BT- Brazilian tensile test; UP - unconfined penetration

\subsection{DATA PROCESSING}

The raw data obtained, as well as the procedures to convert the collected data to tensile strength values, are covered in this section. 


\subsubsection{Data Processing of Brazilian Tensile Test}

The tensile strength through BTS testing was obtained by a mathematical relationship using the force at failure as input. As introduced in Chapter 2, the tensile strength obtained through BTS testing is:

$$
\sigma_{t}=\frac{2 P}{\pi R H}
$$

Where $\sigma_{t}=$ tensile strength of sample

$$
\begin{aligned}
& P=\text { force applied at failure } \\
& R=\text { radius of the sample } \\
& H=\text { length (height) of the sample }
\end{aligned}
$$

\subsubsection{Data Processing of UnConfined Penetration Test}

A relationship to obtain the tensile strength through UPT has been suggested as follows in the early researches:

$$
\sigma_{t}=\frac{P}{\pi *\left(K R H-a^{2}\right)}
$$

Where $\sigma_{t}=$ tensile strength of sample

$$
\begin{aligned}
& P=\text { force applied at failure } \\
& R=\text { radius of the sample } \\
& H=\text { height of the sample } \\
& a=\text { radius of penetration disc } \\
& K=\text { a factor, can be taken as } 1.0 \text { for all soils (Fang \& Chen, 1972) or calculated in } \\
& \text { the equation below (Kim et al., 2012): }
\end{aligned}
$$

$$
K=\tan (2 \alpha+\varphi)
$$

Where $\alpha=$ angle measured at failure cone, as shown in Figure 3-9

$$
\varphi=\text { undrained friction angle of soil }
$$

In this study, the tensile strength obtained through unconfined penetration will first be analyzed using $\mathrm{K}=1.0$, then the effect of the value of $\mathrm{K}$ will be investigated. 


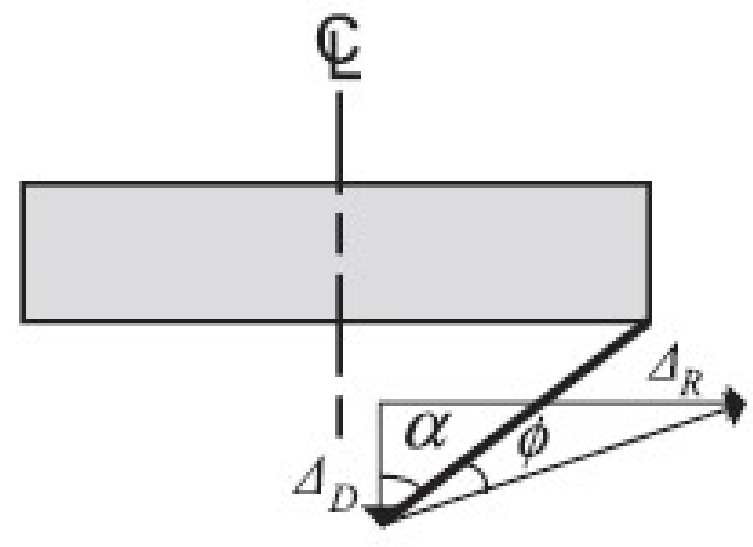

Figure 3-9: Illustration of failure cone angle at penetration disc (Kim et al.,2012)

\subsubsection{Angle Measurement}

The above equation requires the measurement of two angles, undrained angle of friction $(\varphi)$ and angle at failure cone $(\alpha)$. In the case of an UCS test for a cohesive soil, the testing process can be treated as a special case of unconsolidated undrained triaxial test where the confining pressure $\left(\sigma_{3}\right)$ is zero (Das \& Sobhan, 2010). The position of $\sigma_{3}$ is fixed and the failure surface is always the tangent of the Mohr's circle formed by $\sigma_{1}$, the applied stress and origin, which is always parallel to the normal stress axis. Therefore the friction angle is always zero, as shown in Figure 3-10. Since the UPT uses the identical mechanism as the UCS test, only differing in the shape of the testing plates, this leaves $\alpha$ the only angle to be measured to determine the value of $K$.

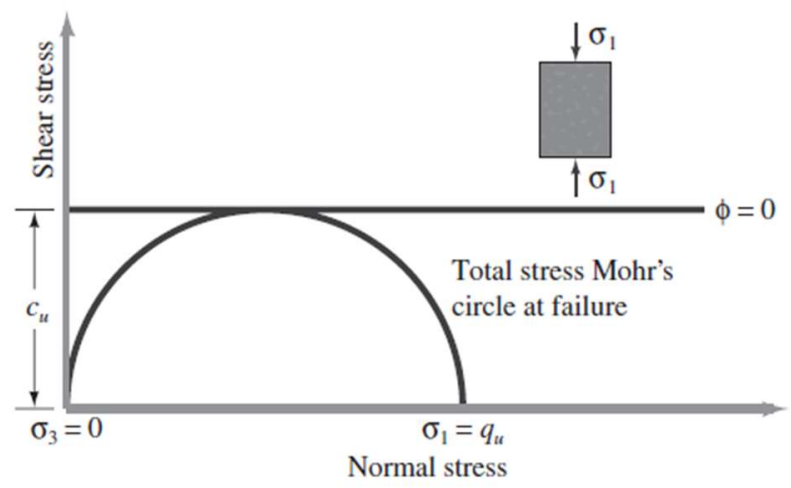

Figure 3-10: Normal-shear Stress Condition of the UCS Test 
Earlier literature on UPT in soils such as Kim et al. (2012) and Liang et al. (2014) did not cover the specifics of measuring the angle of $\alpha$. It is assumed that a simple visual measurement was carried out. In actual specimens, visual approximations were made since the angle of failure cone is almost always imperfect. Using photos of specimens taken after testing, a tangent line of the failure cone is drawn in Microsoft Paint and the angle is determined roughly around 26 degrees as shown in Figure 3-11.

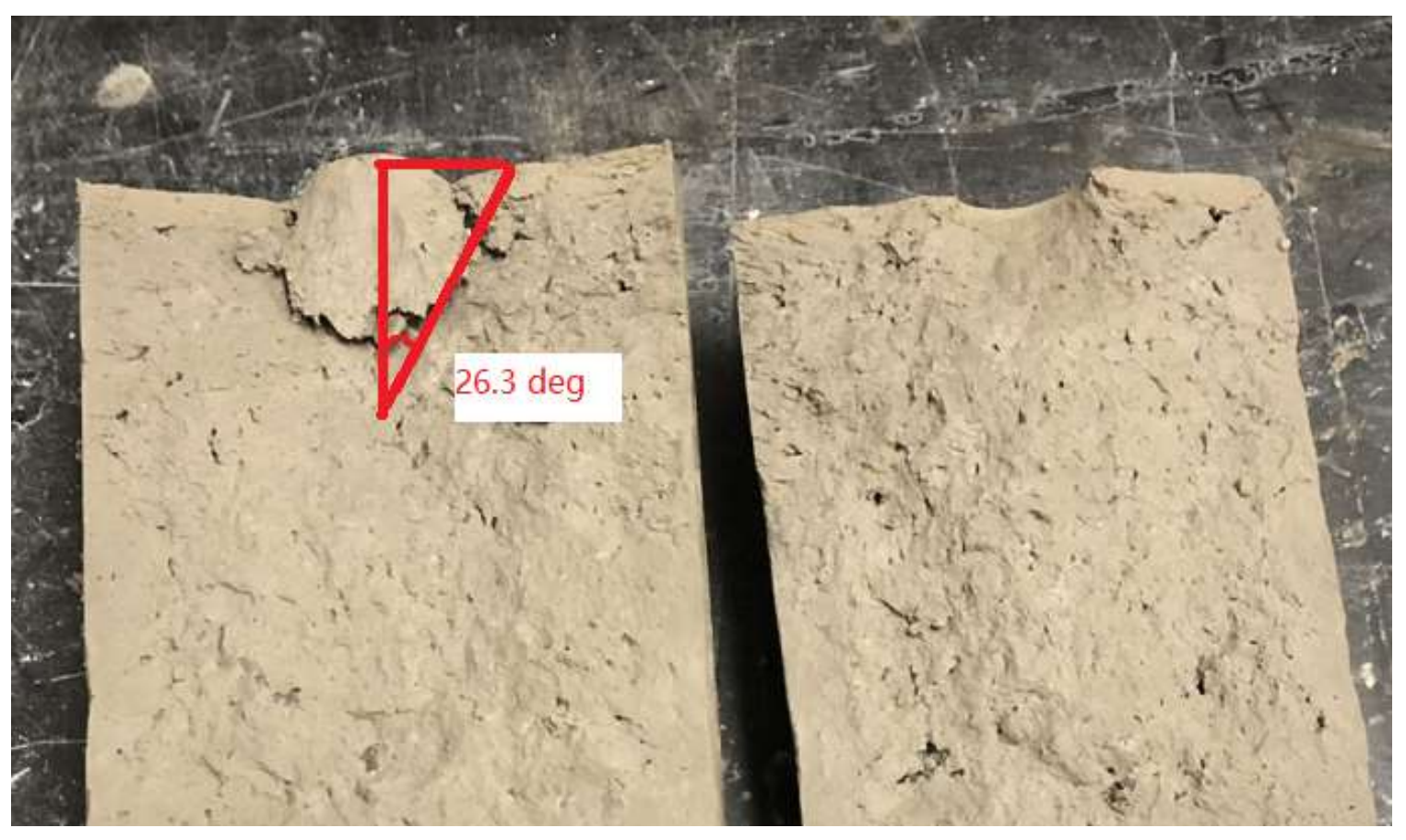

Figure 3-11: Angle $\alpha$ Determination in UPT Specimens

\subsection{SUMMARY}

In this chapter, the index properties of Champlain Sea clay for testing are covered, followed by proposed testing setup and experimental methods for the indirect testing methodss of Brazilian tensile testing and unconfined penetration. For regular testing, binder contents of 50,100 and $200 \mathrm{~kg} / \mathrm{m}^{3}$ general use cement as well as curing times of 7,14 and 28 days would be investigated. Additional investigations on the effect of $\alpha$ in unconfined penetration, the use of penetration discs with $45^{\circ}$ and $60^{\circ}$ angles, as well as the use of smaller length Brazilian test samples, would also be performed. 


\section{LABORATORY RESULTS AND ANALYSIS}

\subsection{INTRODUCTION}

In Chapter 4, the experimental results and analyses are covered in details, which include the test results from both BTS and UPT tests, the effects of sample size on BTS results, and the effects of penetration disc angle on UPT results. The tensile strength from BTS testing was compared with UCS results and a correlation was established for cementtreated Champlain Sea clay.

\subsection{UNCONFINED COMPRESSION RESULTS}

To establish a correlation between the tensile and the compressive strengths, the compressive capacity of the soil must be first investigated. For each combination of cement dosage and curing time, two standard $2 \times 4$-in samples were prepared and tested for a total of 18 samples.

\subsubsection{DesCRIPTION OF UCS SAMPLES IN TESTING}

Cement-treated Champlain Sea clay samples underwent a rather brittle failure under the compressive loading during the UCS tests. Most samples exhibited similar failure patterns of brittle shear failure through the body of the samples as earlier studies (Liu, et al., 2018). A significant number of the samples failed in a conical pattern either at their top or bottom. For those samples failing in this pattern, a failure at the top was more common. In either case, failure occurred fairly at low strain conditions, usually between $1 \%$ and $2 \%$ of axial strain. Most sample tests were terminated until a $10 \%$ strain limit was reached. No sudden and abrupt fractures were observed in UCS testing and all samples remained standing until reaching the designated strain limit of $10 \%$, long after the peak stress was reached. 


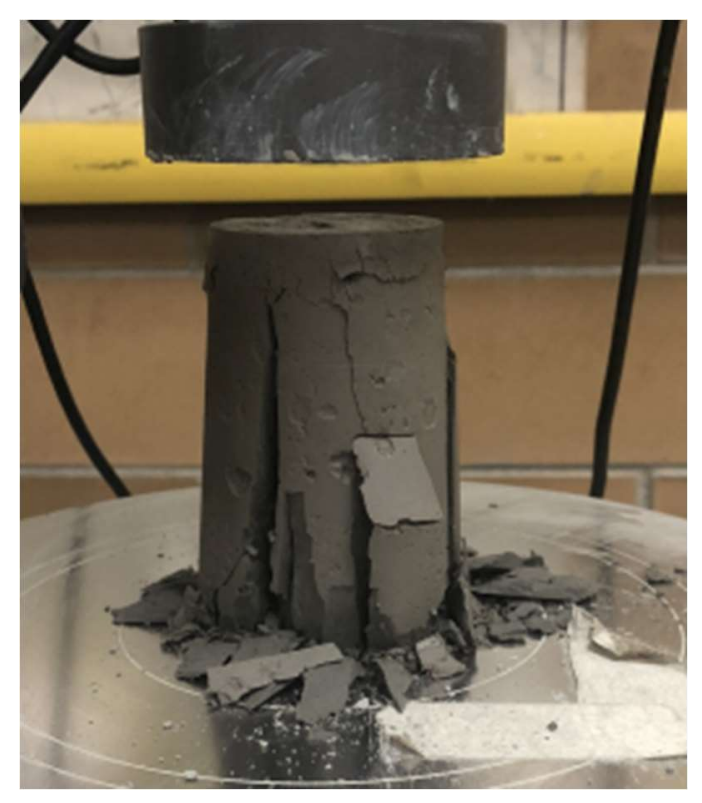

Figure 4-1: Conical Failure Observed in Cement-treated Clay Sample

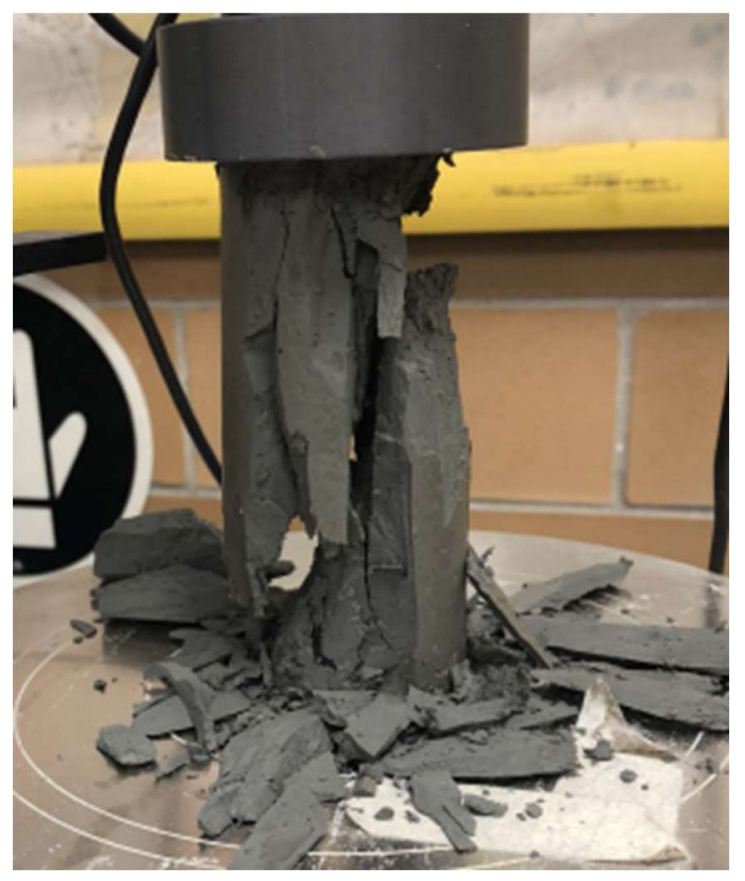

Figure 4-2: Shear Failure Observed in Cement-treated Clay Sample

\subsubsection{UCS TESTING RESUltS}

Samples with cement binder content of 50,100 and $200 \mathrm{~kg} / \mathrm{m}^{3}$ were cured for time periods of 7, 14, and 28 days. As expected, the UCS results were higher in samples with larger binder contents and longer curing times. Strength values are often progressively higher as binder content increases, although UCS values for samples with 100 and $200 \mathrm{~kg} / \mathrm{m}^{3}$ dosage 
and 14 day curing are nearly identical. In general, samples gain strength as the curing time increases. The exception was observed for $100 \mathrm{~kg} / \mathrm{m}^{3}$ samples between 14 days and 28 days, where the samples of the former are stronger. Samples of shorter curing times having greater strength than those of longer curing periods has been also observed in previous studies on cement-treated Champlain Sea clay such as Afroz et al. (2018), where even certain 7-day cured samples were found to be stronger than 28-day cured ones. Such discrepancy is not common in this study, which may be attributed to inconsistency of mixing and the sample preparation procedures. One sample result was removed due to unexpected sample damage before testing. Its testing result proved to be aberrant. In general, the samples showed failure patterns in unconfined compression that are similar to that of concrete as documented by Yang et al. (2019), indicating that the use of BTS and UPT, which are suitable for concrete materials, can be justified.

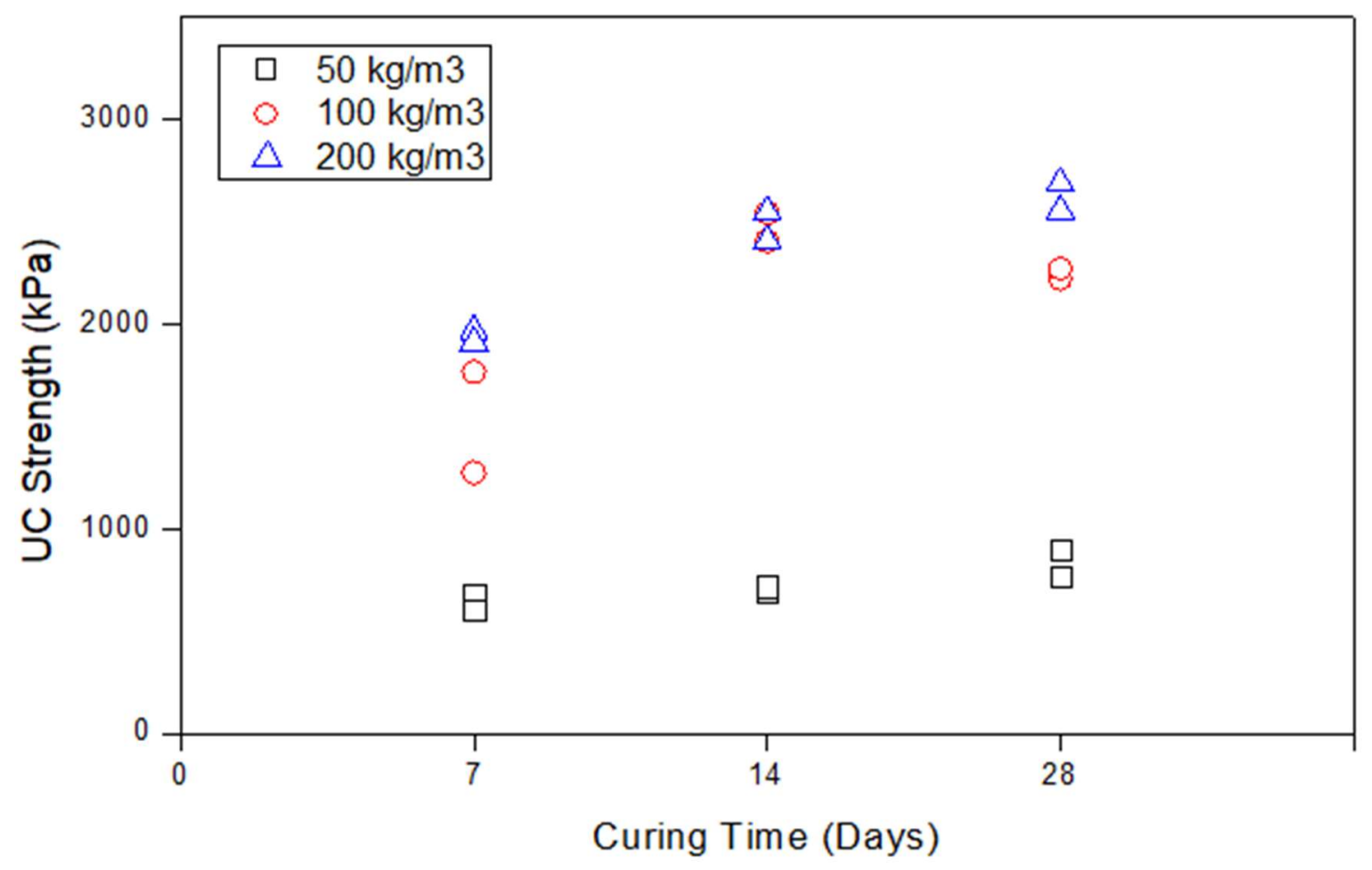

Figure 4-3: UCS Results for different curing days and binder content

It can also be observed that in this study, samples treated with a cement dosage of 100 $\mathrm{kg} / \mathrm{m}^{3}$ exhibits much larger UCS values than those with $50 \mathrm{~kg} / \mathrm{m}^{3}$, but less significant changes in strength were observed between samples with $100 \mathrm{~kg} / \mathrm{m}^{3}$ and the ones with 200 $\mathrm{kg} / \mathrm{m}^{3}$. This phenomena was also observed by Monsif et al. (2019) in their study on the 
same clay. For all samples, between the two samples for each curing-day binder content combination, strength values are in general close to each other, showing rather fair consistency. A set of deviant data points exist for the 14-day cured samples of cement dosage of $100 \mathrm{~kg} / \mathrm{m}^{3}$. However, this is likely due to the individual differences in source soil having more influence on strength than curing time, as the effect of curing time diminishes after 7 to 14 days based on results from Afroz et al. (2018) and Li et al. (2016a).

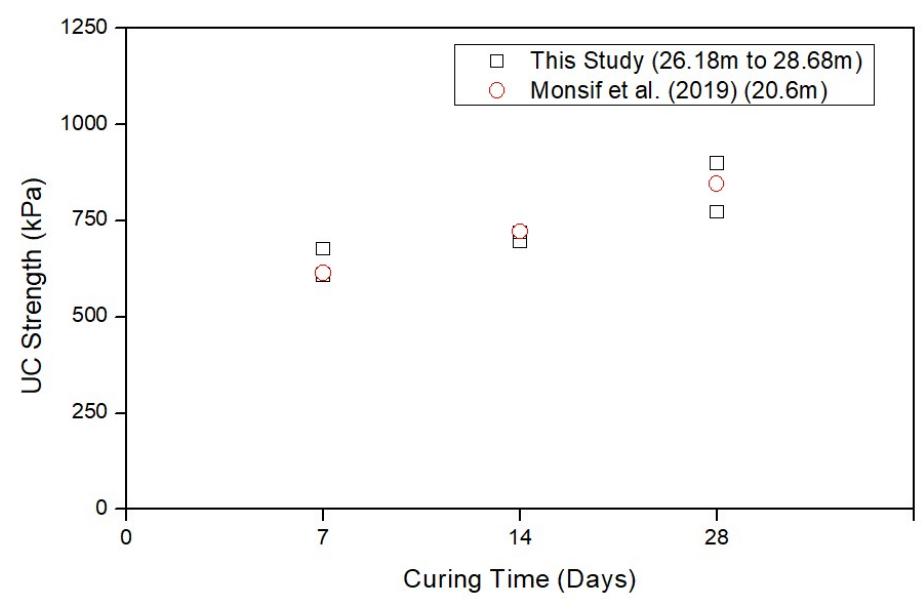

a) Samples treated with a cement dosage of $50 \mathrm{~kg} / \mathrm{m}^{3}$

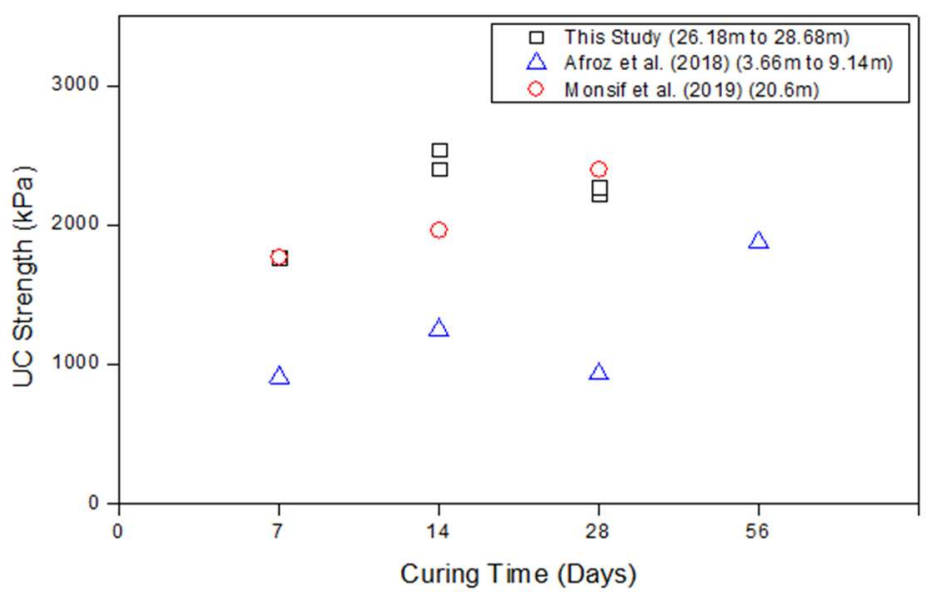

b) Samples treated with a cement dosage of $100 \mathrm{~kg} / \mathrm{m}^{3}$ 


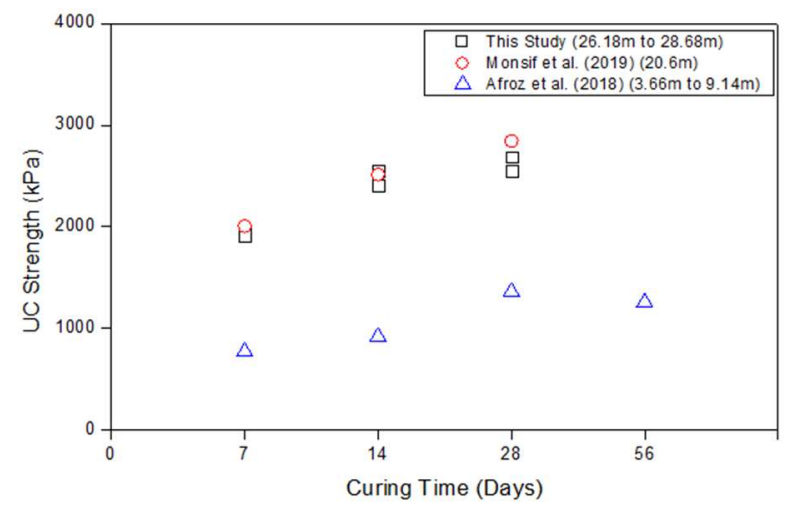

c) Samples treated with a cement dosage of $200 \mathrm{~kg} / \mathrm{m}^{3}$

Figure 4-4: A Comparison of UCS Test Results with Previous Studies on the Same Clay (Monsif et al., 2019; Afroz et al., 2018)

In general, UCS results from this study show agreements with previous studies in both the UCS values as well as the UCS increase trend with increasing binder content and curing time. The UCS values of this study show more similarity with the values from Monsif et al. (2019) due to the fact that clay samples from similar depths were used in both studies (25-30 m for this study, around $20 \mathrm{~m}$ for Monsif et al., 2019), while clay samples from depths between $3.66 \mathrm{~m}$ to $9.14 \mathrm{~m}$ with much lower UCS strengths in the natural condition were used by Liu, et al (2018). An increasing trend in UCS, with respect to both the increase of curing time and the increase of binder dosage, has been observed in experimental UCS results. This trend also closely matched the values and extent of strength gain with higher binder content and curing time observed by Monsif et al, (2019).

The stress-strain curves of the cement-treated clay samples during UCS testing are shown in Figure 4-5. The peak stress generally occurs between $1 \%$ and $2 \%$ axial strain and then followed by sample cracking or failure as the shear strain increases. Similar behavior is also found by Monsif et al. (2019). It can be observed that the soil stiffnesses, the slope of stress-strain curve, for samples with cement dosage of 100 and $200 \mathrm{~kg} / \mathrm{m}^{3}$ are quite high compared with those of $50 \mathrm{~kg} / \mathrm{m}^{3}$ samples. As evident in the three plots, the elastic modulus of a cement-treated Champlain Sea sample increases consistently with the increase of curing time, regardless whether strength increase is profound in the early curing of 7 days or 14 day) or marginal increase beyond 14 days. 
The plotted curves have been corrected for seating errors, which accounts for a slow-rising portion in the stress-strain curve due to partial contact between the sample and loading plate. Similar errors were documented by Kirstein (2010) and Adams (2011). An example of seating error correction is shown in Figure 4-6. The samples all fractured at relatively small stains (around 1\%), indicating brittle failure for this type of cement-treated clay and potential applicability of BTS and UPT testing methods.

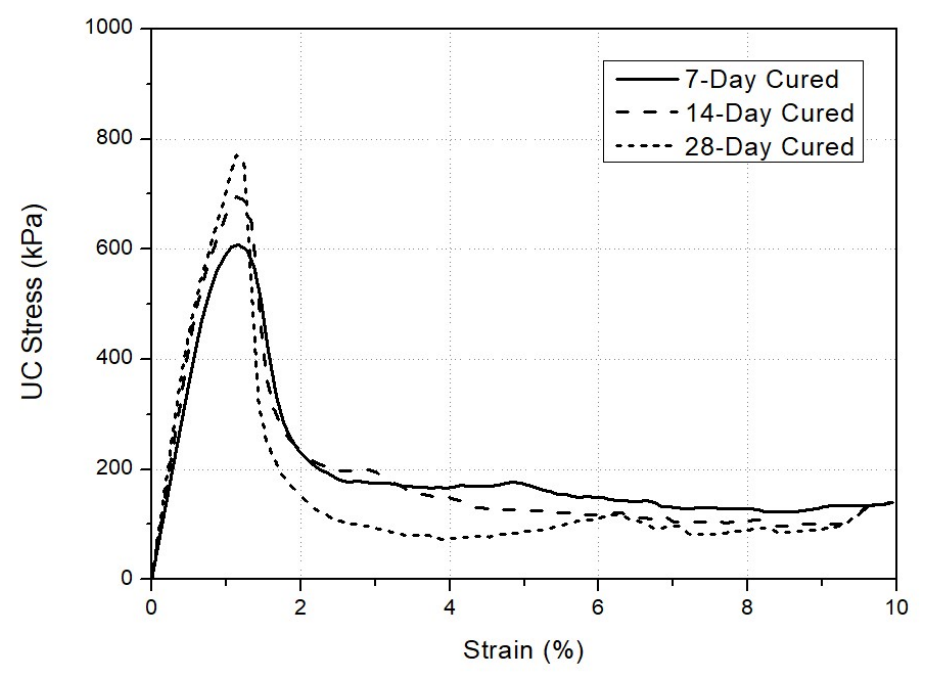

a) Stress-Strain Plot for $50 \mathrm{~kg} / \mathrm{m}^{3}$

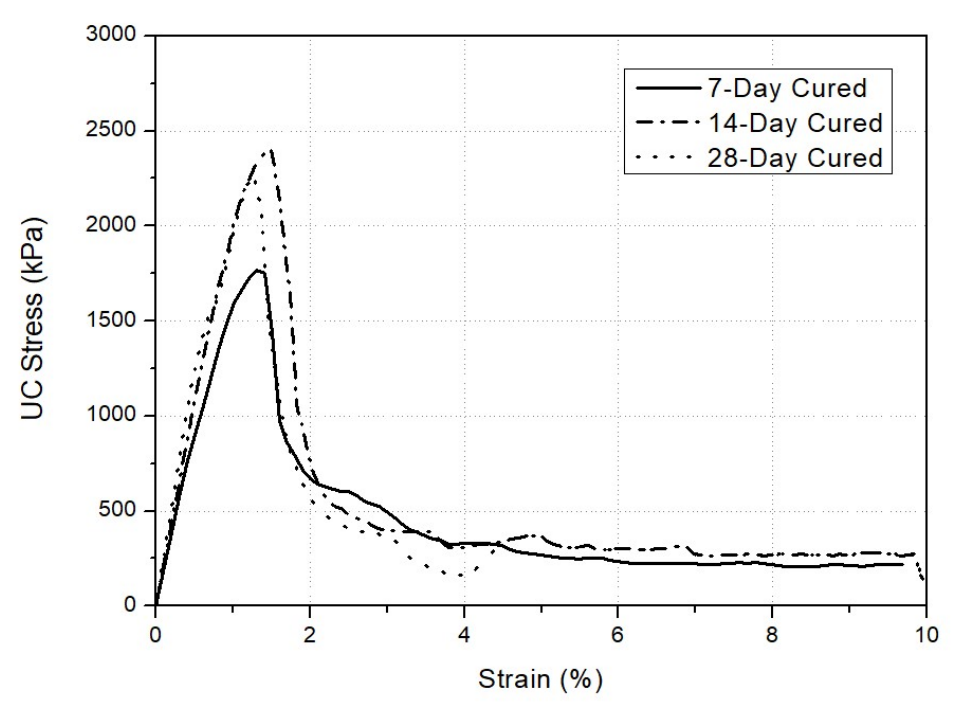

b) Stress-Strain Plot for $100 \mathrm{~kg} / \mathrm{m}^{3}$ 


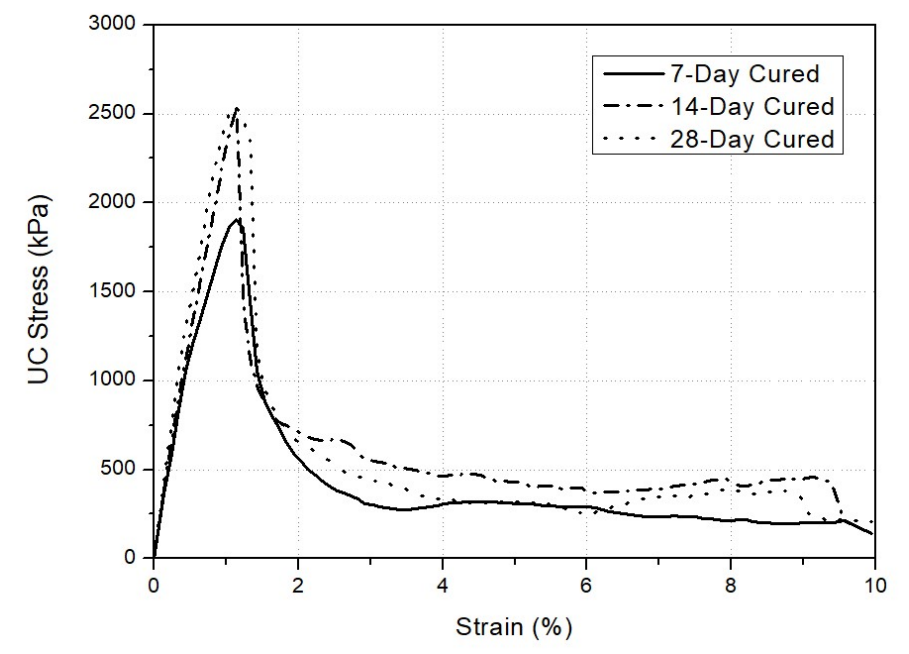

c) Stress-Strain Plot for $200 \mathrm{~kg} / \mathrm{m}^{3}$

Figure 4-5: Sample UCS stress-strain plots

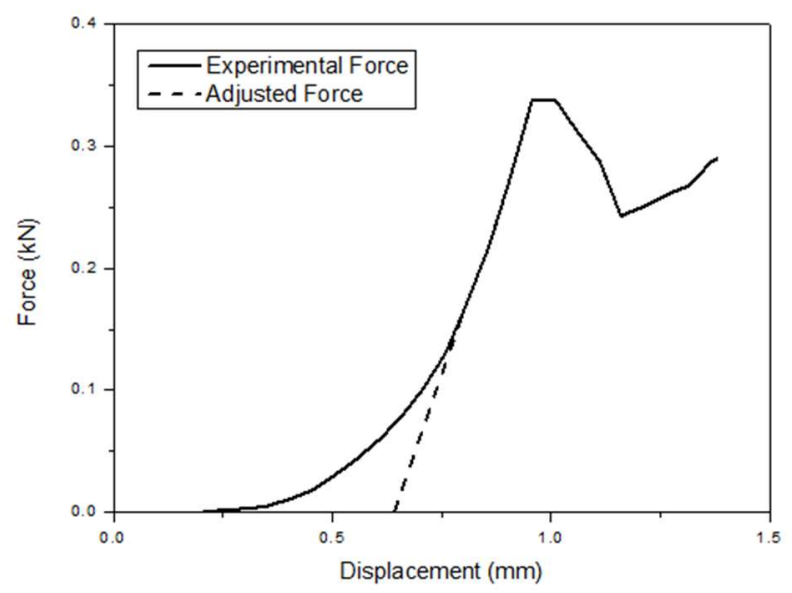

Figure 4-6: An Example for Seating Error Correction

Figure 4-7 shows the UCS values (peak compressive strengths) vs the failure strains for all UCS tests. All samples failed at a shear strain between $1.0 \%$ and $1.5 \%$, which shows the cement-treated Champlain Sea clay tends to exhibit a brittle failure. The 28-day cured samples generally have lower values of the failure strain, no apparent trends can be observed from the chart. It is common for samples to slow in their increase in stress when they approach their peak compressive load in testing. The reduction of rate of stress increase tends to produce more deformation during the brief moment right before brittle fracture. However, this period of reduced rate of stress increase is not uniform throughout the samples and this could have led to non-uniformity in failure strains. 


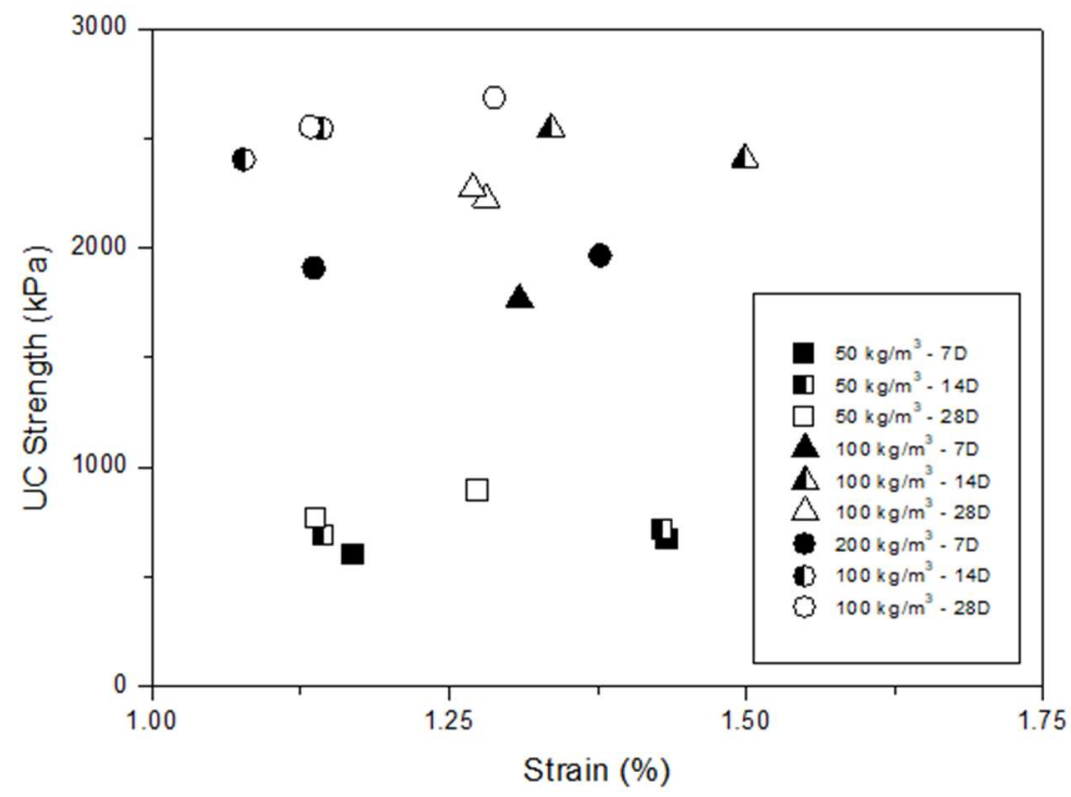

Figure 4-7: A Relationship between UCS values vs Failure Strains for All UCS Samples

\subsubsection{Detailed ANALysis AND Evaluation of UCS Results}

A number of strength parameters are investigated to have a thorough understanding of the behavior of cement-treated Champlain Sea clay. The Young's modulus, E, of a cementtreated clay sample was determined by slope calculation from the stress-strain curve of the UCS test. Data points of at the stress levels roughly $1 / 3$ and $2 / 3$ of the peak strength were selected for the slope calculation.

The Young's modulus of the cement-treated soil shows proportionality to binder content and curing time. A cement-treated sample with a higher amount of binder and a longer curing time would exhibit a higher modulus, showing a stiffer stress-strain response. Though correlation can be seen in both plots, binder content evidently has a significant more direct impact on the cement-treated soil stiffness. Trends in both plots also indicate soil modulus has a much stronger correlation with the binder content than the curing time.

In addition, UCS correlates much closer to soil modulus than the failure strain. The relationship between E and the UCS is shown in Figure 4-8 at E being rough 109.6 multiplied by UCS. The quality of the correlation is quite high and makes the UCS a much better predictor of Young's modulus than failure strain. This increasing trend was also observed by Li et al. (2016b) in their study of Kanata clay from Quebec. The modulus 
values ranged between $70 \mathrm{MPa}$ to over $300 \mathrm{MPa}$. Though a cement-mixed soil, the values of Young's modulus for the treated clay still seem to be much lower than that of concrete, which typically ranges between 20 and $40 \mathrm{GPa}$ (Neville \& Brooks, 2010).

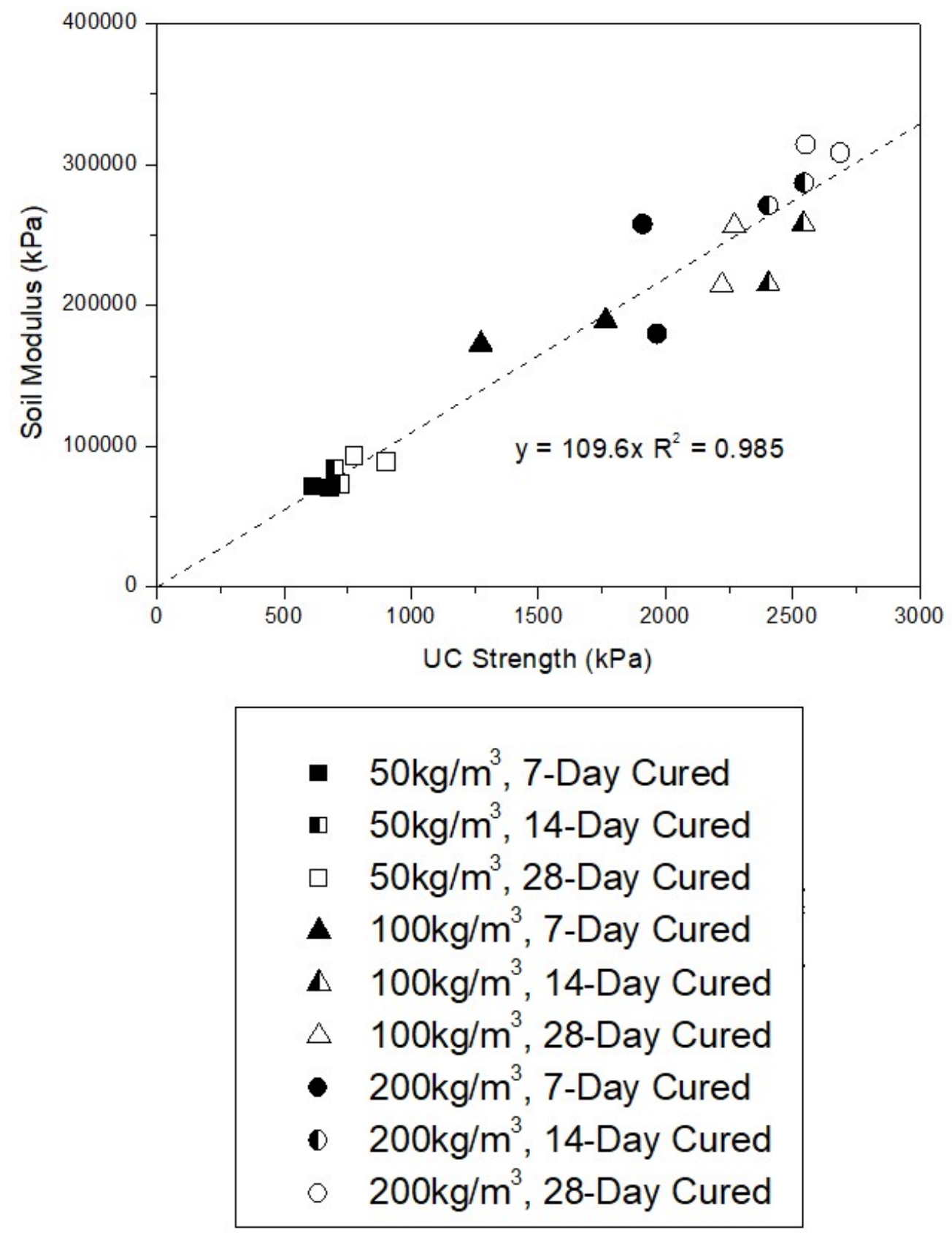

Figure 4-8: Relationship between Soil Modulus and Cement Dosage and Curing Time 


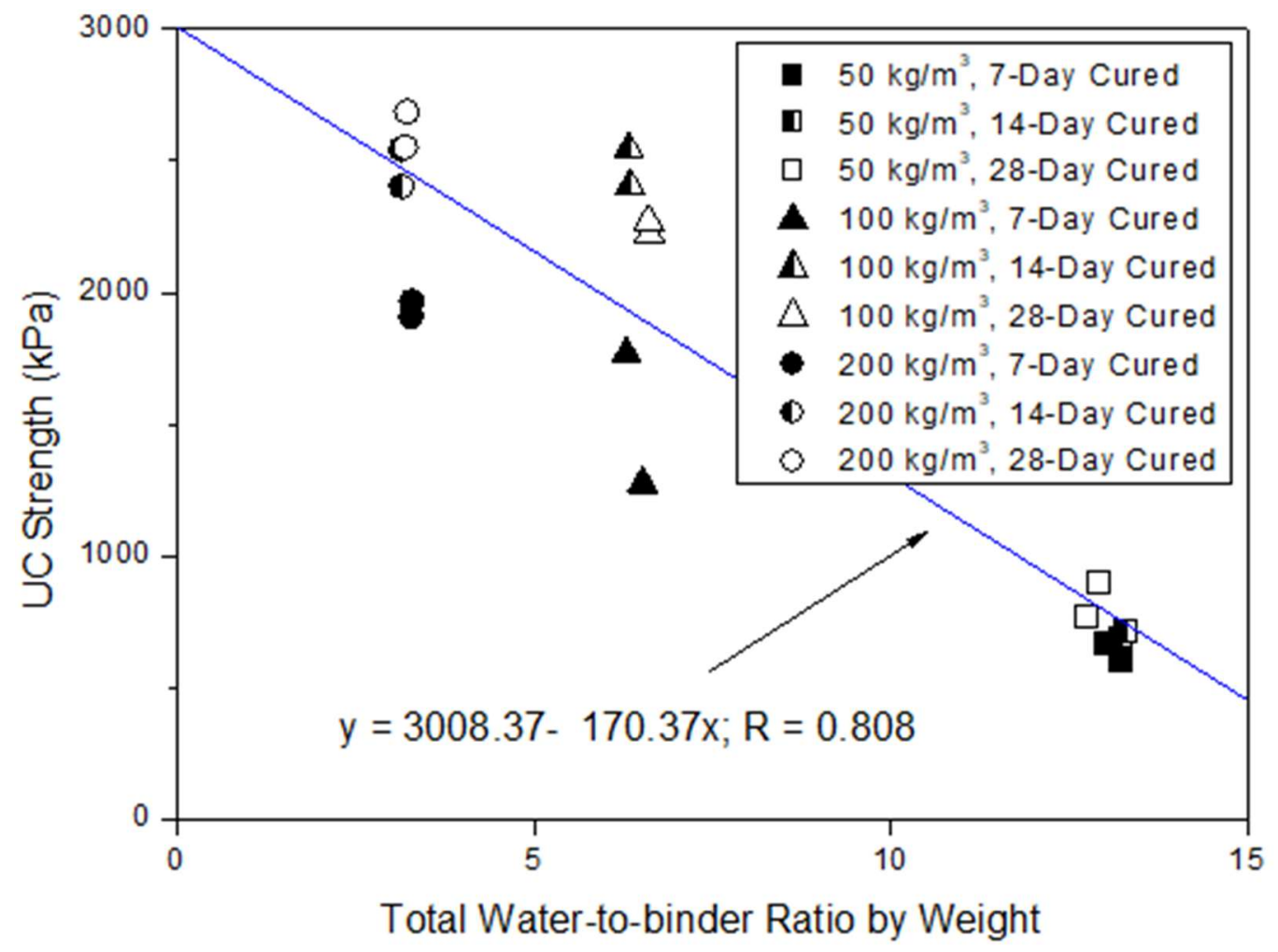

Figure 4-9: Total Water-to-binder Ratio by Weight for UCS Samples

The total water to binder ratio for a cement-treated clay sample was calculated as the ratio between the total mass of water to the mass of added binder, i.e. cement in the sample. It includes the water from the slurry added in mixing as well as the water from the source soil specimen itself, calculated from the water content of the source soil before mixing. As observed in UCS results, water-to-binder ratios are found in clusters, separated by their binder contents. High binder contents result in lower total water-to-binder ratios because of the larger amount of binder present while the water content from the source soil has remained the same. Lower water-to-binder ratios are associated with higher strengths due to association with higher binder contents. As documented by Afroz (2019), higher total water-to-binder ratio indicates lower strength for both concrete. In concrete, a curved trend of total water-to-binder ratio was observed with respect to UCS. However, the data obtained from cement-treated clay in this study showed more scatter in strength and were better suited for a linear approximation than the trend for concrete.

The dry densities of UCS samples exhibit a correlation with the UCS values only to a certain extent. Lower dry densities, those less than $900 \mathrm{~kg} / \mathrm{m}^{3}$, belong exclusively to the 
samples with a cement content of $50 \mathrm{~kg} / \mathrm{m}^{3}$. On the other hand, higher density tends to be associated with higher strength in many samples.

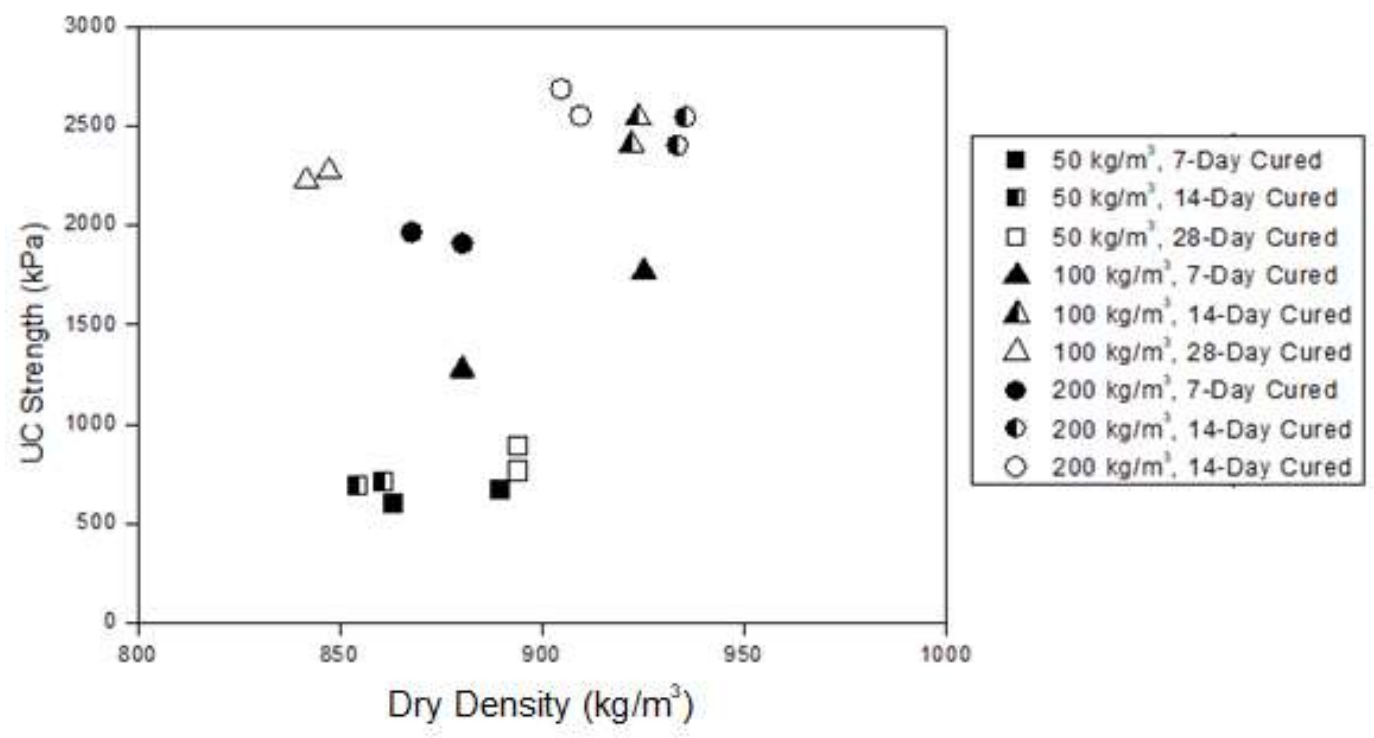

a). Dry Densities of UCS Samples

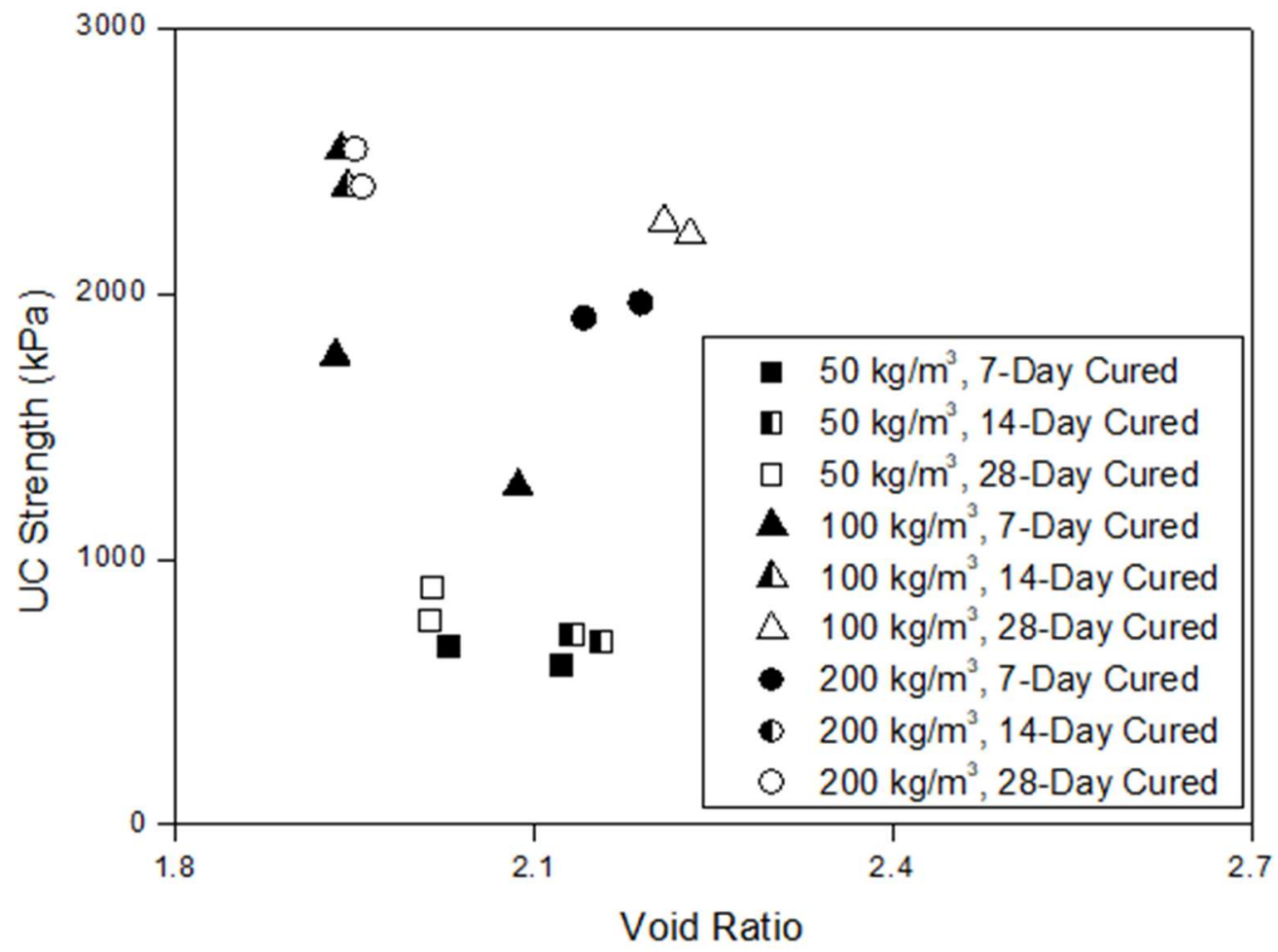

b). Void Ratios of UCS Samples

Figure 4-10: Relationship between UCS and Soil Parameters 
The void ratio of UCS samples show some correlation with cement content, but not so much for curing time. Following a similar pattern as dry density of samples treated with a cement dosage of $50 \mathrm{~kg} / \mathrm{m}^{3}$ have generally higher void ratios with lower cement content than those with higher binder contents. The UCS samples with cement dosages of 100 or $200 \mathrm{~kg} / \mathrm{m}^{3}$ exhibit little correlation between void ratio and strength. For all cement contents, the length of curing appears to have no impact on the void ratio of the samples. All three curing durations have data points which occupy the entire range of measured void ratio values. Due to the addition of equal mass of water in wet mixing (Li et al., 2016b), the addition of solid binder material did not lead to a decrease in void ratio in the mixed sample, either. Therefore, void ratios similar to those of the natural clay, which lay in the range of 1.9 to 2.0 (Ahmad, 2018), were measured.

Based on the data above, it can be concluded that the UCS data obtained from the samples are fairly consistent in soil parameters and in general agreed with data obtained from previous studies (Monsif et al., 2019; Liu et al., 2017). Therefore, the UCS values can be

considered representative of the tested clay and would be suitable to be used as a benchmark for its compressive strengths.

\subsection{BRAZILIAN TENSILE TESTING}

For indirect tensile investigations, BTS testing and UPT testing of 2-inch in diameter by 4inch length samples were investigated. Like UCS, two samples were prepared for Brazilian tensile strength for each combination of cement dosage and curing time.

\subsubsection{Description of Brazilian Tensile Samples in Testing}

Samples under BTS testing failed by splitting through the middle of the sample along the axis of force application. In most cases, the failure plane fell right in the middle of the sample where the force was applied. In a few samples, the splitting location of the sample deviated from the force application axis. This may be due to stress concentration formed at weaker portions inside an uneven sample. The vast majority of samples did fail along the center axis. 
The failure was often quite brittle in BTS testing. As soon as the peak stress was reached, a visible crack began appearing along the axis of force application. Immediately after, the center crack would expand and more cracks would start appearing at other parts of the sample. The load measured by the UCS machine would fall sharply immediately after the peak stress reached due to sample cracking. The load occasionally continued to increase slightly after the fall, presumably due to resistance encountered when the testing plates were further compressing the sample. However, at this point little can be gained by continuing sample crushing and the test was stopped soon after the peak stress was reached.

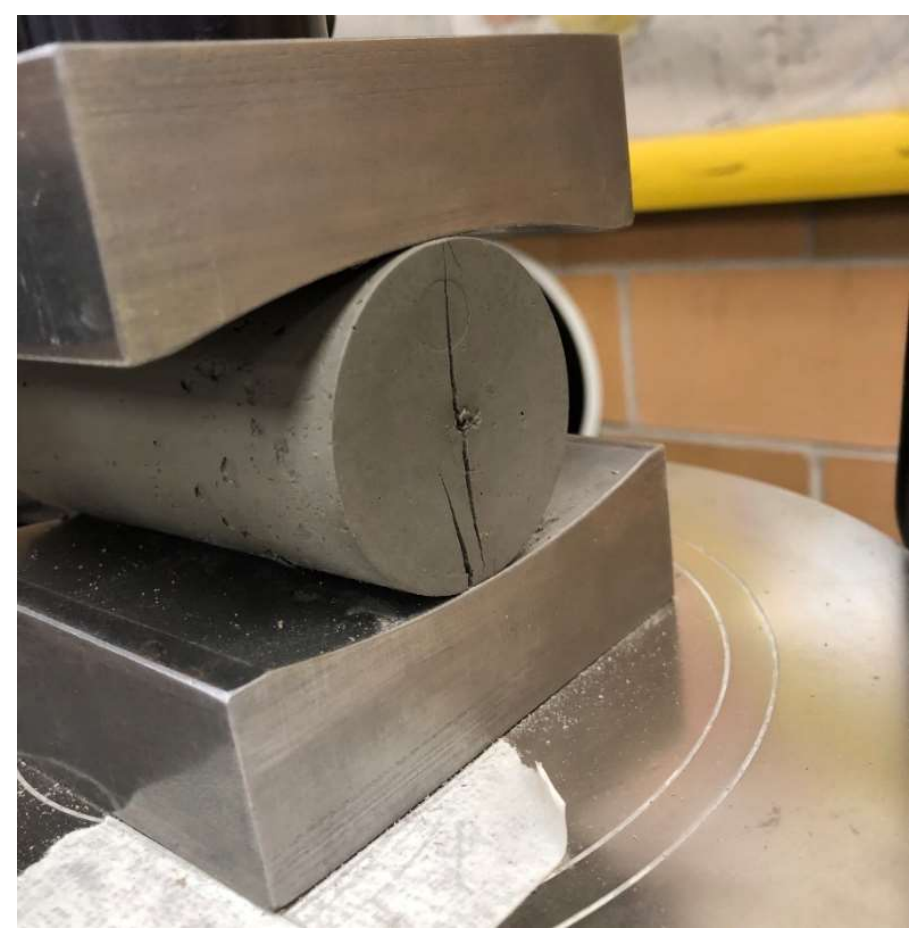

Figure 4-11: Failure and crack formation of a Brazilian tensile specimen 


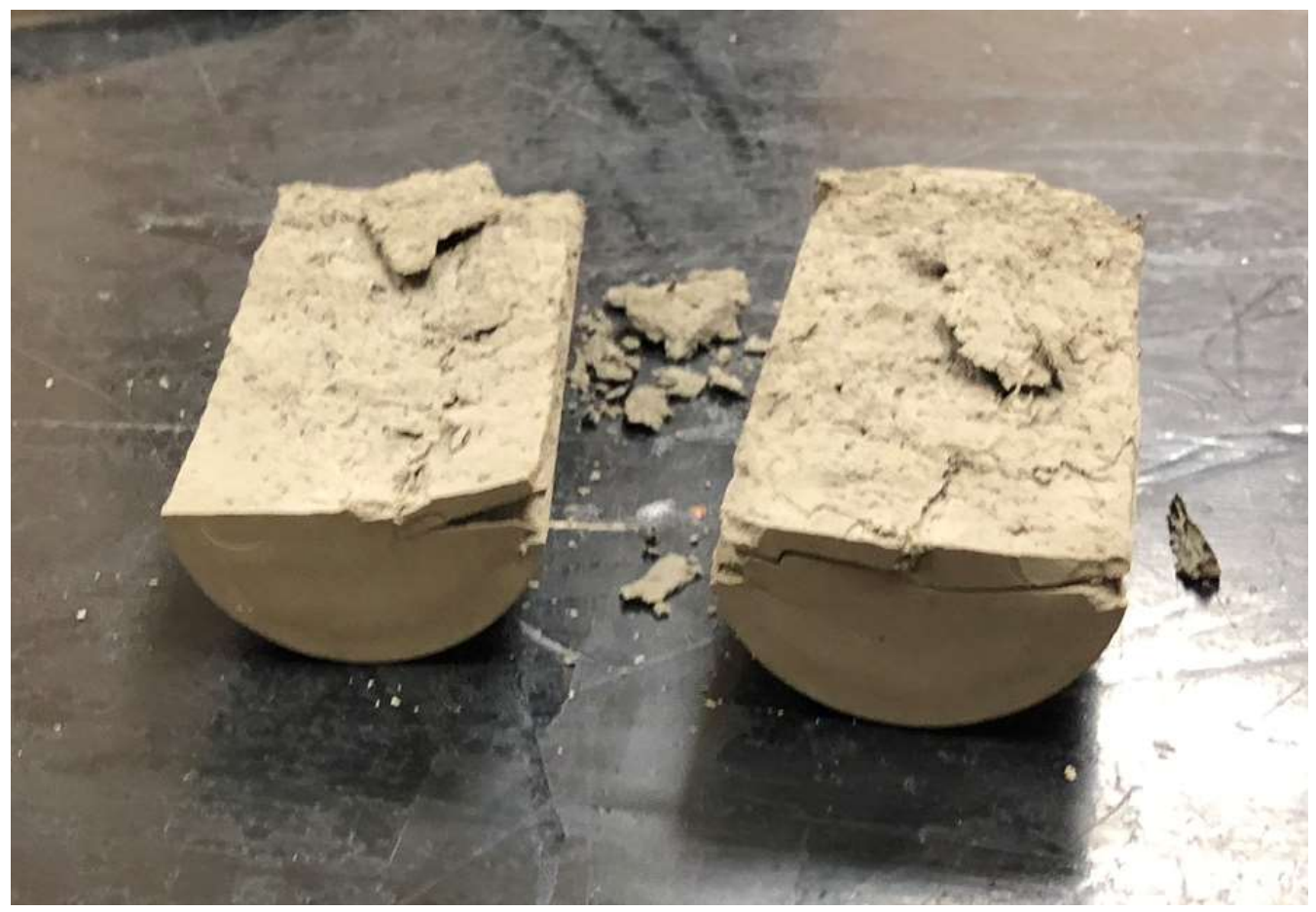

Figure 4-12: Failed Brazilian tensile specimen by splitting

\subsubsection{Brazilian Tensile Testing Results}

In general, the BTS test results follow roughly the same pattern as the UCS results when sorted by both the curing time and the binder content. An increase in tensile strength has been observed with the increase of the binder content and the curing time. Similar to the findings with UCS results, the strength increase from the cement dosage increase from 100 and $200 \mathrm{~kg} / \mathrm{m}^{3}$ is not as significant as the ones from 50 and $100 \mathrm{~kg} / \mathrm{m}^{3}$. The tensile strength of $100 \mathrm{~kg} / \mathrm{m}^{3}$ samples exhibited occasionally higher than that of $200 \mathrm{~kg} / \mathrm{m}^{3}$ samples. Between the two data points for each curing-time binder content combination, those with $50 \mathrm{~kg} / \mathrm{m}^{3}$ dosage are more consistent whereas those at higher binder contents showed a higher variance. It is evident that at higher binder contents, the range of tensile strength of cement-treated samples are higher.

The force-displacement of Brazilian tensile test, where the peak force is used to calculate the tensile strength, generally showed the same trends as the UCS stress-strain curve, with increasing curing time and binder content leading to increasing stiffness. In the case of 14day cured samples having higher strength than the 28-day one, the stiffness of the stronger 
14-day sample tended to also be higher. The failure loads, tensile strengths and soil parameters of the testing samples are summarized below in Table 4-1.

The load displacement curves of BTS generally show linear-elastic behavior up to a point where a drop in load is observed accompanied by sample cracking. The tensile strength was calculated using the force at this peak. After sample cracking, the sample retained some strength and might plateau or remain at a lower strength for an extended amount of displacement. This residual strength may be explained by the fact that, as the loading plates continued to squeeze the sample after initial cracking, the contact surface between the plate and the sample increased due to compression of the sample. Although there was a loss of strength in the cement-treated clay due to cracking after the end of linear-elastic behavior, the increase of contact surface might have caused the total load exerted on the already crack sample to remain at a certain amount, or even increase beyond the load at initial cracking for a few samples. In general, the samples with larger cracking strengths, the 14-day and 28-day cured samples showed a steeper drop after initial cracking than lower strength samples, i.e. 7-day cured and certain 14-day cured samples. This indicates that an intact sample comprised of stronger cement-treated clay is able to hold larger strengths before initial cracking but this does not necessarily lead to higher residual strengths after fracture has appeared in the sample.

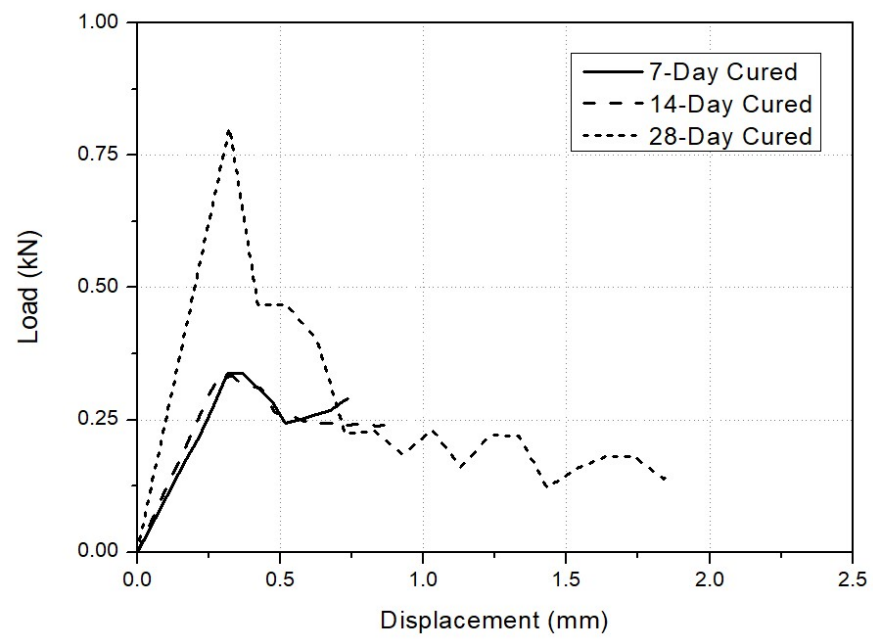

a). Load-Displacement Curves of $50 \mathrm{~kg} / \mathrm{m}^{3}$ Samples 


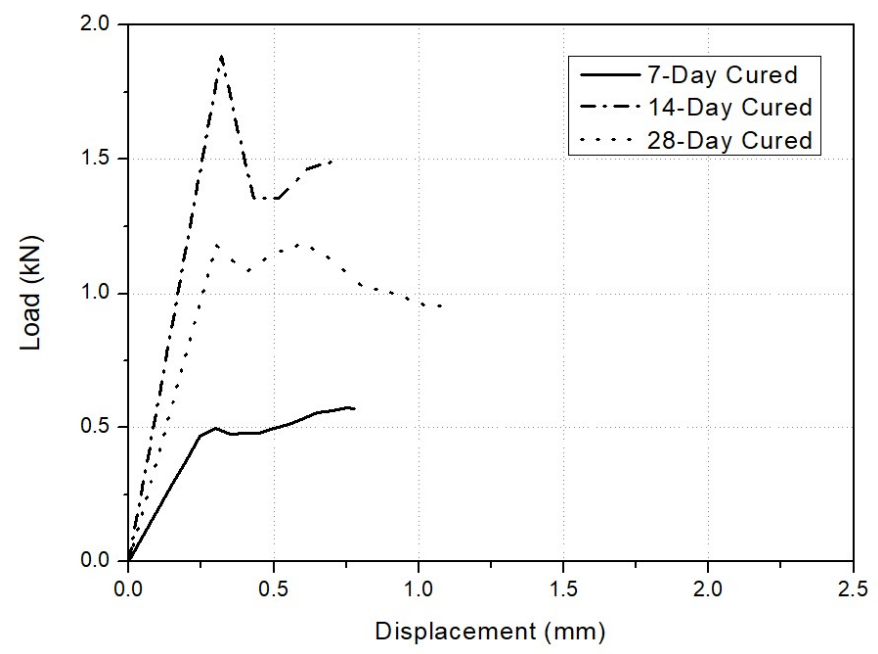

b). Load-Displacement Curves of $100 \mathrm{~kg} / \mathrm{m}^{3}$ Samples

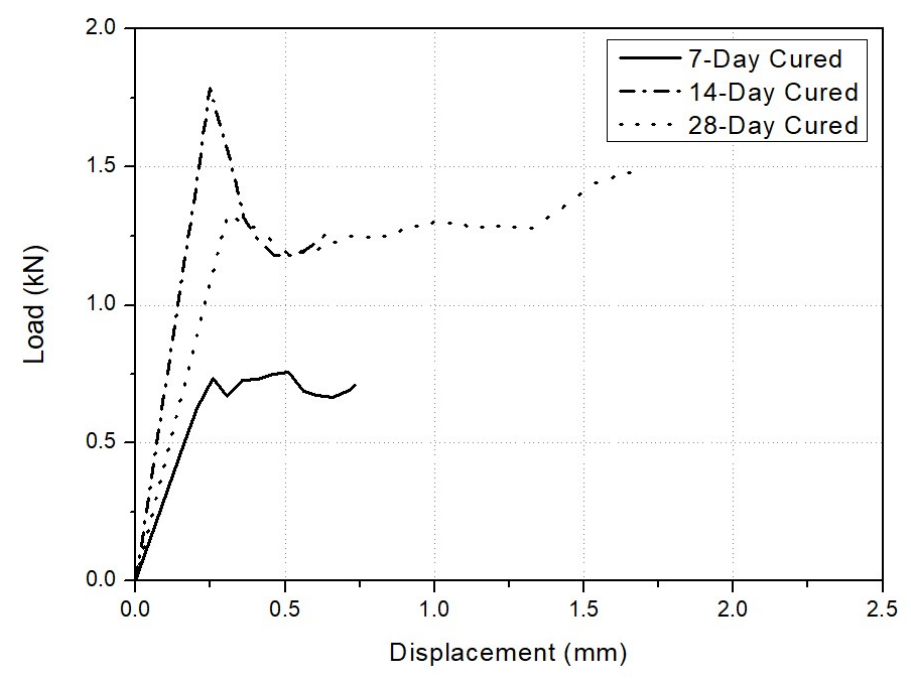

c). Load-Displacement Curves of $200 \mathrm{~kg} / \mathrm{m}^{3}$ Samples

Figure 4-13: Select Load-displacement Curves for BTS Testing Samples

Figure 4-14 shows the change of the tensile strengths calculated from BTS testing with the cement dosage and curing time. A few outliers have been removed for a better trend. Generally speaking, the tensile strength of cement-treated Champlain Sea clay increases with increasing cement dosage and curing time, though exceptions were noticed in 4-day cured $200 \mathrm{~kg} / \mathrm{m}^{3}$ samples. This phenomenon has also been documented in Li et al. (2016a) in UCS results. 


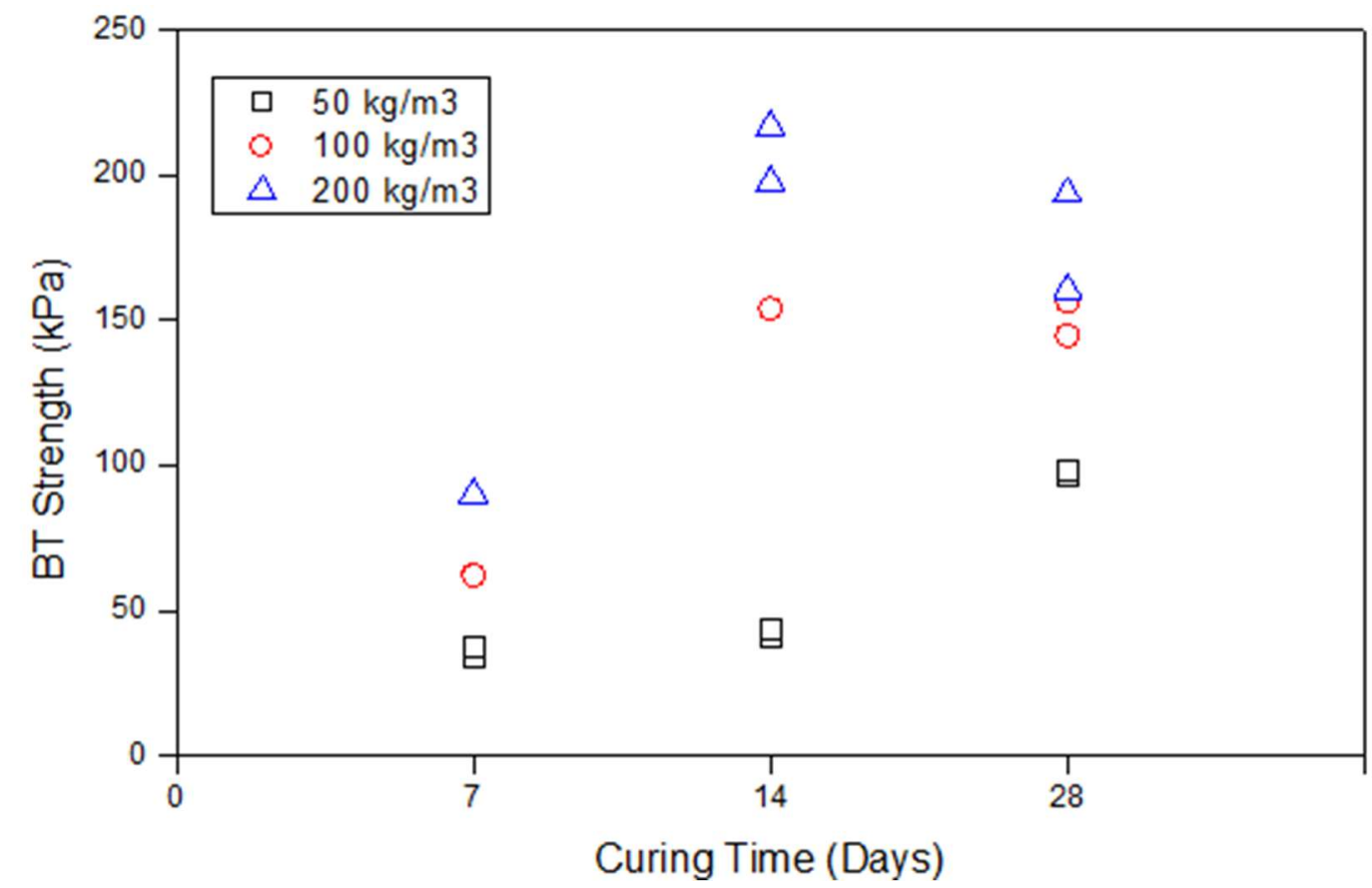

Figure 4-14: Brazilian Tensile Strength Sorted by Curing Time and Binder Content Table 4-1: Information of BTS Testing Samples

\begin{tabular}{|c|c|c|c|c|c|}
\hline Sample name & $\begin{array}{r}\text { Peak } \\
\text { Load } \\
(\mathrm{kN})\end{array}$ & $\begin{array}{c}\text { Tensile } \\
\text { Strength } \\
(\mathrm{kPa})\end{array}$ & $\begin{array}{c}\text { Failure } \\
\text { Displacement } \\
(\mathrm{mm})\end{array}$ & $\begin{array}{c}\text { Dry } \\
\text { Density } \\
(\mathrm{kg} / \mathrm{m} 3)\end{array}$ & $\begin{array}{c}\text { Water } \\
\text { content } \\
(\%)\end{array}$ \\
\hline WD28.30m_50C_7D_BT1 & 0.289 & 34.94 & 0.587 & 887.66 & 73.79 \\
\hline WD26.18m_50C_7D_BT2 & 0.338 & 40.77 & 0.316 & 859.68 & 76.78 \\
\hline WD28.30m_100C_7D_BT1 & 0.517 & 46.04 & 0.299 & 911.58 & 70.50 \\
\hline WD28.30m_100C_7D_BT2 & 0.515 & 40.21 & 0.319 & 937.54 & 67.12 \\
\hline WD28.30m_200C_7D_BT1 & 0.758 & 91.23 & 0.258 & 881.88 & 73.75 \\
\hline WD28.30m_50C_14D_BT1 & 0.346 & 41.82 & 0.332 & 903.68 & 77.40 \\
\hline WD28.30m_50C_14D_BT2 & 0.365 & 44.22 & 0.308 & 905.57 & 70.77 \\
\hline WD28.30m_100C_14D_BT1 & 1.275 & 154.14 & 0.318 & 927.13 & 68.35 \\
\hline WD26.18m_200C_14D_BT1 & 1.787 & 216.72 & 0.249 & 941.94 & 67.33 \\
\hline WD26.18m_200C_14D_BT2 & 1.637 & 197.47 & 0.193 & 935.75 & 66.37 \\
\hline
\end{tabular}




\begin{tabular}{|c|c|c|c|c|c|}
\hline WD26.18m_50C_28D_BT1 & 0.792 & 97.45 & 0.318 & 903.68 & 70.36 \\
\hline WD26.18m_50C_28D_BT2 & 0.801 & 98.57 & 0.322 & 905.57 & 70.28 \\
\hline WD26.18m_100C_28D_BT1 & 1.297 & 156.53 & 0.860 & 858.55 & 75.70 \\
\hline WD26.18m_100C_28D_BT2 & 1.203 & 144.82 & 0.302 & 858.93 & 76.00 \\
\hline WD26.18m_200C_28D_BT1 & 1.328 & 160.50 & 0.308 & 905.69 & 70.69 \\
\hline WD26.18m_200C_28D_BT2 & 1.597 & 193.65 & 0.140 & 908.74 & 69.52 \\
\hline
\end{tabular}

\subsubsection{Detailed Analysis of Brazilian Tensile Testing Results}

The soil parameters for BTS samples generally show similar patterns to those of the UCS tests, as shown in Figures 4-9 and 4-10. The total water-to-binder ratios in BTS samples exhibited similar trends of lower ratio correlating with higher strength as the UCS samples did. The void ratio seems to be a little less correlated with BTS samples than the UCS samples even when sorted by binder content, though it is still observable that samples with higher strengths were generally associated with lower void ratios. However, as strength becomes lower, neither curing time nor binder content seem to have a noticeable influence on the value of void ratio. Curing time remains essentially irrelevant to the void ratiostrength relationship, as shown in Figure 4-16-b). The tensile strength decreases with increasing the dry density of a BTS sample, but varies in a wide range, as shown in Figure 4-16-a).

The water content of the samples differed little from that of natural clay. Due to the method of mixing being wet, equal masses of water and cement were added in the process of mixing. Therefore, the addition of binder materials did not lead to a decrease in water content as a whole in the sample. On the other hand, water content also differed little based on binder content. Compared with another wet mixing study of the same soil type by Li et al. (2016b) where water content was found to increase with increased binder content, the amount of binder added for this study is much lower than the binder dosage found in that study. The above reasons may account for the lack of water content change in experimental mixing. 


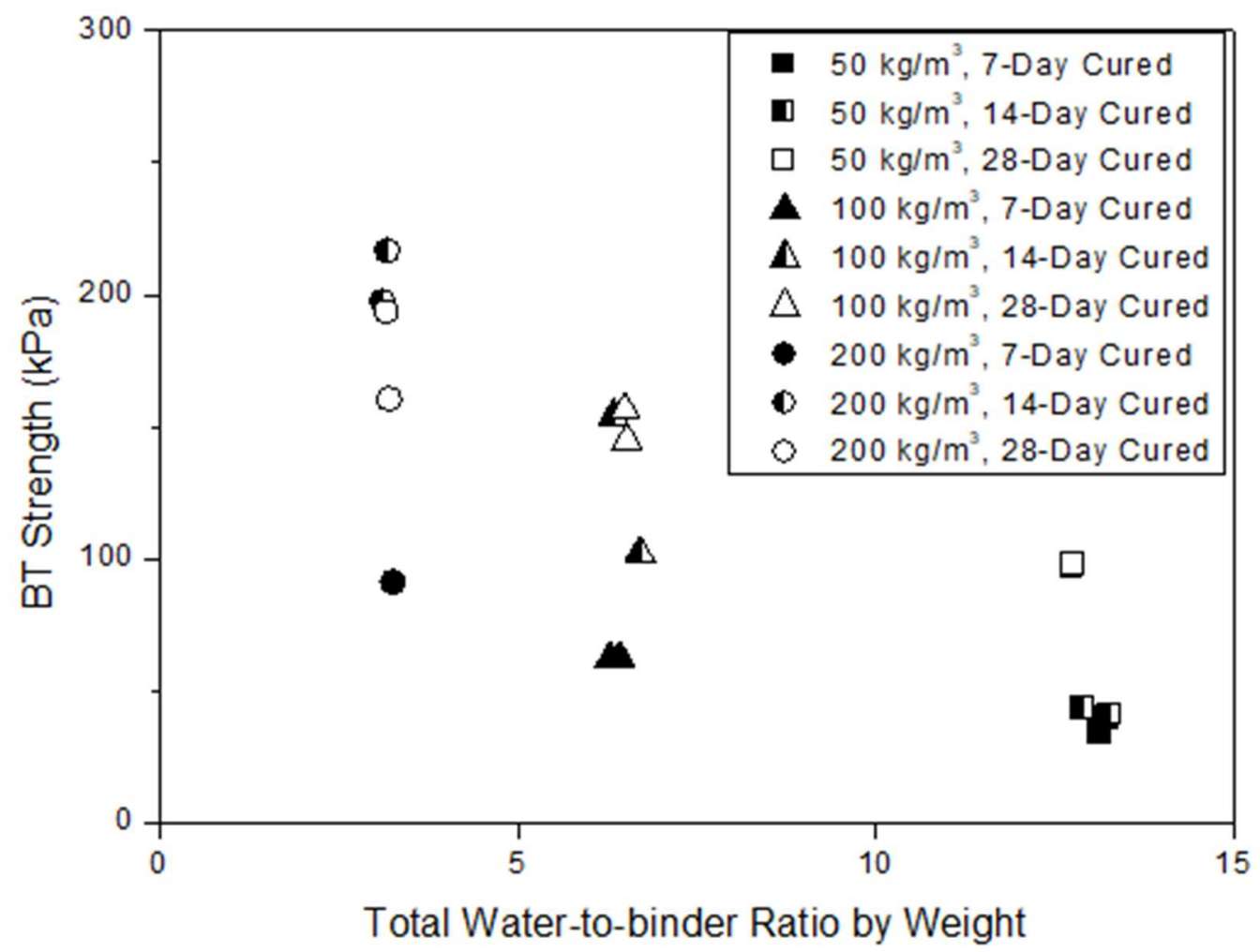

Figure 4-15: Total Water-to-binder Ratios by Weight for Brazilian Tensile Samples

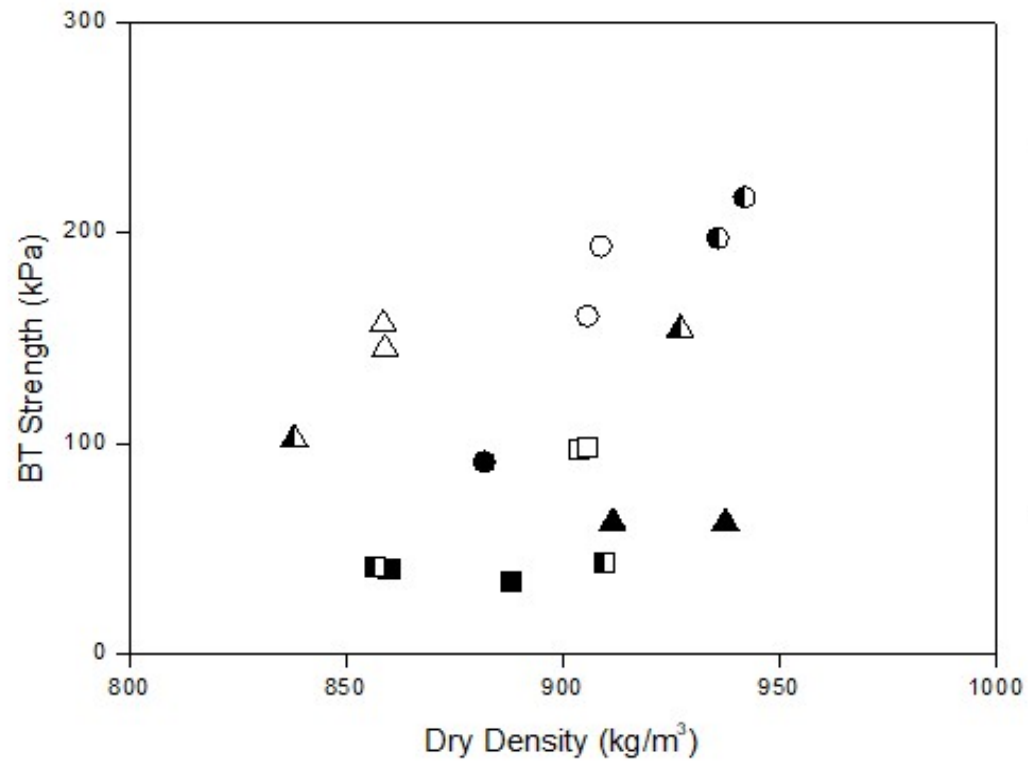

$50 \mathrm{~kg} / \mathrm{m}^{3}, 7-$ Day Cured

- $50 \mathrm{~kg} / \mathrm{m}^{3}, 14-$ Day Cured

$50 \mathrm{~kg} / \mathrm{m}^{3}, 28$-Day Cured

A $100 \mathrm{~kg} / \mathrm{m}^{3}, 7-$ Day Cured

A $100 \mathrm{~kg} / \mathrm{m}^{3}, 14-$ Day Cured

$\triangle 100 \mathrm{~kg} / \mathrm{m}^{3}, 28$-Day Cured

- $200 \mathrm{~kg} / \mathrm{m}^{3}, 7-$ Day Cured

- $200 \mathrm{~kg} / \mathrm{m}^{3}, 14$-Day Cured

200 kg/m ${ }^{3}, 28$-Day Cured

a). Dry Densities of BTS Samples 


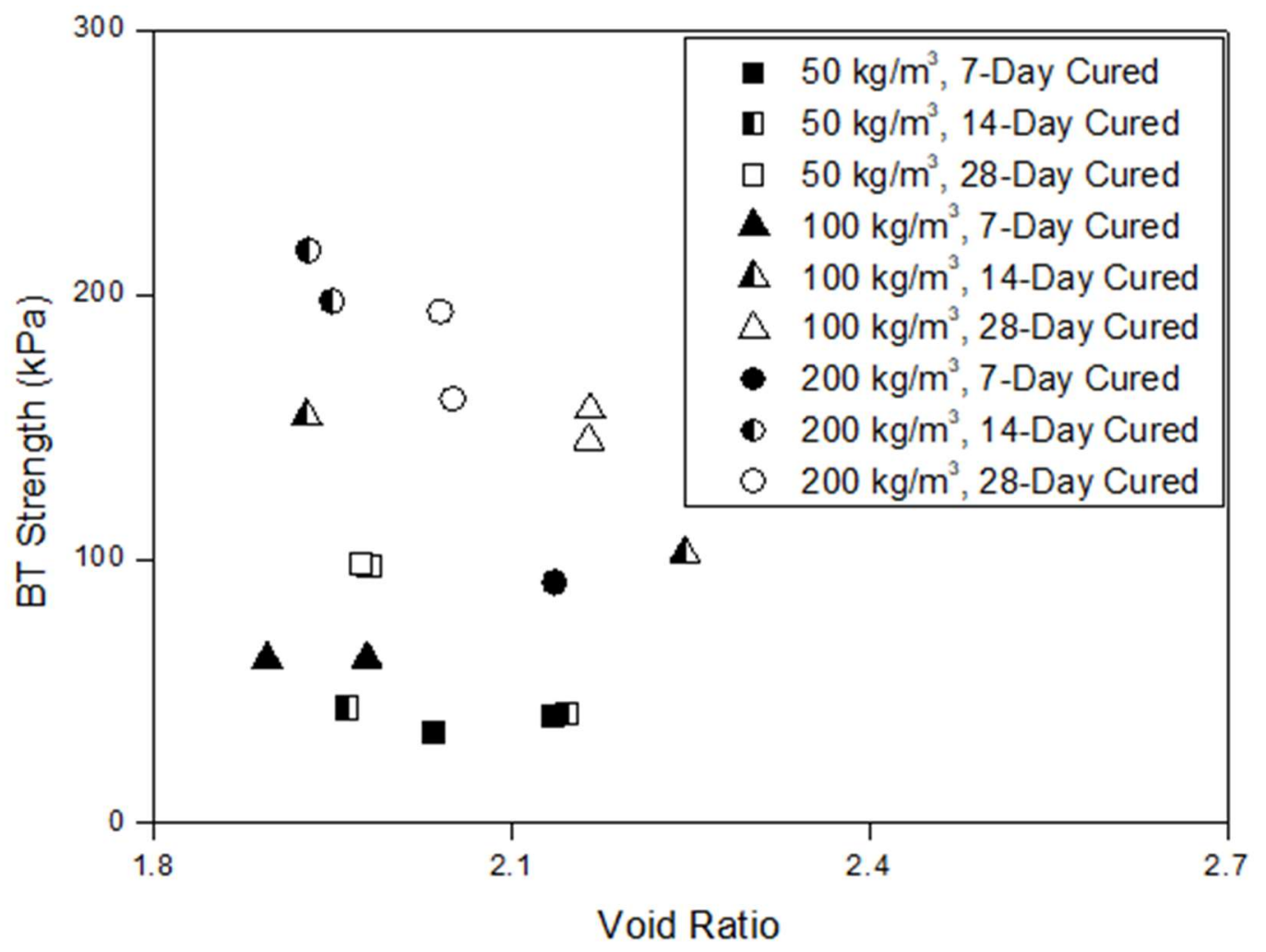

b). Void Ratios of BTS Samples

Figure 4-16: Relationship between BTS and Soil Parameters

\subsubsection{Numerical CORRELATION BETWEen BTS AND UCS RESUltS}

A numerical correlation can be formed to determine the relationship between BTS and UCS results. For each curing time-binder content combination, the average UCS and Brazilian tensile values were calculated and plotted in Figure 4-17, where the average value of two samples for each combination was used in the figure. Error crosses in the plot represent the maximum and minimum extent of individual tensile and compressive strengths for the samples in each combination.

A trend line was established and juxtaposed with the general correlation of $10 \%$ between tensile and compressive strength for cement and lime treated clayey soil obtained by Terashi et al. (1980). Tensile strength of cement-treated Champlain Sea clay generally falls between $5 \%$ and $10 \%$ of its UCS. This is noticeably less than the $10 \%$ factor between tensile strength and compressive strength of concrete (Neville \& Brooks, 2010), as well as a cement-treated Japanese clay by Terashi et al.(1980). 
A linear regression curve was observed between BTS and UCS of cement-treated Champlain Sea clay with an assumption of no cohesion under zero UCS strength condition, as shown in Eq.4-1.

$$
\sigma_{t}=0.0647 \sigma_{U C S} ; R^{2}=0.936
$$

Where $\sigma_{t}$ is tensile strength of the sample obtained in BTS testing.

$\sigma_{U C S}$ is compressive strength of the sample obtained in UCS testing.

As documented in Section 4.3.5, a different ratio between the length and diameter of the sample has a significant effect on the result. Based on test data, a sample shorter in length tends to produce a larger strength. If the relationship between sample length and radius from testing results is considered, the correlation for the experimental sample with length to diameter ratio of $2: 1,6.5 \%$, would translate to about $7.6 \%$ for a length to diameter ratio of 1:1 as used in Terashi et al. (1980).

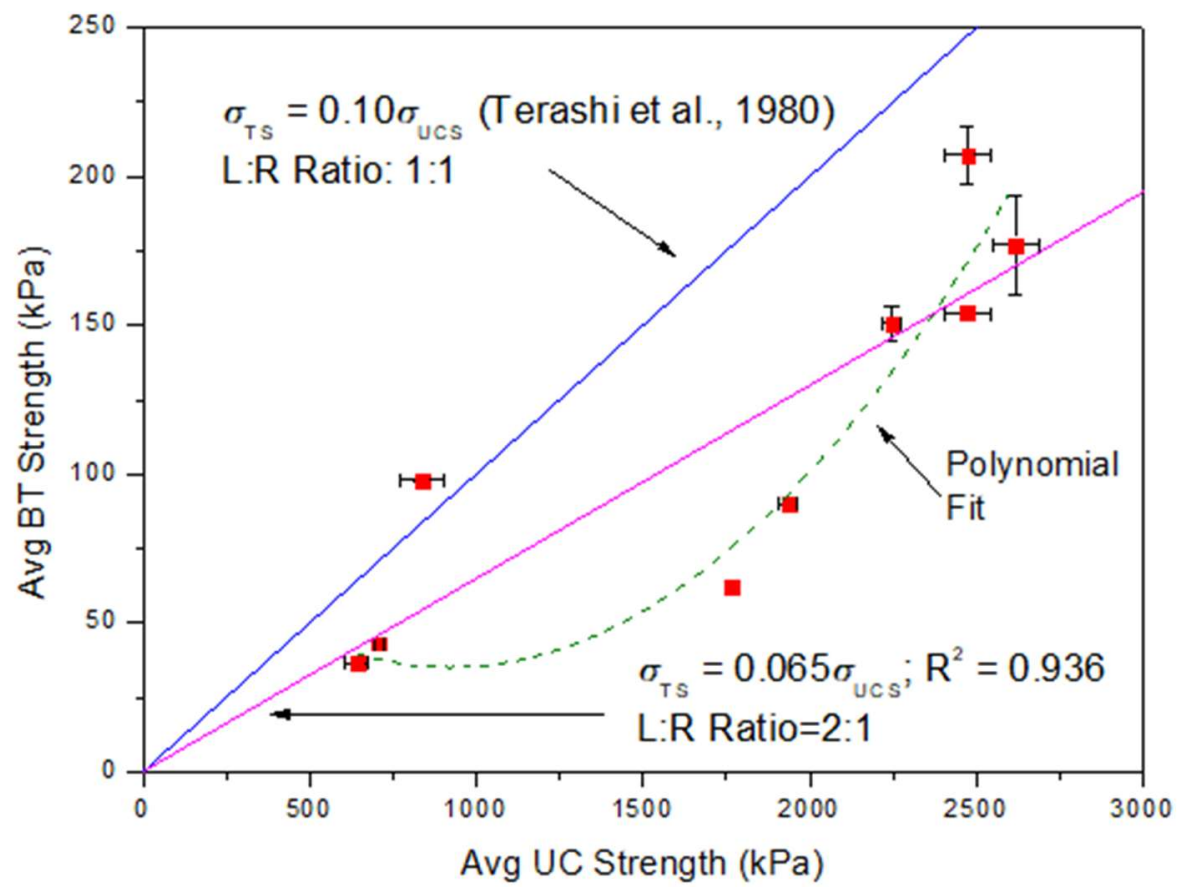

Figure 4-17: Correlation between BTS and UCS for average values of all tests In addition to linear regression with a fixed intercept at zero, polynomial fitting was also performed. $2^{\text {nd }}$ order polynomial fitting, without fixing the intercept produced an R-squared 
value of 0.883 whereas linear fitting without fixing the intercept only produced $0.687 .3^{\text {rd }}$ order polynomial fitting had an R-squared value of 0.894 and $4^{\text {th }}$ order 0.890 , suggesting a diminishing return effect. The details of these polynomial correlations are shown in Table 4-2.

Table 4-2: Polynomial Fits for BTS-UCS Correlation

\begin{tabular}{|c|c|c|c|c|c|c|}
\hline \multirow{2}{*}{$\begin{array}{c}\text { Order of } \\
\text { Polynomial }\end{array}$} & \multicolumn{5}{|c|}{ Intercepts and Coefficients } & \multirow{2}{*}{$\mathrm{R}^{2}$} \\
\cline { 2 - 6 } & Intercept & B1 & B2 & B3 & B4 & \\
\hline 1 st Order & 0.391 & 0.064 & - & - & - & 0.687 \\
\hline $2^{\text {nd }}$ Order & 83.25 & -0.104 & $5.66 \mathrm{E}-5$ & - & - & 0.883 \\
\hline $3^{\text {rd }}$ Order & 408.41 & -0.884 & $5.66 \mathrm{E}-4$ & $-9.98 \mathrm{E}-8$ & - & 0.894 \\
\hline $4^{\text {th }}$ Order & -393.23 & 1.458 & $1.69 \mathrm{E}-3$ & $7.91 \mathrm{E}-7$ & $-1.25 \mathrm{E}-10$ & 0.890 \\
\hline
\end{tabular}

Nevertheless, before new data become available, linear regression with intercept fixed at 0 remains the most practical way of fitting. Firstly, it would be nonsensical to assume a positive tensile strength value at a compressive strength value of 0 . In addition, the use of fixed intercept linear regression was reported in numerous earlier studies about soil tensile strength (Al-Omar, 1983; Mu, 2013; Liang et al., 2014) and its use in our study would enable comparisons with those studies.

\subsubsection{Testing Results for SMall-LEngth BRAZILIAN TEnsile SAMPLES}

The sizing effect of BTS samples are investigated in this study. The standard sample size used in this study are 2-inch in diameter and 4-inch in length. In this investigation, clay samples with lengths varying from 1 inch to 2 inches were prepared under the same conditions with the regular sized ones, including the same cement dosage of $100 \mathrm{~kg} / \mathrm{m}^{2}$, the same curing condition for 14 days, and the same testing condition. During testing, the smaller sized samples tended to form cracks in the center, which are slightly less straight than regular sized ones. It seems that a smaller sized sample exhibited a stronger tensile strength than a larger one under the same cement dosage and curing time, as shown in Figure 4-20. This is likely due to the smaller amount of imperfections in a smaller sample than a larger one, which is consistent with other findings in rocks (Thuro et al., 2001). 
Based on test data for rocks by Thuro et al. (2001), the decreasing trend of tensile strength with increasing sample length gradually diminishes between the sample length to diameter ratios of 1:1 and 2:1. Further decrease in strength for length to diameter ratios beyond 2:1 would be very limited. Because microscopic imperfections in a DSM structure would be essentially unavoidable, our correlation at the length to diameter ratio of 2:1 would provide a conservative tensile strength estimate for design.

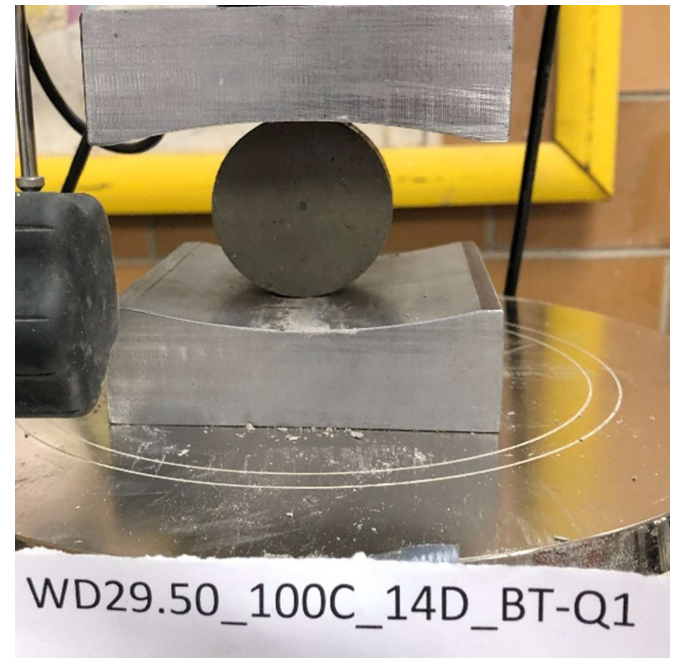

a) before cracking

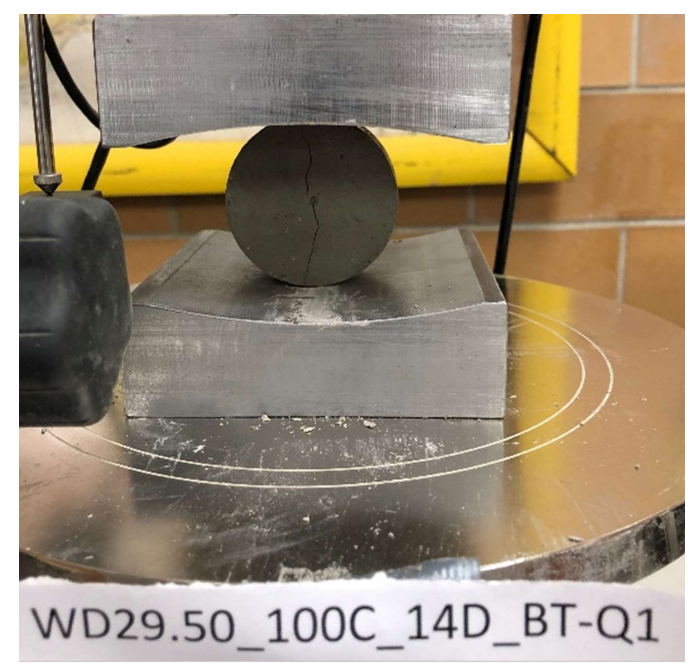

b) after cracking

Figure 4-18: A 1-inch Long BTS Sample under Testing

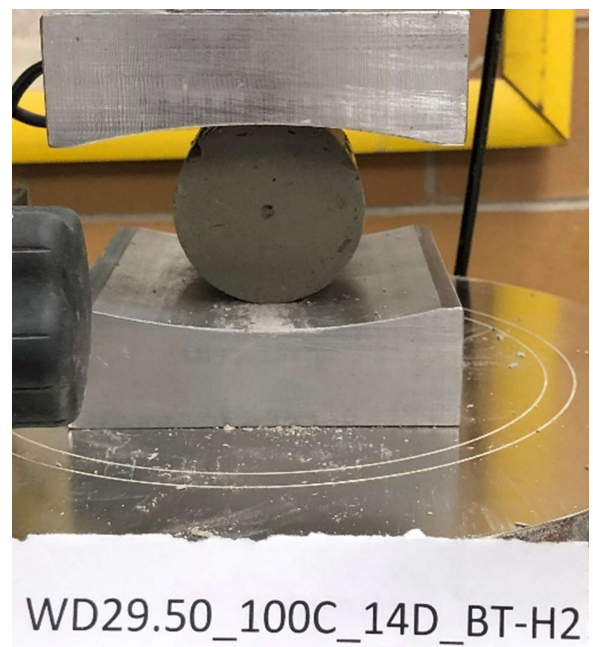

b) before cracking

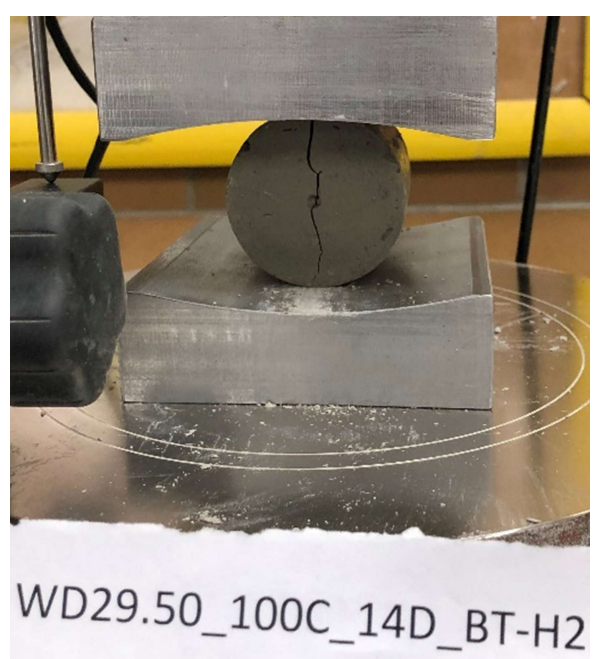

b) after cracking

Figure 4-19: A 2-inch Long BTS Sample under Testing 


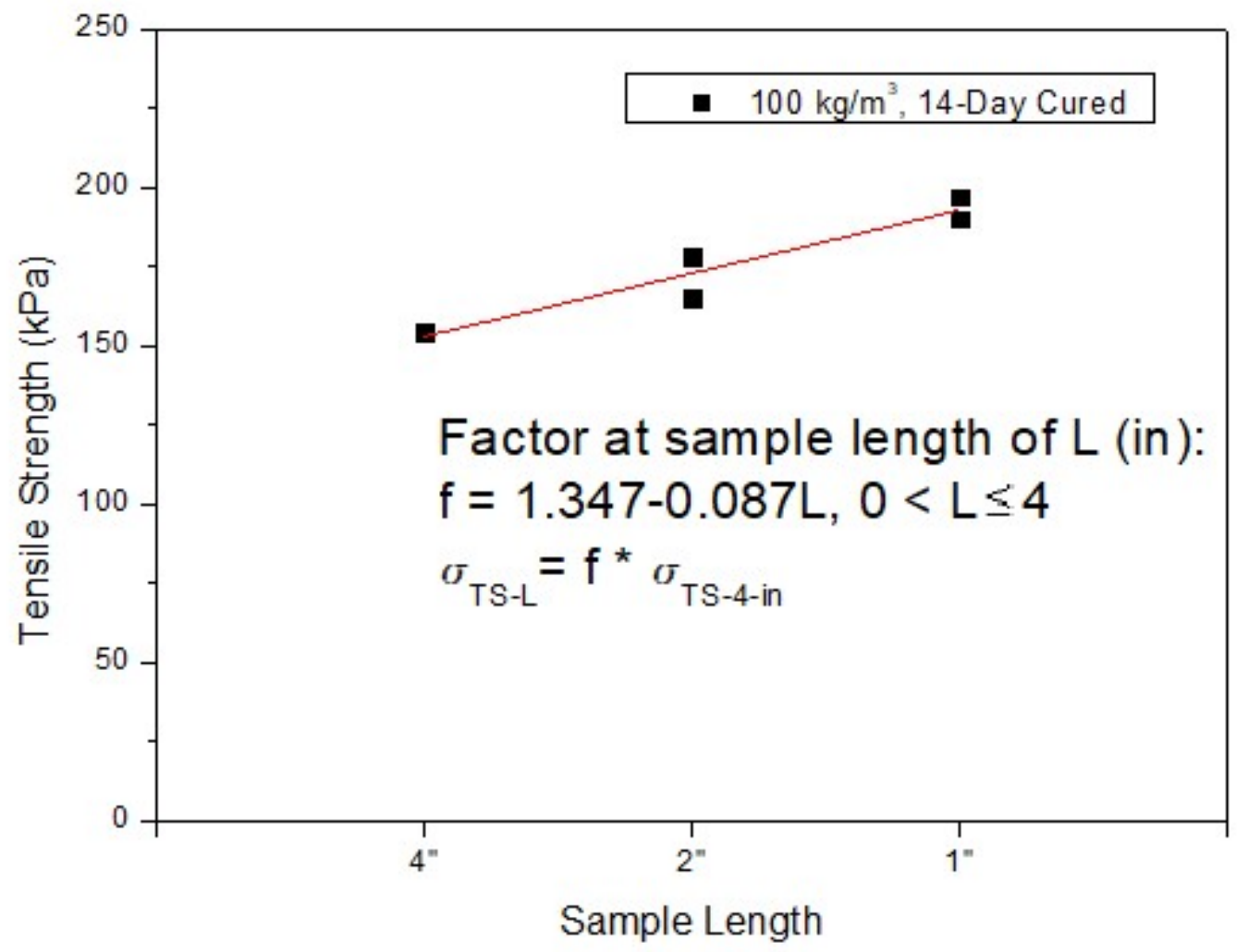

Figure 4-20: The Impact of Sample Sizing on Tensile Strength of BTS Tests

\subsection{UNCONFINED PENETRATION}

The basic UPT testing is similar to the procedure performed by Kim et al. (2012) and Liang et al. (2014) for soils not mixed with cement. Two $1 / 2$ " diameter flat-end discs were used on both ends of the UPT specimen during testing. In addition to flat-end penetration discs, angled discs were also used to investigate the impact of angles on UPT strength.

\subsubsection{Description of UnConfined Penetration SAMPLes IN TeSting}

In a UPT test, clay samples are punched through its vertical axis from the top and bottom of the sample by two $1 / 2$ " diameter penetration discs. Failure was often characterized by an abrupt fracture along a planar failure surface. In addition to the two halves as in failure in BTS, there was also a cone-shaped portion of the sample attached to the penetration disc that had been separated from the two main halves during failure (Figures 4-21 to 4-23).

Though the theoretical failure schematic shows two failure cones, one at the top and one at the bottom, in practice however, only one cone will be formed at failure. As the sample fractures, the energy from the compression exerted by the testing machine would be 
dispersed and no second failure cone would be formed at the other end. A shallow mark left by the disc can usually be seen on the other end though. Failure cones forming at one end only has also been observed failed samples pictures in Liang et al. (2014).

Failure is usually symmetrical, while the unsymmetrical sample failures can be attributed to either heterogeneity in the soil of the sample or in mixing, or improper disc alignment. Non-ideal failures often exhibit jagged surfaces along the plane of cracking (Figure 4-23b). The failure cone is ideally triangular with an easily measurable angle at its tip. However, most failure cones obtained were rather flat at the tip, and the failure cone angle can only be approximated in measurement. Figure 4-24 shows failed UPT samples from their top. Most samples failed in relative uniform and symmetrical manners.

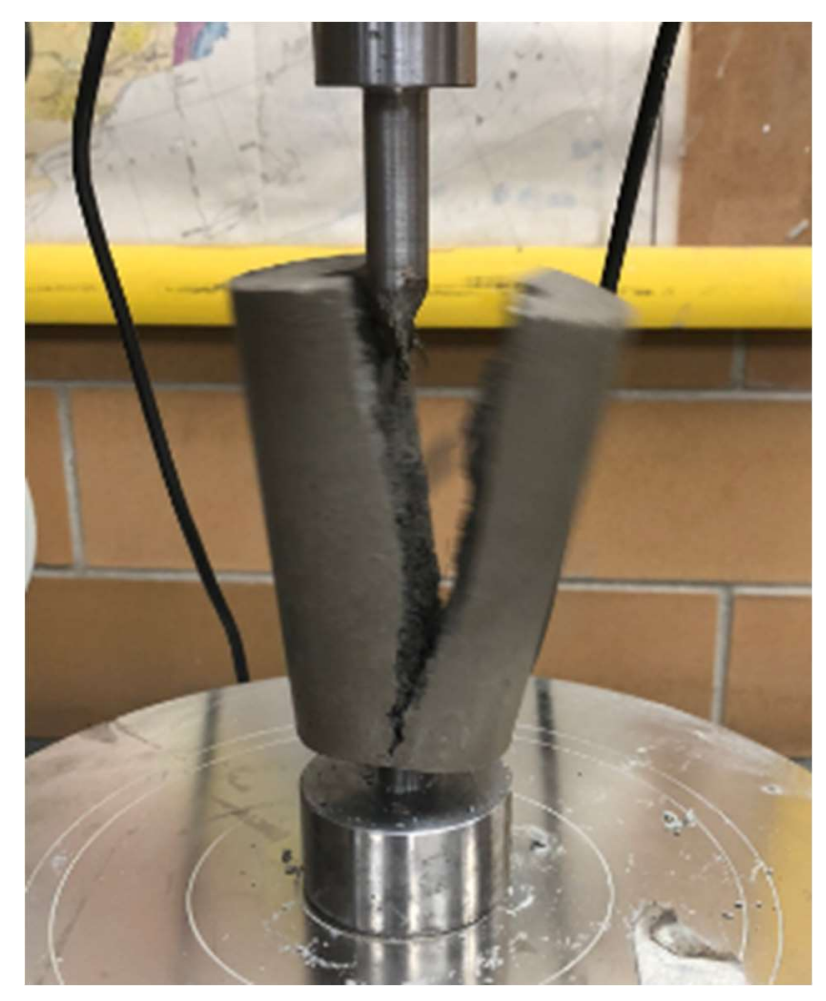

Figure 4-21: A UPT Sample at the Moment of Fracture 


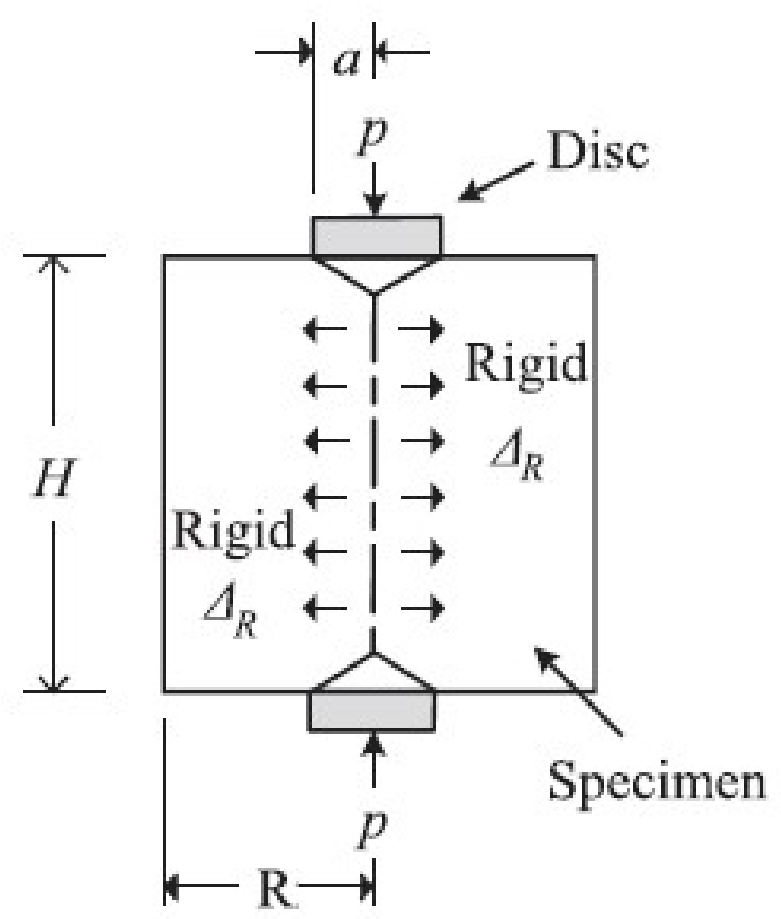

Figure 4-22: A Schematic Failure of A UPT Sample (Kim et al., 2012)

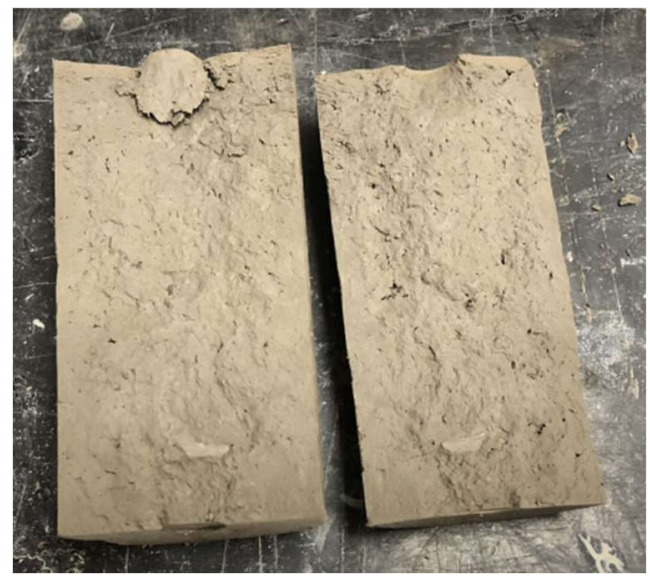

a) A proper split failure

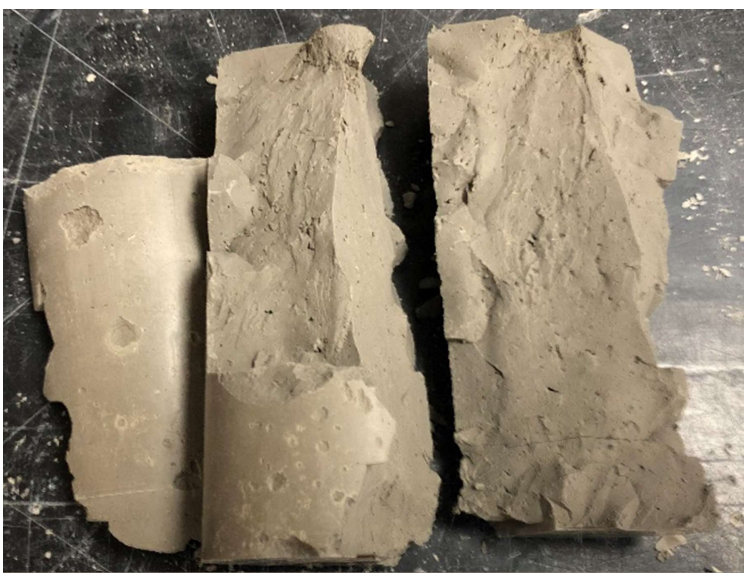

b) A non-ideal failure

Figure 4-23: Typical Failure Surfaces in UPT Samples 


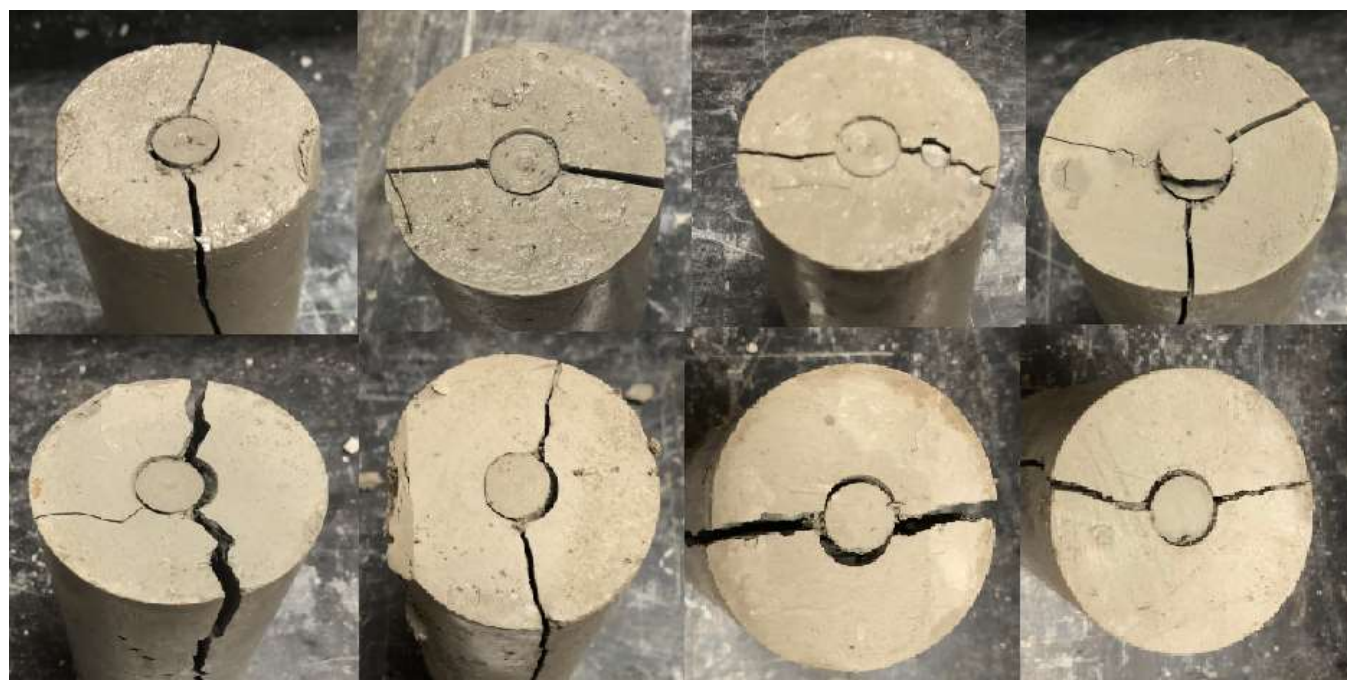

Figure 4-24: Top Views of Failed UPT Samples

\subsubsection{UnConfined Penetration Testing Results}

The results of UPT tests follow similar trends to those of BTS testing. The tensile strength from UPT is obtained in the equation below:

$$
\sigma_{t}=\frac{P}{\pi *\left(K R H-a^{2}\right)}
$$

The tensile strengths obtained from UPT testing are presented in the Figure 4-25. In the beginning of analysis, the $K$ factor is taken as 1.0 following a recommendation for all soils by Fang and Chen (1972). The test results follows the general pattern of BTS testing in progression through different curing time. There was a noticeable spike in the strength of two 14-day cured samples, much larger than those of 28-day samples under the same cement dosage of $200 \mathrm{~kg} / \mathrm{m}^{3}$. Apart from that, the differences between 100 and $200 \mathrm{~kg} / \mathrm{m}^{3}$ samples were less prominent than those of BTS samples, though there was still a prominent change between samples between $50 \mathrm{~kg} / \mathrm{m}^{3}$ samples and $100 \mathrm{~kg} / \mathrm{m}^{3}$ ones. For $50 \mathrm{~kg} / \mathrm{m}^{3}$ samples, the tensile strength increase with curing time from UPT samples was much less than those of UCS and BTS samples.

Figure 4-26 shows typical load-deformation curves for UPT tests for three different binder contents. Compared with BTS tests, it is noticeable that as the UPT samples approached their peak stress, the stiffness gradually decreased as the deformation increased. After the peak stress, the load capacity is gradually lost with increasing deformation. This is likely 
due to the small concentration area in the sample around the penetration disc, plastically deforming it, while much of the sample would still be sound and not fractured yet.

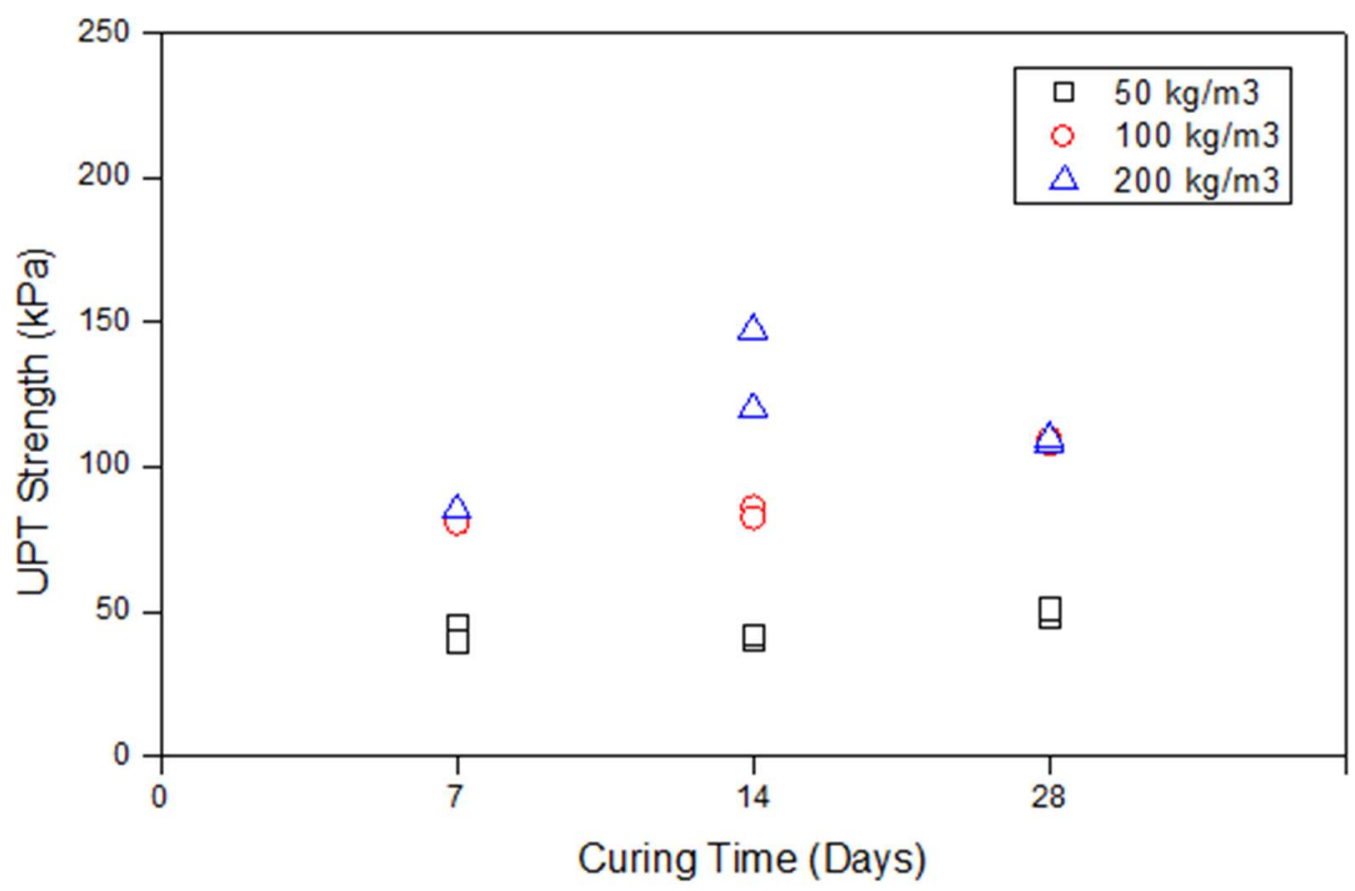

Figure 4-25: Tensile Strength Obtained from Unconfined Penetration, $K=1$

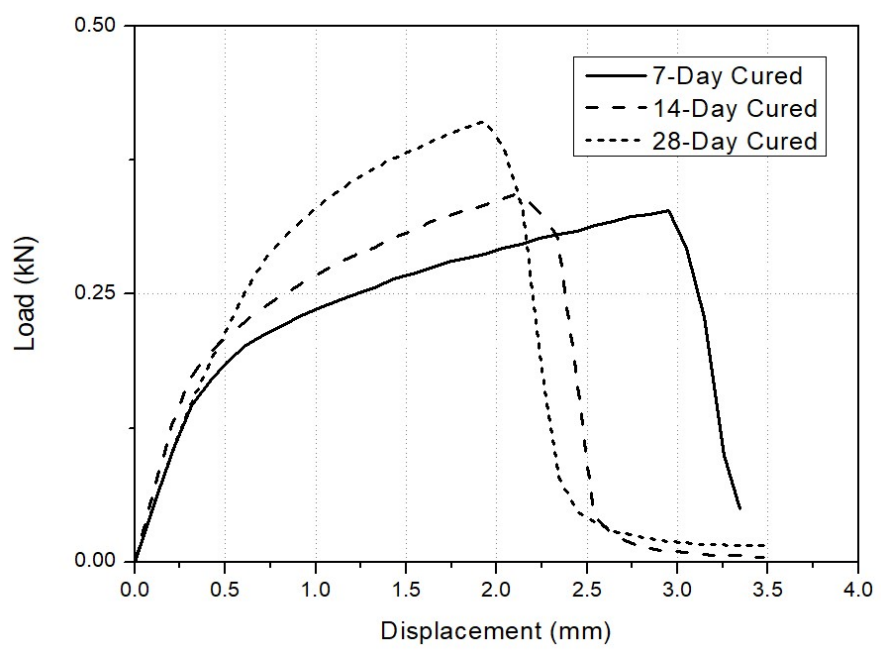

a). Samples with a cement dosage of $50 \mathrm{~kg} / \mathrm{m}^{3}$ 


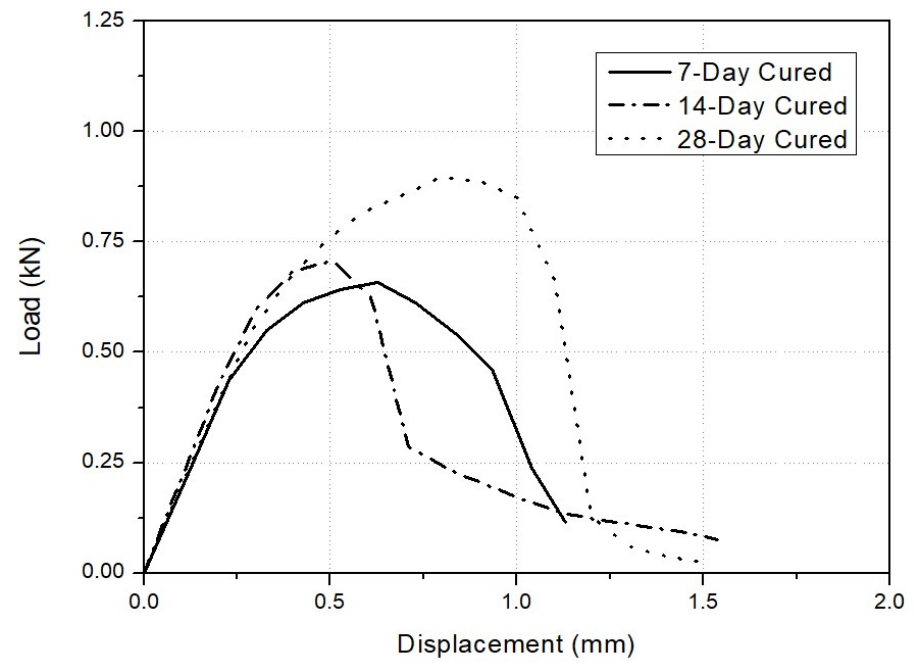

b). Samples with a cement dosage of $100 \mathrm{~kg} / \mathrm{m}^{3}$

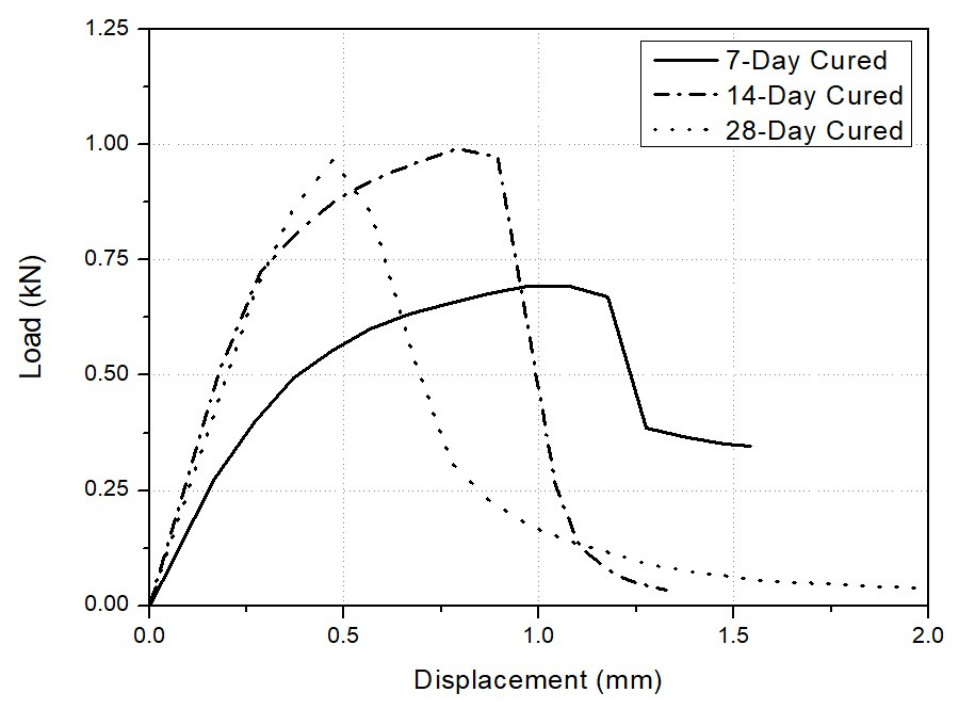

c). Samples with a cement dosage of $200 \mathrm{~kg} / \mathrm{m}^{3}$

Figure 4-26: Typical Load-Deformation Curves for UPT Samples

\subsubsection{Analysis of UnCONFInEd PENETRATION REsults}

The change of tensile strength from UPT tests with soil parameters generally follow the same patterns as those of UCS and BTS samples. A correlation between the total water-tobinder ratio and tensile strength was obtained from UPT tests, which is more prominent than those obtained from UCS and BTS tests, as shown in Figure 4-27-a). The correlations with the dry density and the void ratio for UPT tests are about as weak as those of UCS and BTS tests, as shown in Figure 4-27-b) and Figure 4-27-c). 


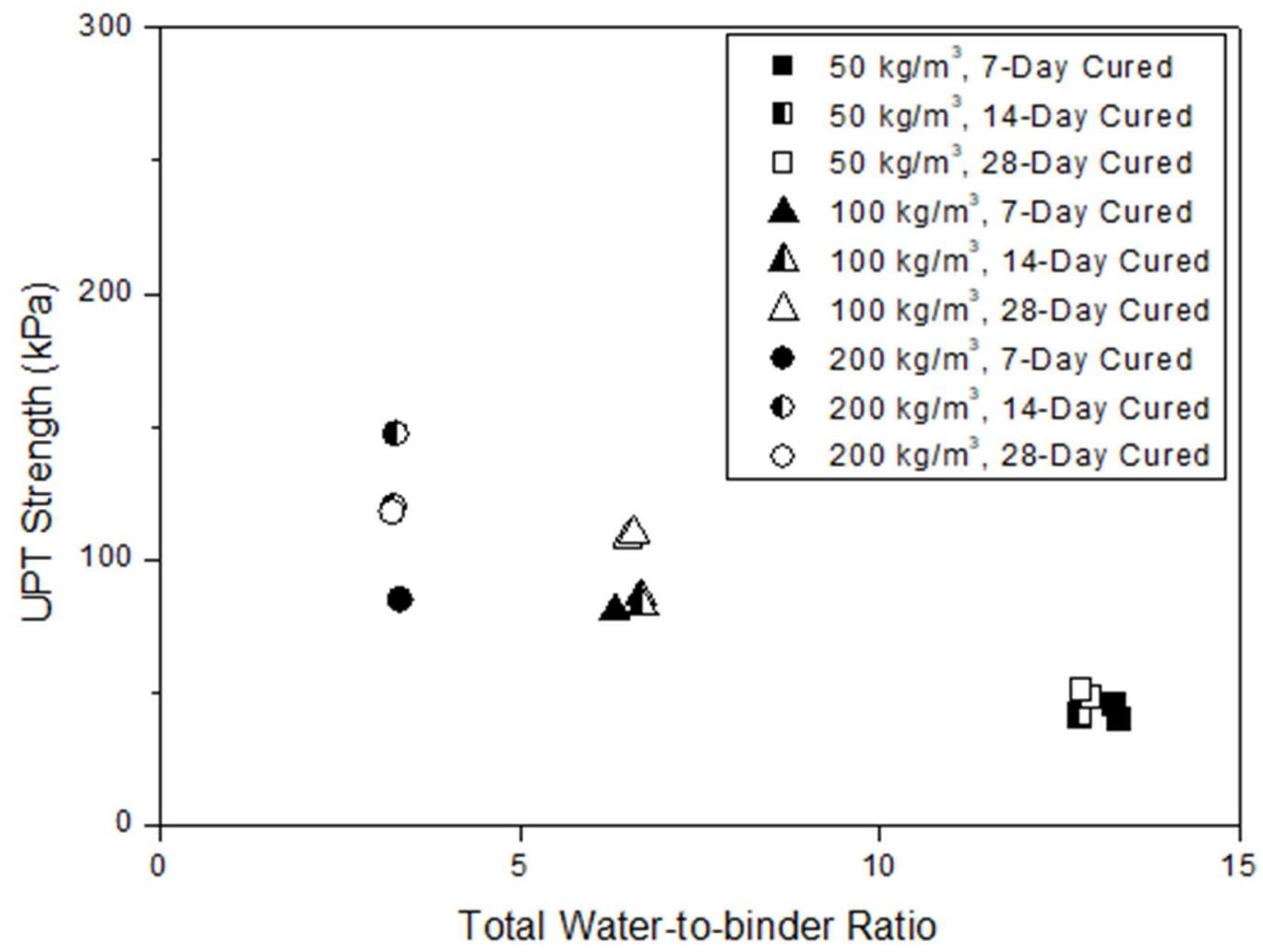

a). Total water-to-binder ratios of UPT samples

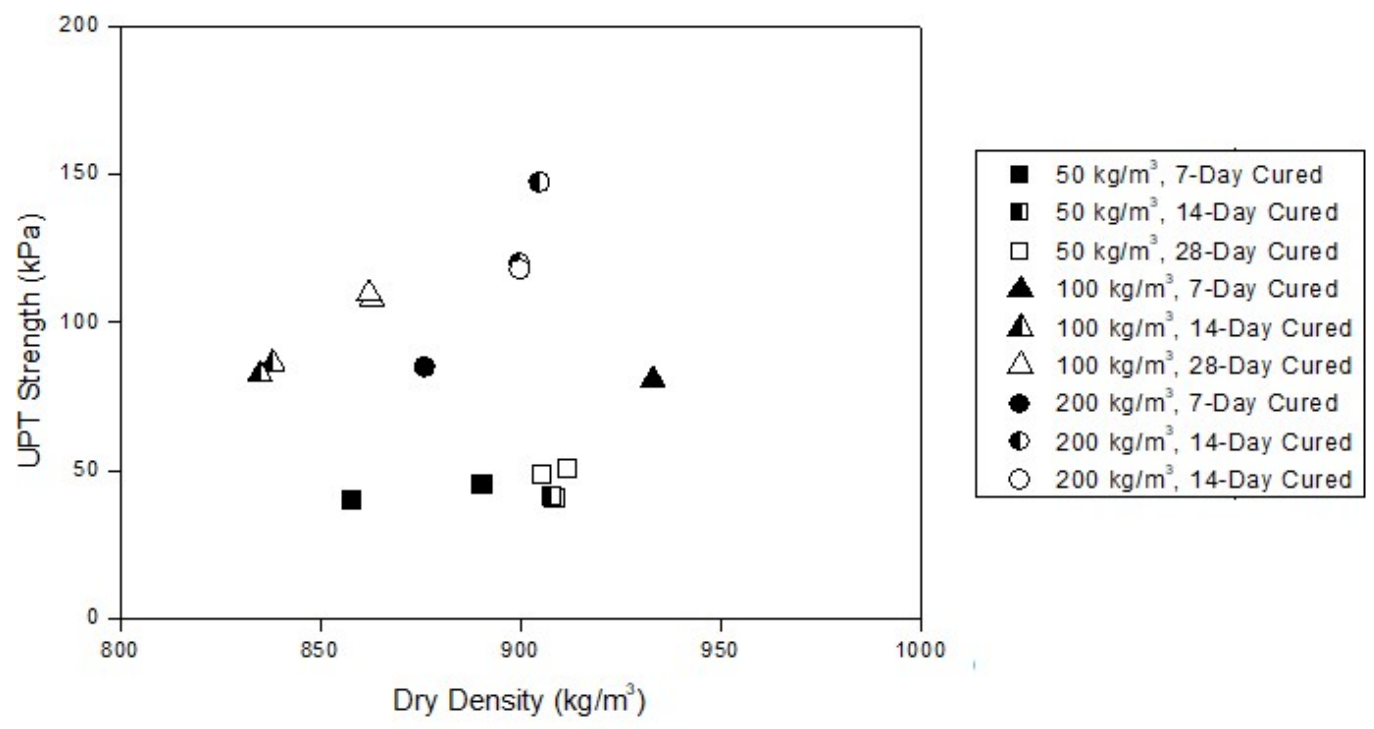

b). Dry densities of UPT samples 


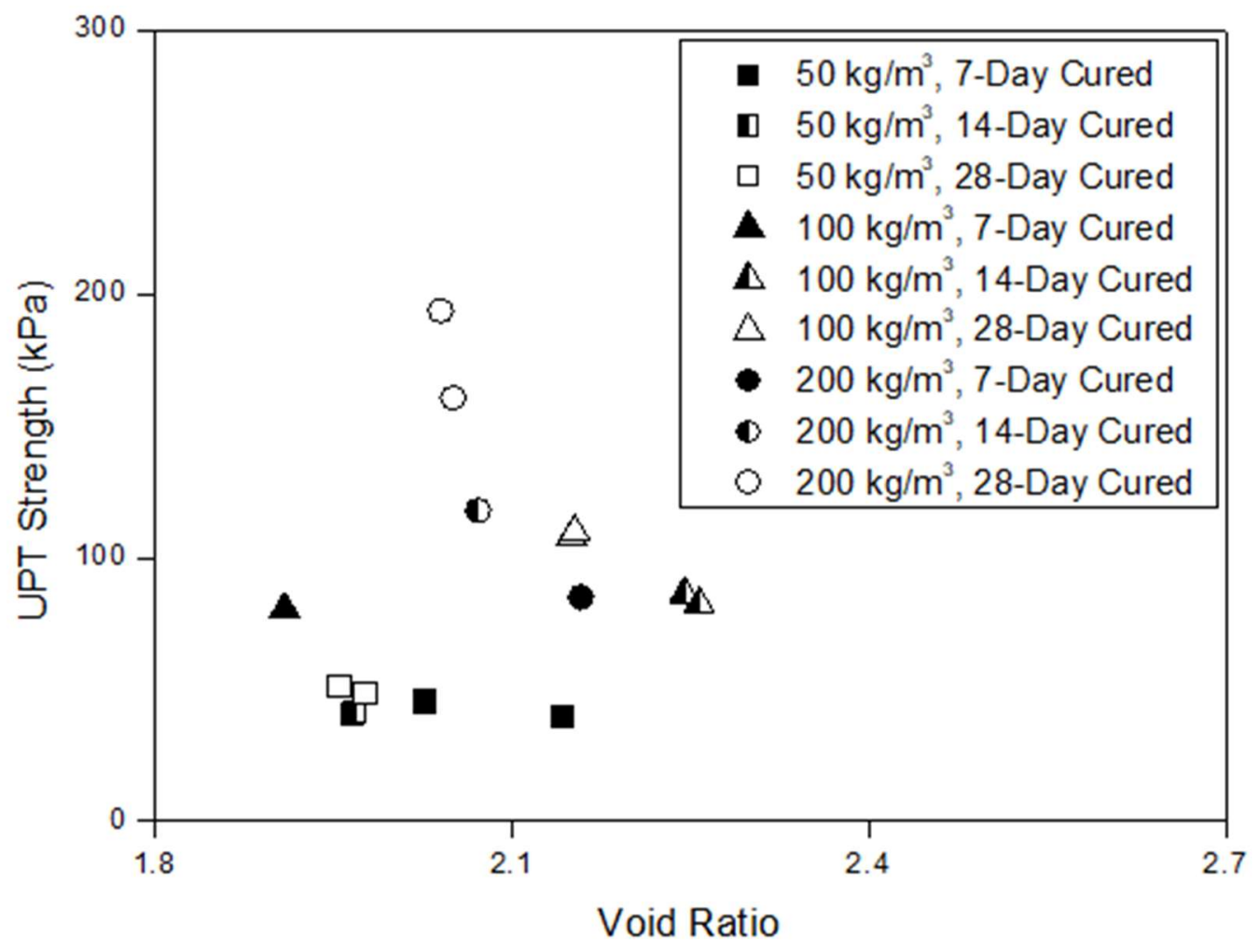

c). Void ratios of UPT samples

Figure 4-27: Relationship between Tensile Strength and Soil Parameters for UPT Samples

\subsubsection{Numerical CORRELATIONS FOR UnCONFINEd PENETRATION}

The averages of UCS and UPT tensile strength were plotted for each curing time-binder content combination along with a similar study using UPT by Liang et al. (2014), as shown in Figure 4-28, where the average values of compressive and tensile strengths for each combination are plotted as data points and the range of individual sample values represented as error crosses. The patterns are similar to BTS, but the scatter seemed to be slightly less in UPT tests. A linear regression was formed between UPT tensile strength and UCS of cement-treated Champlain Sea clay with a slightly better R-squared value than those of BTS tests.

The correlation yields:

$$
\sigma_{t}=18.000+0.0377 \sigma_{U C S} ; R^{2}=0.827
$$


Removing the y-intercept and fitting again yields:

$$
\sigma_{t}=0.046 \sigma_{U C S} ; R^{2}=0.973
$$

Where $\sigma_{t}$ is tensile strength of the sample obtained in UPT testing, $\sigma_{U C S}$ is compressive strength of the sample obtained in UCS testing.

The correlation factors from UPT tests are lower than those from BTS tests. The different failure mechanism may contribute to this discrepancy.

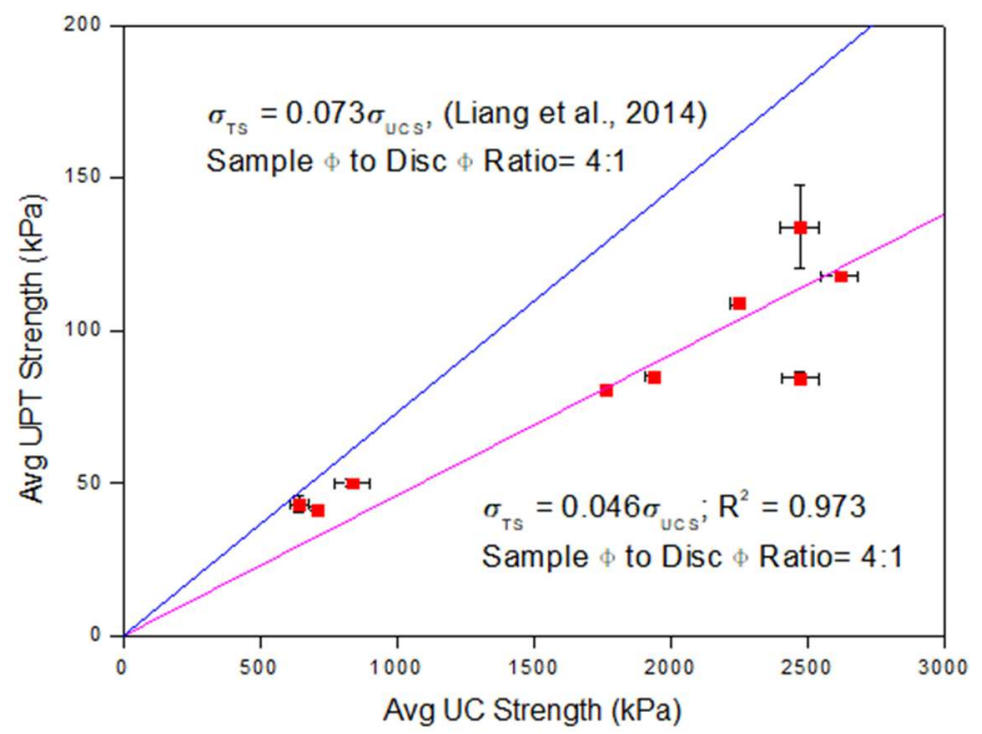

Figure 4-28: Correlation between UP Tensile Strength and UCS, $K=1.0$

\subsubsection{INVESTIGATION OF UNCONFINED PENETRATION ANGLE AND $K$ VALUE}

Using the $K$ value of 1.0 has the advantage of simplicity in that there is no need for the friction angle of the soil or the angle of failure plane. It is necessary to verify the applicability of this simplification for cement-treated Champlain Sea clay. The value of $K$ can be determined by the following equation (Kim et al., 2012):

$$
K=\tan (2 \alpha+\varphi)
$$

Where $\alpha=$ angle measured at failure cone, $\varphi=$ undrained friction angle of soil

The friction angle in undrained shear condition can be assumed as zero for clays (Das \& Sobhan, 2010). The angle of failure plane was approximated from the pictures of freshly tested samples. 
Table 4-1: Angle $\alpha$ of UP samples and Their Resultant $K$ Values

\begin{tabular}{|c|c|c|c|c|c|c|c|}
\hline Sample Name & $\alpha\left(^{\circ}\right)$ & $K$ & $\begin{array}{c}\text { Strength } \\
\mathrm{KPa}, \\
\mathrm{K}=1)\end{array}$ & $\begin{array}{c}\text { UPT } \\
\text { Strength } \\
(\mathrm{KPa}, \\
\mathrm{K}=0.95)\end{array}$ & $\begin{array}{c}\text { Failure } \\
\text { Displacement } \\
(\mathrm{mm})\end{array}$ & $\begin{array}{c}\text { Dry Density } \\
\left(\mathrm{kg} / \mathrm{m}^{3}\right)\end{array}$ \\
WC $(\%)$ \\
\hline WD28.30m_50C_7D_UP1 & 20.91 & 0.89 & 46.04 & 48.46 & 2.450 & 890.06 & 74.46 \\
\hline WD26.18m_50C_7D_UP2 & 17.96 & 0.72 & 40.21 & 42.33 & 2.950 & 857.30 & 77.60 \\
\hline WD28.30m_100C_7D_UP1 & 24.94 & 1.19 & 80.62 & 84.87 & 0.729 & 933.08 & 67.80 \\
\hline WD28.30m_200C_7D_UP1 & 22.38 & 0.99 & 85.14 & 89.62 & 0.972 & 875.95 & 75.96 \\
\hline WD28.30m_50C_14D_UP1 & 23.61 & 1.08 & 41.12 & 43.29 & 2.063 & 908.17 & 70.25 \\
\hline WD28.30m_50C_14D_UP2 & 20.64 & 0.88 & 42.08 & 44.30 & 2.129 & 907.36 & 70.26 \\
\hline WD28.30m_100C_14D_UP1 & 25.33 & 1.22 & 86.24 & 90.78 & 0.506 & 838.05 & 79.75 \\
\hline WD28.30m_100C_14D_UP2 & 21.27 & 0.92 & 82.57 & 86.92 & 0.534 & 834.89 & 80.33 \\
\hline WD26.18m_200C_14D_UP1 & 26.80 & 1.36 & 147.43 & 155.19 & 0.867 & 904.64 & 72.28 \\
\hline WD26.18m_200C_14D_UP2 & 25.83 & 1.26 & 120.17 & 126.50 & 0.895 & 899.61 & 71.94 \\
\hline WD26.18m_50C_28D_UP1 & 19.34 & 0.80 & 48.91 & 51.48 & 2.224 & 904.89 & 71.37 \\
\hline WD26.18m_50C_28D_UP2 & 16.74 & 0.66 & 51.38 & 554.09 & 1.938 & 911.50 & 70.11 \\
\hline WD26.18m_100C_28D_UP1 & 17.79 & 0.72 & 108.05 & 113.74 & 0.649 & 862.84 & 75.36 \\
\hline WD26.18m_100C_28D_UP2 & 19.38 & 0.80 & 109.86 & 115.64 & 0.795 & 862.12 & 76.41 \\
\hline WD26.18m_200C_28D_UP1 & 21.01 & 0.90 & 117.95 & 124.16 & 0.473 & 899.70 & 71.61 \\
\hline
\end{tabular}


According to Kim et al. (2012), the $K$ values were obtained for different soil samples, as shown in Table 4-3.

Table 4-3: Value of $K$ for Different Soil Sample Molds

\begin{tabular}{|l|l|}
\hline Soil Mold & $K$ Value \\
\hline Harvard miniature compaction mold $(3.3 \times 7.2 \mathrm{~cm})$ & $1.05 \sim 1.10$ \\
\hline Proctor mold $(10.2 \times 11.3 \mathrm{~cm})$ & 1.0 \\
\hline CBR mold $(15.2 \times 17.8 \mathrm{~cm})$ & 0.8 \\
\hline Note: Conditions: Disk-specimen ratio: $0.2-0.3$ & \\
Diameter-to-height of specimen tatio: $0.46-1.0$ & \\
Rate of loading: ASTM recommendation for axial strain at a rate of $0.5-2$ percent of \\
height per minute
\end{tabular}

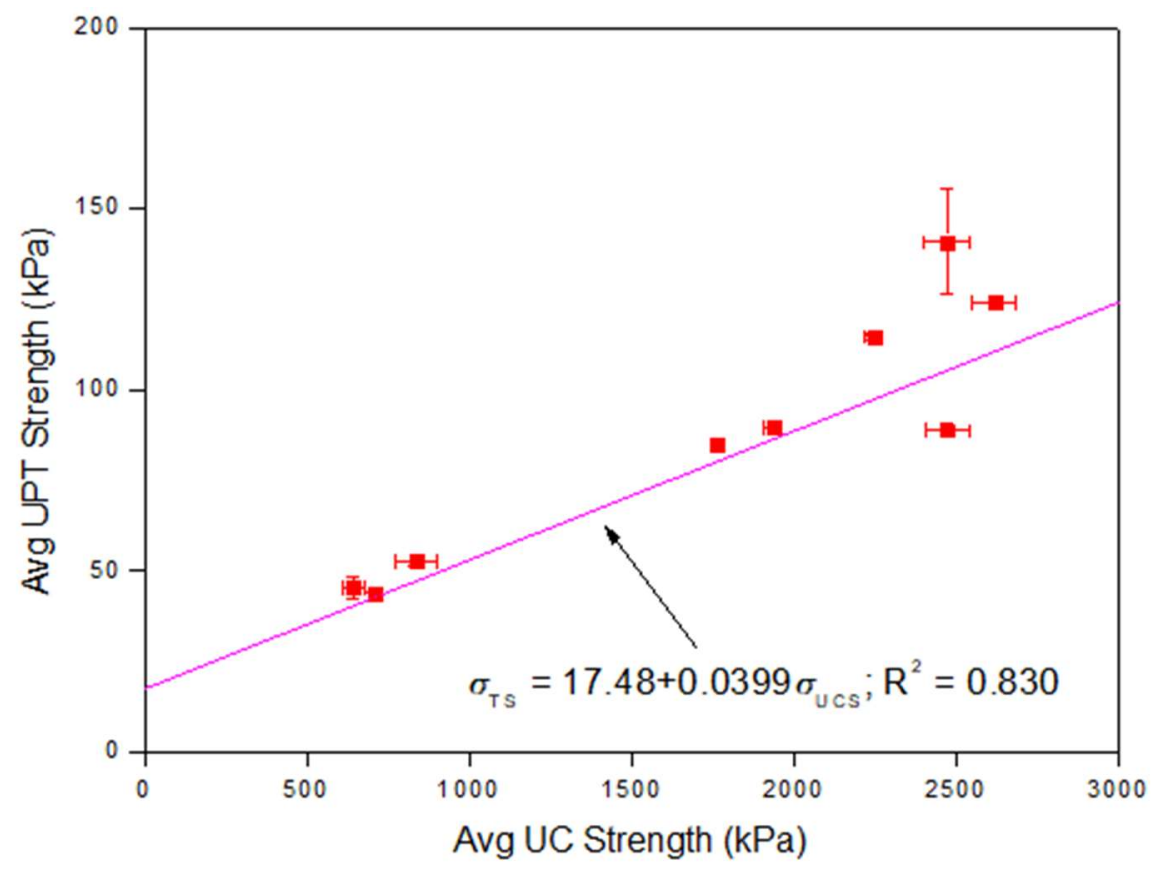

Figure 4-29: UPT Tensile Strength with UCS Using $K=0.95$

Another attempt on obtaining a better correlation was conducted using $K=0.95$. The value 0.95 was the average of $K$ values calculated for each specimen. The resultant correlations is:

$$
\sigma_{t}=17.48+0.099 \sigma_{U C S} ; R^{2}=0.830
$$

When fitted without y-intercept, the correlation becomes:

$$
\sigma_{t}=0.0484 \sigma_{U C S} ; R^{2}=0.929
$$


Which is has a slightly lower R-squared value than $K=1$. It shows that the simplification of $K=1$ may be the best solution in presenting our results.

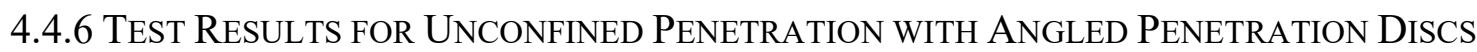

The impact of an angled disc on the UPT results was conducted on clay samples treated with a cement dosage of $100 \mathrm{~kg} / \mathrm{m}^{3}$ and cured the same 28-days. The results from angled penetration discs showed little correlation with curing time. The angled penetration discs appeared to introduce a wedge effect to the sample and reduce the failure load dramatically. The sharper the disc angle, the smaller of failure load. Because of this wedging effect, the angle of the penetration discs cannot be simply taken as the angle $(2 \alpha+\varphi)$ in the UPT formula, which is intended for flat penetration discs. This makes a different method of tensile strength interpretation required if tensile strength were to be reliably estimated using the angled discs. Moreover, the failure surfaces of these angled samples appeared to be even more jagged and less predictable. Therefore, angled penetration discs are not recommended over the flat one.

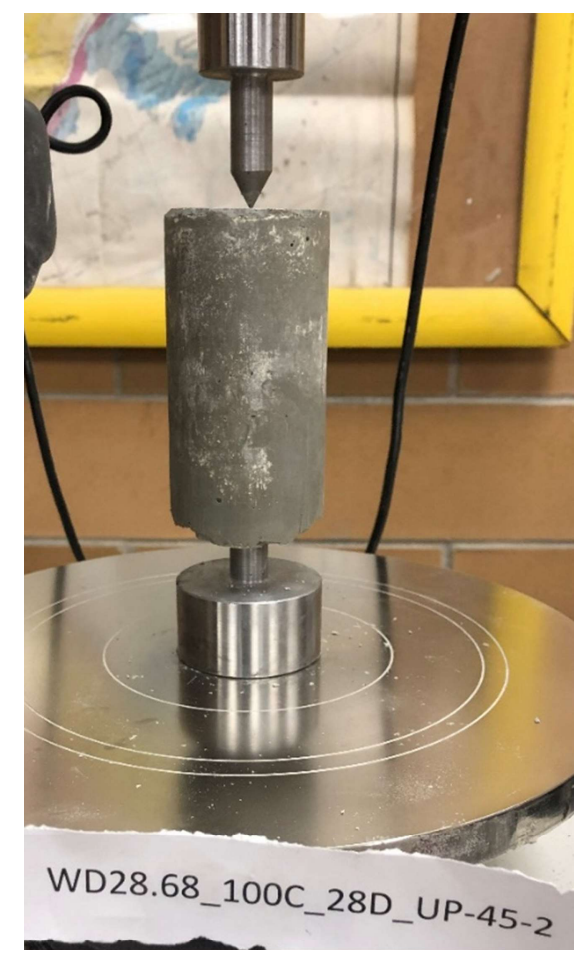

(a) Before testing

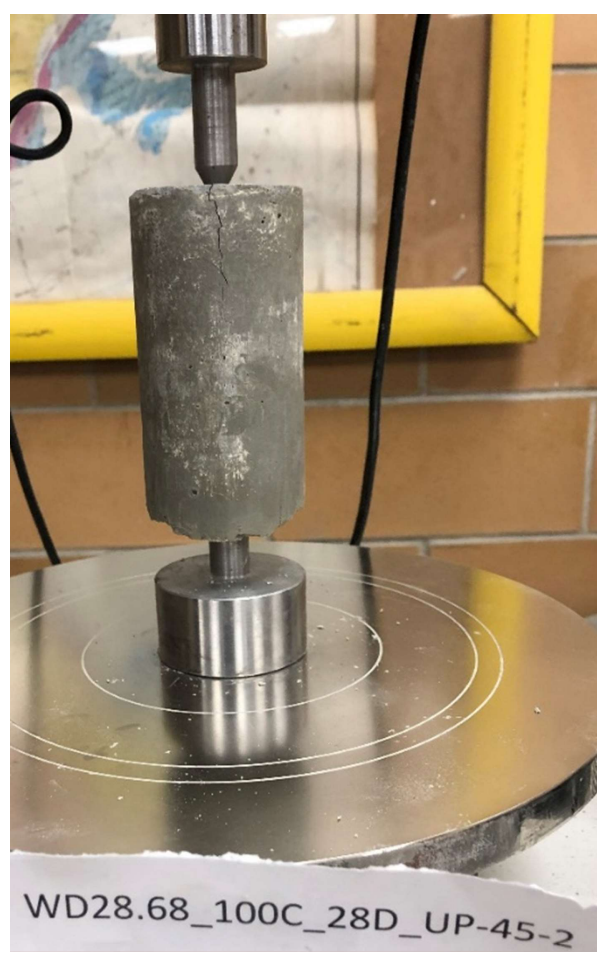

(b) After failure

Figure 4-30: A UPT Sample Tested with a $45^{\circ}$ Penetration Disc 


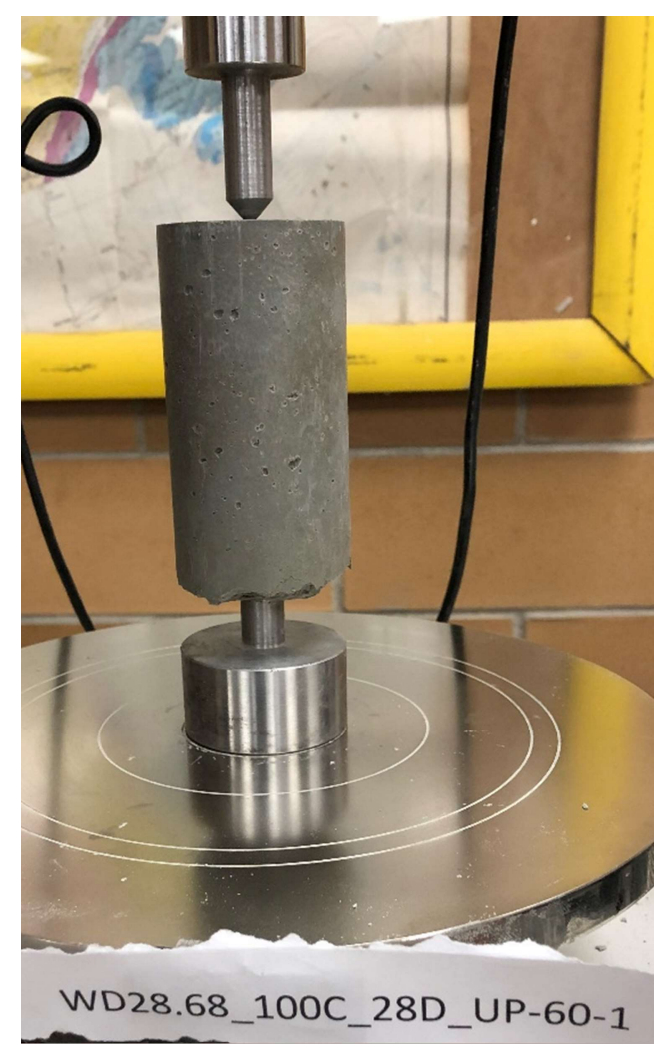

(a) Before testing

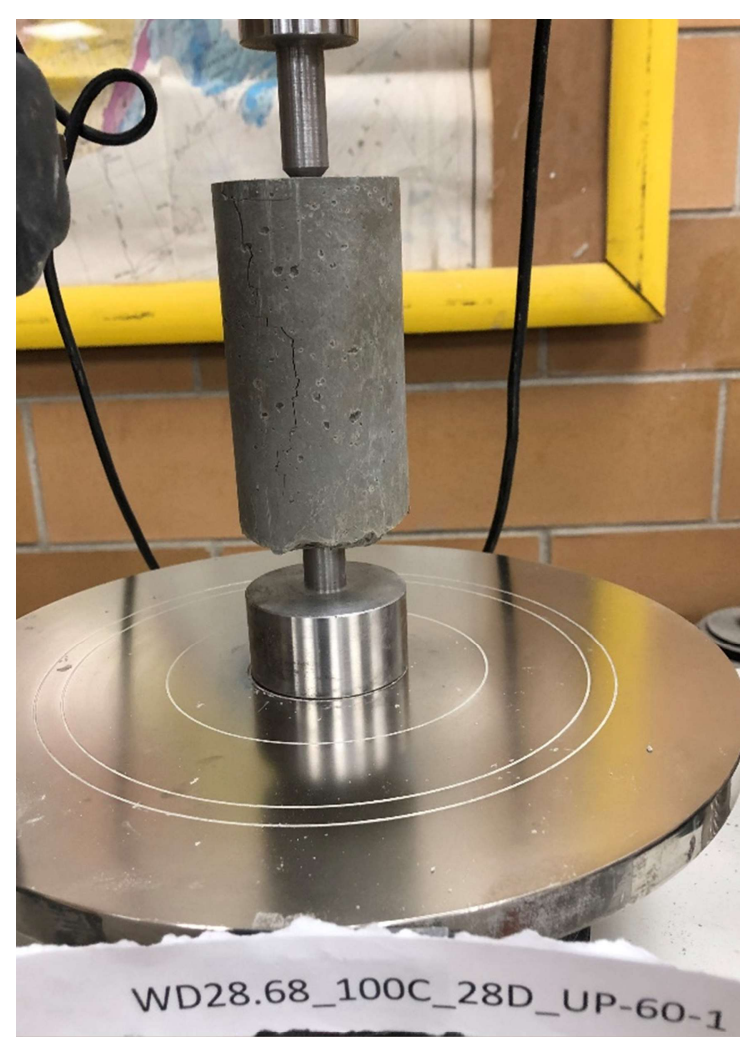

(b) After failure

Figure 4-31: A UPT Sample Tested with a $60^{\circ}$ Penetration Disc

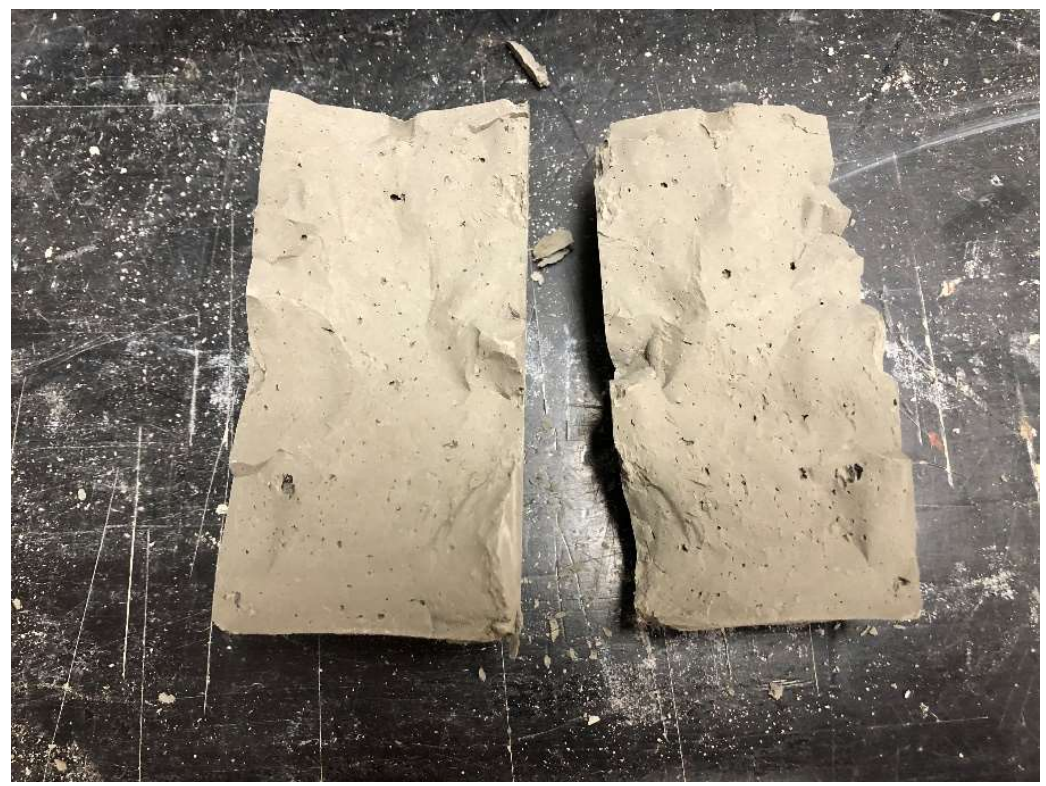

Figure 4-32: A Fractured Surface of Sample Tested with a $60^{\circ}$ Penetration Disc 


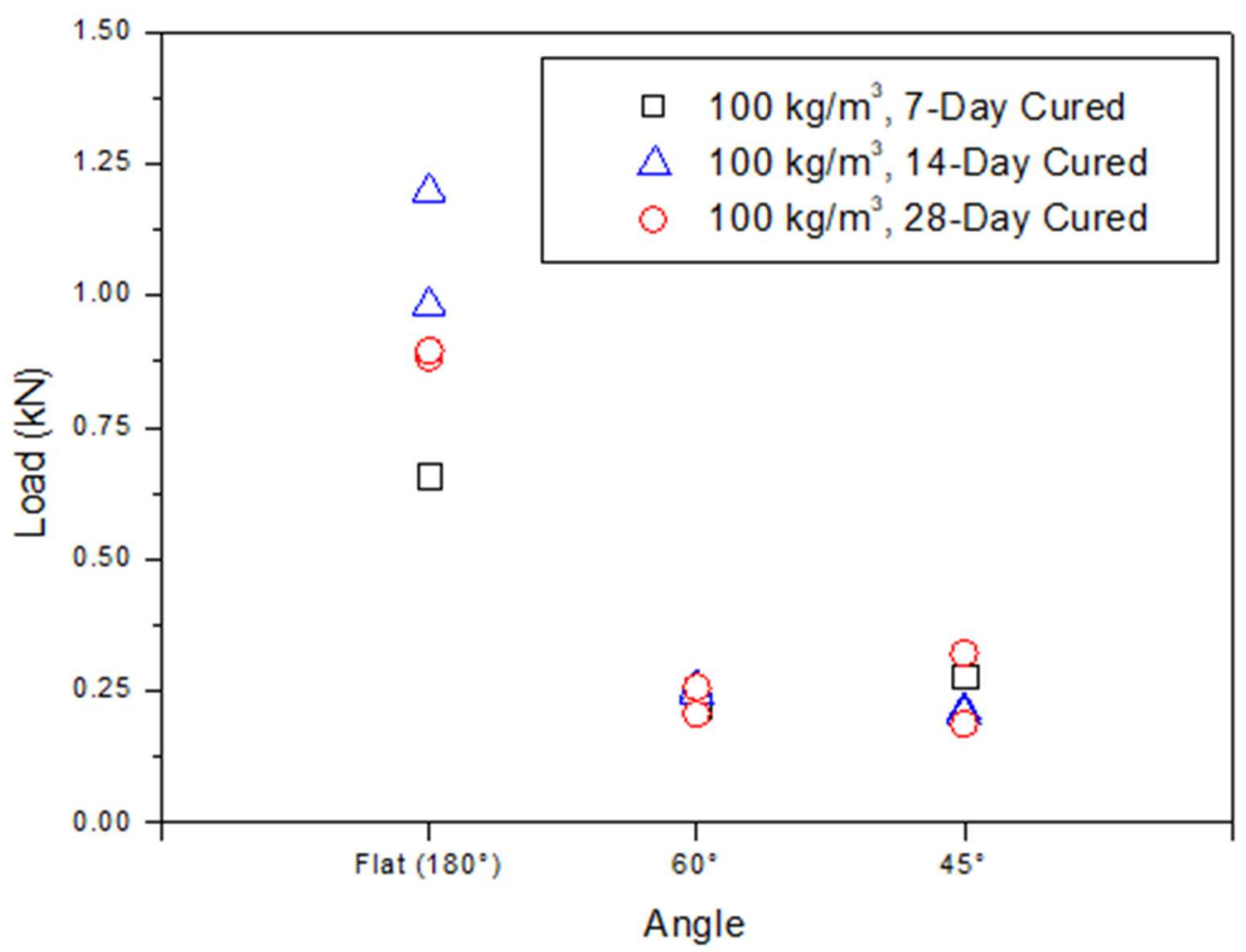

Figure 4-33: Relationship between Failure Loads with Penetration Disc Angle

\subsubsection{Comparison between Brazilian Tensile and Unconfined Penetration RESULTS}

To compare the tensile strengths obtained in Brazilian tensile and UPT tests, the average values for both tests are plotted and fit using a linear regression, as shown in Figure 4-34. According to the resultant plot, UPT and BTSs do not show a good correlation. The tensile strength from the UPT is lower than that of BTS tests. Based on the results obtained, BTS is recommended as an easier and more reliable indirect tensile strength testing method than UPT. The failure from a BTS test is less prone to irregularities and non-ideal fracture conditions due to its more uniform loading method. Moreover, it does not require additional and subjective measurement, such as the angle of a failure surface. Therefore, the BTS method is recommended over UPT as a preferred indirect tensile strength test method. 


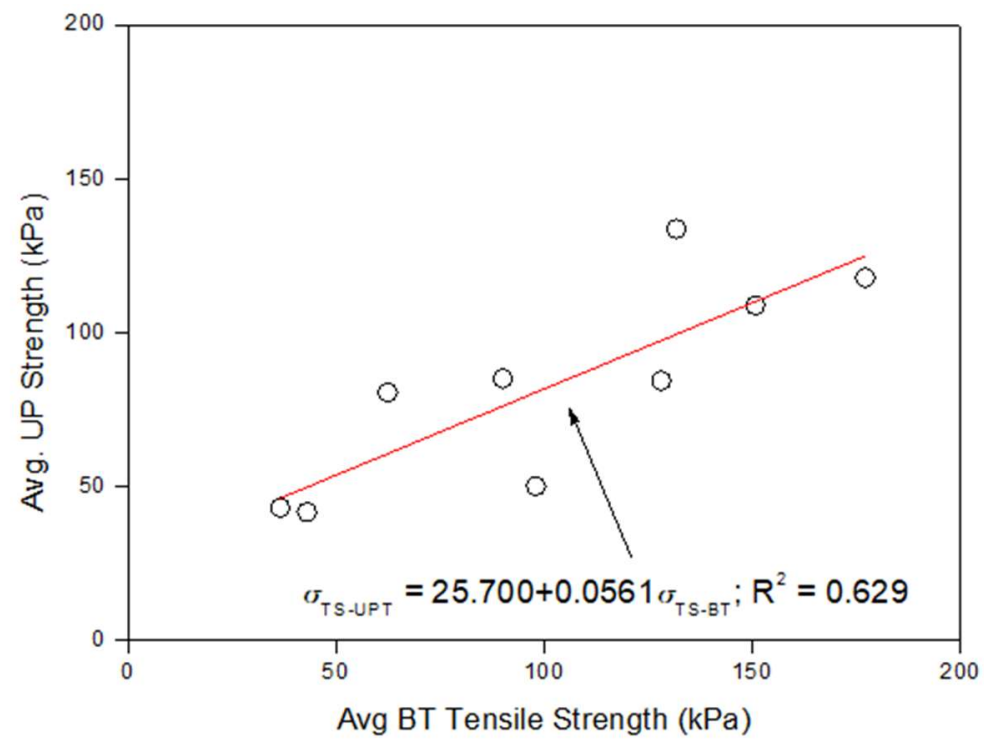

Figure 4-34: Plot of Average Tensile Strengths from UPT against BTS

Figure 4-35 shows the combined correlation of all tensile strength results from BTS and UPT with $K=1$, with tensile strength data from both tests fitted using linear regression in combination. Each data point represents the average compressive and tensile strength for a combination of curing time and binder content. The resultant correlation $(5.3 \%)$ falls near the middle between that of BTS (6.4\%) and UPT (4.6\%).

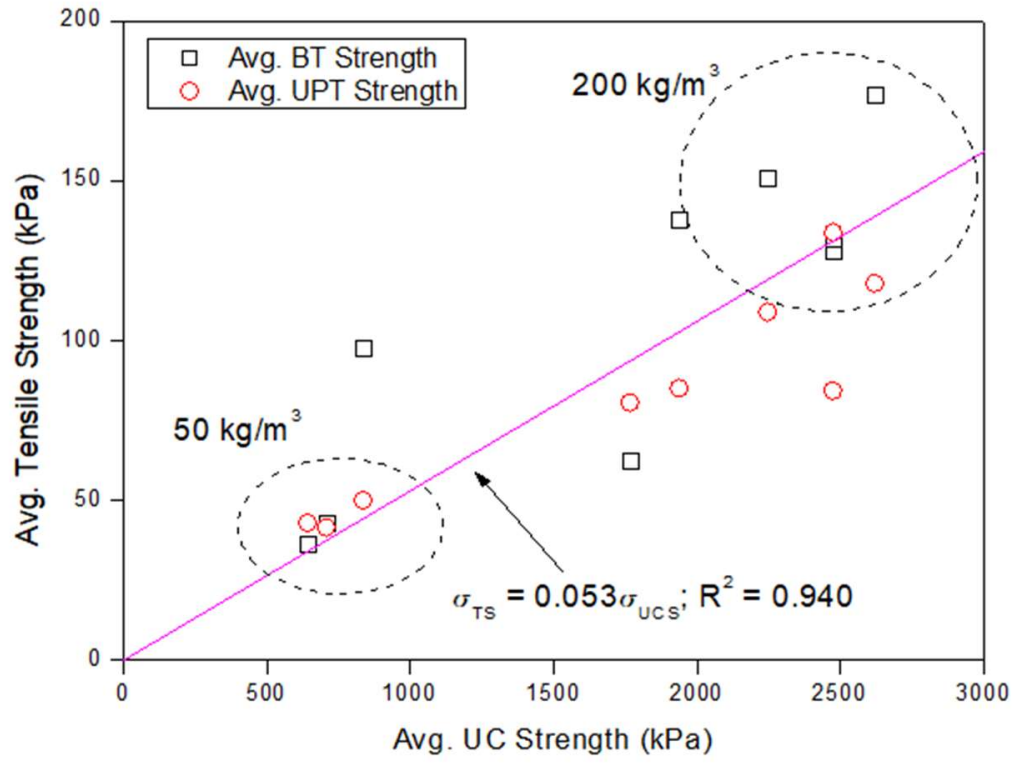

Figure 4-35: Correlation between Tensile Strength and UCS of Cement-Treated Champlain Sea clay 


\subsection{SUMMARY}

In this chapter, the experimental investigation of tensile strength of cement-treated Champlain Sea clay was investigated using both BTS and UPT tests. UCS samples' behavior and strength results aligned with earlier studies with the same clay quite well, providing a sound basis for comparison with tensile strengths. BTS on average correlated to about $6.4 \%$ of compressive strength and UPT strength to about $4.6 \%$. In general, BTS samples exhibit more uniform failure behavior and strength values than UPT samples. Kvalue investigation of UPT samples revealed that a K value of 1.0 may be best suited for cement-treated Champlain Sea clay. Small diameter Brazilian samples had higher tensile strength than regular sized ones, similar to existing observations in rock mechanics. Angled UPT penetration discs produced rather unreliable results where strength values were much less dependent on curing time and non-uniform failures were more common. Based on the results obtained, BTS testing was recommended over UPT as a convenient method for indirect tensile testing in an industrial context. 


\section{Numerical Modelling}

\subsection{INTRODUCTION}

As it has been established in the previous chapters that the Brazilian tensile strength is the preferred tensile testing method for cement-treated Champlain Sea clay, it would be of research interest to investigate the specimen behavior using finite element method (FEM) and compare it with experimental results. The numerical modelling software Abaqus is used in the analysis. A dynamic, plastic model was built to model the loading and cracking of a BTS specimen during testing. The Drucker-Prager plasticity model was used to simulate cement-treated clay behavior using the parameter values obtained from experimental results. The main purpose of FEM is to develop a simulation method for this type of tensile testing that can be applied to cement-treated soils in the future, as well as to verify the experimental results obtained. Comparisons between experimental and simulated results showed a general agreement between the two.

\subsection{LITERATURE REVIEW}

In this section, available literature on soil tensile strength modelling, as well as numerical modelling of a BTS test on both soils and rocks. Though the topic is not very well researched at the current time, the available literature does provide some insights in the methodologies of tensile strength modelling.

\subsubsection{Numerical Modelling OF SoIL Tensile Strength}

In current literature, work on tensile strength simulation of soils, cement-treated or otherwise, is scarce. As covered in Section 2.4.2.1.1, several studies on triaxial tension tests have been performed and a resultant failure surface fell in between an M-C failure surface and a vertical tensile failure surface (Namikawa \& Mihira, 2007; Namikawa et al., 2017).

Numerical modelling of indirect tensile testing methods would be of more interest to this study, as the indirect testing methods such as the Brazilian tensile test are more practically applicable (Leavell \& Peters, 1986). Unfortunately, available literatures on tensile numerical modelling of testing methods other than direct tension is even more sporadic. 
Moreover, to date, there is no study available on numerical simulation of BTS tests of soils. There is an existing study on numerical modelling of desiccation tensile testing of soils upon drying. Gui et al. (2016) performed numerical analysis on the desiccation process of silt and clay using a universal distinct element code, a discrete element method. Simulation results were compared with existing experimental data. Factors affecting shear and tensile strength of the soils were assessed, such as the friction angle and cohesion. However, as discussed previously, the desiccation test may not be suitable for cement-treated soils. On the other hand, Ammeri et al. (2006) performed discrete element analysis on three-point and four-point flexural tests of a compacted clay and good correlations between numerical and analytical results of tensile strength were obtained in their studies.

\subsubsection{Numerical Modelling of Brazilian Tensile Strength}

As it is deemed to be beneficial to perform a numerical simulation on the behavior of cement-treated Champlain Sea clay under Brazilian tensile testing, though the current literature provides limited information on numerical studies on the BTS on soils. Nevertheless, there have been a number of existing studies of Brazilian tensile testing simulation of concrete and more abundantly in rocks. These studies will provide some insight in the methodologies and observations in Brazilian tensile strength modeling.

\subsubsection{Numerical Modelling of Concrete Brazilian Tensile Testing}

Literature is a little more readily available on numerical modelling of BTS on concrete. Lin and Wood (2003) performed numerical analysis on the BTS tests on concrete under the uniaxial tension tests using nonlinear finite element strips. They found the BTS test tends to underestimate the sample tensile strength and recommending a correction factor to consider the discrepancy. Denneman et al. (2011) performed FEM analysis using Abaqus on fiber reinforced concrete. The process of crack initiation from the center of the specimen and propagation towards the top was simulated, as shown in Figure 5-1 where "A" indicates the areas of high stresses in the sample. . Haeri et al. (2016) performed rather an elaborate analysis of Brazilian tensile testing that involved the initiation of tension and shear cracking at different locations of the specimens and compared the results with a novel concrete tension testing method they developed for their studies. 

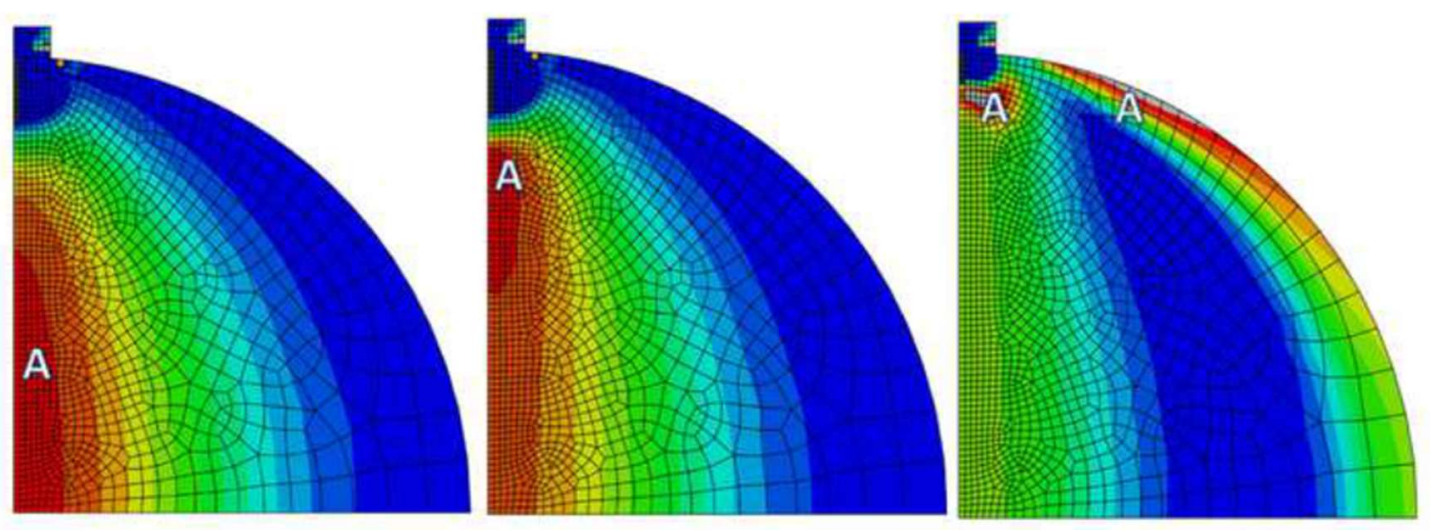

Figure 5-1: Abaqus Simulation of a Concrete Sample in BTS Test (Denneman et al., 2011)

\subsubsection{Numerical Modelling of Rock BraziLian Tensile Testing}

There is large amount of available literature available for BTS tests in rocks. Though rocks exhibit vastly different material properties, numerical results from rocks can still provide general characteristics in the rock behavior during BTS testing, which may prove useful for this study. Mahabadi et al. (2013) performed numerical analysis on homogeneous and anisotropic rock specimens. In the homogeneous specimen, it was found that the initiation of tensile cracks occurred from the center of the specimen and the shear stress concentration was located at the top of the sample near the loading platen, as shown in Figure 5-2, where the contours showing vertical stress $\left(\sigma_{y y}\right)$. This finding is like the stress patterns of a concrete sample investigated by Denneman et al. (2011).

Li and Wong (2013) wrote a comprehensive review on existing literature of rock Brazilian tensile testing and performed an FEM analysis in their study. It was found that the magnitude of tensile stress was the greatest at the top and bottom of the sample, near the point of stress application where shear stress is also concentrated, instead of the center of the specimen where pure tensile stress is present and taken as an output value for material tensile strength (Hudson \& Kennedy, 1968). Wang and Cao (2016) investigated the effect of flattening the top and bottom of a Brazilian sample in their FEM analysis. A flatter surface was found to shift the peak tensile stress towards the center of the specimen as opposed to the top and bottom of the specimen. Yuan and Shen (2017) performed Brazilian 
test using an apparatus very similar to this study and investigated numerically the impact of a cushion between the sample and loading plate on the test results. It was found that simulation without a cushion produced slightly higher strengths.
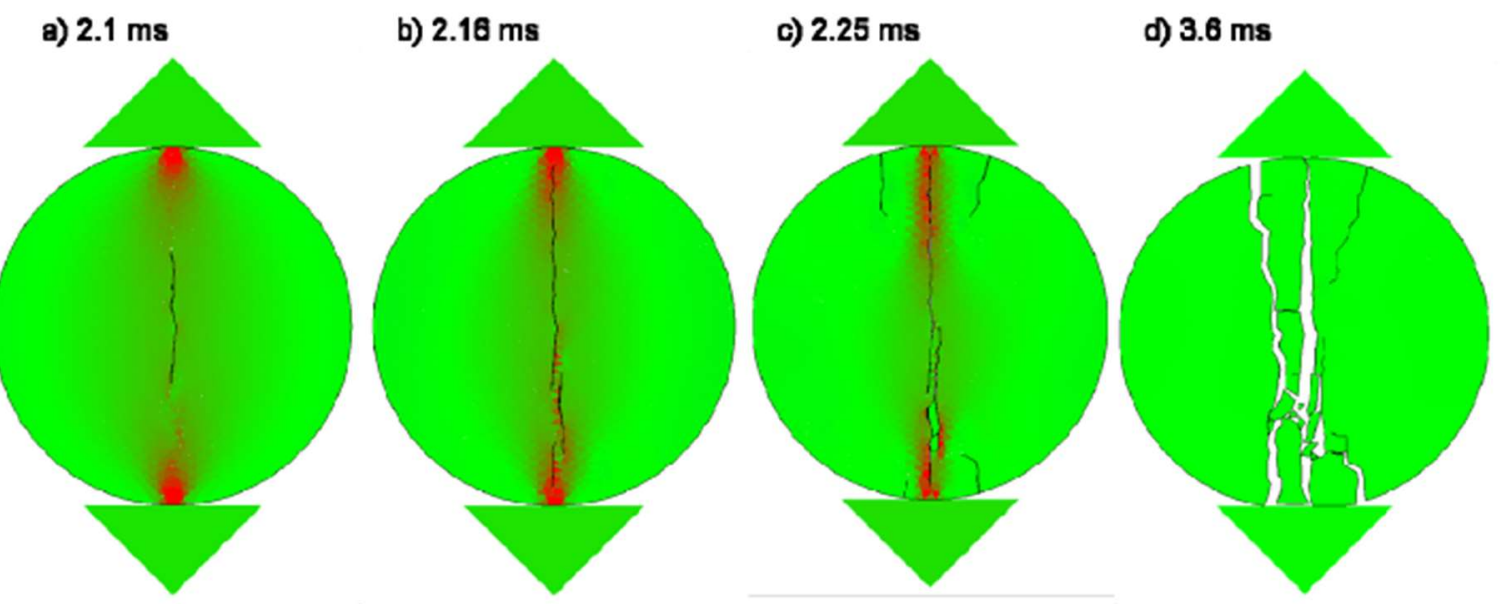

Figure 5-2: Development of Crack Formation in a Rock Sample (Mahabadi et al, 2013)

\subsection{CONSTITUTIVE MODEL OF CEMENT-TREATED CLAY}

The simulation processes of FEM and the Drucker Prager model as the material model for cement-treated clay are introduced in this section. First, the Drucker Prager model is briefed along with the material property identification from the experimental data. Then, the FEM simulation model built in Abaqus is explained along with the determination of any other relevant parameters.

\subsubsection{Soil Plasticity Constitutive Model}

As the M-C model, one of the most commonly used soil material models, does not work with damage definition in Abaqus (Simulia, 2016), the Drucker Prager plasticity model was used to simulate the behavior of a cement-treated Champlain Sea clay sample under BTS testing. The Drucker Prager model, a plasticity model, has been used in a variety of geotechnical applications and is capable of modelling the stress history, stress path, and dilatancy of soils (Helwany, 2007). The yield surface of the Drucker Prager model can be linear, hyperbolic, or exponential (Simulia, 2016), as shown in Figure 5-3. In addition, a modified version of the linear model, known as Modified Drucker Prager model, is 
frequently used in capturing the transition of a linear shear failure surface into an elliptical cap commonly found in soils (Helwany, 2007).

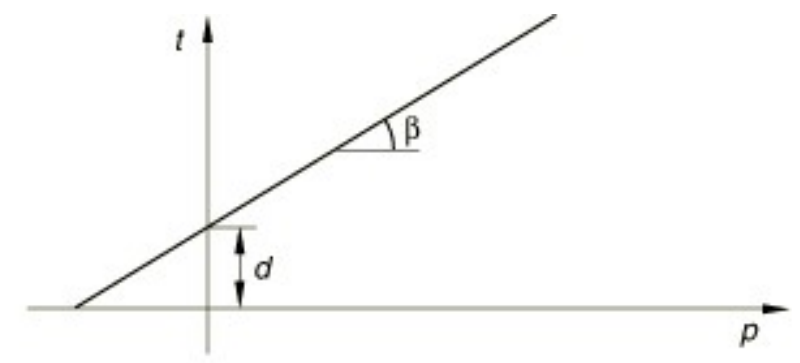

a) Linear Drucker-Prager: $F=t-p \tan \beta-d=0$

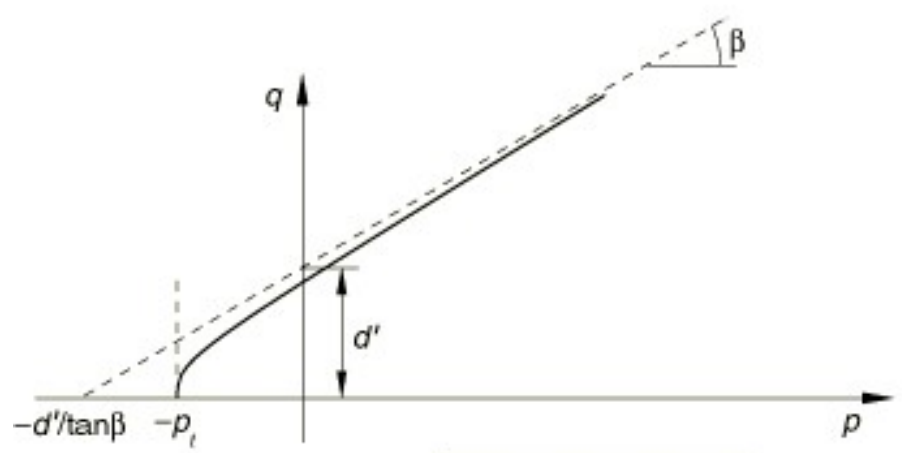

b) Hyperbolic: $\quad F=\sqrt{\left(d^{\prime}\left|0-p_{l}\right| 0 \tan \beta\right)^{2}+q^{2}}-p \tan \beta-d^{\prime}=0$

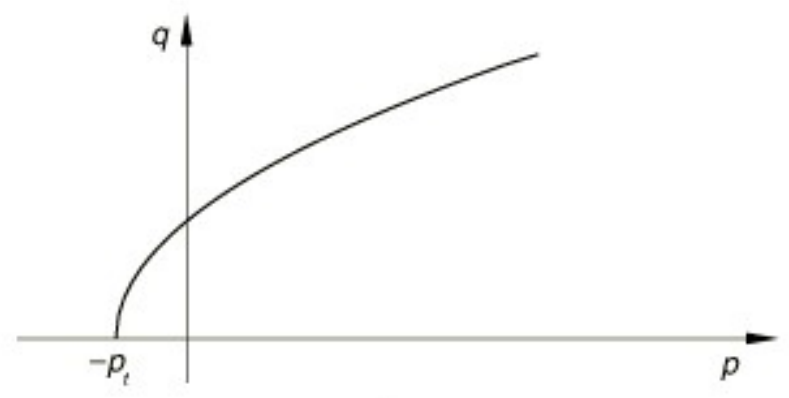

c) Exponent form: $F=a q^{b}-p-p_{t}=0$

Figure 5-3: Drucker Prager Shear Failure Surfaces and Equations (Simulia, 2016)

To simplify the analysis, the linear model will be used in this study. The Drucker Prager parameters, $\beta$ and $d$, can be readily obtained from UCS tests. First the equivalent of M-C parameters are obtained from UCS tests, then convert the M-C parameters of $\varphi^{\prime}$ and $c^{\prime}$ to Drucker Prager parameters of $\beta$ and $d$ are shown below (Mosadegh and Nikraz, 2015): 


$$
\begin{aligned}
& \tan \beta^{\prime}=\frac{3 \sqrt{3} \tan \varphi \prime}{\sqrt{9+1(\tan )^{2}}} \\
& d^{\prime}=\frac{3 \sqrt{3} c^{\prime}}{\sqrt{9+12\left(\tan \varphi^{\prime}\right)^{2}}}
\end{aligned}
$$

In the case of the modelling of a BTS test, an assumption of an unconsolidated, unconfined, and undrained condition will be made as the same as a UCS sample. As explained in Section 3.7.2.1, the friction angle is zero in this case as the failure envelope is a flat line tangent to the peak shear stress. Therefore, the undrained shear strength $c$ obtained from a UCS result is the half of the unconfined compressive strength, $\sigma_{1}$. Substituting into the equation for Drucker Prager parameter $d^{\prime}$, this term simplifies to $\sqrt{3} c$ with the friction angle of zero.

\subsubsection{STRAIN SOFTENING CONSIDERATIONS}

An important phenomenon to consider in numerical simulation of the Brazilian tensile test is strain softening, which refers to the loss of stiffness after the material reaches its peak strength (Pijaudier-Cabot et al., 1988; Li et al., 2019). The loss of stiffness is exhibited through the decrease in slope of the stress-strain curve after the point of yielding. In the case of a brittle failure, a sudden drop in stress occurs after the peak load, which is reached at yielding, due to the sudden fracture inside the sample. After the initialization of cracks, the subsequent stress-strain curve does not increase at the same rate as before and may drop with increasing strain, as shown in Figure 5-4. This behavior of reduced stiffness after the peak load is described as strain softening phenomena, which has been observed in many materials, such as soils, concrete, and rocks (Pijaudier-Cabot et al., 1988; Wakai et al., 2010). In simulation, if no provisions are made, the stiffness would be assumed to remain unchanged by the program and strain hardening, the continual increase in stress after yielding, may be observed in simulation. To properly define strain softening, a function to decrease material strength parameters needs to be defined. Troncone (2005) developed a linearly decreasing function for strain softening in $\mathrm{M}-\mathrm{C}$ model in which shear strength parameters of $\varphi^{\prime}$ and $c^{\prime}$ are reduced linearly with strain to their residual values after the

peak load, as shown in Figure 5-5. $k_{\text {she }}$ is a strain parameter connected with experimental results (Troncone 2005). This principle is adapted in the numerical modelling 
of this study and specific values used for Brazilian tensile simulation will be elaborated in later sections.

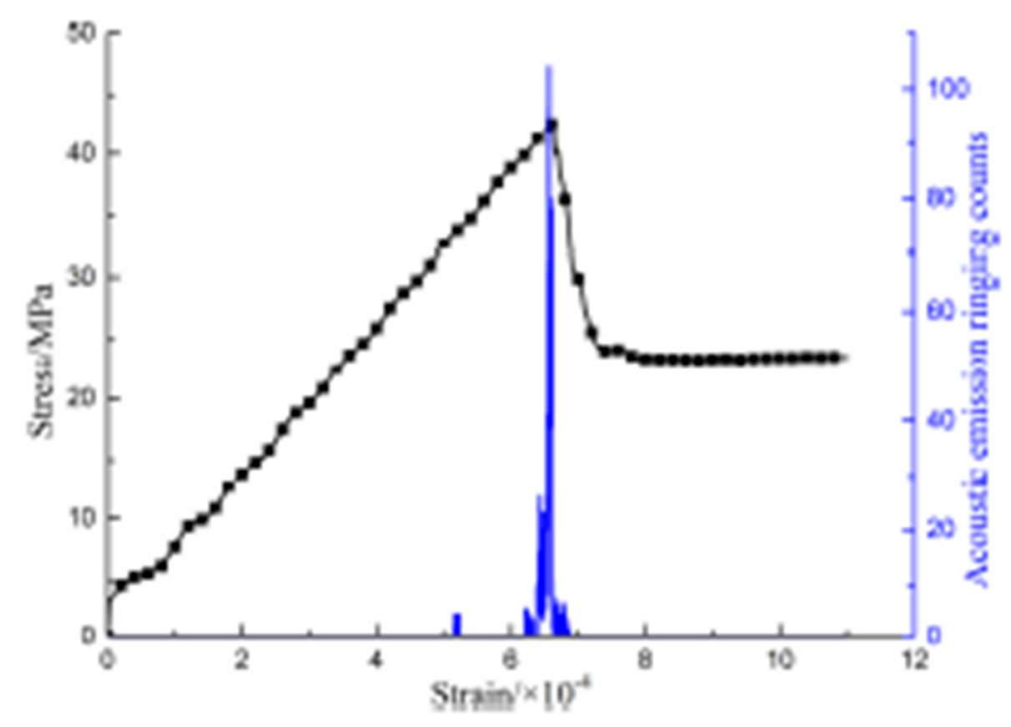

Figure 5-4: Strain Softening as Documented by Li et al. (2019)

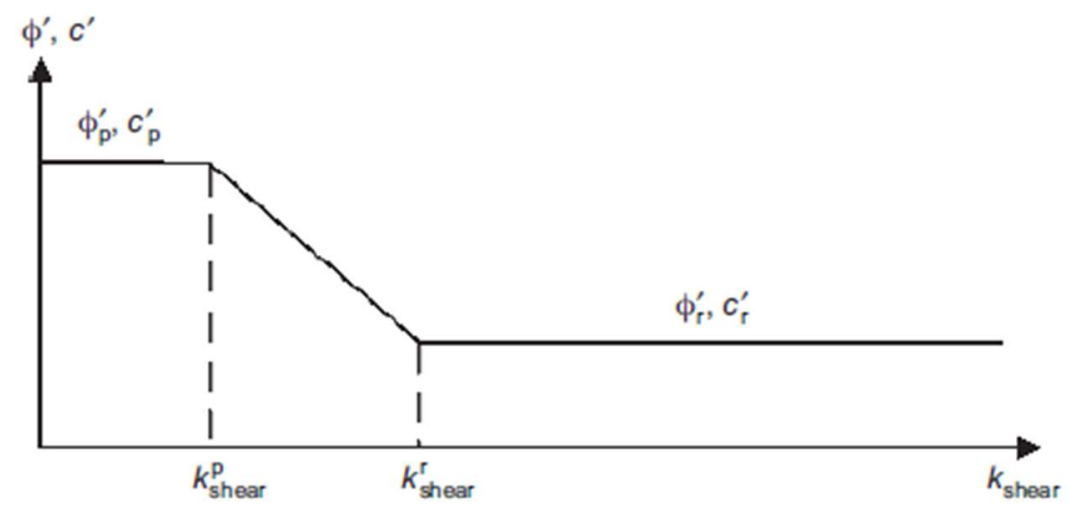

Figure 5-5: One Way for Modelling of Specimen Damage (Troncone, 2005)

\subsubsection{SAMPLE Fracture Modelling}

In BTS testing, the specimen fractures upon reaching the peak load and the fracture would split the sample ideally into two equal halves. Definitions of fracture properties need to be made in order to model the process of fracturing properly. Without such definitions the model would only deform but not crack (Simulia, 2016). A brief discussion on the fracture mechanics will be covered in this section for properly modelling the behavior of a BTS sample during testing. 
The fracture mechanic employed in this study is the traction separation model. In this model, a certain amount of traction exists between two elements. As an external load deforms an element by a certain displacement, a certain amount of energy is exerted on the element. As illustrated in Figure 5-6, $T$ indicates traction, $N$ indicates the stress the element undertakes and $\delta$ is the deformation of the element. The area under the $N-\delta$ function is the energy exerted on the element, expressed as $G_{T C}$. In the traction model, the element first experiences linear-elastic behavior until it reaches its peak strength, after which the stress falls following either a linear (as shown in Figure 5-6), exponential, or other patterns, which can be defined in a tabular form in Abaqus (Simulia, 2012).
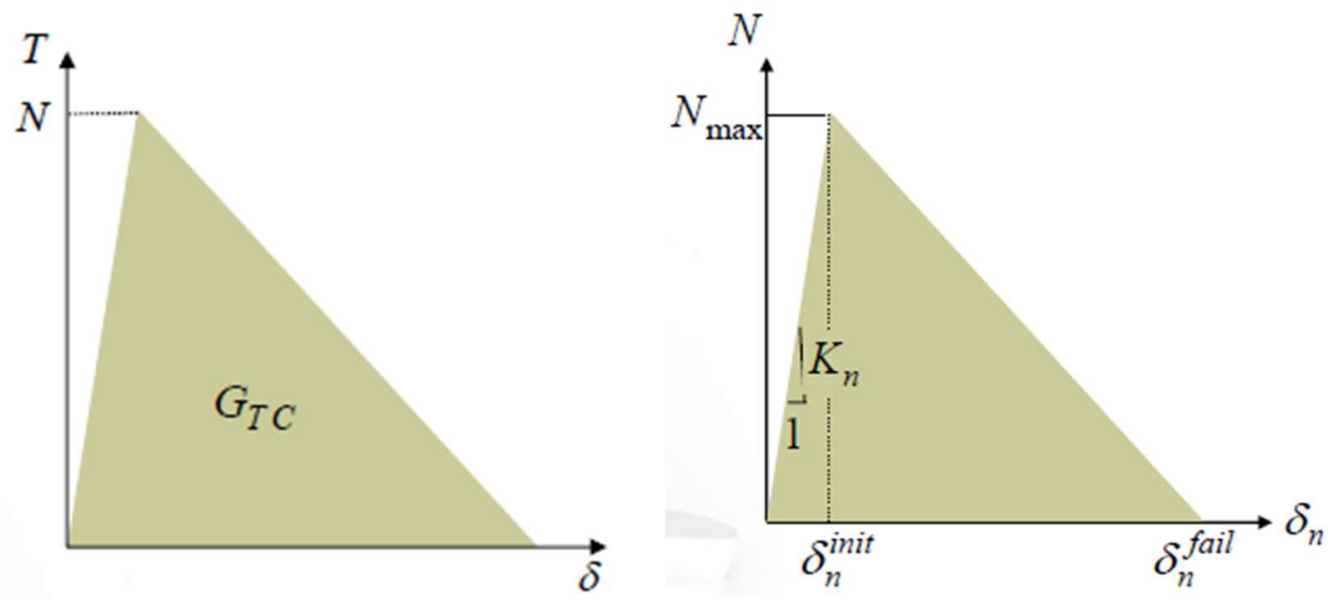

Figure 5-6: Theoretical Illustration of Linear Traction Separation Model (Simulia, 2012)

The stiffness of the linear eleastic region, $K_{n}$, is the slope according to which the stress in the element increases before fracturing. Since the $\mathrm{x}$-axis is a displacement rather than a strain, the unit of this stiffness would be $\frac{N}{m^{2}} / m . K_{n}$ is defined in the formula below :

$$
K_{n}=\frac{N_{\max }}{\delta_{n}^{\text {init }}}
$$

Where $\delta_{n}^{\text {init }}$ is the displacement where the traction element reaches its peak strength.

The displacement where traction stress reaches zero is the failure displacement, $\delta_{n}^{\text {fail }}$. Therefore, the element failure can either be defined by failure displacement or failure energy. Simulia (2012) suggested the value $\delta_{n}^{\text {fail }}$ should be 0.05 multiplied by mesh 
element size in the absense of other information. Because there is no estimate from experimental data on the value of failure energy, the failure displacement was chosen as the criterion used in this study.

Other than the element damage model, Abaqus also requires the definition of a pre-defined fracture surface before fracture modelling. One way to model a fracture surface is the cohesive surface method. Initially, the elements on either sides of the surface are considered connected to each other, hence the name cohesive surface. Once the fracture criteria are met, the elements divided by this cohesive surface will separate (Simulia, 2012). In the cohesive surface method, crack initiation is defined by either maximum stress or maximum separation displacement and the process can be either linear or quadratic. In cohesive surface modelling, the stress can be of pure normal direction or one of two shear directions (Simulia, 2012). As the shear stress can be gained from the UCS tests as the undrained shear strength and a linear analysis is less costly than a quadratic analysis, the MAXS or maximum stress criterion was chosen as the damage initiation criterion for the cohesive surface.

\subsection{SIMULATION SETUP}

In this section, the model parameters and FEM modelling process of a BTS test are covered. A 3-D FEM model is built to simulate the sample during BTS testing. The material model parameters are obtained from the UCS test results. Cement-treated specimens cured for 7 days with binder dosages of 50,100 and $200 \mathrm{~kg} / \mathrm{m}^{3}$ are considered for a total of three FEM simulations. For each simulation, two curves are compared with experimental results: the applied force vs. displacement curve and tensile stress vs. displacement curve.

\subsubsection{Modelling Setup}

To simulate the process of Brazilian tensile testing, a 3-D FEM model consisting of the specimen and the two loading plates are established, as shown in Figure 5-\#\#. The specimen is pre-split into two equal halves using the cohesive surface cracking modelling and is laid horizontally between two testing plates. 


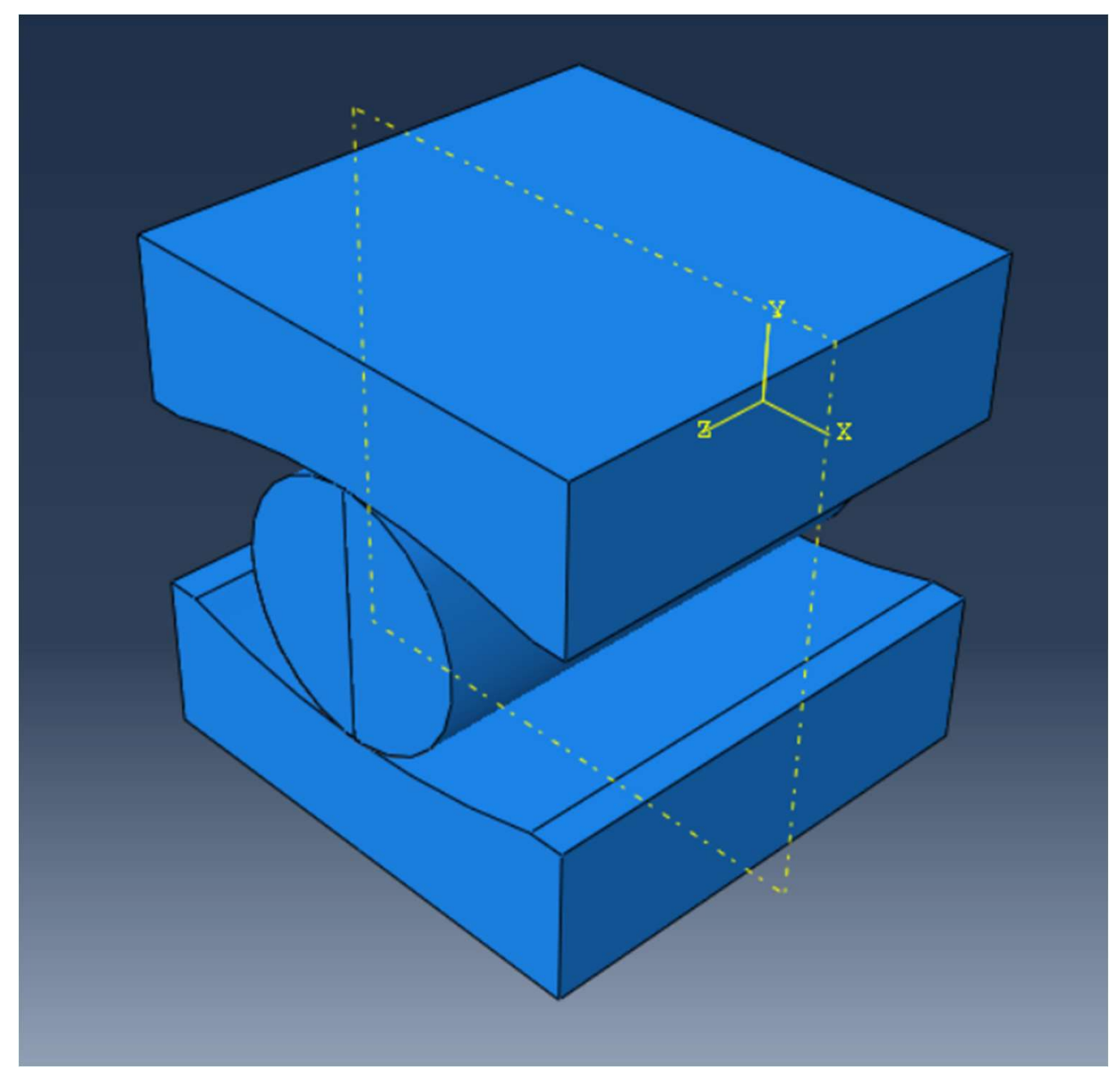

Figure 5-7: A 3-D FEM Model Used in Simulation

\subsubsection{Boundary Conditions and Loading}

For the boundary conditions, the top plate is fixed in translation in all three directions. In addition, the specimen is fixed in displacement in $\mathrm{x}$-axis at a line on its top and bottom where it is tangent to the testing plate to prevent the sample rolling sideways during simulation. The upward motion of the bottom plate is modelled with an upward displacement in the y-axis. The detailed boundary conditions on the model and the sample can be found in Figure 5-8. 

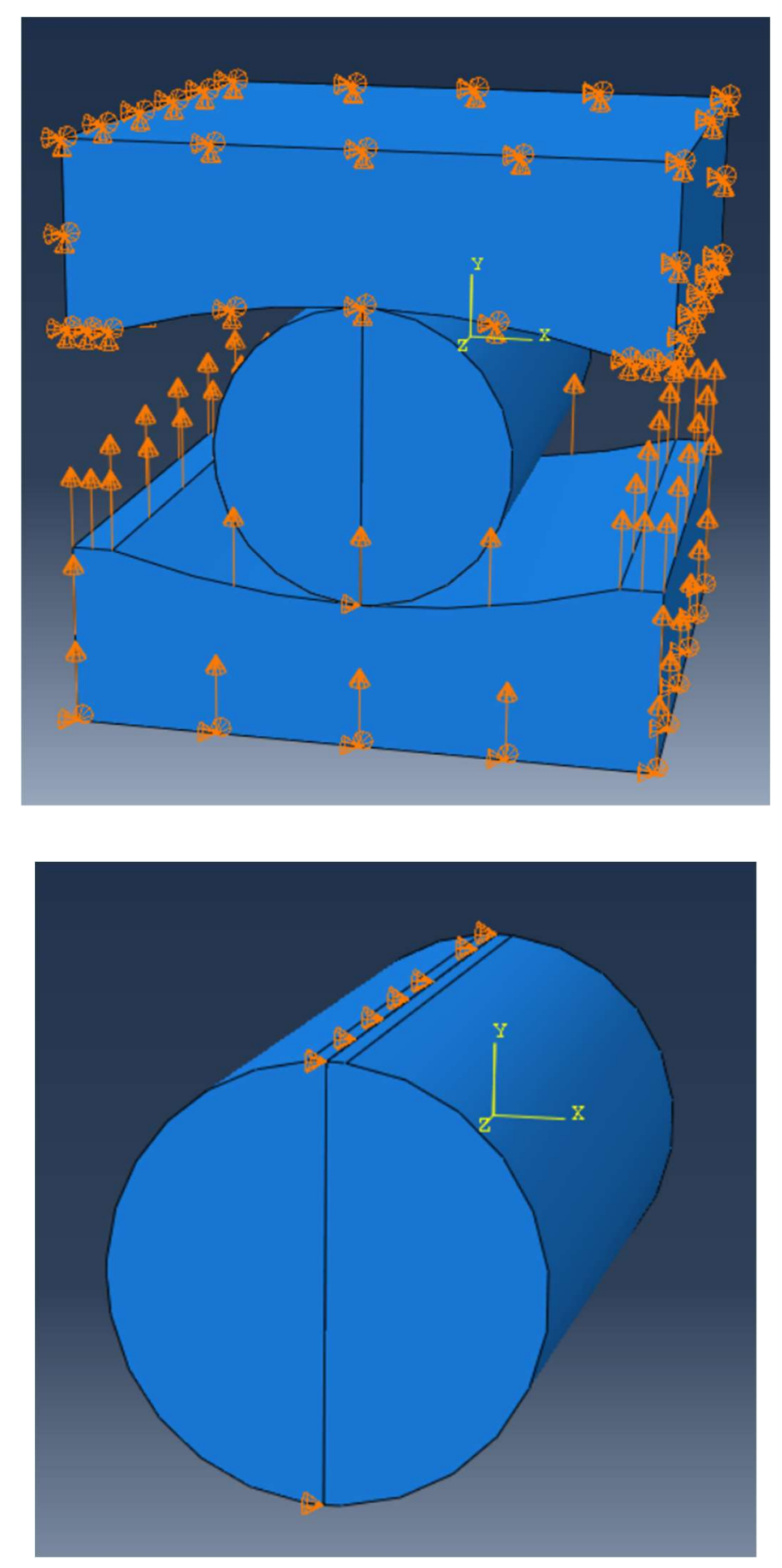

Figure 5-8: Boundary Conditions and Loading on Model

\subsubsection{Time Steps and Load Amplitude}

As the experimental loading rate was $0.5 \mathrm{~mm} / \mathrm{min}$, the time step was defined in minutes in Abaqus where the 1 unitless time value would be considered as 1 minute. Excluding the seating error, an axial displacement of $0.375 \mathrm{~mm}$ would be well for fracturing the sample 
in the BTS testing. Since no seating error was considered in the FEM simulation, it took the testing plate to move $0.375 \mathrm{~mm}$ in the analysis. That means that a time value of 0.75 was used as the total time of the simulated loading process.

\subsubsection{FEM Meshing}

For the FEM model, a final element size of $0.0025 \mathrm{~m}$ was selected as a balance between the model accuracy and the calculation cost. The C3D8R element, a linear element that is an 8-node brick with reduced integration, was chosen as the element type. Both a reduced integration and a linear analysis methods were used to help reduce the calculation cost and avoid non-convergence issues.

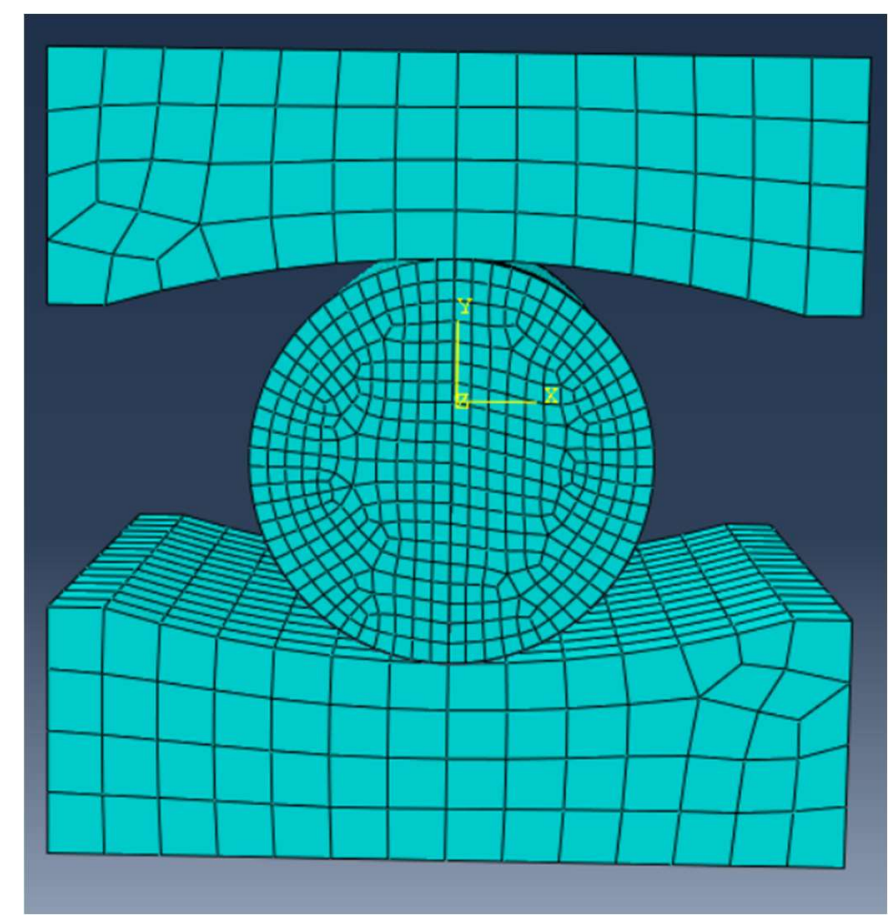

Figure 5-9: Mesh of the Simulation Model

\subsubsection{SOIL MATERIAL PRoPerties}

\subsubsection{Density}

As covered in Section 3.2.6, the average wet density of $1549 \mathrm{~kg} / \mathrm{m}^{3}$ was used the cementtreated Champlain Sea clay. 


\subsubsection{Young's Modulus}

The Young's modulus was taken as the slope of the stress-strain curves of the linear elastic region in the UCS tests after the adjustment of any seating errors.

\subsubsection{Poisson's Ratio}

As the Poisson's ratio for natural Champlain Sea clay is about 0.30 (Shi, 2019) and that for concrete can be taken as 0.2 (Allos \& Martin, 1981), the Poisson's ratio for cement-treated Champlain Sea clay was taken as 0.25 .

\subsubsection{Drucker Prager Parameters}

\subsubsection{1 $\beta$ and $d$}

Based on Equations 5-1 and 5-2, a value of zero can be taken for $\beta . d$ can be obtained by multiplying $\sqrt{3}$ with the undrained shear strength.

\subsection{Flow stress ratio}

The flow stress ratio, $K$, will be assumed to be 1 to satisfy the assumption that the yield surface lies at the von Mieses circle of the deviatoric principle stress plane. This assumption is necessary for Abaqus to process strain hardening or softening behavior using cohesion as input (Simlia, 2016).

\subsection{Strain Softening}

In Abaqus, Drucker-Prager strain hardening and softening can be defined using a tabulated form of increasing or decreasing strength with respect to the absolute plastic strain, which is the strain after yielding occurs (Simulia, 2016). There are three options available for strength input for Drucker Prager plasticity: compressive strength, tensile strength and undrained shear strength. The undrained shear strength option, which requires only the $d$ value, was used for this study (Table 5-1).

Table 5-1: Drucker Prager Softening Definitions for Cement-Treated Sample $\left(50 \mathrm{~kg} / \mathrm{m}^{3}\right)$

\begin{tabular}{|c|c|}
\hline Cohesion Yield Strength $(\mathrm{Pa})$ & Absolute Plastic Strain \\
\hline 900000 & 0 \\
\hline 900000 & 0.001 \\
\hline 800000 & 0.002 \\
\hline
\end{tabular}




\begin{tabular}{|c|c|}
\hline 700000 & 0.003 \\
\hline 600000 & 0.004 \\
\hline 500000 & 0.005 \\
\hline 400000 & 0.006 \\
\hline 300000 & 0.007 \\
\hline 300000 & 1 \\
\hline
\end{tabular}

\subsubsection{Cohesive Surface Parameter Definitions}

\subsection{Normal Stress}

The normal stress is a parameter defined for the cohesive surface cracking mechanism in Abaqus. As shown in Figure 5-6, an element predefined for cracking experiences element yielding and fracture initialization at a certain stress threshold. This stress can be defined as compressive, tensile or shear stress and are all referred as "Normal Stress" in the software regardless which one is used (Simulia, 2016). Since the cohesion of the cementtreated clay is used to define the strain softening behavior of the specimen, the shear stress criterion was selected to define element yielding at the cohesive surface. The shear was obtained by dividing the compressive stress obtained in UCS testing by 2 . The rationale lies in the cohesive soil having zero confining pressure or friction angle in the unconfined, undrained and unconsolidated state of UCS testing (Das \& Sobhan, 2010), as covered in Section 3.7.2.1. The failure envelope then becomes a semicircle and shear strength equals to half of UCS.

\subsubsection{2 $K_{n}$ Value and Failure Displacement}

The element crack initiation stiffness, $K_{n}$ is defined as the stress used as maximum stress in cohesive surface modelling divided by the displacement it needs to reach peak stress in element yielding. As failure strain from UCS averaged around 2\% and the Poisson's ratio of the clay is taken as 0.25 , a factor of $0.5 \%$ may be applied to the element size to gain its yield displacement. Note the stiffness here is not defined by stress divided by strain, but rather stress divided by displacement (Simulia, 2012). Therefore, the $K_{n}$ value would be

$$
K_{n}=\frac{N}{0.0025 m * 0.005}
$$


Where $N$ is the stress used for cohesive surface element failure, in this case the undrained shear stress, and $0.0025 m * 0.005$ is the element failure displacement.

Due to the fracture strains obtained in UCS testing not showing significant variations with respect to curing time or binder content, and the small size of individual elements, the element failure displacement for cohesive surface was not separately calculated for each simulation but assumed to be $0.000125 \mathrm{~m}$ or $1.25 \times 10^{-4} \mathrm{~m}$ for all samples.

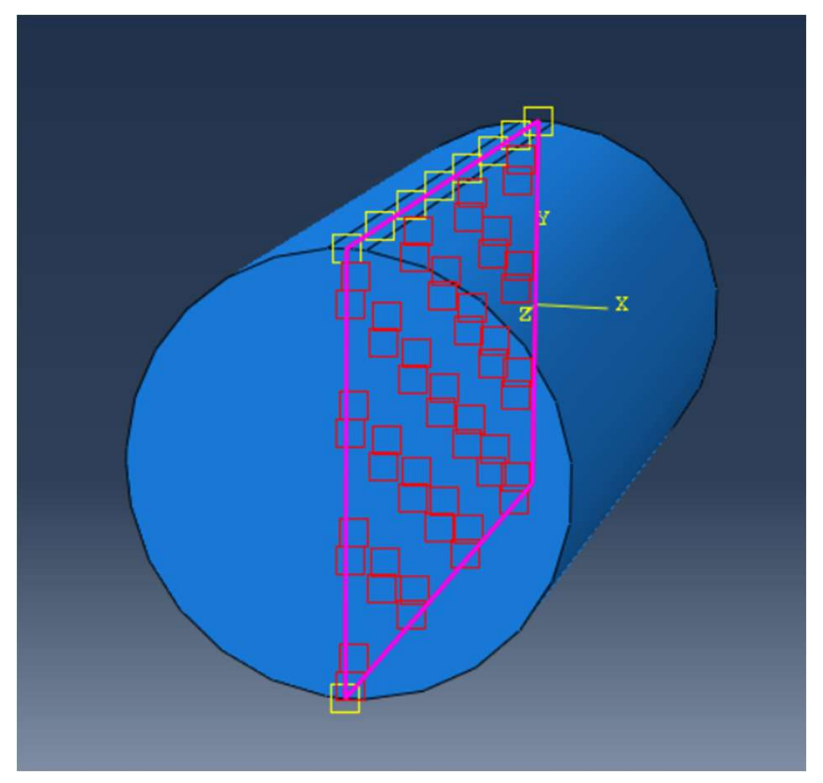

Figure 5-10: Cohesive Surface of Specimen Model

\subsubsection{Experimental Parameter Values}

The majority of input parameters can be obtained based on data from UCS testing or earlier literature. However, based on a trial and error method, it was found that multiplying a factor of 0.9 to Young's modulus of the soil tends to give slightly more accurate results to the elastic portion of tensile strength-displacement curve. This may indicate that a possible discrepancy between stiffness values in compression testing and stiffness values of samples subject to the Brazilian test. The model parameters are summarized in Table 5-2. 
Table 5-2: Summary of Modelling Input Parameters Used in FEM

\begin{tabular}{|c|c|c|c|}
\hline Parameter & $50 \mathrm{~kg} / \mathrm{m}^{3}$ Sample & $100 \mathrm{~kg} / \mathrm{m}^{3}$ Sample & $200 \mathrm{~kg} / \mathrm{m}^{3}$ Sample \\
\hline Density $\left(\mathrm{kg} / \mathrm{m}^{3}\right)$ & 1549 & 1549 & 1549 \\
\hline Young's Modulus $\left(\mathrm{N} / \mathrm{m}^{2}\right)$ & $5.51 \times 10^{7}$ & $1.62 \times 10^{8}$ & $1.96 \times 10^{8}$ \\
\hline Poisson's Ratio & 0.25 & 0.25 & 0.25 \\
\hline Normal Stress $\left(\mathrm{N} / \mathrm{m}^{2}\right)$ & $3.4 \times 10^{5}$ & $4.5 \times 10^{5}$ & $9.6 \times 10^{5}$ \\
\hline$d\left(\mathrm{~N} / \mathrm{m}^{2}\right)$ & $5.88 \times 10^{5}$ & $1.29 \times 10^{6}$ & $1.67 \times 10^{6}$ \\
\hline Failure Displacement $(\mathrm{m})$ & $1.25 \times 10^{-4}$ & $1.25 \times 10^{-4}$ & $1.25 \times 10^{-4}$ \\
\hline$K_{n}\left(\mathrm{~N} / \mathrm{m}^{2} / \mathrm{m}\right)$ & $2.72 \times 10^{10}$ & $3.60 \times 10^{10}$ & $7.68 \times 10^{11}$ \\
\hline
\end{tabular}

\subsection{SIMULATION RESULT AND DISCUSSIONS}

In this section, the results of FEM simulation and the comparison of simulated load- and stress-displacement curves with experimental ones are discussed.

\subsubsection{BEHAVIOR OF SPECIMEN MODEL UNDER LOADING}

In the linear elastic region, the tensile stress increased linearly with increasing displacement. The tensile stress is higher in the center of the sample compared with the rest part of the sample, as shown in Figure 5-11-a). However, a few clusters of tensile stress concentration were noticed near the loading plates, which was also documented by Denneman et al. (2011) and $\mathrm{Li}$ and Wong (2013). The residual stress concentration at the bottom of the specimen after cracking can be explained as the effect of loading by the bottom plate as the same as the BTS testing, which is slightly different from an ideal, symmetrical loading case.

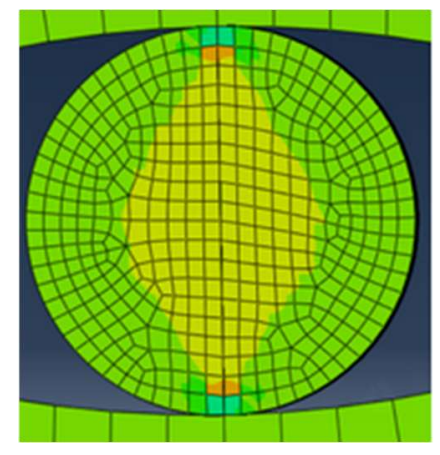

a) Pre-cracking

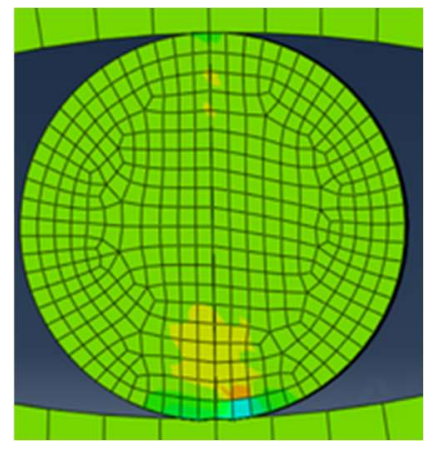

b) Post-cracking

Figure 5-11: The Tensile Stress Contour of a BTS Specimen during Loading 


\subsubsection{Simulation OF ForCE- AND StRESS-DisPlacement CURVES}

The numerical values of applied force and tensile stress can be logged as an output in the numerical modelling process. As explained earlier, the Brazilian tensile strength is based on the tensile strength at the center point of the sample. Therefore, tensile stress can be directly monitored from an element in the center of the specimen by logging its $\sigma_{11}$ value with respect to displacement. The vertical stress, $\sigma_{22}$, of the element immediately contacting the loading plate can be used to calculate the applied forces. In general, the simulated tensile stress vs displacement curves exhibited a better fit with experimental ones than the force-displacement curves.

\subsubsection{Comparison between Experimental and Simulated Results for Applied Load}

In the FEM simulation, the force cannot be directly extracted in the output. Certain calculations are required to obtain the force value, where the stress values of contact elements were multiplied by their element areas to obtain the force value.

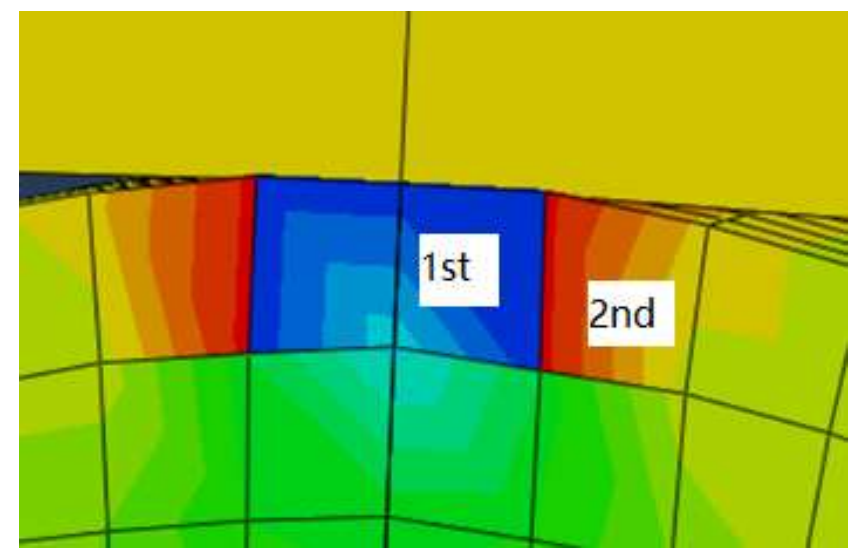

Figure 5-12: Vertical Stress Details of Elements in Contact with Loading Plates

Figure 5-12 was the screenshot taken prior to the sample reaching its peak stress. The elements in contact with the loading plate were selected as two blue $\left(1^{\text {st }}\right)$ elements plus two red $\left(2^{\text {nd }}\right)$ elements. Based on the assumption that element stress values represent the centroids of the element (Simulia, 2012), the individual stress values of the $1^{\text {st }}$ and $2^{\text {nd }}$ elements were used to form an average stress value between the centroids of those two elements. As shown in Table 5-3, taking the stress in the $1^{\text {st }}$ element as 1 , on average the $2^{\text {nd }}$ element can be assumed to be -0.37 . The negative stress value is likely due to the limited 
nature of the finite element mesh, as a large downward stress was exerted on the $1^{\text {st }}$ element, the $2^{\text {nd }}$ element likely experienced a reaction to the opposite direction thus was deemed by the program to have an upward stress. This is not in line with material behavior in actual testing, but rather based on an idealized interaction between the specimen and the testing plate simulated by the program. In actual testing, the element surface is not perfectly smooth and the testing plate would come in full contact with more than a very narrow strip of sample surface area at topmost of the specimen. This may account for seating errors found in experiments as it took a certain amount of time for the apparatus to enter a stage that the sample can undergo linear-elastic deformation utilizing the sample's material stiffness fully. However, in the case of a finite element simulation, the simulated testing plate begins to exert vertical stress and the elements in the sample begins to engage full linear-elastic deformation instantly after the testing plate comes in contact with the sample. Therefore, during most of the linear-elastic stage, the testing plate does not come in full contact with the $2^{\text {nd }}$ element and the 2 nd element, without fully undergoing compressive loading from the testing plate, is pushed upward by the downward-deforming $1^{\text {st }}$ element which is being compressed by the testing plate. This slight deviation does not seem to impact the overall tensile strength value or load-displacement curve. However, adjustments would need to be made to obtain an accurate reading of the vertical stress in the elements.

In the simulation, as the downward stress value given by the program was calculated under the assumption that there has been a negative stress value in the element next to it $\left(2^{\text {nd }}\right.$ element), it would still be reasonable to include the negative value of that element for a better approximation of the stress and force values.

Table 5-3: Relationship between Stresses on Two Elements for Force Calculation

\begin{tabular}{|c|c|c|c|}
\hline Elem Stress $(\mathrm{MPa})$ & $1^{\text {st }}$ Elem & $2^{\text {nd }}$ Elem & $\begin{array}{c}\text { Ratio between } 2^{\text {nd }} \text { and } \\
1^{\text {st }} E l e m\end{array}$ \\
\hline Simulation for $50 \mathrm{~kg} / \mathrm{m}^{3}$ Sample & 0.789 & -0.29 & -0.368 \\
\hline Simulation for $100 \mathrm{~kg} / \mathrm{m}^{3}$ Sample & 1.667 & -0.614 & -0.368 \\
\hline Simulation for $200 \mathrm{~kg} / \mathrm{m}^{3}$ Sample & 2.195 & -0.809 & -0.369 \\
\hline \multicolumn{2}{|c|}{ Approx. Average } & -0.37 \\
\hline
\end{tabular}


Table 5-4: Calculation of Average Vertical Load on the Sample

\begin{tabular}{|c|c|c|c|c|}
\hline Region & Weight & Avg. Stress & $\begin{array}{c}\text { Weight * } \\
\text { Avg. Stress }\end{array}$ & \\
\cline { 1 - 4 } Center Axis to 0.5 of $1^{\text {st }}$ Elem & 0.5 & 1 & 0.5 \\
\cline { 1 - 3 } 0.5 of $1^{\text {st }}$ Elem to 0.5 of $2^{\text {nd }}$ Elem & 1 & 0.315 & 0.315 & \\
\hline \multicolumn{2}{|r|}{ Average Stress of the 1.5-elem area, as a factor of 1st Elem stress } & 0.54 \\
\hline
\end{tabular}

The next step was to calculate the weighted average stress over the approximately area of 1.5-elements under direct contact with the loading plate, as shown in Table 5-3-b). The overall stress can be taken as 0.54 of simulated vertical stress of the $1^{\text {st }}$ element obtained in FEA. Therefore, the peak applied load value can be calculated as follows:

$$
F=\sigma_{22-\text { elem }} * 0.54 * 1.5 * 2 * 0.0025 m * 0.1016 m \quad \text { (Equation 5-4) }
$$

Where $\sigma_{22-e l e m}$ - the elemental vertical stress $\left(\sigma_{22}\right)$ of the 1 st element from central axis.

$1.5 * 2$ - Over the area of 1.5 elements on both sides

$0.0025 \mathrm{~m}-$ Width of the element

$0.1016 \mathrm{~m}$ - Length of the Brazilian tensile specimen.

Using the above relationship, the force values can be calculated from the FEM simulation and compared with experimental values.

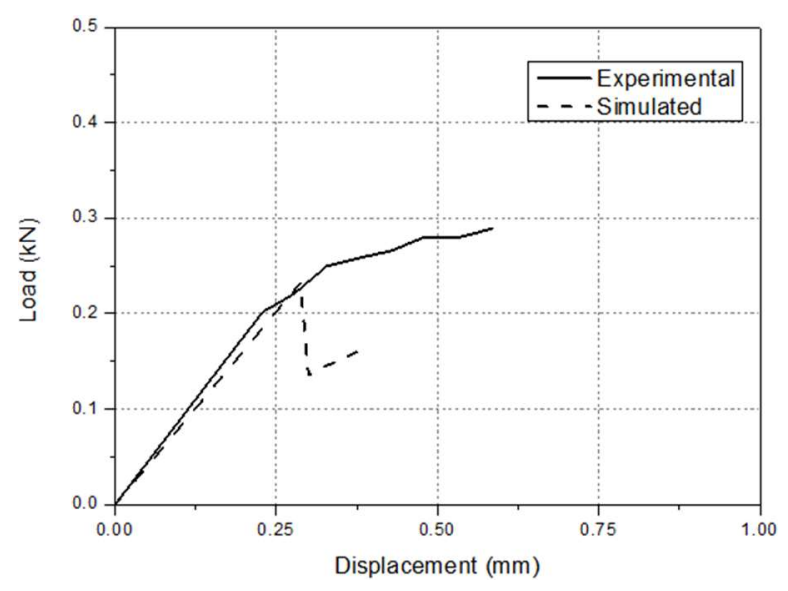

a). BTS sample treated with a cement dosage of $50 \mathrm{~kg} / \mathrm{m}^{3}$ and cured 7 days 


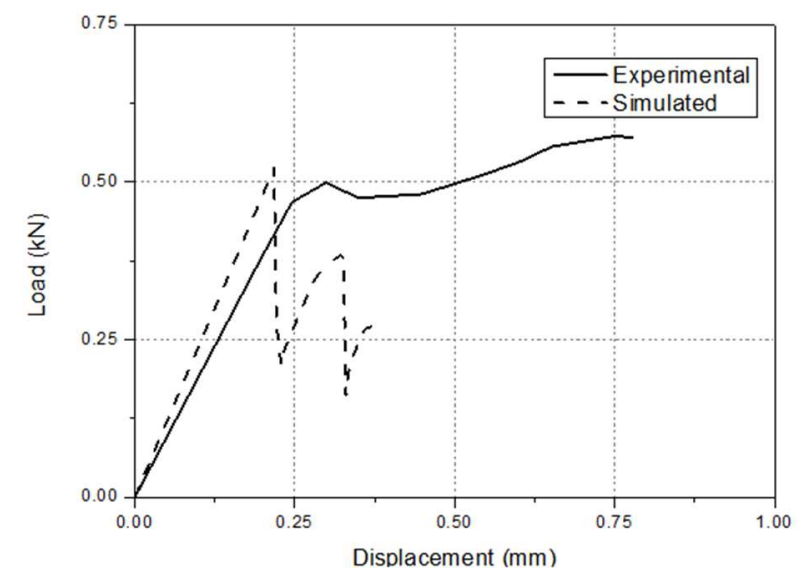

b). BTS sample treated with a cement dosage of $100 \mathrm{~kg} / \mathrm{m}^{3}$ and cured 7 days

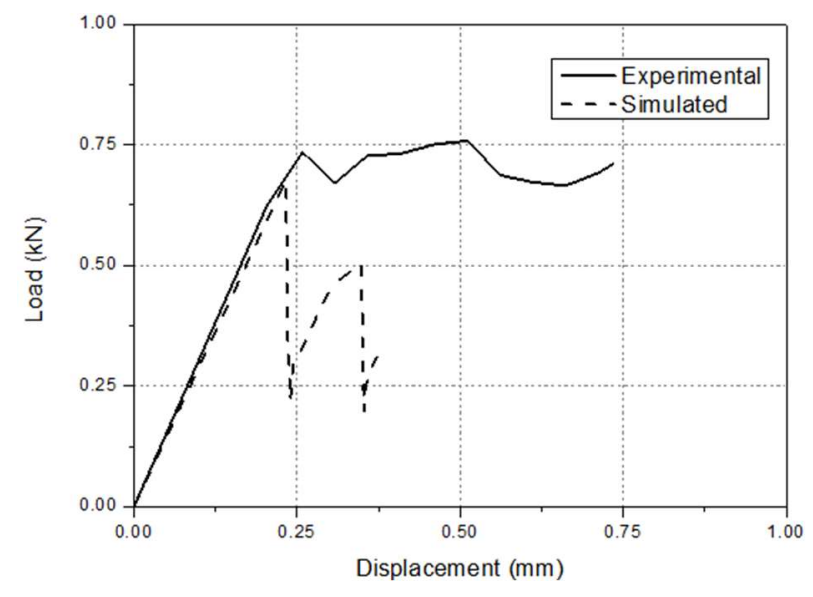

c). BTS sample treated with a cement dosage of $200 \mathrm{~kg} / \mathrm{m}^{3}$ and cured 7 days

Figure 5-13: Comparisons between FEM Simulated and Experimental LoadDisplacement Curves

With the exception of the sample with $100 \mathrm{~kg} / \mathrm{m}^{3}$ cement content, the other two samples showed fair adherence to experimental curves. Peak load values were close to experimental ones, although the error is a bit high for the $50 \mathrm{~kg} / \mathrm{m}^{3}$ sample. Displacements corresponding to the peak load were not as far off, but FEM simulated results still showed smaller displacement values.

\subsubsection{Comparison between Experimental and FEM Results for Tensile Stress}

The tensile stress was obtained directly in Abaqus by tracking the $\sigma_{11}$ value at an element close to the center of the specimen. On the other hand, the tensile stress obtained from 
experimental results were not directly obtained but calculated from the vertical load using a formula.

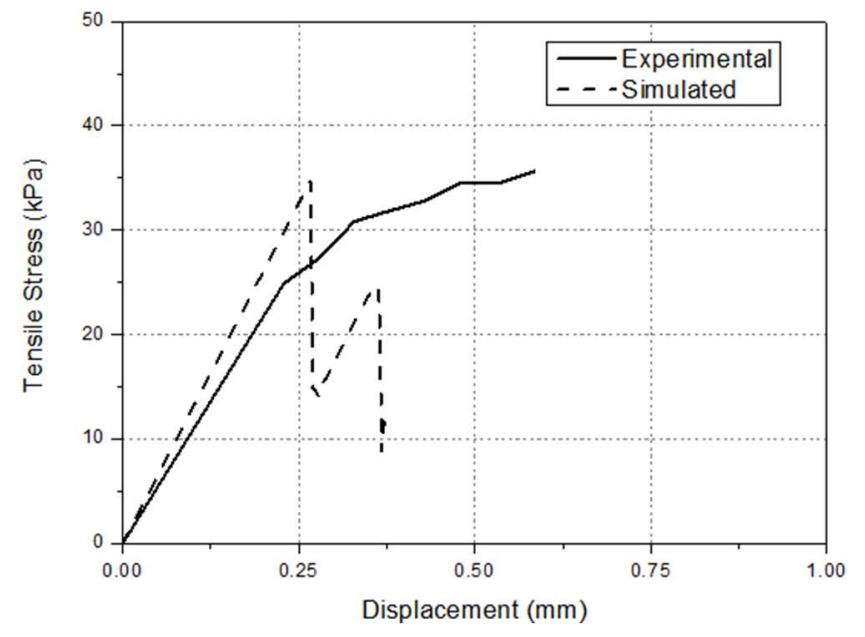

a). BTS sample treated with a cement dosage of $50 \mathrm{~kg} / \mathrm{m}^{3}$ and cured 7 days

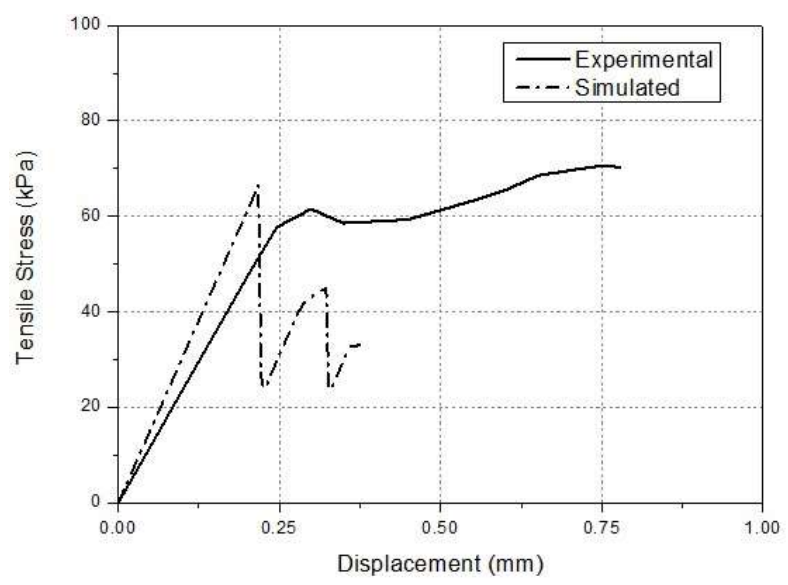

b). BTS sample treated with a cement dosage of $100 \mathrm{~kg} / \mathrm{m}^{3}$ and cured 7 days 


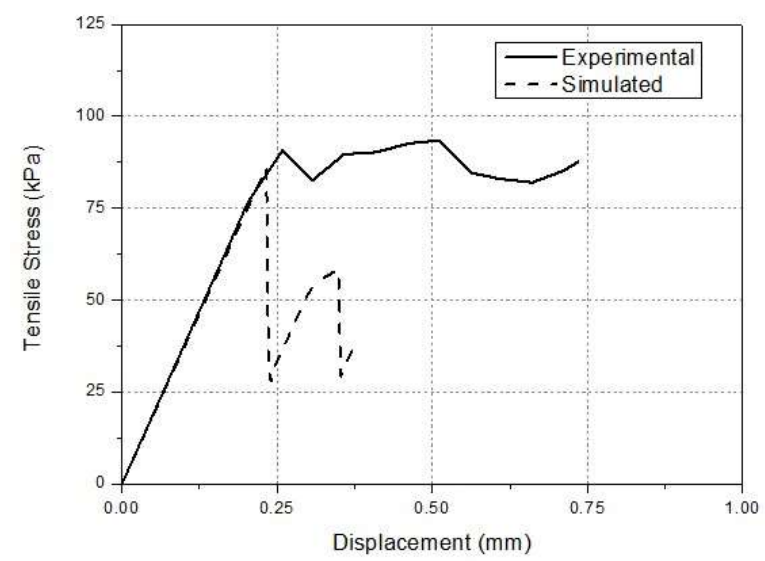

c). BTS sample treated with a cement dosage of $200 \mathrm{~kg} / \mathrm{m}^{3}$ and cured 7 days

Figure 5-14: Comparisons between Simulated and Experimental Tensile StressDisplacement Curves

The simulated curves for tensile stress in general showed slightly less agreement with experimental curve shapes but slightly better agreement in peak tensile strength values. However, slight disagreements with experimental tensile strength values still exist, as there is a slight overestimate for 50 and $100 \mathrm{~kg} / \mathrm{m}^{3}$ samples.

\subsubsection{SUMMARY AND DisCUSSION OF FEM SIMULATION}

The comparison for the peak load at failure and the tensile strength values are summarized between FEM simulation and BTS tests, as shown in Table 5-5. It can be seen that the simulation approximated experimental load and tensile strength modestly well, with errors no greater than $15 \%$. There are differences between the error for load and the error for tensile strength for each sample. This is due to the simulated results for both tensile and compressive strengths were derived from element stress values at their respective points of output (Top of sample for load and center of sample for tensile strength). Though the experimental values which they were compared to were derived from the same loaddisplacement curve from experimentation, the individual differences in stress output from the software at these different elements has led to different error values. This indicates the model, to certain extent, reinforces our experimental result. On the other hand, the model may be acceptable to be adopted for numerical modelling of BTS samples of cementtreated soils. 
The FEM simulation has a number of limitations, which may contribute to existing errors and deviations in simulated curves from experimental ones. First of all, there is not an established material model for cement-treated clay, which behaves somewhere between soil and concrete. The model used in this study was basically M-C model adapted to Drucker Prager, which may not be able to model the behavior of clay optimally, not to mention of its limitations in modelling cement-treated clay. A more suitable material model can be used for better simulation. Secondly, the simulation of a fracture in a BTS sample during loading is a very complex process, which takes account of frack initialization on the top of elastic-plastic behavior. There are many different ways to model fracturing, however no single modelling method can provide the perfect simulation. Thirdly, the trial and error method was used in the simulation to get the best fit of the results. An optimized procedure or method should be implemented in the future. Fourthly, the sample continued to deform and form additional cracks after the initial crack was formed in laboratory testing. However, in this model, no additional cracks can form because there would be no definition for them. This makes the behavior after fracture very unreliable as a prediction of post-peak behavior. Another limitation would be the stiffness used in crack initiation and damage not having a precise experimental basis, which could account for the slope on the load- or stress-displacement curves deviating from the experimental curve by a certain amount.

Table 5-5: Comparison between Experimental Results and FEM Simulation

\begin{tabular}{|c|c|c|c|c|c|c|}
\hline \multirow{2}{*}{ Sample No.* } & \multicolumn{3}{|c|}{ Peak Load } & \multicolumn{3}{c|}{ Peak Tensile Strength } \\
\cline { 2 - 7 } & $\begin{array}{c}\text { Test } \\
(\mathrm{kN})\end{array}$ & $\begin{array}{c}\text { FEM } \\
(\mathrm{kN})\end{array}$ & $\begin{array}{c}\text { Error } \\
(\%)\end{array}$ & $\begin{array}{c}\text { Test } \\
(\mathrm{kPa})\end{array}$ & $\begin{array}{c}\text { FEM } \\
(\mathrm{kPa})\end{array}$ & $\begin{array}{c}\text { Error } \\
(\%)\end{array}$ \\
\hline $50 \mathrm{~kg} / \mathrm{m}^{3}$ Sample & 0.289 & 0.239 & 14 & 34.5 & 34.7 & 1 \\
\hline $100 \mathrm{~kg} / \mathrm{m}^{3}$ Sample & 0.499 & 0.522 & 4 & 61.5 & 66.5 & 8 \\
\hline $200 \mathrm{~kg} / \mathrm{m}^{3}$ Sample & 0.735 & 0.676 & 8 & 90.6 & 86.1 & 5 \\
\hline
\end{tabular}

*-All samples were cured for 7 days

\subsection{SUMMARY}

Numerical simulation on the behavior of a BTS sample under loading was performed using a finite element software package, Abaqus CAE. The loading process was simulated as an upward movement of the bottom loading plate against the sample. Cracking behavior of 
the brittle failure of Brazilian tensile specimens was modelled using a cohesive surface using the traction separation model. The FEM simulation results showed general agreements with those of BTS test results. The simulated load-displacement curves or the stress-displacement curves resembled generally the test curves, where the load and stress increases almost linearly until the peak value was reached and then dropped with deformation increased after the initialization of cracks occurred inside the sample. This indicated that the model could be reinforcing the confidence in experimental results. Moreover, the model may be acceptable for BTS simulation of other cement-treated soils. However, a certain amount of discrepancy still exists between the FEM simulation and experimental results. All the factors including the material model limitations, limited accuracy of model parameters, and the methods for load or stress calculation, are all contributing to the differences. More studies are needed for better FEM simulation of BTS testing. 


\section{SUMMARY AND CONCLUSIONS}

\subsection{INTRODUCTION}

In this study, tensile strength of cement-treated Champlain Sea clay were investigated using the indirect tensile strength testing methods, including the Brazilian tensile strength (BTS) testing and the unconfined penetration testing (UPT) methods. The tensile strength was correlated with the unconfined compressive strength (UCS) of cement-treated Champlain Sea clay. In the end, the finite element method (FEM) was used to simulate the sample behavior during BTS testing.

\subsection{MAIN CONCLUSIONS}

General use Portland cement was used as the binder in this study. The soil mixing parameters investigated in this study included cement dosage and curing time. Samples were prepared for a cement dosage of 50,100 , or $200 \mathrm{~kg} / \mathrm{m}^{3}$ per mixture volume and cured for 7, 14, or 28 days before testing. Curing was done by submerging the cement-treated clay samples in water inside a chamber with a relative humidity of constantly above $95 \%$. Based on the test results from UCS, BTS, UPT and the FEM analysis, the following conclusions can be drawn:

1. All tests including UCS, BTS, and UPT exhibited similar trends in the strength changes with the curing time and the binder content. It was observed that both the tensile and compressive strengths increased significantly from a cement dosage change from $50 \mathrm{~kg} / \mathrm{m}^{3}$ to $100 \mathrm{~kg} / \mathrm{m}^{3}$, not as much for the change from $100 \mathrm{~kg} / \mathrm{m}^{3}$ to $200 \mathrm{~kg} / \mathrm{m}^{3}$. It implies that the cement dosage between 50 to $100 \mathrm{~kg} / \mathrm{m}^{3}$ may be an cost-effective dosage for field applications.

2. BTS values roughly correlates to roughly $6.4 \%$ of UCS of cement-treated Champlain Sea clay. Tensile strength from UPT tests correlates to about $4.6 \%$ of UCS of cement-treated clay. Individual tensile strength values ranged from $30 \mathrm{kPa}$ to 160 $\mathrm{kPa}$ for BTS samples and $40 \mathrm{kPa}$ to $150 \mathrm{kPa}$ for UPT samples.

3. Tensile strengths obtained the BTS tests did not neatly correlate with those of UPT tests. In most cases, the tensile strengths from UPT tests were less than those of BTS tests. The differences increased as cement content increased. At $50 \mathrm{~kg} / \mathrm{m}^{3}$ dosage, 
the difference was about $10 \mathrm{kPa}$, while at $200 \mathrm{~kg} / \mathrm{m}^{3}$ dosage, BTS was as much as $50 \mathrm{kPa}$ higher than UPT strength.

4. The failure cone angle in UPT tests varied greatly from sample to sample. Though it is part of the equation for tensile strength calculation, the value of the angle was found to have no significant impact on the tensile strength values of the sample. Based on this study, the $\mathrm{K}$ value in the tensile strength calculation formula for UPT tests can be taken as 1.0 for the most reliable results.

5. Based on this study, the BTS testing method is recommended over UPT as the preferred indirect tensile strength testing method for cement-treated Champlain Sea clay. BTS can be easily implemented in practice and does not require any additional measurement, such as the angle of a failure surface.

6. The FEM model was able to simulate the behavior of a cement-treated Champlain Sea clay sample under BTS testing. A cohesive surface using the traction separation model in Abaqus can simulate the initialization of cracking and the brittle failure of a Brazilian tensile specimen. The FEM simulated load-displacement curves or the stress-displacement curves resembled the test curves in general. However, some discrepancy was found between the FEM simulation and experimental results due to the material model limitations, inaccurate model parameters, and the methods for load or stress calculation.

\subsection{RECOMMENDATIONS FOR FUTURE RESEARCH}

1. Though good trends were shown for strength values of all three types of testing, sample strength values in certain curing times and binder dosages nevertheless had high variances. Additional investigation should be performed to determine ways to better control sample quality and uniformity in order to achieve more consistent results.

2. BTS and UPT testing are both indirect tensile testing methods. It would be of research interest to compare the results direct tensile testing results, either through an uniaxial tension test or triaxial tension test, and see whether any numerical correlation can be established. 
3. So far the clay sample used are all cement-mixed clay, It would be interesting to investigate the tensile performance of undisturbed Champlain Sea clay as well as the clay treated with other binder materials.

4. The test apparatus and methods used in this study can be easily implemented in any laboratory with access to any conventional compression testing machine. However, additional development is needed before fully adapting the test methods into field application.

5. The tensile strengths of other soft and sensitive clays such as Bangkok clay and Norwegian clay can therefore be investigated, and their tensile strength-compressive strength relationships can be compared with those of Champlain Sea clay.

6. As documented in the previous studies (Ahmad, 2018; Afroz, 2019), salinity has a significant impact on the strength of Champlain Sea clay. Salt concentration at a certain level is associated with the highest strength. It would be of research interest to investigate the effect of salinity on tensile strength of cement-treated Champlain Sea clay and provide a full picture of salt variation on the field applications. 


\section{REFERENCES}

Abramson, L. W. \& Brinckerhoff, P. (1997). 3.0 Ground Treatment. In Schaefer, V. R. (Ed.). Ground Improvement, Ground Reinforcement, Ground Treatment Developments 1987-1997. American Society of Civil Engineers.

Adams, A. L. (2011). Laboratory Evaluation of the Constant Rate of Strain and Constant Head Techniques for Measurement of the Hydraulic Conductivity of Fine Grained Soils [Master's Thesis, Massachusetts Institute of Technology]. DSpace@MIT.

Afroz, M., Ahmad, A., Sangiuliano, T., Lesage, K., Cavers, W., \& Liu, J. (2018). Experimental Investigation of Cement Mixing to Improve Champlain Sea Clay: A Case Study. GeoEdmonton 2018 - 71st Canadian Geotechnical Conference. Canadian Geotechnical Society and International Association of Hydrogeologists.

Afroz, M. (2019). Leaching Impact on Shear Strength and Compressibility of Undisturbed and Cement-treated Champlain Sea clay [Unpublished master's thesis]. Ryerson University.

Ahmad, A. (2018). Leaching Impact on Compressibility of Untreated and Cement-Treated Champlain Sea Clay. [Unpublished master's thesis]. Ryerson University.

Akin, I. D., \& Likos, W. J. (2017). Brazilian tensile strength testing of compacted clay. Geotechnical Testing Journal, 40(4), 608-617.

Allos, A. E., \& Martin, L. H. (1981). Factors affecting Poisson's ratio for concrete. Building and Environment, 16(1), 1-9.

Al-Omar, A. J. A., (1983). Tensile Strength of Lime-stabilized Soil. [Master's thesis, University of Texas at El Paso]. ProQuest Dissertations \& Theses Global.

American Society for Testing and Materials. (2017). ASTM D1633-17, Standard Test Methods for Compressive Strength of Molded Soil-Cement Cylinders. ASTM International.

American Society for Testing and Materials. (2016). ASTM D3967-16, Standard Test Method for Splitting Tensile Strength of Intact Rock Core Specimens. ASTM International.

Ammeri, A., Jamei, M., Guiras, H., Bouassida, M., Villard, P., Plé, O., ... \& Gourc, J. P. (2006). A Numerical study of compacted clay tensile strength by discrete element modelling: A bending test application. https://hal.archivesouvertes.fr/hal-01099835 
Bauer Maschinen GmbH. (2016). Cutter Soil Mixing Process and equipment. Bauer Maschinen $\mathrm{GmbH}$.

Bergado, D. T., Anderson, L. R., Miura, N., \& Balasubramaniam, A. S. (1996). Soft ground improvement in lowland and other environments. American Society of Civil Engineers.

Blackwell, J. (1994). A case history of soil stabilisation using the mix-in-place technique for the construction of deep manhole shafts at Rochdale. In Grouting in the ground: Proceedings of the conference organized by the Institution of Civil Engineers and held in London on 25-26 November 1992 (pp. 497-509). Thomas Telford Publishing.

Bruce, D. A., Cali, P. R. \& Woodward, M. L. (2012). The History of Deep Mixing in New Orleans. Proceedings of the Fourth International Conference on Grouting and Deep Mixing. New Orleans: LA. 10.1061/9780784412350.0049

Brydon, J. E., \& Patry, L. M. (1961). Mineralogy of Champlain Sea sediments and a Rideau clay soil profile. Canadian Journal of Soil Science, 41(2), 169-181.

Bryson, S. L. (2014). Optimization of Ground Improvements and Sandwich Construction for Land Reclamation Applications. [Doctoral dissertation, University of New Brunswick]. UNB Scholar Research Repository.

Consoli, N. C., da Fonseca, A. V., Cruz, R. C., \& Silva, S. R. (2011). Voids/cement ratio controlling tensile strength of cement-treated soils. Journal of geotechnical and geoenvironmental engineering, 137(11), 1126-1131.

Consoli, N. C., Rizzatti de Moraes, R., \& Festugato, L. (2013). Variables controlling strength of fibre-reinforced cemented soils. Proceedings of the Institution of Civil Engineers-Ground Improvement, 166(4), 221-232. http://dx.doi.org/10.1680/grim.12.00004

Dahlström, M. (2013). Dry soil mixing. In Kirsch, K. \& Bell, A. (Ed.), Ground Improvement (3rd ed., pp. 329-433). CRC Press.

Das, B. M., \& Sobhan, K. (2010). Principles of geotechnical engineering (7th ed.). Cengage learning.

Denies, N., \& Huybrechts, N. (2017). Deep mixing method for the construction of earth and water retaining walls. RILEM Technical Letters, 2, 1-9. http://dx.doi.org/10.21809/rilemtechlett.2017.27

Denneman, E., Kearsley, E. P., \& Visser, A. T. (2011). Splitting tensile test for fibre reinforced concrete. Materials and structures, 44(8), 1441-1449.

Eden, W. J., \& Mitchell, R. J. (1970). The mechanics of landslides in Leda clay. Canadian Geotechnical Journal, 7(3), 285-296. 
European Committee for Standardization [CEN]. (2005). European Standard EN 14679 Execution of Special Geotechnical Works - Deep Mixing. Brussels, Belgium: European Committee for Standardization

Evans, J. C. (2008). Alamitos Gap: A Case Study Using the Trench Remixing and Deep Wall Method. 6th Conference on Case Histories in Geotechnical Engineering.

Fang, H. Y., \& Chen, W. F. (1971). New method for determination of tensile strength of soils. Highway Research Board.

Federal Highway Administration. (2000). An Introduction to the Deep Soil Mixing Methods as Used in Geotechnical Applications (Publication No. FHWA-RD99-138). U.S. Department of Transportation Federal Highway Administration

Frikha, W., Zargayouna, H., Boussetta, S., \& Bouassida, M. (2017). Experimental study of Tunis soft soil improved by deep mixing column. Geotechnical and Geological Engineering, 35(3), 931-947. 10.1007/s10706-016-0151-2

Frocht, M. M., (1957). Photoelasticity, Vol 2, John Wiley \& Sons, Inc.

Gui, Y. L., Zhao, Z. Y., Kodikara, J., Bui, H. H., \& Yang, S. Q. (2016). Numerical modelling of laboratory soil desiccation cracking using UDEC with a mixmode cohesive fracture model. Engineering Geology, 202, 14-23. http://dx.doi.org/10.1016/j.enggeo.2015.12.028

Haeri, H., Sarfarazi, V., \& Hedayat, A. (2016). Suggesting a new testing device for determination of tensile strength of concrete. Struct. Eng. Mech, 60(6), 939952.

Han, J., Zhou, H.-T., \& Ye, F. (2002). State-of-Practice Review of Deep Soil Mixing Techniques in China. Transportation Research Record, 1808(1), 49-57. https://doi.org/10.3141/1808-06

Helwany, S. (2007). Applied Soil Mechanics with ABAQUS Applications. John Wiley Sons \& Inc.

Higashi, S., Harada, K., Nitao, H., Hashimoto, N., Suzuki, A., Hatsuyama, Y., ... \& Nakazawa, H. (2010). Study on Liquefaction Countermeasure Effectiveness of Lattice-Type Deep Mixing Based on Full-Scale Field Test. Journal of the Society of Materials Science, Japan, 59(1), 14-19.

Holm, G. (2002). Nordic dry deep mixing method execution procedure. In Proceedings of Deep Mixing Workshop 2002 in Tokyo. Port and Airport Research Institute \& Coastal Development Institute of Technology.

Hudson, W. R., \& Kennedy, T. W. (1968). An indirect tensile test for stabilized materials. Center for Highway Research, University of Texas at Austin. 
Keller Holding GmbH. (2017). Deep Soil Mixing. Available: https://www.kellerholding.com/deep-soil-mixing.html

Keller Holding GmbH. (2020). Deep soil mixing - wet method. Available: https://www.kellerme.com/expertise/techniques/deep-soil-mixing-wetmethod

Kim, T. H., Kim, T. H., Kang, G. C., \& Ge, L. (2012). Factors influencing crack-induced tensile strength of compacted soil. Journal of materials in civil engineering, 24(3), 315-320. 10.1061/(ASCE)MT.1943-5533.0000380

Kirstein, A., (2010). Evalulation of Different Methods to Identify Preconsolidation Pressure of Champlain Sea Clay from CRS Tests [Master's Thesis, Ryerson University]. Ryerson University Digital Library.

Kitazume, M. (2017). Deep Mixing Method, The Japanese Experience and Recent Advancement. Advance in Concrete Technology by Hong Kong Concrete Institute (Seminar).

Kitazume, M., \& Terashi, M. (2013). The deep mixing method. CRC press.

La Rochelle, P., Chagnon, J. Y., \& Lefebvre, G. (1970). Regional geology and landslides in the marine clay deposits of eastern Canada. Canadian Geotechnical Journal, $7(2), 145-156$.

Leavell, D. A., \& Peters, J. F. (1987). Uniaxial Tensile Test for Soil (No. WES/TR/GL-8710). Army Engineer Waterways Experiment Station Vicksburg, MS Geotechnical Lab. U.S. Army Corps of Engineers.

Lewis, C. M., \& Todd, B. J. (2019). The Early Lake Ontario barrier beach: evidence for sea level about 12.8-12.5 cal. ka BP beneath western Lake Ontario in eastern North America. Boreas, 48(1), 195-214. 10.1111/bor.12351

Li, D., \& Wong, L. N. Y. (2013). The Brazilian disc test for rock mechanics applications: review and new insights. Rock mechanics and rock engineering, 46(2), 269287. $10.1007 / \mathrm{s} 00603-012-0257-7$

Li, G., Ma, F., Liu, G., Zhao, H., \& Guo, J. (2019). A Strain-Softening Constitutive Model of Heterogeneous Rock Mass Considering Statistical Damage and Its Application in Numerical Modeling of Deep Roadways. Sustainability, 11(8), 2399.

Li, H. D., Tang, C. S., Cheng, Q., Li, S. J., Gong, X. P., \& Shi, B. (2019). Tensile strength of clayey soil and the strain analysis based on image processing techniques. Engineering

Geology,

253 ,

137-148.

https://doi.org/10.1016/j.enggeo.2019.03.017 
Li, J., Tang, C., Wang, D., Pei, X., \& Shi, B. (2014). Effect of discrete fibre reinforcement on soil tensile strength. Journal of Rock Mechanics and Geotechnical Engineering, 6(2), 133-137. http://dx.doi.org/10.1016/j.jrmge.2014.01.003

Li, S., Kirstein, A., Gupersaud, N. \& Liu, J. (2016a). Deep Mixing for Ground Improvement of Champlain Sea Clay Preliminary Experimental Investigation: A Project Funded by Natural Sciences and Engineering Research Council of Canada and Supported by Geo-Foundations Contractors Inc. Department of Civil Engineering, Ryerson University.

Li, S., Kirstein, A., Gurpersaud, N., \& Liu, J. (2016b). Experimental investigation of cement mixing to improve Champlain Sea clay. 69th Canadian Geotechnical Conference - GeoVancouver 2016. Canadian Geotechnical Society and Vancouver Geotechnical Society.

Li, S., Poudyal, C., Liu, J., \& Sangiuliano, T. (2017). Experimental Investigation of Soil Mixing to Improve Clayey Soils in Ontario: A Case Study. 70th Canadian Geotechnical Conference - GeoOttawa 2017. Canadian Geotechnical Society.

Liang, Q., Wu, X., Li, C., \& Wang, L. (2014). Mechanical analysis using the unconfined penetration test on the tensile strength of Q3 loess around Lanzhou City, China. Engineering geology, 183, 324-329. http://dx.doi.org/10.1016/j.enggeo.2014.10.016

Lin, Z., \& Wood, L. (2003). Concrete uniaxial tensile strength and cylinder splitting test. Journal of Structural Engineering, 129(5), 692-698. 10.1061/(ASCE)07339445(2003)129:5(692)

Linares-Unamunzaga, A., Pérez-Acebo, H., Rojo, M., \& Gonzalo-Orden, H. (2019). Flexural Strength Prediction Models for Soil-Cement from Unconfined Compressive Strength at Seven Days. Materials, 12(3), 387. 10.3390/ma12030387

Liu, J., Shi, C., Afroz, M., \& Kirstein, A. (2017). Numerical Investigation of Long-Term Settlement of Waba Dam.

Locat, J., Lefebvre, G., \& Ballivy, G. (1984). Mineralogy, chemistry, and physical properties interrelationships of some sensitive clays from Eastern Canada. Canadian Geotechnical Journal, 21(3), 530-540.

Mahabadi, O. K., Grasselli, G., \& Munjiza, A. (2009). Numerical modelling of a Brazilian Disc test of layered rocks using the combined finite-discrete element method. In RockEng09: 3rd Canada-US rock mechanics symposium (pp. 87-88).

Maher, A., Douglas, W. S., Yang, D., Jafari, F., \& Schaefer, V. R. (2007). Cement deep soil mixing (CDSM) for solidification of soft estuarine sediments. Marine Georesources and Geotechnology, 25(3-4), 221-235. 
Mairesse, J. (1976). Static and dynamic behaviour of a sensitive clay. [Unpublished master's thesis]. McGill University.

Massarsch, K. R. \& Topolnicki, M. (2005). Regional Report: European Practice of Soil Mixing Technology. International Conference on Deep Mixing Best Practice and Recent Advances. Swedish Deep Stabilization Research Centre.

Menard Canada. (2020). Deep Soil Mixing. Available: https://menardcanada.ca/groundimprovement-solutions/deep-soil-mixing/

Monsif, M.Y. \& Liu, J. (2019). Fundamental mechanism of cement in stabilizing Champlain Sea clay. 72nd Canadian Geotechnical Conference - Geo St. John. Canadian Geotechnical Society.

Mosadegh, A., \& Nikraz, H. (2015). Bearing Capacity Evaluation of Footing on a Layered - Soil using ABAQUS. J Earth Sci Clim Change, 6(3), 1000264.

Morris, P. H., Graham, J., \& Williams, D. J. (1992). Cracking in drying soils. Canadian Geotechnical Journal, 29(2), 263-277.

Mu, T. (2013). Soil Stabilization with Fly Ash and Fibers. [Master's thesis, Southern Illinois University Carbondale]. ProQuest Dissertations \& Theses Global.

Nahlawi, H., Chakrabarti, S., \& Kodikara, J. (2004). A direct tensile strength testing method for unsaturated geomaterials. Geotechnical Testing Journal, 27(4), 356-361.

Namikawa, T., Hiyama, S., Ando, Y., \& Shibata, T. (2017). Failure behavior of cementtreated soil under triaxial tension conditions. Soils and Foundations, 57(5), 815-827. https://doi.org/10.1016/j.sandf.2017.08.011

Namikawa, T., \& Koseki, J. (2007). Evaluation of tensile strength of cement-treated sand based on several types of laboratory tests. Soils and Foundations, 47(4), 657674.

Namikawa, T., \& Mihira, S. (2007). Elasto-plastic model for cement-treated sand. International journal for numerical and analytical methods in geomechanics, 31(1), 71-107. 10.1002/nag.550

Neville, A. M., \& Brooks, J. J. (2010). Concrete technology (2nd ed.). Longman Scientific \& Technical.

Nozu, M. (2005). Regional Report: Asia. International Conference on Deep Mixing Best Practice and Recent Advances. Swedish Deep Stabilization Research Centre.

Nguyen, B., Takeyama, T., \& Kitazume, M. (2016). Internal failure of deep mixing columns reinforced by a shallow stabilized soil beneath an embankment. 
International Journal of Geosynthetics and Ground Engineering, 2(4), 30. 10.1007/s40891-016-0072-4

Onwuka, M. K. (1983). Tensile and Unconfined Compressive Strength of Lightly Cemented Sand. [Master's thesis, University of Texas at El Paso]. ProQuest Dissertations \& Theses Global.

Ouhadi, V. R., Yong, R. N., Amiri, M., \& Ouhadi, M. H. (2014). Pozzolanic consolidation of stabilized soft clays. Applied Clay Science, 95, 111-118. http://dx.doi.org/10.1016/j.clay.2014.03.020

Pacific Ground Engineering. (2020). Deep Soil Mixing. Available: http://www.pacge.com/services/deep-soil-mixing

Pijaudier-Cabot, G., Bazant, Z. P., \& Tabbara, M. (1988). Comparison of various models for strain-softening. Engineering computations, 5(2), 141-150.

Porbaha, A., Zen, K., \& Kobayashi, M. (1999). Deep mixing technology for liquefaction mitigation. Journal of infrastructure systems, 5(1), 21-34.

Qualitas Group. (2016). Experimental Data.

Quigley, R. M. (1980). Geology, mineralogy, and geochemistry of Canadian soft soils: a geotechnical perspective. Canadian Geotechnical Journal, 17(2), 261-285.

Quigley, R. M., Gwyn, Q. H. J., White, O. L., Rowe, R. K., Haynes, J. E., \& Bohdanowicz, A. (1983). Leda clay from deep boreholes at Hawkesbury, Ontario. Part I: Geology and geotechnique. Canadian Geotechnical Journal, 20(2), 288-298.

Rajesh, S., \& Viswanadham, B. V. S. (2015). Numerical simulation of geogrid-reinforced soil barriers subjected to differential settlements. International Journal of Geomechanics, 15(4), 04014062. 10.1061/(ASCE)GM.1943-5622.0000405

Ryan, C. R. \& Jasperse, B. H. (1989). Deep Soil Mixing at Jackson Lake Dam. ASCE 1989 Foundation Engineering Conference. American Society of Civil Engineering.

Saitoh, S., Suzuki, Y., \& Shirai, K. (1985). Hardening of soil improved by deep mixing method. International conference on soil mechanics and foundation engineering. 11 (pp. 1745-1748). International Society for Soil Mechanics and Geotechnical Engineering.

Shao, Y., Macari, E. J., \& Cai, W. (2005). Compound deep soil mixing columns for retaining structures in excavations. Journal of geotechnical and geoenvironmental engineering, 131(11), 1370-1377. 10.1061/(ASCE)10900241(2005)131:11(1370)

Shi, C. (2019). A Deviatoric Softening Model to Simulate Compressibility Properties of Soft Clays [Unpublished Doctor's Dissertation]. Ryerson University. 
Simulia. (2012). Abaqus Modelling - Failure and Fracture.

Simulia. (2016). Abaqus 2016 Documentation.

Tang, C. S., Pei, X. J., Wang, D. Y., Shi, B., \& Li, J. (2015). Tensile strength of compacted clayey soil. Journal of Geotechnical and Geoenvironmental Engineering, 141(4), 04014122. 10.1061/(ASCE)GT.1943-5606.0001267

Tang, C. S., Shi, B., Liu, C., Gao, L., \& Inyang, H. I. (2011). Experimental investigation of the desiccation cracking behavior of soil layers during drying. Journal of Materials in Civil Engineering, 23(6), 873-878. 10.1061/(ASCE)MT.19435533.0000242

Terashi, M. (1980). Fundamental properties of lime and cement treated soils. Report of PHRI, 19(1), 33-62.

Terashi, M. (1997). Theme lecture: Deep mixing method-Brief state of the art. In Proc. 14th ICSMFE (Vol. 4, pp. 2475-2478). International Society for Soil Mechanics and Geotechnical Engineering.

Terashi, M. (2002). Development of deep mixing machine in Japan. In Proceedings of Deep Mixing Workshop 2002 in Tokyo. Port and Airport Research Institute \& Coastal Development Institute of Technology.

Terashi, M. (2003). The state practice in deep mixing methods. Proceedings of the 3rd International Conference on Grouting and Ground Treatment, February 10-12, 2003. ASCE Geotechnical Special Publication No. 120. pp. 25-29. American Society of Civil Engineering.

Thuro, K., Plinninger, R. J., Zäh, S., \& Schütz, S. (2001, June). Scale effects in rock strength properties. Part 1: Unconfined compressive test and Brazilian test. In ISRM regional symposium, EUROCK (pp. 169-174).

Topolnicki, M. (2013). In-situ soil mixing. In Kirsch, K. \& Bell, A. (Ed.), Ground Improvement (3rd ed., pp. 329-433). CRC Press.

Torrance, J. K. (1984). A comparison of marine clays from Ariake Bay, Japan and the South Nation River landslide site, Canada. Soils and foundations, 24(2), 75-81.

Troncone, A. (2005). Numerical analysis of a landslide in soils with strain-softening behaviour. Geotechnique, 55(8), 585-596.

Varsei, M., Miller, G. A., \& Hassanikhah, A. (2016). Novel approach to measuring tensile strength of compacted clayey soil during desiccation. International Journal of Geomechanics, 16(6), D4016011. 10.1061/(ASCE)GM.1943-5622.0000705

Voottipruex, P., Suksawat, T., Bergado, D. T., \& Jamsawang, P. (2011). Numerical simulations and parametric study of SDCM and DCM piles under full scale 
axial and lateral loads. Computers and Geotechnics, 38(3), 318-329. 10.1016/j.compgeo.2010.11.006

Wakai, A., Ugai, K., Onoue, A., Kuroda, S., \& Higuchi, K. (2010). Numerical modeling of an earthquake-induced landslide considering the strain-softening characteristics at the bedding plane. Soils and foundations, 50(4), 533-545.

Wang, M., \& Cao, P. (2016). Numerical analysis of flattened Brazilian disc test based on the cusp catastrophe theory. Mathematical Problems in Engineering, 2016. http://dx.doi.org/10.1155/2016/4517360

Wang, J. J., Zhu, J. G., Chiu, C. F., \& Zhang, H. (2007). Experimental study on fracture toughness and tensile strength of a clay. Engineering Geology, 94(1-2), 65-75. 10.1016/j.enggeo.2007.06.005

Yang, K. H., Lee, Y., \& Mun, J. H. (2019). A Stress-Strain Model for Unconfined Concrete in Compression considering the Size Effect. Advances in Materials Science and Engineering, 2019. https://doi.org/10.1155/2019/2498916

Yuan, R., \& Shen, B. (2017). Numerical modelling of the contact condition of a Brazilian disk test and its influence on the tensile strength of rock. International Journal of Rock Mechanics and Mining Sciences, 93, 54-65. http://dx.doi.org/10.1016/j.ijrmms.2017.01.010

Zhang, H., Zhu, H., Wang, J., Yuan, Y., \& Feng, Y. (2006). Experimental study on tensile strength of compacted gravel soil. Chinese Journal of Rock Mechanics and Engineering, 25(S2), 4186-4190. 